Universidad Nacional de La Plata

Facultad de Ciencias Naturalesy Museo

Trabajo de Tess para optar por el titulo de Dottor en Ciencias Naturales

Ecotoxicología de matrices sólidastit fi.

Lic. Silvana Patricia Curieses

Diftctori: Dra, Maria Elena Sáenz-

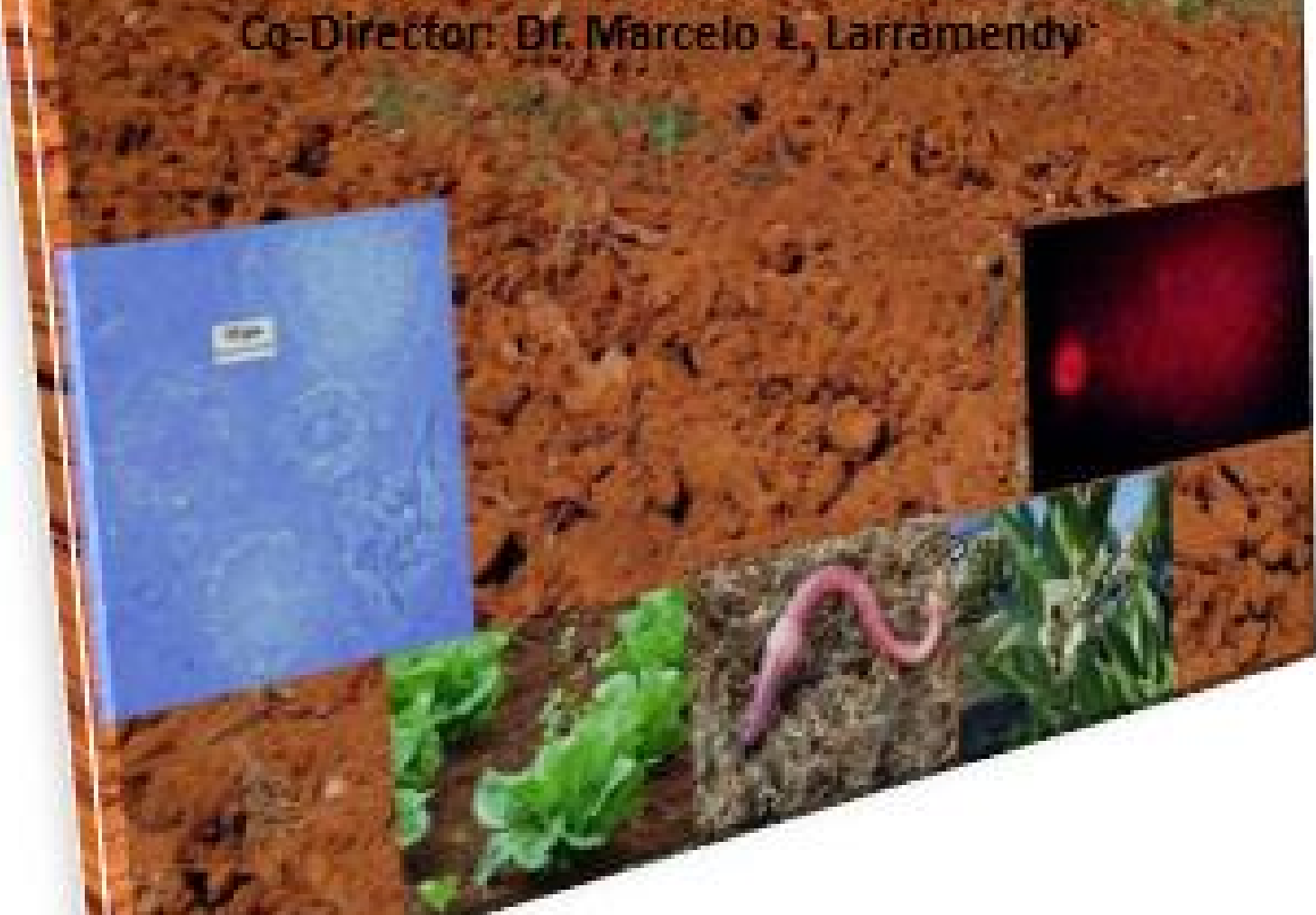

Aก๊๊ 2016 
Universidad Nacional de La Plata

Facultad de Ciencias Naturales y Museo

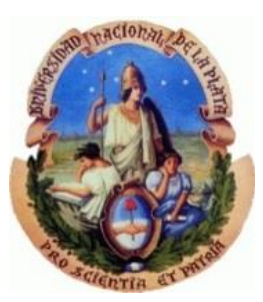

Trabajo de Tesis para optar por el título de Doctor en Ciencias Naturales

\title{
Ecotoxicología de Matrices sólidas
}

\author{
Lic. Silvana Patricia Curieses
}

Director: Dra. María Elena Sáenz -

Co-Director: Dr. Marcelo L. Larramendy

Año 2015 
A mis padres

A mis hermanos

A mi ahijada María Luján

A mi abuela Ángela 


\section{Ítaca}

De Konstantínos Pétrou Kaváfis (1863-1933)

Cuando te encuentres de camino a Ítaca, desea que sea largo el camino,

lleno de aventuras, lleno de conocimientos.

A los Lestrigones y a los Cíclopes,

al enojado Poseidón no temas,

tales en tu camino nunca encontrarás,

si mantienes tu pensamiento elevado, y selecta

emoción tu espíritu y tu cuerpo tienta.

A los Lestrigones y a los Cíclopes,

al fiero Poseidón no encontrarás,

si no los llevas dentro de tu alma,

si tu alma no los coloca ante ti.

Desea que sea largo el camino.

Que sean muchas las mañanas estivales

en que con qué alegría, con qué gozo

arribes a puertos nunca antes vistos,

detente en los emporios fenicios,

y adquiere mercancías preciosas,

nácares y corales, ámbar y ébano,

y perfumes sensuales de todo tipo,

cuántos más perfumes sensuales puedas,

ve a ciudades de Egipto, a muchas,

aprende y aprende de los instruidos.

Ten siempre en tu mente a Ítaca.

La llegada allí es tu destino.

Pero no apresures tu viaje en absoluto.

Mejor que dure muchos años,

y ya anciano recales en la isla, 
rico con cuanto ganaste en el camino,

sin esperar que te dé riquezas Ítaca.

Ítaca te dio el bello viaje.

Sin ella no habrías emprendido el camino.

Pero no tiene más que darte.

Y si pobre la encuentras, Ítaca no te engañó.

Así sabio como te hiciste, con tanta experiencia, comprenderás ya qué significan las Ítacas. 
ÍNDICE 


\section{Índice}

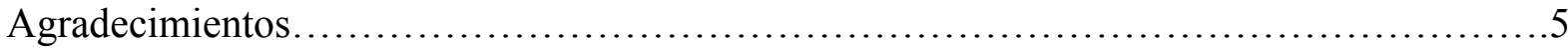

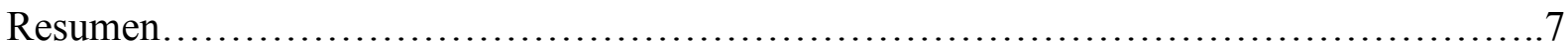

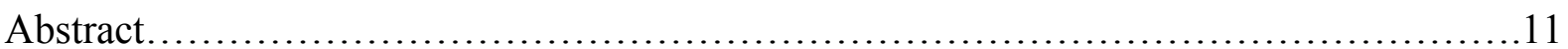

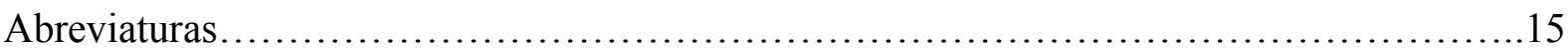

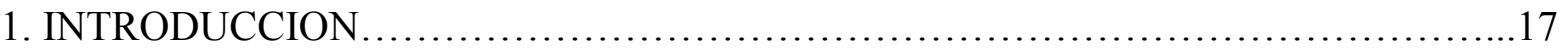

1.1. Consideraciones Generales.................................................. 18

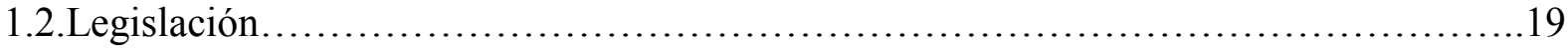

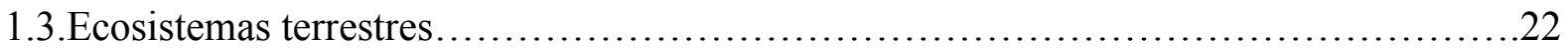

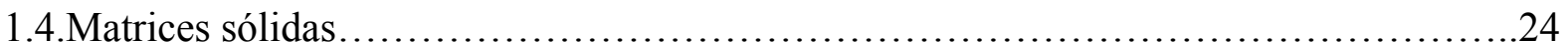

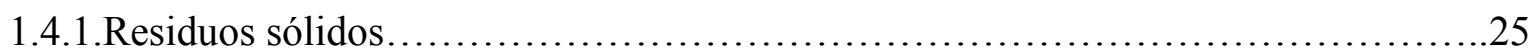

1.4.1.1. Arena de fundición..................................................... 25

1.4.1.2. Residuo de cosmética................................................26

1.4.2. Suelos tratados con plaguicidas ............................................ 27

1.4.2.1. Glifosato............................................................... 31

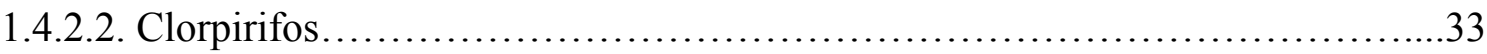

1.5.Ensayos de toxicidad .......................................................... 34

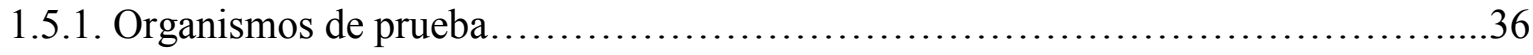

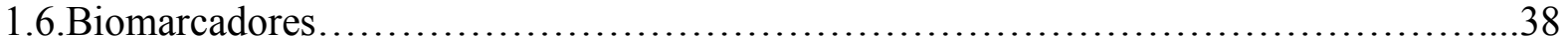

1.6.1. Enzimas de estrés oxidativo..............................................

1.6.2. Genotoxicidad............................................................ 40

1.7. Hipótesis............................................................46

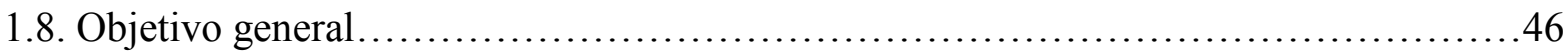

1.8.1. Objetivos específicos................................................... 46

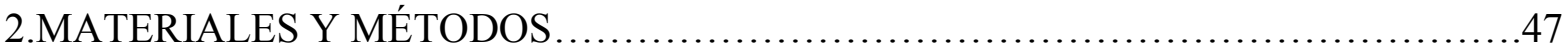

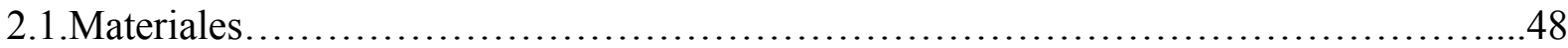

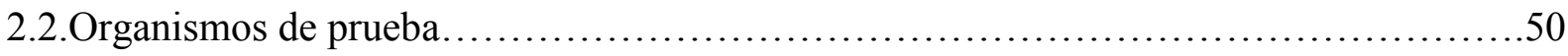

2.2.1.Plantas Terrestres..............................................................

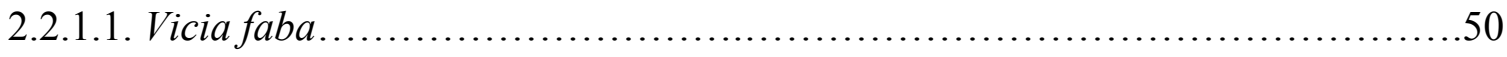

2.2.1.2. Lactuca Sativa ..................................................... 51

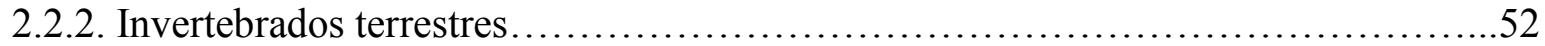

2.2.2.1. Lombrices de tierra (Anélidos) .............................................52

2.3. Matrices sólidas evaluadas..................................................... 
2.3.1. Muestreo y preservación de las muestras....................................57

2.4. Caracterización química de las matrices sólidas................................60

2.4.1. Muestras enteras............................................................

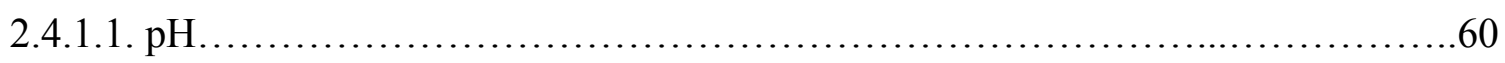

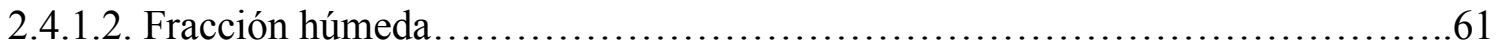

2.4.1.3. Sólidos volátiles......................................................61

2.4.1.4. Capacidad de retención de agua........................................61

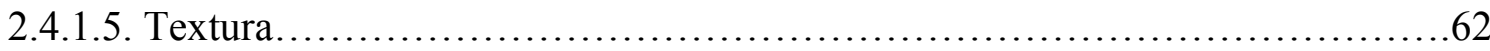

2.4.1.6. Clasificación de suelos según clave taxonómica de USDA...................62

2.4.1.7. Determinación de Carbono Orgánico Total (COT).............................................62

2.4.1.8. Cuantificación de metales...........................................63

2.4.1.9. Determinación de compuestos orgánicos...............................63

2.4.1.11. Determinación de Hidrocarburos Totales..................................64

2.4.2. Fracciones líquidas- Eluciones......................................65

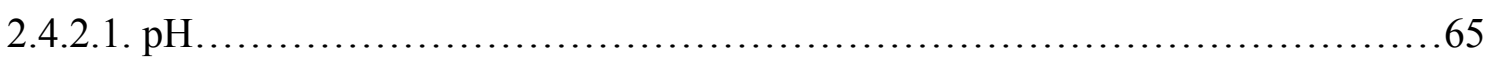

2.4.2.2. Amonio................................................................65

2.4.2.3. Determinación de metales.............................................65

2.4.2.4. Demanda química de Oxígeno (DQO) .................................66

2.4.2.5. Carbono Orgánico Total (COT) ....................................66

2.5. Evaluaciones ecotoxicológicas .........................................66

2.5.1. Ensayos con semillas de Lactuca sativa .............................67

2.5.2. Ensayos con plántulas de Vicia faba .................................... 72

2.5.3. Ensayos con Eisenia fetida .......................................... 77

2.6.Análisis estadístico...................................................... 95

3.RESULTADOS Y DISCUSIÓN .............................................. 97

3.1.Residuos sólidos.....................................................98

3.1.1. Arena de Fundición........................................................ 98

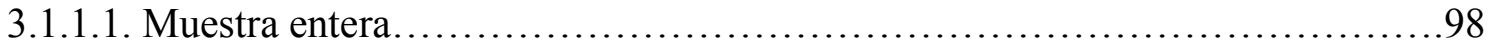

3.1.1.2. Fracción líquida-Elución..........................................110

3.1.2. Residuo de cosmética................................................... 121

3.1.2.1. Muestra entera..................................................... 121

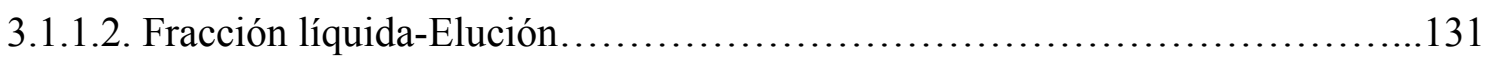

3.1.3. Evaluación integrada de los residuos sólidos estudiados..................... 140 
3.1.4. Conjunto de variables seleccionadas para la evaluación ecotoxicológica de residuos sólidos .141

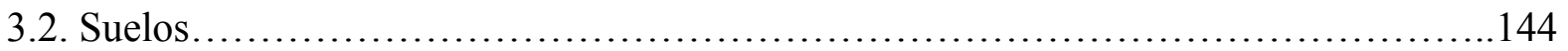

3.2.1.Muestras ambientales de suelos post aplicación de plaguicidas.....................145

3.2.1.1. Post-aplicación de glifosato............................................ 145

3.2.1.1.1. Muestra entera.................................................... 145

3.2.1.1.2. Fracción líquida-elución....................................... 150

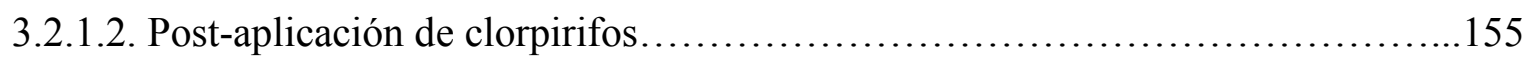

3.2.2.2.1. Muestra entera............................................... 155

3.2.1.2.2. Fracción líquida- elución.......................................... 160

3.2.2. Suelos tratados artificialmente con plaguicidas.................................. 164

3.2.2.1. Parámetros físicoquímicos del suelo..................................... 164

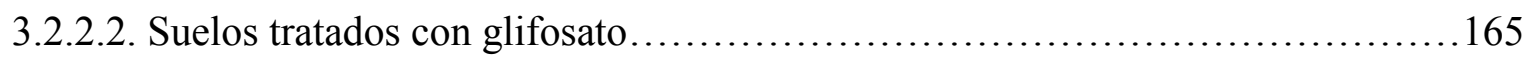

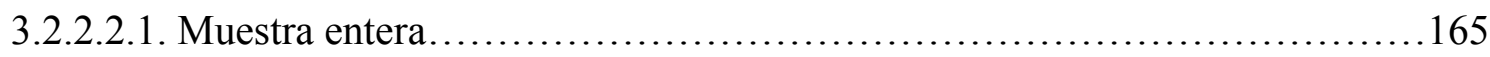

3.2.2.2.2. Fracción líquida- elución........................................ 171

3.2.2.3. Suelos tratados con clorpirifos ........................................ 176

3.2.2.3.1. Muestra entera.................................................... 176

3.2.2.3.2. Fracción líquida-Elución......................................... 182

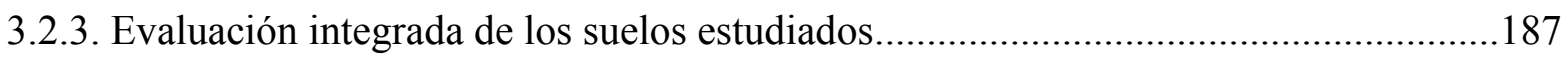

3.2.4. Conjunto de variables seleccionadas para la evaluación ecotoxicológica de suelos...188

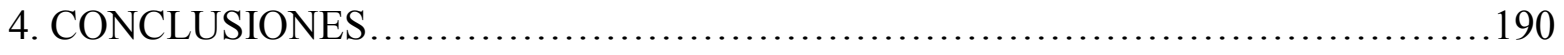

5. Referencias bibliográficas................................................. 196

Trabajos relacionados a la Tesis docotoral..........................................209 


\section{Agradecimientos}

Cuando decidí emprender este maravilloso viaje hacia Ítaca imaginé que las cosas no serían fáciles, sin embargo, durante la aventura y con la aparición de adversidades a veces me desanimé y otras veces aprendí a superarme. Nada en estos años ha sido fácil, pero hoy estoy feliz por este camino transitado junto a tantas personas que me han acompañado. Ítaca no me ha defraudado, atravesar este viaje ha sido una experiencia gratificante. Gracias a todos aquellos que fueron parte de este viaje.....

Al Dr. Walter Darío Di Marzio, por recibirme en el Programa de Investigación en Ecotoxicología, y sobre todo por depositarme su confianza. Quiero agradecerle especialmente su compromiso para el desarrollo de esta Tesis, su orientación en los aspectos conceptuales y experimentales, sus críticas constructivas que me ayudaron a crecer profesionalmente, y sobre todo por el apoyo recibido en todo momento.

A la Dra. María Elena Sáenz, por brindarme la posibilidad de realizar mi trabajo de Tesis doctoral. Por cada charla, cada explicación, cada experimento, cada crítica constructiva y cada corrección compartida. Por transmitirme su experiencia en cada momento y sobre todo por su apoyo a lo largo de este camino.

Al Dr. Marcelo Larramendy, por su invaluable aporte científico a lo largo de esta tesis, que me ayudaron en mi desarrollo profesional.

A mi padres, Cecilia y José, porque me dieron la vida, y su propia vida de trabajo y esfuerzo para ayudarme a llegar hasta aquí. Por su apoyo incondicional en todo momento, por su cariño y por su entrega generosa.

A mis hermanos, Daniela y Marcelo, por su apoyo cada vez que lo necesité, por compartir la vida, por cada charla por cada lágrima y por cada risa.

A mi sobrina y ahijada María Luján por regalarme sus sonrisas y su cariño, porque muchas veces fueron el motor que me dió las fuerzas para seguir adelante.

A todos mis familiares, por estar presentes siempre.

A cada uno de mis amigos (Marisol, Carla, Florencia, Sergio, Gimena, Sebastián, Álvaro, Mariela, Lucas, Hugo, José, Paula, Vale y Yanina) porque siempre estuvieron presentes a lo largo del camino. Todos contribuyeron con sus palabras y compartiendo conmigo momentos felices y difíciles.

A mis compañeros del Programa de Investigación en Ecotoxicología Lic. José Luis Alberdi y Lic. Santiago Martinez, por todos los momentos compartidos. De manera particular quiero agradecer a José Luis por cada charla y consejo recibido a lo largo de estos años. 
A mis compañeros de camino, tanto de grado como de posgrado, por las experiencias compartidas.

A la Universidad Nacional de Luján, por mi formación de grado y por brindarme un lugar de trabajo para realizar mi Tesis doctoral.

A la Universidad Nacional de La Plata, por permitirme realizar mi Doctorado.

Al Consejo Nacional de Investigaciones Científicas y Técnicas por las Becas otorgadas.

Al grupo de Biología Celular y Toxicología Ambiental de la Universidad del País Vasco, por recibirme en su laboratorio para realizar mis estadías de doctorado. Al Dr. Manu Soto por aceptarme, Dra. Amaia Irizar y Mg. Nerea García por enseñarme. Unai, Oihane, Alba, Txema, Joshua, Iratxe, Herminia, Eider, Ainize, Amaia, Beñat, Maren, Cristina, Alberto, Luisma... eskerrik asko*!!!!

A todos los que colaboraron de diferente manera para ayudarme a llegar a este momento...

Gracias a todos por acompañarme en este viaje hacia mi Ítaca, porque a pesar de haber llegado, la vida me seguirá llevando hacia otras Ítaca disfrutando de esta aventura.

- Muchas gracias en idioma Euskera 


\section{Resumen}

El crecimiento de la industrialización, la expansión poblacional, el desarrollo de nuevas tecnologías, la aplicación de agroquímicos para mejorar el rendimiento de las cosechas, son factores que generan el vertido de sustancias químicas al ambiente. Estas sustancias principalmente sintéticas, se incorporan al ambiente e incrementan su concentración de forma tal que pueden ejercer efectos perjudiciales sobre los seres vivos. Los ecosistemas terrestres reciben descargas puntuales de contaminantes provenientes de la disposición final de residuos de la actividad industrial. Por otro lado, los agro-ecosistemas reciben la aplicación de diferentes clases de plaguicidas de modo difuso, provenientes del empleo de los mismos para aumentar el rendimiento de los cultivos, minimizando las pérdidas por la presencia de malezas, agentes patógenos y acción de herbívoros. Estas descargas pueden convertirse en continuas por el aumento de la frecuencia de ambos procesos y pudiendo producir efectos a largo plazo en los ecosistemas.

Debido al interés creciente desde nuestra comunidad por la presencia de diferentes contaminantes que pueden afectar la salud humana, es sumamente necesario el desarrollo de herramientas para la evaluación ecotoxicológica de los residuos y/o plaguicidas que se liberan en el medio ambiente y afectan los ecosistemas circundantes.

Es objetivo del presente trabajo de tesis es brindar herramientas para la evaluación ecotoxicológica de residuos sólidos y suelos tratados con plaguicidas para comprender los efectos que estos pueden tener en los ecosistemas terrestres.

La evaluación ecotoxicológica integrada de matrices sólidas debe incluir el análisis químico de las mismas y biomarcadores sobre diferentes especies biológicas que permitan evaluar los efectos perjudiciales a fin de comprender su acción perjudicial en el ambiente.

Por lo antes expuesto, cada matriz sólida y su respectiva elución acuosa fueron químicamente caracterizadas. De forma paralela, se utilizó una batería de ensayos de diferentes organismos para evaluar los efectos de dos residuos industriales y de suelos tratados con dos plaguicidas. Los dos residuos provinieron de la actividad industrial, el primero correspondió a una arena de fundición perteneciente a la industria metalúrgica; y el segundo consistió en un lodo de depuradora generado por una industria cosmética. Ambos residuos son importantes, debido a que pertenecen a industrias con alta productividad en Argentina, así como también por la presencia de sustancias altamente peligrosas para el ambiente. Además, se evaluaron suelos tratados artificialmente con formulados comerciales del herbicida glifosato y del insecticida clorpirifos, en dosis de aplicación recomendadas por los fabricantes. Adicionalmente se 
evaluaron suelos naturales provenientes de zonas de cultivo intensivo de soja que recibieron la aplicación de ambos plaguicidas. Los mismos fueron elegidos ya que estos plaguicidas constituyen los más utilizados en los cultivos de soja que cubren 16 millones de hectáreas de área cultivada en el país.

En el presente trabajo se utilizaron como organismos de prueba ejemplares de las especies de planta Lactuca sativa y Vicia faba, y la especie de oligoqueto Eisenia fetida, responsable del ciclado de nutrientes en el suelo. Siguiendo las recomendaciones de las normas europeas se trabajó tanto con el residuo y/o suelo sólido entero y con su elución acuosa. Es importante remarcar que la evaluación de la elución acuosa permite evaluar la movilidad de los componentes del residuo y/o del suelo entre diferentes compartimentos ambientales.

La evaluación de la matriz sólida se llevó a cabo determinando la inhibición de la germinación y la elongación de la raíz en semillas de L. sativa, expuestas durante 120 h, siguiendo los protocolos establecidos por US EPA (USEPA, 1989). Además se determinó la mortalidad, cambios en la fórmula celular, determinación de índices indicadores de estado nutricional, cito y genotoxicidad, en E. fetida, expuestas de manera in vivo durante 7 y 14 días, siguiendo los protocolos estandarizados de OECD (OECD, 1989). En el caso de las eluciones líquidas la evaluación de su toxicidad se llevó a cabo mediante la determinación biomasa y de biomarcadores de estrés oxidativo en raíces de $V$. faba expuestas durante $48 \mathrm{~h}$. Los biomarcadores elegidos fueron actividad de enzimas antioxidantes (catalasa y guayacol Peroxidasa), y grado de peroxidación de lípidos (PL). En el caso de E. fetida se utilizaron sus celomocitos expuestos de manera ex vivo durante $1 \mathrm{~h}$ a las eluciones de las diferentes matrices evaluadas, para la determinación de proporciones celulares, índices trófico y cito y genotoxicidad de las mismas. Se obtuvo como resultado un amplio abanico de respuestas en los diferentes biomarcadores evaluados.

Para la evaluación de la matriz sólida de los dos residuos industriales, la germinación de semillas de L. sativa estuvo inhibida de manera dosis-dependiente. Sin embargo el efecto tóxico del residuo de cosmética fue evidente a menores concentraciones. En el caso de los suelos tratados con glifosato la germinación sólo se vio inhibida a la mayor dosis de aplicación utilizada, mientras que clorpirifos inhibió la germinación de manera significativa a la menor dosis de aplicación evaluada. La elongación de las raíces fue en todos los residuos y suelos evaluados en su forma sólida, el parámetro más sensible, ya que la CMEO derivada de esta variable de respuesta resultó ser la más baja, considerando el total de parámetros evaluados. 
Todas las matrices sólidas evaluadas ejercieron efectos genotóxicos en celomocitos de $E$. fetida expuestos in vivo durante 7 y 14 días. Los estudios y evaluaciones realizados sobre los celomocitos permitieron establecer la acción sobre proporciones de tipos celulares, índices nutricionales y la viabilidad celular, reflejando un claro efecto tóxico de la fracción sólida en las condiciones de ensayo.

Las eluciones acuosas de las matrices sólidas evaluadas ejercieron acción sobre la actividad de las enzimas involucradas en la respuesta al estrés oxidativo, dependiente de la concentración y del tipo de residuo. Las enzimas resultaron inhibidas o estimuladas evidenciando efectos a nivel de la producción de especies reactivas del oxígeno. El orden de sensibilidad para los biomarcadores en $V$. faba fue CAT $>$ GPOD $>$ PL. La acción sobre PL fue el biomarcador menos sensible de toda la batería realizada, ya que no evidenció efectos para todas las dosis y muestras ensayadas. En el caso de los celomocitos de E. fetida expuestos de manera ex vivo durante $1 \mathrm{~h}$, las eluciones de todos los residuos y suelos evaluados resultaron ejercer efectos cito y genotóxicos. Asimismo la exposición ex vivo produjo alteraciones en la fórmula celular y en los índices tróficos, para las células expuestas a las eluciones de residuos sólidos y suelos tratados con plaguicidas.

Respecto a la problemática de los residuos sólidos, la disposición final de los mismos se basa en determinar su peligrosidad. En la legislación europea la caracterización ecotoxicológica de un residuo es parte de su definición de peligroso o no peligroso, incluido en el criterio de peligrosidad "Ecotóxico" (H14), determinándose en base al riesgo que el residuo representa para uno o más sectores del ambiente. En Argentina, la definición de un residuo en peligroso o no se basa en algunos parámetros considerados bajo la Ley Nacional de residuos peligrosos 24.051 y la Ley Provincial 11.720, incluyendo el criterio de "ecotoxicidad" que se estima a partir de la información disponible del residuo. En el caso que no se disponga de información, se deben realizar ensayos de ecotoxicidad utilizando una batería de organismos pertenecientes a tres niveles ecológicos. De todas maneras, los tipos de ensayos o si los mismos deben incluir exposiciones agudas o crónicas, no están definidos en las leyes. A nivel mundial se han propuesto tanto la batería de ensayos a utilizar, como los criterios a utilizar para la definición de valores umbrales que permitan la determinación del criterio H14 de ecotoxicidad, encontrándose todavía en discusión.

En consonancia con las recomendaciones internacionales, los resultados obtenidos permiten proponer la determinación de ciertos parámetros para evaluar la ecotoxicidad de un residuo antes de ser liberado en el ambiente. La determinación de índices y citotoxicidad en celomocitos de E. fetida expuestos de manera ex vivo durante $1 \mathrm{~h}$, para las eluciones acuosas y 
la elongación de raíces en L. sativa para residuos sólidos, constituyen dos métodos rápidos, sencillos y reproducibles para la clasificación y separación de residuos ecotóxicos. Las evaluaciones ecotoxicológicas mencionadas consideran también la reducción de tiempos de ensayo y el número de individuos involucrados en la evaluación de los efectos perjudiciales.

La batería de ensayos propuesta conjuntamente con la determinación de los parámetros fisicoquímicos de las muestras permitió separar residuos ecotóxicos de los no ecotóxicos. En nuestro caso ambos residuos resultaron ecotóxicos y no deberían ser liberados al ambiente.

Los resultados del presente trabajo ponen de manifiesto la necesidad de evaluar ecotoxicológicamente los residuos antes de su disposición final en el ambiente. En el caso de los plaguicidas glifosato y clorpirifos, los resultados obtenidos evidencian efectos perjudiciales de ambos plaguicidas, en todos los organismos no-blanco utilizados como modelos de ensayo. En este aspecto es destacable remarcar que tanto los suelos contaminados artificialmente como los suelos provenientes de la zona de cultivo intensivo de soja y sus correspondientes eluciones ejercieron efectos nocivos sobre los organismos utilizados y los biomarcadores evaluados.

La aplicación de una batería de ensayos estandarizados considerando diferentes variables de respuestas en conjunto con diversos biomarcadores a nivel bioquímico, celular y molecular constituyen una estrategia integrada para la evaluación de residuos y suelos agrícolas, generando herramientas de gran utilidad para determinar la ecotoxicidad de un residuo y/o suelo. 


\section{Abstract}

The growth of industrialization, population expansion, development of new methodologies and strategies for using agrochemicals to improve crop yields are factors that cause the discharge of chemicals into the environment. These substances, mainly synthetic, are incorporated into the environment increase its concentration, and thus causing potential harmful effects on living organisms.

Terrestrial ecosystem receives point sources discharges from industrial activity, while agroecosystems receives diffuse ones, such as pesticides, minimizing loss by weeds, pathogenic agents and herbivore action, among other factors. These discharges can become continuous by increasing the frequency of processes producing long-term side effects on ecosystems.

Due to growing interest and concern about the presence of different pollutants that can affect human health, is extremely necessary the development of new tools for the ecotoxicological evaluation of waste and/or pesticides that are released into the environment affecting, then, the surrounding ecosystems.

The aim of this Doctoral Thesis is to provide new tools for an ecotoxicological assessment of solid wastes and soils treated with pesticides in order to understand their effects on terrestrial ecosystems.

Comprehensive ecotoxicological evaluation of solid matrix must include chemical analysis and biomarkers employing different biological species to assess the adverse effects to understand its harmful action on the environment. Thus, each solid matrix and its aqueous elution were chemically characterized.

Simultaneously, a battery of bioassays with different organisms was used to evaluate the effects of two industrial waste and soils treated with two commonly employed pesticides in our country.

The industrial wastes corresponded to foundry sand, related to metallurgical activity, and sludge produced by cosmetic industry. Both wastes become important for their high production in Argentina and for the content of hazardous elements released into the environment. Besides, soils sprayed with commercial formulations of chlorpyrifos and glyphosate were evaluated. In addition, soils of extensive fields were analyzed. The herbicide glyphosate and the organophosphorus insecticide chlorpyrifos are frequently used not only in Argentine fields but also worldwide. In Argentina, the extension of the soybean crops region has reached around sixteen millions of hectares. 
In this work the plant species Lactuca sativa and Vicia faba and the oligochaete species Eisenia fetida were used as test organisms.

Following the recommendations of European standards, both the solid waste and its aqueous elution were evaluated. It is important to emphasize that the evaluation of the aqueous elution allows to evaluate the mobility of chemical substances present in the waste or soil throughout different environmental compartments.

The solid matrix was evaluated by means of the inhibition of seed germination and root elongation in L. sativa seeds exposed during $120 \mathrm{~h}$ following standardized protocols (US EPA, 1989). Besides, the mortality, change in cellular proportions, nutritionals indices, cyto and genotoxicity in E. fetida exposed in vivo during 7 and 14 days were evaluated following OECD protocols (OECD, 1989). Biomass growth, level of lipid peroxidation (LP) and antioxidative stress enzymes (CAT and GPOD) were assayed in Vicia faba roots exposed to aqueous elutions. The coelomocytes of E. fetida were exposed ex vivo during $1 \mathrm{~h}$ to aqueous elutions determining the change in the proportion coelomocyte subpopulations, nutritionals indices, cyto and genotoxicity at the end of the exposure time. A large range of toxicity responses were obtained through the analysis of different endpoints.

For the solid matrix corresponding to industrials wastes, seed germination was inhibited in a dose dependent manner. However, the toxic effect of cosmetic sludge was evident at lower concentrations (3-25\% for cosmetic sludge and $50-100 \%$ for foundry sand waste). In the case of soils treated with glyphosate, germination was inhibited only at the highest application rate (6 L/ha), while chlorpyrifos significantly inhibited germination at the lowest one $(1 \mathrm{~L} / \mathrm{ha})$. The L. sativa root elongation appeared as the most sensitive parameter among all assayed endpoints for both waste and soil since the LOEC values derived from this variable were the lowest ones.

The evaluated solids (both waste and soils) induced genotoxic effects on coelomocytes of $E$. fetida exposed in vivo during 7 and 14 days. The evaluation performed over the coelomocytes allowed to establish effects on cellular proportions, nutritionals indices and cellular viability. These responses showed a clear toxic effect of the elutions.

The aqueous elution of solid matrix exerted action over the activity of enzymes involved in antioxidative stress defense mechanisms in a dependent manner to both concentration and waste type. The enzymes showed inhibition or stimulation as a response of the production of reactive oxygen species. The order of sensibility of these biomarkers in roots of $V$. faba seedlings was $\mathrm{CAT}>\mathrm{GPOD}>\mathrm{LP}$. 
Lipid peroxidation was not modified regardless of the concentration assayed. Aqueous elution of both waste and soils exerted cyto and genotoxic effects on E. fetida coelomocytes exposed ex vivo for $1 \mathrm{~h}$. Also, in ex vivo exposure, aqueous elutions of solid matrix produced alterations in cellular proportion and in nutritional indices.

Considering solid waste disposal, some aspect related to the choice of geographical location, the way they are buried as well as transportation between generation sites and places for their final deposition are established based on the presence or not of hazardous properties indicated in the European legislation about wastes. According to these criteria, a waste is classified as hazardous or non-hazardous. Ecotoxicological criteria for the classification of wastes are present in the European Legislation. The hazard Ecotoxicity criteria (H14) is defined based on the potential risk of a waste for one or more sectors of the environment. In Argentina, in particular, same parameters are required to define whether a waste is hazardous or not under both the National 24.051 and Provincial 11.720 laws. Among them, ecotoxicity is included and it is estimated from the available information of the waste. In the case this information does not exist, toxicity tests must be performed using a battery of assays employing species belonging to three ecological levels. However, the type of toxicity tests to be employed or whether evaluation should be performed after acute or chronic exposure, for example, is not stated. Worldwide, a battery of tests has been proposed, although criteria used to define thresholds that allow the determination of ecotoxicity following the Ecotoxic Guidelines (H14) is still under discussion.

In accordance to international recommendations, the results presented in the current Doctoral Thesis allow to propose the determination of some parameters to evaluate the ecotoxicity of waste before being released into the environment. The determination of nutritionals indices and cytotoxicity in E. fetida coelomocytes exposed ex vivo for $1 \mathrm{~h}$ for evaluation of aqueous elutions as well as the root elongation in L. sativa seed, are fast, easy and reproducible methods to perform for the classification of wastes in terms of their ecotoxicity. Ecotoxicological assessments, as previously highlighted, consider reduced both length of the assay and the number of individuals involved in the evaluation of harmful effects.

The battery of biological assays proposed herewith together with the physico-chemicals parameters of samples allowed us to discriminate between ecotoxic and non-ecotoxic wastes. In the case of wastes we evaluated, results demonstrated that both were of ecotoxic concern and they should be not released into the environment.

The results of this study highlight the need of an ecotoxicological evaluation of wastes before final disposal in the environment. In the particular case of two pesticides, namely glyphosate 
and chlorpyrifos, the results demonstrate the jeopardizing effects of both agrochemicals on all non-target organisms used as test models. Thus, it seems remarkable to note that artificially contaminated soils and soils from an area of intensive cultivation of soybeans and its corresponding elutions are able to exert adverse effects on soil organisms and with the biomarkers assayed.

Finally, the use of a battery of standardized tests considering different response variables together with various biochemical biomarkers, both at cellular and molecular levels, are an integrated strategy for the assessment of agricultural soils and industrial wastes and, thus, to be considered as useful and valid tools for ecotoxicity determination. 


\section{Abreviaturas}

$\mu \mathrm{L}:$ microlitros

ADN: ácido desoxirribonucleico

AIA: Ácido indolacético

ALMP: Agarosa de bajo punto de fusión

ANMAT: Administración Nacional de Medicamentos, Alimentos y Tecnología médica Argenbio: Consejo Argentino para la Información y el Desarrollo de la Biotecnlogía ASAE: American Society for Agricultural Engineers Standard

CASAFE: Cámara Argentina de la Sanidad Agropecuaria y Fertilizantes

CAT: Catalasa

CE50: Concentración Efectiva 50

CENO: máxima concentración en la cual no se observan efectos significativamente diferentes respecto de los organismos controles.

CHO: Chinese hamster ovary (células de ovario de hámster chino)

CIC: Capacidad de Intercambio de Cationes

CL50: Concentración Letal 50

cm: centímetros

CMEO: Concentración Mínima en la cual se observan efectos significativamente diferentes respecto de los organismos control.

COT: Carbono Orgánico Total

CRA: Capacidad de Retención de Agua

DDT: dicloro-difenil-tricloroetano

DMSO: sulfóxido de dimetilo

DQO: Demanda Química de Oxígeno

DSS: Duodecil Sulfato Sódico

EC: ensayo cometa

EDTA: ácido etilendiaminotetraacético

EPSPS: Enzima enolpiruvilsiquimato-3-fosfatosintasa

ESP: 5-enolpiruvilsiquimato-3-fosfato

ERO: Especies Reactivas del Oxígeno

g: gramos

GPOD: Guaiacol Peroxidasa

h: hora 
ha: hectárea

HCH: Hexaclorociclohexanos

HCL: ácido clorhídrico

IARC: International Agency for Research on Cancer (Agencia Internacional de Investigación em Cancer)

ISO: International Organization for Standardization (Organización Internacional de

Normalización)

L: litro

LITA: Lombriz Índice Trófico Absoluto

LITAR: Lombriz Índice Trófico Relativo

ICCT: Índice Corporal de Celomocitos Totales

MDA: malonaldehido

min: minutos

$\mathrm{mL}$ : mililitros

mM: milimolar

nm: nanometro

OECD: Organization for Economic Co-operation and Development (Organización para la

Cooperación y el Desarrollo Económico)

OP: insecticidas organofosforados

PBS: buffer fosfato salino

PFCP: productos farmacéuticos y de cuidado personal

TBA: ácido tiobarbitúrico

TBARS: sustancias reactivas al ácido tiobarbitúrico

TCA: ácido tricloroacético

TCDD: 2,3,7,8-tetraclorodibenzo-p-dioxina

TCLP: Toxicity Characteristic Leaching Procedure

US EPA: United States Environmental Protection Agency (Agencia de Protección Ambiental de los Estados Unidos)

WHO: World Health Organization (Organización Mundial de la Salud) 
1. INTRODUCCION 


\subsection{Consideraciones Generales}

El crecimiento y desarrollo de las poblaciones humanas implican un impacto directo sobre las condiciones naturales de los ecosistemas (Harrison, 1996). Entre otros aspectos, traen aparejado un aumento en la incorporación de sustancias químicas en el ambiente. En términos generales este proceso de incorporación de sustancias puede ser gobernado por descargas puntuales y continuas o por fuentes difusas (Newman y Clements, 2008). Las primeras tienen relación principalmente con los procesos depurativos, los cuales generan dos tipos de efluentes o residuos, uno líquido y otro sólido. La segunda clase se asocia principalmente a la aplicación de plaguicidas como parte de la actividad agrícola (Walker et al, 2006). El posible efecto que estas sustancias pueden ejercer sobre el ambiente y su vinculación con la salud humana ha generado la necesidad de desarrollar métodos eficaces para determinar su riesgo ecológico. En este marco, el enfoque Toxicológico centra sus estudios en la determinación de efectos tóxicos, generalmente letales, utilizando una especie de mamífero como organismo de prueba y la extrapolación de la información obtenida a la especie humana. Por otro lado, la Ecotoxicología, que tiene sus orígenes en la Toxicología tradicional, surge como una de las primeras aproximaciones de considerar al hombre interconectado con el ambiente que lo rodea (Römbke y Moltmann, 1996). En este sentido, uno de los objetivos principales que comparten ambas disciplinas es relacionar la cantidad de una sustancia tóxica, a la cual serán expuestos los organismos, con los efectos producidos por la misma. Para la Toxicología el centro de estudio es el hombre y para la Ecotoxicología, el ambiente. Truhaut (1977) es el primero que introduce una definición para esta última, como la ciencia que estudia los efectos de las sustancias químicas sobre organismos, presentes en los ambientes acuáticos y terrestres evaluando la toxicidad sobre poblaciones, comunidades y ecosistemas. La misma se plantea como una herramienta de caracterización toxicológica de los diferentes compartimentos ambientales que reciben la incorporación de las sustancias químicas por la acción antropogénica. Puede afirmarse, entonces, que la evaluación química de la calidad y cantidad de compuestos presentes en una matriz compleja es insuficiente para predecir sus efectos toxicológicos (Ferrari et al, 1999; Stiernströn et al, 2011). Surge entonces la necesidad de caracterizar los efectos causados por las diferentes matrices ambientales mediante el empleo de métodos biológicos o la realización de bioensayos. La principal ventaja en la utilización de bioensayos para la evaluación de la ecotoxicidad de un residuo, suelo o una muestra líquida, es el carácter integral de los mismos. La evaluación integral de los efectos permiten poner en 
evidencia la existencia de toxicidades aditivas, antagónicas o sinérgicas (Wilke et al, 2008; Pandard et al, 2006). De esta manera, un estudio integral en la evaluación del riesgo potencial de una determinada muestra ambiental implica la combinación del análisis químico junto con la ejecución de una batería de ensayos biológicos (Moser y Römbke, 2005). Estos estudios ecotoxicológicos utilizan especies denominadas estándares para evaluar los efectos potencialmente tóxicos producidos por las sustancias químicas, y generalmente son llevados a cabo en condiciones controladas de laboratorio. Intentan incluir además de la toxicidad, la evaluación de la disponibilidad biológica y las interacciones de los tóxicos en cada compartimento ambiental. Uno de los desafíos de la Ecotoxicología es correlacionar el grado en que las respuestas biológicas de las especies utilizadas en el laboratorio representan o se relacionan con las respuestas de las especies expuestas en condiciones naturales o de campo (Clements y Newman, 2002).

En la evaluación ecotoxicológica de muestras sólidas, como suelos y residuos, se realizan dos enfoques o estrategias de estudio: por un lado puede evaluarse la toxicidad de la fase sólida en sí misma, y por otra parte estudiar el efecto sobre las variables de respuesta seleccionadas producidos por su fracción líquida o elución (Ferrari et al, 1999; Stiernström et al, 2012). Este enfoque tiene particular importancia porque permite conocer la movilidad de las sustancias tóxicas en la matriz que las contiene y su capacidad de migrar entre los distintos compartimientos del ecosistema (van Gestel et al, 2001; Domene et al, 2008; Widziewicz et al, 2012). De esta manera, pueden generar efectos no deseados sobre aguas subterráneas o llegar por escorrentía o lavado a cuerpos de agua, alterando su dinámica natural. Estos procesos pueden darse en los suelos agrícolas que reciben la aplicación de plaguicidas y en suelos que son sujetos a disposición final de residuos sólidos industriales y/o municipales (Tarradellas et al, 1997).

Por otro lado, desde el punto de vista regulatorio es importante contar con resultados derivados de ensayos ecotoxicológicos a la hora decidir la disposición final de un residuo sólido. De este modo, uno de los objetivos de la Ecotoxicología es brindar herramientas para la correcta clasificación de los mismos, basada en su potencial tóxico.

\subsection{Legislación}

La liberación de sustancias en el ambiente debe estar debidamente controlada para evitar la dispersión entre los diferentes compartimentos del ecosistema de sustancias nocivas para los 
seres vivos, incluido el hombre. La mayoría de los residuos sólidos, de origen industrial, son depositados dentro de los predios industriales en sectores determinados para tal fin. En otros casos son enterrados en canteras o cavas las cuales deben acondicionarse de manera particular para evitar contaminación del ambiente circundante así como del agua subterránea. En el caso particular de lodos activados producidos por plantas de depuración biológica de efluentes líquidos, éstos pueden utilizarse como fertilizantes debido a su elevada concentración en nutrientes. Para ello, deben recibir un tratamiento adicional para la reducción de patógenos. Sin embargo, estos sólidos pueden presentar elevadas concentraciones de elementos perjudiciales como metales o sustancias orgánicas liposolubles. Estos residuos dispuestos en suelos naturales, sin las protecciones necesarias ni su monitoreo permanente, independientemente de su contenido de humedad, quedan expuestos a condiciones ambientales que pueden dispersar sustancias nocivas para los seres vivos entre los diferentes compartimentos ambientales. El agua de lluvia puede generar procesos de lixiviación de metales y otros compuestos solubles que pudiesen encontrarse presentes en los residuos movilizándolos hacia el agua subterránea o por vía superficial hacia ríos o arroyos. En nuestro país, la Ley Nacional 24051 regula la generación, manipulación, transporte y tratamiento de los Residuos peligrosos en el territorio Nacional. Los residuos son considerados como peligrosos según las siguientes características: corrosividad, reactividad, inflamabilidad y toxicidad. Un residuo será considerado peligroso cuando presenta más de una de estas propiedades. Sin embargo, puede no presentar ninguna de las características consideradas peligrosas para esta Ley y ser perjudicial para el medio ambiente. Esto se debe a que la clasificación de los residuos no se basa en criterios de toxicidad sino en la presencia o ausencia de sustancias químicas consideradas peligrosas. El anexo II de esta Ley establece qué sustancias son las que si se encuentran presentes en un residuo le conferirán la clasificación de peligroso. El criterio H14 de esta ley establece que serán consideradas ecotóxicas aquellas "Sustancias o desechos que, si se liberan, tienen o pueden tener efectos adversos inmediatos o retardados en el ambiente debido a la bioacumulación o los efectos tóxicos en los sistemas bióticos". Este criterio, si bien define como debe ser interpretada la ecotoxicidad de un residuo, no define los bioensayos ni la metodología que deben ser realizados para definir si es considerado ecotóxico o no. Tampoco este punto establece qué criterio de toxicidad debe ser tomado para definir un residuo cómo peligroso para el ambiente. Así esta definición resulta incompleta, por lo que se deberían aportar herramientas que permitan definir con claridad y precisión la ecotoxicidad de un residuo. El mismo anexo también define que pueden ser consideradas peligrosas a "Sustancias que pueden por algún 
medio, después de su eliminación, dar origen a otra sustancia, por ejemplo un producto de lixiviación, que posee alguna de las características arriba expuestas”. Este criterio enfatiza la necesidad de evaluar no sólo los residuos sólidos sino también los productos de su elución o lixiviación, para regular la eliminación de residuos que podrían ser peligrosos para los diferentes compartimentos del ambiente. A nivel de la Provincia de Buenos Aires, la resolución 1532/06 establece un criterio de toxicidad a fin de evitar el traslado de residuos tóxicos en el territorio provincial. En el anexo III de la misma, se establece que "para definir la toxicidad potencial de los residuos que pretendan ingresar al territorio de la Provincia de Buenos Aires, se deberá realizar sobre estos ensayos de toxicidad. En todos los casos, los ensayos de toxicidad deberán incluir una especie representante del nivel trófico denominado productores primarios y una especie del grupo de los consumidores o detritívoros según el ambiente". La normativa establece qué ensayos estandarizados y qué organismos deben utilizarse para evaluar tanto residuos líquidos como sólidos. En el caso de los residuos líquidos (efluentes) se establecen los ensayos de toxicidad en algas (productores primarios) y cladóceros y/o peces (consumidores). Por otro lado, para los residuos sólidos se establecen los ensayos de germinación de semillas en diferentes especies de plantas superiores (productores primarios) y el ensayo de toxicidad aguda en oligoquetos tales como Eisenia fetida. Además, esta normativa establece un criterio de aceptabilidad para que los residuos sean o no considerados como ecotóxicos. Este criterio establece que "Un residuo será considerado tóxico si en su forma "original" o sin diluir, tanto líquido, sólido como semisólido, produce un efecto inhibitorio o estimulatorio, en al menos una de las especies de prueba, superior al $30 \%$ sobre las variables de respuesta medidas en cada caso, respecto de las mismas variables en los grupos considerados controles". Cuando se evalúa la ecotoxicidad de un residuo pueden tomarse dos enfoques diferentes. Por un lado se puede determinar la toxicidad del residuo en su forma sólida original y por otro lado, su elución acuosa. La evaluación integrada de los parámetros generados durante el desarrollo de ambas etapas permite una mayor comprensión de la toxicidad asociada a los diferentes tipos de residuos, mejorando de esta manera la información utilizada en la toma de decisiones para su disposición final.

Por lo expresado anteriormente queda evidenciado que es sumamente necesaria la evaluación ecotoxicológica de los residuos antes de su disposición final. Esta evaluación no sólo debe incluir análisis químicos, sino que debe complementarse con una batería de ensayos biológicos a fin de comprender los posibles efectos de las matrices sólidas, tales como los residuos sólidos (Pandard y Römbke, 2013). Sin embargo, es necesario definir qué ensayos realizar y sobre qué organismos así como las variables de respuestas más adecuadas y 
prácticas a la hora de realizar las experiencias. En este aspecto, ensayos de corta duración con organismos representativos del ambiente y la determinación de parámetros de respuesta sensible podrían ser los más recomendables para ser incorporados en la ejecución de la legislación vigente. Asimismo, contribuirían a establecer reglamentariamente un nivel de aceptabilidad que permitiera clasificar de manera efectiva a los residuos como ecotóxicos y no ecotóxicos.

\subsection{Ecosistemas terrestres}

El suelo es un sistema abierto, heterogéneo y dinámico, posee factores bióticos y abióticos que interactúan y se modifican entre sí. Por lo tanto, el suelo es un recurso que no puede ser estudiado separando la matriz física de sus componentes biológicos debido a que todas las características que el mismo presenta son consecuencia de las interacciones entre ambos factores (Breure et al, 2005).

La matriz física o abiótica del suelo, según los estados de agregación de la materia en los que se encuentran sus componentes, se encuentra constituida de tres fases. La fase sólida se halla compuesta por los componentes orgánicos e inorgánicos que dan lugar a la estructura del suelo. La forma, el tamaño y la resistencia constituyen parámetros para la clasificación de la estructura del mismo. Estos arreglos también incluyen el espacio poroso dentro y entre las partículas de los agregados, que de acuerdo al diámetro de los mismos cumplen la función de almacenar agua o gases, facilitar el drenaje y participar del intercambio gaseoso. Este espacio poroso posibilita, además, las interacciones de las partículas de suelo con la biota presente en el ecosistema. Las partículas del suelo tienen tamaños muy variables. La textura de un suelo define la relación porcentual de los grupos de partículas menores a $2 \mathrm{~mm}$ de diámetro, conocidas como arena, limo y arcilla. La textura dota al suelo de diferentes características en cuanto a su permeabilidad, porosidad y capacidad de retención de agua. Los suelos presentan además sustancias coloidales tales como las arcillas, los óxidos y las sustancias húmicas (Conti, 2005).

La introducción de sustancias químicas en el suelo puede conducir a cambios en la estructura del mismo que pueden afectar a las comunidades que lo habitan (Saterbak et al, 1999). Factores físicos (como la erosión) o antropogénicos (como la ganadería y la agricultura intensiva) pueden deteriorar la estructura del suelo, alterando las relaciones naturales entre sus componentes. El suelo puede presentar características propias tales como acidez, capacidad de 
intercambio catiónico, capacidad de intercambio aniónico y cantidad de materia orgánica presente. El pH es una de las determinaciones químicas más importantes y simples que pueden realizarse en un suelo (Vazquez, 2005). Este parámetro brinda información crucial para conocer el potencial agrícola del mismo, estimar la disponibilidad de nutrientes esenciales y predecir el comportamiento y disponibilidad de diferentes contaminantes. Adicionalmente, permite predecir los cationes dominantes en los coloides del suelo y está involucrado en la retención de plaguicidas, factor crucial al momento de evaluar la toxicidad de los mismos y su persistencia. Diferentes factores pueden influir en la variación del pH de un suelo. Algunos son de origen natural, mientras que otros factores son causados por actividades humanas (Casas, 2003; Vazquez, 2006). En el primer caso podemos citar el origen geológico del propio suelo, las precipitaciones (que tienden a acidificar el suelo por lixiviación de las bases disueltas), procesos de mineralización que liberan protones y la presencia de ácidos húmicos que presentan grupos ácidos. Entre los factores no naturales, la agricultura puede afectar el pH del suelo por diferentes procesos. Por un lado, la extracción de bases por parte de los cultivos acidifica los suelos y por otro lado el uso de fertilizantes puede dejar residuos ácidos o alcalinos de acuerdo a su estructura química de los mismos. La calidad del suelo es uno de los factores más importantes en el mantenimiento de la biosfera (Wang y Gong, 1998). En general se sostiene que la materia orgánica de un suelo es su principal indicador de la calidad y productividad. En términos generales, la materia orgánica de los suelos está constituida por todas las sustancias carbonadas orgánicas presentes en el mismo. En este grupo amplio podemos incluir desde materiales vegetales frescos sin descomponer hasta cadenas carbonadas muy transformadas y estables como los ácidos húmicos. Cuanto mayor sea el porcentaje de materia orgánica en un suelo mayor será su capacidad de retener agua. Además, el contenido de materia orgánica de un suelo influye sobre la toxicidad de diferentes compuestos químicos, sobre todo, modificando la biodisponibilidad de los compuestos químicos (van Herwijnen et al, 2007). La materia orgánica tiene una elevada capacidad para secuestrar especies químicas con cargas positivas, propiedad definida como CIC. Suelos con alta CIC reducen la toxicidad de elementos positivamente cargados, tales como metales pesados y/o no pesados. La preservación de la calidad del suelo es de suma importancia tanto para áreas urbanas como rurales debido a que éste es el soporte de las mismas (Breure et al, 2005). Esta calidad debe mantenerse en base a la evaluación conjunta de aspectos químicos y biológicos. Debido a que los suelos son ambientes comúnmente utilizados para la disposición de residuos, es importante evaluar los efectos adversos que los mismos pudieran tener en la estructura y función del ecosistema terrestre. La disposición final 
de residuos que contengan sustancias perjudiciales, en las áreas urbanas, o el uso intensivo de plaguicidas en las áreas rurales, pueden generar la pérdida o alterar la calidad del suelo. Así, es dable resaltar la importancia de la evaluación ecotoxicológica de manera global de los efectos que podrían causar la disposición final incorrecta de residuos industriales en términos de su caracterización toxicológica. Asimismo, la aplicación agrícola de plaguicidas, sobre todo en las zonas de cultivo intensivo, también contribuye a la degradación del ecosistema terrestre. En ambos casos la alteración de la calidad del suelo puede deberse a cambios en la matriz físico-química como así también a la pérdida de biodiversidad debido a la presencia de sustancias tóxicas.

\subsection{Matrices sólidas}

Las matrices sólidas son sistemas heterogéneos de distinta naturaleza y características que constituyen mezclas complejas de sustancias orgánicas e inorgánicas. Tanto los ecosistemas acuáticos como terrestres contienen compartimentos constituidos por estos sistemas heterogéneos (Römbke y Moltmann, 1996). En los ecosistemas acuáticos, los sedimentos constituyen una matriz sólida donde se producen fenómenos de degradación, depósito de sustancias orgánicas e inorgánicas, procesos de transformación biótica y abiótica, entre otros (Ingersoll, 1995). En los ecosistemas terrestres, el suelo constituye una matriz sólida con características que permiten tanto el desarrollo de una comunidad biótica natural como su utilización para la actividad agrícola (Nogueira Cardoso y Lopes Alves, 2012; Burton et al, 2002). Pueden ser utilizados como rellenos sanitarios o como sitios de disposición de los residuos sólidos generados por los sistemas de tratamientos de efluentes líquidos provenientes de la actividad industrial (Manahan, 1990; Manahan, 2001). Los suelos destinados a uso agrícola reciben el aporte de distintas sustancias químicas que son utilizadas para disminuir la acción desfavorable sobre el rendimiento de los cultivos de plagas animales y malezas.

Los residuos sólidos de la actividad industrial representan una matriz sólida que al ser depositados en los suelos, aportan sustancias inorgánicas y orgánicas que no solo afectan la comunidad biológica presente, sino que las mismas, se dispersan, distribuyen y retienen entre los distintos compartimentos del suelo, mediante mecanismos como la percolación, adsorción, absorción, infiltración y escurrimiento vertical y horizontal (Brusseau, 1991). Tanto los residuos sólidos generados en los procesos industriales, como aquellos suelos destinados a la actividad agrícola, representan matrices sólidas que implican riesgos ambientales, por lo tanto 
los estudios de evaluación ecotoxicológica resultan de gran interés para la protección de los sistemas naturales involucrados.

En el presente trabajo se realizó la evaluación ecotoxicológica de matrices sólidas de diferente naturaleza, correspondiendo a residuos sólidos provenientes de diferentes actividades industriales y a muestras ambientales de suelos tratados con plaguicidas.

\subsubsection{Residuos sólidos}

Uno de los residuos sólidos evaluados en este estudio fue de origen metalúrgico correspondiente a una arena de fundición con una alta concentración de metales. El otro residuo estudiado provino de la producción de cosméticos, particularmente de los lodos purgados del sedimentador secundario de la planta de tratamiento de efluentes líquidos por lodos activados, con un alto contenido de metales y sustancias orgánicas con diferentes grupos funcionales.

\subsubsection{Arena de fundición}

Las arenas de fundición son el principal residuo producido por las industrias de moldeo de metales (Miguel et al, 2006). La industria metalúrgica correspondiente al sector de las fundiciones genera mundialmente alrededor de 100 millones de toneladas anuales de este residuo (Carnin et al, 2012). En Argentina, existen aproximadamente 300 fundiciones que producen unas 200.000 toneladas anuales de arenas (Miguel et al, 2013). Estas cifras indican que en nuestro país este residuo se produce en cantidad elevada por lo que es importante considerar su peligrosidad antes de ser dispuesto en el ambiente. Las piezas metálicas son producidas en moldes o matrices, generalmente elaborados en dos mitades, que reproducen la pieza a replicar. Estos moldes son elaborados a partir de materiales refractarios como arena. Los moldes reciben, en su cavidad hueca o núcleo, el metal fundido y permiten su solidificación adquiriendo la forma deseada. Para retirar las piezas industriales obtenidas en tales condiciones es necesario colapsar dicho molde, etapa conocida como desmoldeo, transformando a las arenas de moldeo en residuos sólidos con bajo contenido de humedad. Las arenas utilizadas en el proceso de fundición tienen la necesidad de ser suplementadas con una proporción de aglomerantes. Los aglomerantes confieren a la arena del molde una mayor resistencia debido a las altas temperaturas que deben soportar los moldes de fundición para evitar desmoronamientos internos de las piezas y favoreciendo la calidad del producto 
terminado. Entre los agentes aglomerantes sintéticos utilizados comúnmente por la industria podemos encontrar las resinas fenólicas, de fenol-formaldehido, formaldehido de urea, formaldehido de urea/alcohol furfurílico, isocianato fenólico e isocianatoalquídico (Miguel et al, 2006; Miguel et al, 2013). Tanto la presencia de estos aglomerantes químicos como sus productos de transformación pueden ser considerados peligrosos o especiales para la legislación ambiental vigente (Miguel et al, 2012). Generalmente la arena utilizada en un proceso de moldeado es reutilizada en la mayor cantidad de oportunidades como sea posible (Siddique et al, 2010). Sin embargo, cuando esto ya no es posible, las arenas se descartan en cavas o sobre el terreno de las propias industrias que las generaron Si bien se trata de un residuo seco, esta forma de disposición favorece el contacto del residuo sólido con el ambiente, pudiendo favorecer la movilidad de sustancias peligrosas entre los diferentes compartimentos (van Herwijnen et al, 2007). Estos productos generados por el lavado a partir del agua de lluvia por ejemplo, pueden alcanzar las aguas subterráneas por infiltración o llegar por escurrimiento a cuerpos de agua cercanos, afectando a los organismos presentes (Miguel et al, 2009; Carnin et al, 2012).

\subsubsection{Residuo de cosmética}

Se entiende como Productos Cosméticos a aquellas preparaciones elaboradas con sustancias naturales o sintéticas o sus mezclas, para uso externo en la higiene y el cuidado personal de las diversas partes del cuerpo humano, no siendo utilizados en actividades terapéuticas. Los productos cosméticos representan una amplia gama de formulaciones que poseen funciones o usos muy diferentes, pueden agruparse en cuatro familias: productos de aseo (jabones, pastas de diente), perfumería, cosmética (maquillajes, cremas, protectores solares) y productos capilares (champú, cremas de peinado, coloración) (ANMAT, 2015). El origen de los cosméticos y perfumes data de la Edad Antigua. Para los egipcios, los cosméticos eran una parte importante de la higiene personal y de la salud de las personas. Los aceites y las cremas eran de vital importancia contra el sol y los vientos secos. Asimismo, los perfumes eran utilizados en las ceremonias religiosas (Stead, 1998). Sin embargo, Francia fue identificada como la cuna del maquillaje, en donde los integrantes de la Corte se blanqueaban las caras con polvos y cremas nacaradas brillantes. En Argentina, la industria comenzó a desarrollarse de manera incipiente a finales del siglo XIX (CAPA 2015). En 1920, la mayoría de los productos se importaban siendo los principales proveedores Francia, Estados Unidos, Reino Unido y España. A partir de ese momento, este sector industrial sufrió un notorio incremento en su producción y hasta se convirtió en exportador de algunos productos (CAPA, 2015). 
Dicho incremento de la actividad trajo aparejado un incremento del volumen de residuos producidos por esta actividad industrial. Los residuos de la industria cosmética constituyen una matriz compleja formada por compuestos orgánicos e inorgánicos (Fatta-Kassinos et al, 2011). En general, debido a la presencia de metales, detergentes, surfactantes, solventes, hormonas y otros compuestos orgánicos, el tratamiento preliminar o primario consiste en la aplicación de métodos fisicoquímicos. Posteriormente son sometidos a depuración biológica, generalmente por lodos activados o lagunas de oxidación (Puyol et al, 2011). Los residuos sólidos resultantes contienen altas concentraciones de nutrientes y pueden ser utilizados como fertilizantes bajo la presunción de su inocuidad para los seres vivos. Sin embargo, la presencia de sustancias de baja biodegradabilidad puede ser perjudicial para los mismos. Además, en muchas oportunidades, ciertas impurezas presentes en las materias primas son retenidas y concentradas. Tal es el caso de metales como cadmio, cobalto y cromo que son retenidos como impurezas de los colorantes utilizados en productos como sombras de ojos y lápices labiales (Reif et al, 2008; Volpe et al, 2012). Debido a su complejidad, peligrosidad potencial y a la cantidad elevada en que son producidos, es de suma importancia la realización de estudios ecotoxicológicos a fin de evaluar los riesgos ambientales previamente a su liberación, como así también las gestiones y controles necesarios a realizar antes de su disposición final (Manaham, 1990).

\subsubsection{Suelos tratados con plaguicidas}

Los plaguicidas son productos químicos sintéticos o naturales que presentan propiedades que disminuyen, alteran o inhiben diferentes procesos biológicos, capaces de combatir diversas plagas (Carlile, 2006, Costa 2008; CASAFE, 2009). Es deseable que los plaguicidas sólo causen efectos nocivos sobre los organismos a los que están dirigidos, denominados organismos blanco. Sin embargo, el uso de plaguicidas puede afectar a otros organismos del ecosistema, los cuáles reciben el nombre de organismos no blanco (Carlile, 2006, Costa, 2008, Ntalli y Menkissoglu-Spiroudi, 2011). Cuando hablamos de plaguicidas podemos referirnos al ingrediente activo o a la formulación comercial. El ingrediente o principio activo es el responsable de ejercer el efecto correspondiente sobre el organismo blanco. El formulado comercial está compuesto por diferentes sustancias químicas que pueden pertenecer a dos grupos diferentes según la acción que ejercen sobre el principio activo. Por un lado, tenemos las sustancias inertes que cumplen funciones diluyentes sobre el mismo; por 
el otro tenemos a los coadyuvantes, quienes potencian la acción del principio activo, modificando sus propiedades, físicas, químicas o biológicas (Yu, 2008). Los plaguicidas pueden clasificarse en diferentes grupos dependiendo del criterio empleado. Una primera clasificación puede dividir a los plaguicidas en dos grandes grupos: plaguicidas de contacto o no sistémicos y los plaguicidas sistémicos. Los primeros no penetran notablemente en los tejidos del sistema vascular vegetal o insecto, mientras que los segundos penetran efectivamente en la cutícula del vegetal o animal y se pueden trasladar a través del sistema vascular/ circulatorio (Royal Society of Chemistry 1987; Di Marzio y Sáenz, 2013). Por otra parte, los plaguicidas pueden clasificarse según el organismo blanco al que estén dirigidos, así, los plaguicidas se clasifican en insecticidas (insectos), herbicidas (vegetales), acaricidas (ácaros), molusquicidas (moluscos), rodenticida (roedores), fungicidas (hongos) y nematicidas (nematodes), entre otros (Khan, 1980; Connell, 2005; Di Marzio y Sáenz 2013). Los insecticidas pueden clasificarse en base a su estructura química como organoclorados, organosfosforados, carbamatos y piretroides (Blus, 2002; Hill, 2002; Carlile, 2006; Yu, 2008; Di Marzio y Sáenz, 2013). Los insecticidas organoclorados pueden reunirse, según su estructura química, en cinco grupos principales: DDT y sus análogos, hexaclorociclohexanos, ciclodienos y compuestos similares, toxafenos y compuestos emparentados, y los estructurales en caja mirex y clordecone (Connell, 2005). Cuando el DDT y sus análogos fueron descubiertos produjeron importantes beneficios para el control de plagas y enfermedades en todo el mundo. Posteriormente, se fue acumulando evidencia acerca de sus efectos adversos sobre los organismos no blanco. Así se contó con mayor información acerca de su toxicidad, persistencia y características lipofílicas, las cuales determinaron acumulación de residuos, mortalidad, disminución del éxito reproductivo, declinación y hasta extinción de ciertas poblaciones salvajes. Los insecticidas órganosforados son ésteres, amidas o tioles derivados de ácidos fosfóricos, fosfónicos, fosforotiónicos o fosfonotiónicos. La mayoría son levemente solubles en agua y tienen un alto coeficiente de partición octanol/agua y baja presión de vapor. Son fácilmente metabolizados por las enzimas de los mamíferos y se degradan rápidamente en el ambiente. Su forma de acción principal en los animales es la inhibición de la enzima acetilcolinesterasa (WHO, 1986; Habig y Di Giuglio, 1991; Hill, 1995; Connell 2005). Los carbamatos han sido desarrollados más recientemente que los dos grupos anteriores. Se trata de compuestos derivados del ácido carbónico. Como los órganofosforados, actúan inhibiendo la enzima acetilcolinesterasa. Son rápidamente degradados por procesos químicos y biológicos y no presentan problemas de persistencia. Existen carbamatos insecticidas como Aldicarb, Carbofuran y Metiocarb, entre otros y también carbamatos que 
tienen propiedades herbicidas, con baja toxicidad para los mamíferos como Profam y Clorprofam (Hill, 1995; Connell, 2005). Los insecticidas piretroides son derivados de compuestos naturales que se encuentran en las inflorescencias de Chrysanthemum sp. Son rápidamente biodegradados. Presentan una solubilidad en agua muy baja. Su acción es neurotóxica, similar al DDT. Son muy selectivos para los insectos y son efectivos en muy bajas concentraciones, presentando toxicidad a corto plazo. Presentan muy baja toxicidad para los mamíferos (Walker et al, 1996).

Los herbicidas pueden clasificarse según su forma de acción en: a) inhibidores de la fotosíntesis; b) desviadores de la energía fotosintética; c) inhibidores del desarrollo de los cloroplastos; d) desacopladores y e) reguladores del crecimiento (Moreland, 1980; Duffus, 1983; Carlile, 2006; Di Marzio y Sáenz, 2013). Los inhibidores de la fotosíntesis impiden la transferencia de electrones entre el fotosistema II y el fotosistema I. Entre los compuestos que podemos citar en este grupo se encuentran monurón, diurón, atrazina, simazina, entre otros. Los desviadores de la energía fotosintética compiten por el flujo de electrones en el extremo reductor del fotosistema I. Ejemplos de este tipo de herbicidas son el paraquat y diquat. Los inhibidores del desarrollo de los cloroplastos inhiben la formación de la estructura interna de los cloroplastos y bloquean la síntesis de carotenoides. Cómo ejemplo de este grupo se encuentran los plaguicidas amitrol, dicloromato y pyriclor. Los desacopladores, afectan las reacciones relacionadas con la fotofosforolización cíclica y no cíclica, pudiendo mencionar el 2,4-Dinitrofenol, dinoseb, hidroxibenzonitrilos y benzimidazoles. Los reguladores del crecimiento son compuestos derivados del AIA, principal substancia que regula el crecimiento de las plantas, produciendo la muerte de las mismas por deformaciones y crecimiento descontrolado (Carlile, 2006). Se incluyen también algunos herbicidas que actúan como inhibidores del crecimiento, como glifosato, 2,4-D y 2,4,5-T, entre otros.

El incremento del uso de plaguicidas a nivel mundial para mejorar el rendimiento de los cultivos conlleva una degradación de la estructura y función del suelo (Römbke et al, 2005; Reinecke y Reinecke, 2007). En la República Argentina las superficies cultivadas se han incrementado notoriamente en los últimos años. Como consecuencia, cantidades importantes de diferentes plaguicidas son liberados al ambiente afectando la dinámica natural de los ecosistemas. Particularmente las áreas sembradas con cultivos transgénicos han tenido un notorio y sostenido incremento desde 1996 cuando el primer cultivo transgénico de soja resistente al glifosato fue aprobado. Según estadísticas de Argenbio (Consejo Argentino para la Información y el Desarrollo de la Biotecnología), el área de superficie sembrada con cultivos de organismos genéticamente modificados aumentó de 370 mil hectáreas en los años 
1996/7 a casi 25 millones de hectáreas en 2013/14. El 78\% de la producción de soja en Argentina está acotada a tres provincias: Buenos Aires, Córdoba y Santa Fe, que conforman la denominada "zona núcleo". Este número de hectáreas cultivadas ocasiona el uso de cantidades crecientes de plaguicidas para mejorar los rendimientos de las cosechas minimizando las pérdidas por fitofagia y malezas. Dentro de los plaguicidas más comercializados durante el año 2012 encontramos a los herbicidas, con un 64\% de la facturación de agroquímicos. En este grupo, el Glifosato es quien encabeza la lista de los más vendidos. El segundo segmento en importancia por su consumo está representado por los insecticidas, con un 16\% de volumen de facturación. Dentro de este grupo, el organofosforado clorpirifos es el principio activo más utilizado por encima de otros grupos como piretroides y organoclorados (CASAFE, 2012). En este escenario, podemos considerar la importancia de evaluar los potenciales efectos que la aplicación de estos plaguicidas puede producir sobre organismos no blanco.

La utilización de los plaguicidas debería de llevarse a cabo con el objetivo de maximizar los beneficios en los cultivos pero minimizando sus riesgos. Este punto debe tener en cuenta no sólo las dosis de aplicación recomendadas, el período adecuado para su aplicación sino también poner énfasis en los sistemas de aplicación de los plaguicidas en los cultivos. Existen diferentes formas de aplicar plaguicidas los que también varían con el estado de agregación del producto comercial que se desea emplear. En el caso de los formulados comerciales líquidos, una forma de aplicación muy extendida es la utilización de pulverizadores terrestres tales como mochilas o equipos de arrastre. Un aspecto muy importante a ser considerado en la aplicación de plaguicidas es la deriva de los mismos. Se denomina deriva al desplazamiento de un plaguicida más allá del blanco determinado, transportado por masas de aire o por difusión (ASAE S-327.1). La deriva puede clasificarse en dos categorías como endo-deriva, la que ocurre dentro del lote cultivado, y exo-deriva, a la externa al mismo (Massaro, 2013). Esta última está asociada al efecto no deseado de la aplicación de plaguicidas que es alcanzar otros organismos no blanco distintos a los cuales están destinados. No sólo pueden ejercer efectos no deseados sobre especies vegetales no cultivadas, sino que además pueden ejercer efectos perjudiciales sobre animales, tanto invertebrados como vertebrados, dentro de los cuales puede verse afectada la salud humana. Un factor directamente ligado a la deriva de plaguicidas aplicados en cultivos es el tamaño de gota con el cual es pulverizado. Cuanto menor es el tamaño de la gota producida en la pastilla del pulverizador, más alto es el riesgo de perder esta gota durante la aplicación y por lo tanto, mayor riesgo de deriva (Massaro 2013). Una vez que un plaguicida es liberado en el ambiente es capaz de interaccionar con los 
componentes bióticos y abióticos del mismo alterando su estructura fisicoquímica y su acción biológica (Khan, 1980; Leng et al, 1995; Hornsby et al, 1996). La degradación ambiental puede dar lugar a productos menos tóxicos que el precursor mediante procesos de inactivación o detoxificación, u opuestamente, productos más tóxicos que el precursor en procesos de activación. Las reacciones de degradación son muy variadas e incluyen oxidación, reducción, hidrólisis, sustitución y eliminación de grupos funcionales, entre otras, pudiendo estar mediadas tanto por agentes biológicos (principalmente bacterias del suelo) como inorgánicos (Khan, 1980; Connell, 2005). Otro proceso importante de degradación de plaguicidas es la fotólisis. La cinética de degradación de los plaguicidas en el campo puede verse afectada por varios factores, tales como la accesibilidad de los microrganismos del suelo al plaguicida, cantidad de microrganismos presentes, factores abióticos como el $\mathrm{pH}$, temperatura y humedad del mismo, entre otros (Leng et al, 1995; Hornsby et al, 1996)

\subsubsection{Glifosato}

Como fue mencionado previamente, los herbicidas pueden clasificarse según su modo de acción en diferentes grupos. El glifosato es el herbicida sistémico de amplio espectro más utilizado, no sólo a nivel mundial, sino en nuestro país en lo particular. El glifosato actúa inhibiendo el crecimiento vegetal debido a que interfiere con la producción de aminoácidos aromáticos esenciales por inhibición de la enzima enolpiruvilsiquimato-3-fosfatosintasa (EPSPS, por sus siglas en inglés) (Duke, 1988; WHO, 1994). Esta enzima es responsable de la síntesis de corismato, un intermediario de la biosínteis de fenilalanina, tirosina y triptófano (Williamns et al, 2000). Esta ruta biosintética de aminoácidos aromáticos no es compartida por los miembros del reino animal, por lo cual el bloqueo de esta ruta por parte del glifosato representaría una acción selectiva y específica sobre las plantas. Más detalladamente, una vez absorbido por la planta, el glifosato se une a la enzima EPSPS y la bloquea. La enzima EPSPS se encuentra en el inicio de la vía del ácido siquímico, que convierte a los precursores, carbohidratos simples derivados de la glucólisis y la vía de la pentosa fosfato, en aminoácidos aromáticos y otros metabolitos. La enzima se encuentra dentro de los cloroplastos donde cataliza la reacción de siquimato-3-fosfato (S3P) y fosfenolpiruvato para formar 5enolpiruvilsiquimato-3-fosfato (ESP). ESP es un precursor de aminoácidos aromáticos y, en última instancia, de proteínas, hormonas, vitaminas y otros metabolitos esenciales de las plantas (Figura 1). Las similitudes estructurales con el fosfenolpiruvato permiten al glifosato unirse al lugar de unión de sustrato de EPSPS para inhibir su actividad y bloquear su integración al cloroplasto. 


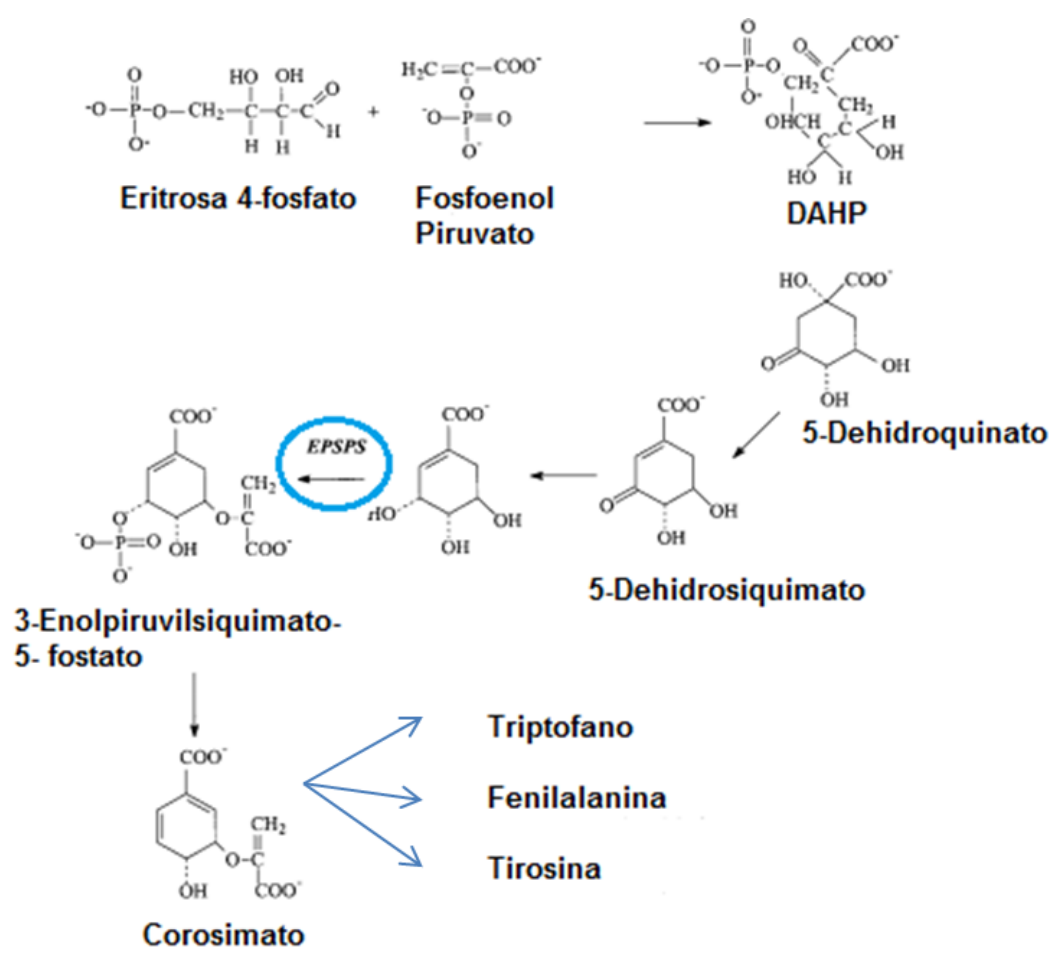

Figura 1: Ruta del ácido siquímico. (Modificado de Williamns et al, 2000)

Dado que el sitio activo de la enzima EPSPS es un dominio conservado en las plantas superiores, el glifosato puede ejercer su efecto herbicida sobre un amplio espectro de malezas indiscriminadamente. La inhibición de la función de la vía del ácido siquímico produce una deficiencia en los aminoácidos aromáticos, lo que eventualmente provoca la muerte de la planta a causa de desnutrición. Debido a su modo de acción específico sobre rutas metabólicas presentes en el reino vegetal, se considera al glifosato como levemente tóxico para invertebrados y vertebrados. Respecto a su acción sobre organismos no blanco, existen antecedentes bibliográficos que demuestran efectos sobre componentes de la comunidad fitoplanctónica y perifiton (Sáenz el al, 1997; Wong et al, 2000; Cedergreen y Streibig, 2005; Vendrel et al, 2009; Romero et al, 2011; Qiu et al, 2013) como así también de vegetales acuáticos y terrestres (De Simone et al, 1992; Fuchs et al, 2002; Kogan, 2004; de María et al, 2005; Martin y Ronco, 2006; Petersen et al, 2007; Sobrero et al, 2007; Tesfamariam et al, 2009; Mateos-Naranjo y Perez-Martin, 2013; Kielak et al, 2011). Se han registrado acciones perjudiciales sobre diferentes invertebrados acuáticos y terrestres (Tsui y Chu, 2003; Jackson et al, 2004; Casabé et al, 2007; Schneider et al, 2009; Contardo-Jara et al, 2009; Hammad y Gürkan 2012, Sihtmäe et al, 2013; Mottier et al, 2013; Currie et al, 2015; Bakry et al, 2015) y sobre vertebrados como peces y anfibios (Calvacante et al, 2008; Lushchak et al, 2009; 
Grisolia 2002; Lajmanovich et al, 2003a y 2003b; Cavas y Könen, 2007; Takahashi 2007; Ronco et al, 2008; Vera-Candioti et al, 2013a; 2013b). La Agencia Internacional de Investigación sobre el Cáncer (International Agency for Research on Cancer, IARC) ha clasificado al herbicida glifosato como un compuesto perteneciente a la categoría $2 \mathrm{~A}$, la cual incluye aquellas sustancias probablemente carcinogénicas para el hombre (IARC, 2015).

\subsubsection{Clorpirifos}

El clorpirifos es un insecticida de la familia de los organofosforados, con amplio espectro de acción, el que se utiliza para el control de diversas plagas presentes en cultivos y en la eliminación de larvas de insectos en sistemas acuáticos. El uso de los plaguicidas organofosforados se ha incrementado en la agricultura con el fin de sustituir a los organoclorados y carbamatos debido a que presentan como principales ventajas su alta eficiencia y baja persistencia en el ambiente. Los OP, en general, pueden penetrar en el organismo por inhalación (debido a su volatilidad), ingestión y a través de la piel debido a su relativa liposolubilidad, característica que facilita el pasaje a través de las membranas biológicas (WHO, 1986; Hill, 2002). Una vez absorbidos y distribuidos en el organismo son metabolizados principalmente en el hígado, en el caso de los vertebrados, por un grupo de enzimas (esterasas, enzimas microsomales, transferasas) ocurriendo una serie de transformaciones químicas que tienden a aumentar su hidrosolubilidad para facilitar su excreción por vía renal o branquial. Los OP desarrollan su mecanismo de acción tóxica a través de la fosforilación de la enzima acetilcolinesterasa presente en los tejidos nerviosos, enzima encargada de hidrolizar al neurotransmisor acetilcolina (Habig y Di Giuglio, 1991; Hill, 2002; Yu, 2008). Los OP reaccionan formando una unión estable irreversible, quedando la enzima inhibida para su función normal. La pérdida de la función enzimática conduce a la acumulación de acetilcolina en las sinapsis del sistema colinérgico. Este último es común en la mayoría de organismos tanto vertebrados como invertebrados. Existen antecedentes bibliográficos respecto a la acción del clorpirifos sobre invertebrados terrestres y acuáticos indicando acciones adversas sobre la reproducción, morfología, actividad alimentaria y actividades enzimáticas (Booth et al, 2000; Booth y O'Halloran, 2001; Jin-Clark et al, 2002; Venkateswara Rao et al, 2003; Zhou et al, 2007; Fountain et al, 2007; Piola et al, 2009; Colange et al, 2010; Vejares et al 2010; Mugni et al, 2011; Wang et al, 2012; SanchezHernández et al, 2014). Si bien, el insecticida clorpirifos no ha sido clasificado dentro de las categorías definidas por la IARC, su peligrosidad ha sido indicada por otras entidades internacionales. La OMS ha clasificado al clorpirifos como un químico de Clase II, grupo 
dentro del que se incluyen compuestos moderadamente peligrosos. En el mismo sentido la US EPA ha catalogado al clorpirifos dentro de la Clase 2, donde se encuentran compuestos moderadamente tóxicos (US EPA, 2006). Por otra parte, si bien, no se han observado efectos mutagénicos del clorpirifos sobre bacterias y levaduras (Eaton et al, 2008); el insecticida ha demostrado ejercer otros efectos tales como disfunciones hepáticas (Slotkin, 2011) y endócrinas (Betts, 2010), alteraciones inmunológicas (Noworyta-Glowacka et al, 2012), teratogénesis (McCollum et al, 2011; Uggini et al, 2012), perturbaciones neuroquímicas y del comportamiento (Turgeman et al, 2011), embriotoxicidad (Tian et al, 2005) y genotoxicidad (Ali et al, 2009; Vera-Candioti et al, 2014) tanto en estudios in vivo e in vitro empleando diferentes matrices biológicas.

\subsection{Ensayos de toxicidad}

La herramienta experimental más frecuentemente utilizada en Ecotoxicología para evaluar la toxicidad de las sustancias se denomina como bioensayo o test de toxicidad (Rand, 1995; Di Marzio y Sáenz, 2013). Es importante destacar que un bioensayo describe una metodología de laboratorio que utiliza como modelo experimental organismos vivos, sin estar limitados a la determinación de la peligrosidad de una sustancia. En forma general, podemos decir que para realizar un ensayo de toxicidad los organismos seleccionados son expuestos al agente químico que se desea estudiar por un período de tiempo determinado (Sprague, 1973). Asimismo, se cuenta con organismos que son mantenidos en las mismas condiciones experimentales pero en un medio inocuo, denominado grupo control negativo. Al finalizar el período de exposición se cuantifican los efectos biológicos observados en los grupos tratados y control y se efectúa el análisis estadístico de los datos. Entre los aspectos de diseño de los ensayos deben considerarse, por un lado el sistema de exposición, según se renueven o no las soluciones de ensayo. Así existen tres tipos principales estáticos, semi-estáticos y de flujo continuo (Rand, 1995; Walker et al, 2006). En el caso de los ensayos estáticos, las soluciones de prueba no se renuevan durante el período de exposición. En los semi-estáticos, se realiza una renovación parcial mientras que en los ensayos de flujo continuo, las soluciones con las sustancias a evaluar realizan un circuito abierto de entrada y salida permanente durante el lapso de exposición.

Los ensayos pueden también clasificarse en función del tiempo de exposición en relación con la duración del ciclo de vida de las especies estudiadas. En general, dos conceptos relativos 
son utilizados frecuentemente: toxicidad aguda y toxicidad crónica. La primera es aquella que se manifiesta en un período relativamente breve (horas, días), la segunda implica un mayor tiempo de exposición que puede durar semanas o meses (Römbke y Moltmann, 1996; Newman y Jagoe, 1996). Los aspectos más relevantes a tener en cuenta respecto de la selección de las especies de prueba, los cuales fueron motivo de discusión durante los años ‘70 a ‘90, básicamente son:

- Importancia ecológica relativa

- Sensibilidad relativa a los tóxicos

- Información disponible sobre su biología y comportamiento

- Facilidad de cultivo y reproducción en laboratorio

- Tamaño adecuado para su manejo

- Interés comercial, recreativo, biodiversidad

- Estadios de vida bien diferenciados

- Amplia distribución y abundancia

Dentro de este marco, los ensayos de toxicidad deberán contar además con la aceptación de la comunidad científica, poseer habilidad para predecir los efectos de una gran variedad de sustancias químicas sobre diferentes organismos, contar con bases estadísticas y reproducibilidad de sus resultados, generar datos útiles en estudios de riesgo ambiental, poseer sensibilidad y realismo ecológico, ser costo-eficientes, realizarse en condiciones ambientales controladas fácilmente establecidas en cada laboratorio de ensayo y poder ser validados desde el punto de vista de la calidad de los resultados obtenidos. Asimismo, la medida de los efectos no debe dejar dudas acerca de las relaciones cantidad de tóxicorespuesta obtenida. Es decir, debe ser inequívoco, relevante, fácilmente observable y describible, mensurable, significante desde el punto de vista biológico y reproducible (Newman y Jagoe, 1996; Newman y Clements, 2008; Di Marzio y Sáenz, 2013).

Existen diferentes índices que permiten cuantificar la respuesta obtenida durante el desarrollo de un ensayo para evaluar la toxicidad de una sustancia determinada. El índice de toxicidad universalmente utilizado para cuantificar la toxicidad aguda es la concentración que afecta al $50 \%$ de la variable de respuesta elegida. Cuando esta variable es la letalidad se la indica como CL50- $t$, donde $t$ representa el tiempo de exposición. En el caso de los ensayos de mayor duración que abarcan todo o parte del ciclo de vida de la especie prueba, se pueden determinar otros índices tales como:

CENO: es la máxima concentración evaluada en la cual no se registran efectos significativamente diferentes respecto de los organismos controles. 
CMEO: es la mínima concentración evaluada en la cual se registran efectos significativamente diferentes respecto de los organismos control.

Estos índices están incorporados en la mayoría de los protocolos estándares, como por ejemplo aquellos generados por la US EPA (1996a; 1996b; 1996c; 2002a; 2002b).

\subsubsection{Organismos de prueba}

Para el caso de los ensayos ecotoxicológicos existe un consenso establecido en utilizar organismos de diferentes niveles tróficos para obtener una visión más general del efecto del tóxico en el ambiente (Römbke y Moltmann, 1996). Las plantas constituyen el grupo de los productores primarios por lo que representan un grupo de notable importancia dentro del ecosistema (Tarradellas et al, 1997; Foester et al, 2009). Mediante el proceso fotosintético son capaces de convertir la energía solar en biomasa. Esta biomasa brinda alimento y soporte para los niveles tróficos superiores. Pueden ser utilizadas como organismos indicadores de cambios o alteraciones de las condiciones naturales y, además, algunas especies reúnen las características mencionadas previamente para ser utilizadas en pruebas de laboratorio. Permiten registrar los efectos sobre un amplio número de variables de respuesta desde cambios en la biomasa y producción primaria, inhibición de la germinación, elongación de las raíces, actividad enzimática, peroxidación de lípidos, expresión de genes, entre otros (Ferrari et al, 1999; Cordova Rosa et al, 2001; Klaine et al, 2002; Radetski et al, 2004; Foester et al, 2009).

Para el desarrollo del presente trabajo de Tesis Doctoral la elección de las especies vegetales se realizó teniendo en cuenta aquellas recomendadas para la realización de ensayos estandarizados, propuestos por organizaciones nacionales o internacionales (US EPA, ISO, OECD, AFNOR). Entre ellas se incluyen:

\section{Lycopersicon esculentum}

Cucumis sativus

Lactuca sativa

Glycine max

Brassica oleracea

Avena sativa,

\section{Lolium perenne}

\section{Allium cepa}




\section{Daucus carota}

\section{Zea mays}

Vicia faba

De este grupo de especies se optó por Vicia faba debido a su amplia distribución y a que corresponde a una especie utilizada para la evaluación ecotoxicológica de un amplio abanico de matrices sólidas y líquidas (Cordova Rosa et al, 2001, 2003; Wang et al, 2008; Radic et al, 2009; Foltete et al, 2012). Conjuntamente se eligió Lactuca sativa para la realización de los ensayos de germinación y elongación de las raíces ya que se trata de una especie sensible y recomendada para la evaluación de matrices sólidas sobre todo debido a su simplicidad, bajo costo y sobre todo por la elevada reproducibilidad de sus ensayos (US EPA 1989, 1991, 1996). Cabe destacar que el ensayo de toxicidad con L. sativa forma parte de los protocolos de evaluación de calidad ambiental establecidos por la Norma IRAM 29114 (2008).

Vicia faba (Fabales, Fabaceae) fue la especie elegida para evaluar los efectos subletales de las eluciones acuosas de residuos y suelos contaminados con plaguicidas. Se trata de una especie de distribución cosmopolita, y ampliamente utilizada en la evaluación de matrices líquidas (Radic et al, 2009). Lactuca sativa (Asterales, Asreraceae) fue la especie seleccionada para evaluar los efectos fitotóxicos causados por los residuos sólidos y los suelos contaminados con plaguicidas.

En el caso de los invertebrados terrestres, existe una amplia cantidad de familias y especies potencialmente utilizables Dentro de este amplio grupo, las lombrices de tierra son utilizadas preferentemente para la evaluación de suelos contaminados (Neuhauser et al, 1985; Spurgeon y Hopkin, 1994; Lock y Janssen, 2001; Sánchez-Hernández, 2006). Este grupo taxonómico resulta particularmente interesante debido a que participan en el sostenimiento de la estructura y fertilidad del suelo, constituyendo alrededor de 60\% de la biomasa del mismo (Moser et al, 2009). Las especies de lombrices de tierra potencialmente utilizadas son:

\section{Allolobophora chlorotica}

\section{Eisenia andrei}

Amynthas diffringens

Eisenia fetida

Amynthas gracilis

Enchytraeus albidus

Aporrectodea trapezoides

Enchytraeus doerjesi

Lumbricus rubellus 


\section{Dendrobaena rubida}

\section{Lumbricus terrestris}

Dendrobaena veneta

\section{Perionyx excavatus}

\section{Dendrodrilus rubidus}

De todos estas especies de lombrices de tierra potenciales para la realización de bioensayos, Eisenia fetida (Oligochaeta, Lumbricidae) es la especie más recomendable para ser utilizada en evaluaciones ecotoxicológicas. Sus principales ventajas radican en su fácil mantenimiento en el laboratorio, y que ya han sido estandarizados para ensayos destinados a evaluar la toxicidad aguda y crónica de un xenobiótico (OECD 1984, 2004), demostrando ser un organismo adecuado para la evaluación de la ecotoxicidad de diferentes tipos de muestras sólidas (Sauvé et al, 2002; Xiao et al, 2006). Asimismo Eisenia fetida ha demostrado ser una especie sensible para la evaluación de toxicidad de diversas sustancias químicas tales como metales y plaguicidas al ser comparada con otras especies de oligoquetos (Spurgeon y Hopkin, 1995; Heimbach 1985, 1992; van Gestel et al, 1992). Por lo anteriormente expresado, Eisenia fetida fue la especie animal utilizada para evaluar tanto la fracción líquida (exposición ex vivo de celomocitos) como el residuo sólido (exposición in vivo de organismos).

La utilización de estos organismos de prueba en la realización de ensayos de toxicidad permite evaluar el efecto tóxico de sustancias simples o mezclas complejas. Sumados a estos índices universalmente aceptados, los ensayos de toxicidad pueden ser empleados para la determinación de biomarcadores en otros niveles de organización que permitan complementar la evaluación ecotoxicológica de manera holística.

\subsection{Biomarcadores}

Un biomarcador representa la medida de la respuesta biológica frente al efecto de un xenobiótico a nivel sub-individual o individual (van der Oost et al, 2005; Vasseur y CossuLeguille, 2003; Di Marzio y Sáenz, 2013). Desde el punto de vista ambiental, un biomarcador puede utilizarse una señal de alerta temprana de la respuesta a la exposición de sustancias tóxicas (Cajaraville et al, 2000). El uso de biomarcadores a nivel sub-celular constituye una herramienta de gran utilidad para diagnosticar el grado de estrés al que están sometidos los organismos cuando se encuentran expuestos a tóxicos simples o complejos. La vinculación de estas respuestas con aquellas obtenidas a nivel poblacional son de suma importancia para 
evaluar el riesgo ambiental de un xenobiótico (Newman y Clements, 2008). Así, desde el punto de vista de la Ecotoxicología, la determinación de biomarcadores, cuantificados a nivel individual, permiten la detección de alteraciones incipientes de manera que contribuyen en la prevención de efectos en los niveles de organización superiores, como poblaciones y comunidades biológicas (Vasseur y Cossu-Leguille, 2003).

Los biomarcadores más utilizados incluyen la determinación de efectos sobre:

- Actividades enzimáticas

- Respuestas genotóxicas

- Respuestas citotóxicas

- Proporciones de poblaciones celulares

- Proteínas asociadas a la detoxificación o procesos de reparación del material genético

- Integridad de membranas celulares (si se habla sólo a nivel de lisosoma, estaríamos solo incluyendo a ensayos de captación de rojo neutro entre otros colorantes supravitales y dejando de lado a otros biomarcadores como es el ensayo de MTT (nivel mitocondrial), entre otros.

- Estudios histopatológicos

- Respuestas fisiológicas y morfológicas

- Expresión de genes asociados a la detoxificación

En el presente trabajo se eligieron como biomarcadores la evaluación de enzimas vinculadas con los procesos de detoxificación que regulan los niveles celulares de especies químicas relacionadas con el estrés oxidativo en raíces de Vicia faba y la genotoxicidad en celomocitos de Eisenia fetida.

\subsubsection{Enzimas de estrés oxidativo}

El estrés oxidativo es definido como un desbalance entre agentes oxidantes y antioxidantes en favor de los oxidantes (Sies, 1985). Este fenómeno conlleva una disrupción del potencial redox de la célula induciendo daño celular (Schröder y Krutmann, 2005; Demidchik 2014).

Tanto los factores bióticos como abióticos pueden incrementar la presencia de especies reactivas del oxígeno (ERO) tales como el peróxido de hidrógeno, anión superóxido, grupos hidroxilo, entre otros. El estrés oxidativo puede causar modificaciones reversibles o irreversibles en biomoléculas tales como proteínas, ácidos nucleicos, carbohidratos y lípidos 
(Demidchik, 2014). Los organismos han desarrollado sistemas de defensa antioxidantes que se basan en mecanismos enzimáticos y no enzimáticos. Estos sistemas de defensa son capaces de estimularse en presencia de los ERO para proteger a las células contra el efecto o estrés oxidativo inducido por las ERO. El sistema de enzimas antioxidantes está representado por las superóxidodismutasas, peroxidasas, catalasas, glutatión reductasas, ascorbatoperoxidasas, monooxigenasas de acción múltiple, entre otras (Heldt, 2005; Demidchik, 2014; Bernard et al, 2015). Los sistemas no enzimáticos se corresponden con moléculas orgánicas con función antioxidante, tales como grupos tioles, flavonas, hidroquinonas, vitaminas E, C y metalotioneínas, entre otras. La oxidación de lípidos de membrana (Figura 2) es particularmente importante debido a que si el daño es irreversible puede verse afectada la permeabilidad celular y por ende su funcionalidad (Griffiths 2005; Dietz et al, 2008; Foyer et al, 2008). La cuantificación de los productos de degradación producida por peroxidación de lípidos puede realizarse en base a la determinación de la concentración de TBARS (Gutteridge y Halliwell, 2000; Wu et al, 2003; Groppa et al, 2007). La toxicidad de muestras sólidas y/o eluciones líquidas puede realizarse a partir de la evaluación conjunta de estos parámetros, sumado a la determinación de la biomasa y producción primaria.

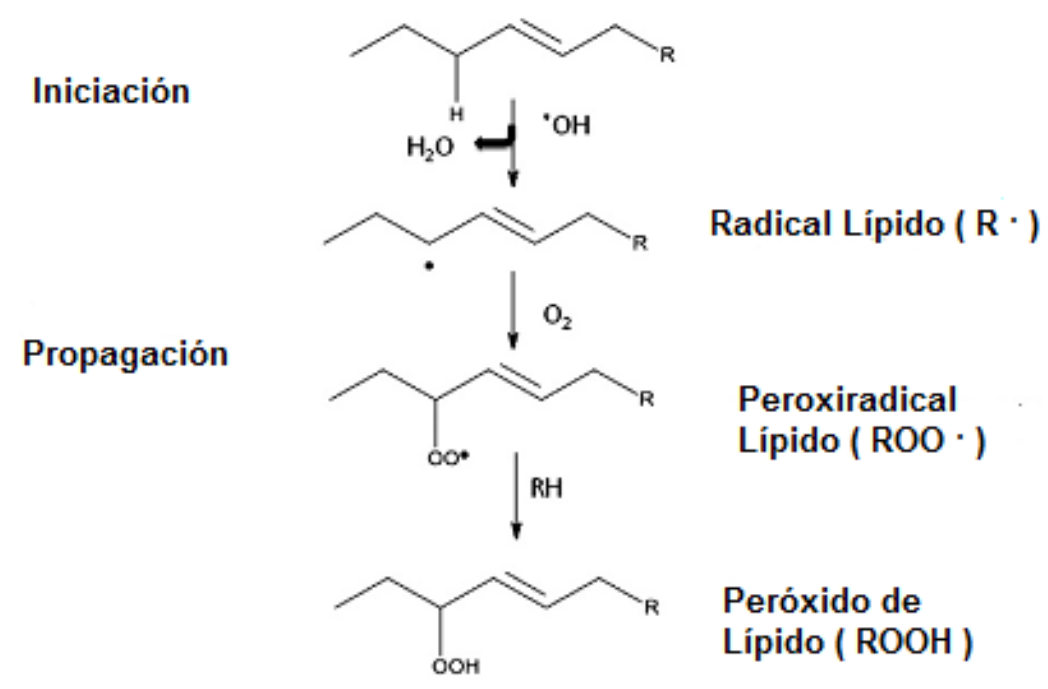

Figura 2. Proceso de peroxidación de lípidos (Modificado de Sultana et al, 2013)

\subsubsection{Genotoxicidad}

Se denomina genotoxidad a la capacidad de un agente de interaccionar con el material genético alterando su estructura normal (Preston y Hoffman, 2008). El concepto de 
compuesto genotóxico abarca un abanico de compuestos mayor que el de mutágenos, ya que en este caso sólo nos referimos a un agente capaz de interaccionar con la secuencia de bases del ADN (Preston y Hoffman, 2008; Mudry y Carballo, 2006).

La reacción potencial de una sustancia tóxica con el material génetico o ADN de un organismo dependerá de factores tales como la concentración del compuesto en el ambiente, la vía de entrada y distribución en el organismo, la activación metabólica del mismo, la reactividad del compuesto y/o sus metabolitos con las moléculas blanco, la capacidad celular de reparar el daño, el estado fisiológico o inmunitario del organismo, entre otros (Mudry y Carballo, 2006). Si el daño en el ADN no es reparado, este podría transmitirse a la siguiente generación (células de la línea germinal) y, si la exposición es prolongada, podría afectar el potencial reproductivo de una especie causando una depleción en el número de organismos de la población afectada (Jha 2004, Widziewicz et al, 2012).

Existen diferentes ensayos que permiten evaluar la interacción de un tóxico con el material genético tales como el de Aberraciones Cromosómicas (Preston et al, 1981; Salazar y Herrera, 1992), Intercambio de Cromátides Hermanas (Taylor, 1958; Perry y Wolff, 1974; Wolf et al, 1974; Shafer, 1982), formación de Micronúcleos (Fenech y Morley 1985) o a través de la Electroforesis de una Sola Célula entre otras (Ashby, 1988; Carrano y Natarajan, 1988; Wogan, 1992), entre los más empleados y aceptados en la comunidad científica mundialmente. El ensayo de aberraciones cromosómicas ha sido muy utilizado (Preston et al, 1981; Salazar y Herrera, 1992, Mudry y Carballo, 2006). Sin embargo, este bioensayo presenta algunas desventajas tales como el elevado tiempo de análisis, el grado de entrenamiento del observador y la subjetividad al momento del análisis/interpretación (Miller et al, 1997). La frecuencia de micronúcleos que revela la acción tóxica de tipo clastogénica o aneugénica (Schmid, 1976; Fenech y Morley, 1985; Fenech 2000; Lee y Steinier 2003); el intercambio de cromátides hermanas que revela inestabilidad cromosómica (Taylor, 1958; Perry y Wolff, 1974; Wolf et al, 1974; Shafer, 1982). Actualmente, el método más utilizado tanto por su simplicidad, sensibilidad y por la reproducibilidad de resultados obtenidos es el ensayo de electroforesis de una sola célula o ensayo cometa (Cotelle y Ferard 1999; Tice et al, 2000; Jha 2004; 2008; Collins et al, 2008; Dhawan et al, 2008). El fundamento de este ensayo consiste en incluir las células que se van a evaluar en un gel de agarosa sobre un portaobjetos para luego proceder a la lisis celular por medio de la acción de detergentes y concentraciones salinas altas. De esta forma, se libera el ADN super-enrollado en forma de "nucleoides". Posteriormente, éstos son sometidos a la acción de un campo eléctrico a un pH determinado según el tipo de lesión a analizar. Durante la electroforesis, los fragmentos de diferente 
tamaño del ADN dañado migran hacia el polo positivo del campo eléctrico de una manera diferencial pudiéndose cuantificar respecto al ADN total (Singh et al, 1988; Cotelle y Ferard, 1999; Tice et al, 2000).

Östlling y Johanson (1984) fueron los primeros en desarrollar una técnica con electroforesis en microgel para la detección de daño en el ADN utilizando células aisladas. En esta técnica las células embebidas en agarosa fueron colocadas en un portaobjetos y lisadas en presencia de altas concentraciones de sales y detergentes, realizando la electroforesis en condiciones neutras. A continuación, Singh et al (1988) introdujeron algunas modificaciones en la metodología, sobre todo a nivel de la electroforesis, la cual tomó un carácter fuertemente alcalino $(\mathrm{pH}>13)$. A este $\mathrm{pH}$ se observa un incremento en la migración del ADN relacionado con la detección de roturas de simple cadena y sitios álcali-lábiles, por lo que esta versión ofrece una mayor sensibilidad para la identificación de agentes genotóxicos (Tice et al, 2000). El ensayo cometa es un efectivo biomarcador capaz de detectar diferentes tipos de daño a nivel del material genético:

- $\quad$ Roturas de ADN de cadena doble

- $\quad$ Roturas ADN de cadena simple

- $\quad$ Sitios alcali-lábiles

- $\quad$ Aductos en el ADN

- Uniones cruzadas ADN-ADN y ADN-proteína

- Roturas simples asociadas con mecanismos de reparación incompletos

Desde su introducción, el ensayo cometa ha sido muy utilizado debido a las siguientes ventajas:

- Ha demostrado ser sensible para detectar bajos niveles de daño en el ADN

- Requiere un número reducido de células

- Es versátil ya que puede ser aplicado en diferentes tipos celulares

- Posee relativamente costo bajo

La determinación de los efectos genotóxicos inducidos por sustancias químicas introducidas al ambiente, a partir de la disposición final de residuos sólidos y/o por la aplicación de plaguicidas, constituye una herramienta ecotoxicológica de importancia en la evaluación del riesgo ambiental asociado a dichos escenarios. Las consecuencias de daño genético inducido por los contaminantes ambientales y su correlación con las rupturas en el ADN pueden ser debidamente descriptos mediante la utilización del ensayo cometa (Jha, 2008). Puede ser 
aplicado potencialmente a cualquier tipo celular tanto de células animales como vegetales (Cotelle y Férard, 1999). Vera-Candioti et al (2013) determina los efectos genotóxicos de los plaguicidas clorpirifos, pirimicarb y glifosato sobre eritrocitos de sangre periférica en peces pertenecientes a la especie Cnesterodon decemmaculatus. Martínez et al (2015) demuestran los efectos genótoxicos de los plaguicidas clorpirifos y tebuconazole sobre las especies de algas dulceacuícolas Pseudokirchneriella subcapitata y Nannochloris oculata. Ha sido aplicado en diferentes líneas celulares tales cómo las células $\mathrm{CHO}$ y células humanas para la evaluación de la genotoxicidad del principio activo zineb y su formulación comercial Azurro ${ }^{\circledR}$ (Soloneski et al, 2001; Soloneski et al, 2002; González et al, 2003, Soloneski et al, 2015), y productos de desinfección del agua potable (Plewa et al, 2000). Además fue utilizado en la evaluación de genotoxicidad en trabajadores expuestos a mezclas de plaguicidas a través de su aplicación en cultivos de linfocitos humanos (Simoniello et al, 2008).

En oligoquetos terrestres el ensayo ha demostrado ser sensible para la detección de daño genotóxico de diferentes especies: Lumbricus terrestris y E. fetida para la evaluación de suelos contaminados (Verschaeve y Gilles, 1995); E. andrei para la evaluación de la genotoxicidad del $\alpha$-Benzopireno y 2,3,7,8-tetraclorodibenzo-p-dioxina (TCDD) (Sforzini et al, 2012). En particular, E. fetida también ha sido sensible para la detección de daño genotóxico aplicando en ensayo comenta originado por radionúclidos (Lourenco et al, 2012), metales como Cd (Reinecke y Reinecke, 2007, Di Marzio et al, 2005, 2007), Ni y Cr (Bigorgne et al, 2010), $\mathrm{Pb}$ y Cd (Wu et al, 2012) y compuestos orgánicos tales como ácidos ftálicos (Du et al, 2015), productos de protección personal (Lin et al, 2010), plaguicidas (Zang et al, 2000; Reinecke y Reinecke, 2004; Casabe et al, 2007) y suelos industrialmente contaminados (Quiao et al, 2007; Bonnard et al, 2009).

En el presente trabajo la genotoxicidad se determinó en células extraídas de manera no invasiva del celoma o celomocitos de E. fetida. Los celomocitos constituyen un grupo celular heterogéneo presentes en el fluido celómico de los anélidos (Adamowiz, 2005). Debido a que se hallan en suspensión en el líquido celómico dentro de la cavidad celómica del animal, reflejan una exposición integral del organismo a los tóxicos ambientales. Así de igual forma que los linfocitos humanos pueden utilizarse en la determinación de biomarcadores de efecto de importancia clínica, los celomocitos pueden ser utilizados para el biomonitoreo ambiental. Son un grupo morfológicamente diverso y funcionalmente versátil de células en el cual su composición relativa puede variar según la estación, las condiciones de vida y la condición general del animal (Adamiwicz, 2005). Es difícil establecer un criterio de clasificación para estos tipos celulares debido no sólo a los diferentes tipos que pueden encontrarse entre 
animales de diferentes especies, sino también a la presencia de distintos estadios de maduración de las células. Sin embargo, una clasificación basada en las propiedades citomorfométricas, ultraestructurales e histoquímicas permite distinguir tres tipos celulares principales: eleocitos (células cloragógenas), amebocitos y granulocitos (Adamowicz, 2005). Los eleocitos se originan a partir del tejido cloragógeno que rodea al intestino. Estas células son responsables de mantener constante el pH y del balance iónico. Se encargan de sintetizar pigmentos respiratorios y son capaces de almacenar sustancias endógenas, tales como glucógeno y lípidos, y sustancias exógenas tales como pigmentos o metales. Los eleocitos juegan un papel importante en los procesos inmunológicos humorales de las lombrices, ya que producen sustancias bactericidas, y participan de reacciones tales como la encapsulación y la formación de cuerpos marrones (Adamowicz y Wojtaszek, 2001). Los eleocitos presentan como característica principal la presencia de los cloragosomas, los cuales poseen una membrana frágil y propensa a romperse liberando su contenido. Los amebocitos, participan en el transporte y almacenamiento de sustancias nutritivas, la coagulación del fluido celómico y la curación de heridas, participa además en reacciones inmunitarias, tanto en la defensa humoral como celular, la fagocitosis, la encapsulación y la nodulación. Generalmente son pequeños, con un núcleo central o periféricamente ubicado, que puede tener diferentes formas, ya sea oval o arriñonado. Su citoplasma posee pocos gránulos basofílicos, y se caracterizan sobre todo, por su capacidad de formar pseudopodos. Algunos autores utilizan el tipo de pseudopodos formados para realizar una clasificación entre amebocitos tipo I y tipo II (Fugére et al, 1996; Cossarizza et al, 1996, Adamowicz y Wojtaszek, 2001; Adamowicz 2005). Los granulocitos, en general, constituyen la menor población de los tres tipos celulares, son muy pequeños y su pequeño núcleo se encuentra periféricamente ubicado. Se caracterizan por la presencia de gránulos acidófilos ubicados en el citoplasma. Debido a sus características distintivas cada grupo celular se comporta de manera diferencial ante la exposición a un tóxico. La realización del ensayo cometa en celomocitos de E. fetida es un biomarcador adecuado para determinar la genotoxicidad de los matrices complejas evaluadas en el presente trabajo de Tesis Doctoral tal lo demostrado oportunamente (Zang et al, 2000; Reinecke y Reinecke, 2004; Di Marzio et al, 2005; 2007; Casabe et al, 2007; Quiao et al, 2007; Bonnard et al, 2009; Bigorgne et al, 2010; Lin et al, 2010; Wu et al, 2012; Du et al, 2015)

En el desarrollo de la presente Tesis Doctoral se realizó la caracterización ecotoxicológica de matrices sólidas, tales como residuos sólidos derivados de la producción industrial y suelos agrícolas. Para tal fin, se trabajó con una combinación de una batería de ensayos estandarizados con organismos terrestres, acoplada al desarrollo de biomarcadores de 
exposición a sustancias tóxicas y en conjunción con el análisis fisicoquímico de las matrices sólidas estudiadas. En el siguiente esquema se resumen las evaluaciones a realizar con las matrices sólidas:

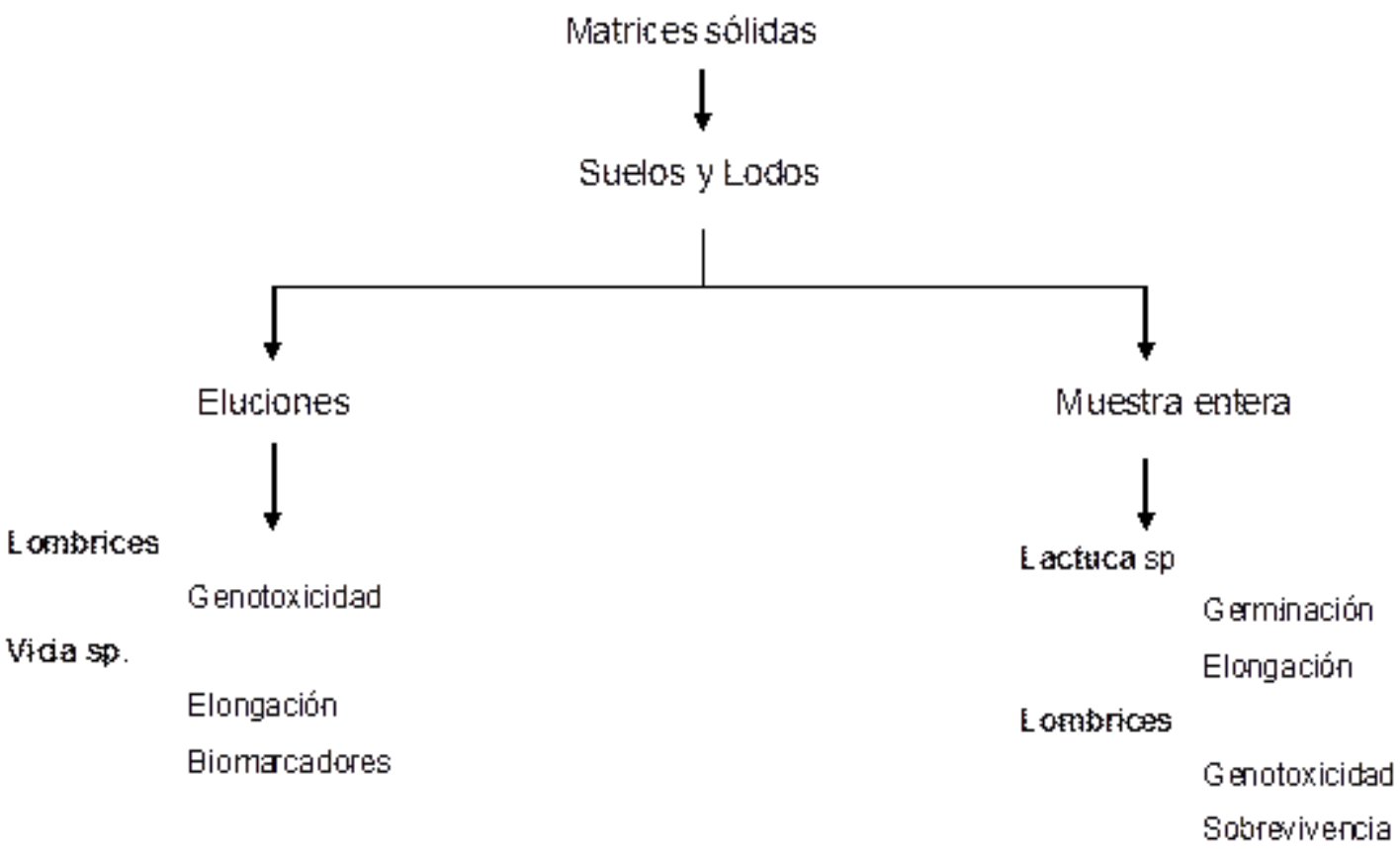




\subsection{Hipótesis}

- $\quad$ El grado de contaminación de una matriz sólida (suelo, residuo) puede evidenciarse integralmente determinando efectos biológicos sobre distintas variables de respuesta.

- Las muestras ambientales deben ser estudiadas utilizando especies de niveles tróficos diferentes para definir la presencia / efecto de sustancias tóxicas.

\subsection{Objetivo general}

El objetivo general fue el estudio ecotoxicológico de matrices sólidas como residuos sólidos de la actividad industrial y suelos afectados por la actividad agrícola, mediante una valoración biológica que integra distintas variables de respuesta de organismos terrestres, a fin de desarrollar herramientas de evaluación de matrices sólidas contribuyendo a la definición de criterios en el ámbito del control y gestión ambiental.

\subsubsection{Objetivos específicos}

- Caracterizar el peligro ambiental de diferentes tipos de matrices sólidas mediante el empleo integrado de herramientas ecotoxicológicas.

- Combinar los resultados de la determinación de diferentes variables de respuesta, obtenidas a partir de especies de niveles tróficos distintos, con el grado de contaminación de las muestras ambientales estudiadas.

- Seleccionar el conjunto de variables o ensayos más adecuado para cada matriz sólida.

- Contribuir con la definición de criterios acerca de la disposición y/o la necesidad de realizar tratamientos depurativos adicionales sobre los residuos, reutilización y recuperación de suelos contaminados 


\section{MATERIALES Y MÉTODOS}




\subsection{Materiales}

Los compuestos químicos utilizados en el presente trabajo se detallan en la Tabla 1.

Tabla 1. Compuestos químicos utilizados en los ensayos de laboratorio

\begin{tabular}{|c|c|c|}
\hline Reactivo & $\mathbf{N}^{\circ} \mathbf{C A S}$ & Origen \\
\hline Acetona & $67-64-1$ & Biopack, Argentina \\
\hline Ácido clorhídrico & $7647-01-0$ & ANEDRA, Argentina \\
\hline Ácido nítrico & $7697-37-2$ & ANEDRA, Argentina \\
\hline Ácido sulfúrico & $7664-93-9$ & ANEDRA, Argentina \\
\hline Ácido tiobarbitúrico & $504-17-6$ & Sigma-Aldrich, USA \\
\hline Ácido tricloroacético & $76-03-9$ & ANEDRA, Argentina \\
\hline Agarosa LMP & 1690701 & $\begin{array}{c}\text { Boehringer Mannheim, } \\
\text { Alemania }\end{array}$ \\
\hline Albúmina bovina & $9048-46-8$ & Sigma-Aldrich, USA \\
\hline Azul de Tripán & $72-57-1$ & Sigma-Aldrich, USA \\
\hline Biftalato de potasio & $877-24-7$ & Sigma-Aldrich, USA \\
\hline Bromuro de etidio & $1239-45-8$ & BIO-RAD, USA \\
\hline Carbonato de sodio anhidro & $947-19-8$ & Biopack, Argentina \\
\hline Cloruro de potasio & $7447-40-7$ & Sigma-Aldrich, USA \\
\hline Cloruro de sodio & $7647-14-5$ & Sigma-Aldrich, USA \\
\hline Dicromato de potasio & $7778-50-9$ & Merck KgaA, Alemania \\
\hline DMSO & $67-68-5$ & Sigma-Aldrich, USA \\
\hline Duodecil Sulfato Sódico & $151-21-3$ & Sigma-Aldrich, USA \\
\hline Etanol absolute & 20821.296 & Biopack, Argentina \\
\hline Fosfato de sodio dibásico & $7558-79-4$ & Sigma-Aldrich, USA \\
\hline Fosfato monobásico de potasio & $7778-77-0$ & Sigma-Aldrich, USA \\
\hline Guaiacol & $90-05-1$ & Sigma-Aldrich, USA \\
\hline Hexano & $110-54-3$ & Biopack, Argentina \\
\hline Hidróxido de sodio & $1310-73-2$ & Sigma-Aldrich, USA \\
\hline $\begin{array}{l}\text { Malonaldehido bis (dimetil } \\
\text { acetal) }\end{array}$ & $102-52-3$ & Sigma-Aldrich, USA \\
\hline N- laurylsarcosinato & $137-16-6$ & Sigma-Aldrich, USA \\
\hline
\end{tabular}




$\begin{array}{ccc}\mathrm{Na}_{2} \text { EDTA } & 6321-92-6 & \text { Sigma-Aldrich, USA } \\ \text { Nitrato de calcio tetrahidratado } & 13477-34-4 & \text { Biopack, Argentina } \\ \text { Nitrato de potasio } & 7757-79-1 & \text { Biopack, Argentina } \\ \text { Peróxido de Hidrógeno } & 7722-84-1 & \text { Sigma-Aldrich, USA } \\ \text { Reactivo de Folin Ciocalteu } & \text { F9252 } & \text { Sigma-Aldrich, USA } \\ \text { Sulfato de cobre (II) } & 7758-99-8 & \text { Biopack, Argentina } \\ \text { pentahidratado } & & \\ \text { Sulfato de magnesio } & 7487-88-9 & \text { Biopack, Argentina } \\ \text { heptahidratado } & & \text { Biopack, Argentina } \\ \text { Tartrato de sodio } & 921-53-9 & \text { Sigma-Aldrich, USA } \\ \text { Tris } & 77-86-1 & \text { Sigma-Aldrich, USA } \\ \text { Triton X-100 } & 9002-93-1 & \end{array}$

Los formulados comerciales para los plaguicidas utilizados en el presente trabajo se detallan en la Tabla 2.

Tabla 2. Formulados comerciales utilizados

\begin{tabular}{cccc}
\hline Formulado Comercial & Principio activo & Concentración & Empresa productora \\
\hline Round-up $^{(B)}$ & Glifosato & $48 \%$ & Monsanto S.A.I.C. \\
Terfos $^{(B)}$ & Clorpirifos & $48 \%$ & Chemotecnica S.A. \\
\hline
\end{tabular}

El agua Milli-Q utilizada en el presente trabajo fue obtenida a partir de un equipo de purificación Heal Force Super serie PW (Shanghai), con filtro de 0,2 $\mu \mathrm{m}$. Las características químicas de la misma se detallan en la Tabla 3

Tabla 3. Características químicas del agua Milli-Q

\begin{tabular}{cc}
\hline Parámetro & Valor \\
\hline Resistividad $(\mathrm{m} \Omega \times \mathrm{cm})$ & 18,2 \\
Conductividad $(\mu \mathrm{S} / \mathrm{cm})$ & 0,055 \\
COT $(\mathrm{ppb})$ & $<10$ \\
Partículas $0,22 \mu \mathrm{m}$ & $<1 / \mathrm{mL}$ \\
Bacterias & $1 \mathrm{UFC} / \mathrm{mL}$ \\
\hline
\end{tabular}




\subsection{Organismos de prueba}

\subsubsection{Plantas Terrestres}

\subsubsection{Vicia faba}

Descripción morfológica

Desde el punto de vista sistemático, Vicia faba (n.v. habas) pertenece a la división Spermatophyta, subdivisión Angiospermae, clase Dicotyledoneae, subclase Rosidae, orden Fabales, familia Fabaceae, tribu Vicieae y género Vicia. (Cronquist, 1981).

Las leguminosas son un conjunto de especies pertenecientes a la familia Fabaceae, que se diferencian de otras familias por un rasgo morfológico muy característico, la presencia de semillas contenidas en una vaina constituyendo el fruto o legumbre. Sus semillas maduras se emplean en alimentación principalmente por su elevado contenido proteico (17-30\%). Esta familia comprende unos 600 géneros y 13.000 especies, de las cuales unas 200 son de consumo humano y animal.

La planta de habas era conocida por los antiguos egipcios, griegos y romanos, por quienes era consumida seca, como grano verde y como vaina verde. Hoy en día es una planta de distribución cosmopolita y con cierta importancia agronómica por el valor nutritivo de sus granos.

En cuanto a sus características botánicas, $V$. faba es una planta herbácea anual, erecta y glabra, que en condiciones naturales noduliza mediante la asociación simbiótica con Rhizobium leguminosarum. Posee tallos firmes y huecos de sección cuadrangular que pueden alcanzar entre 30 y $80 \mathrm{~cm}$ de altura. Cuenta con grandes flores en forma de mariposa, con un tamaño aproximado de $2 \mathrm{~cm}$ de color blanco, con una mancha negro-purpúrea en cada pétalo, dispuestas en racimos axilares y casi sentados de 2-6 flores. Las hojas son compuestas, presentando entre 1 y 4 pares de folíolos grandes, ovales, gruesos, glaucos, sin zarcillos y provistos en su base de unas estípulas grandes, dentadas y maculadas. El fruto en legumbre es verde-negruzco, carnoso, inflado y putrescente. En general contiene unas ocho semillas de 2-3 $\mathrm{cm}$, ovales, oblongas, comprimidas, tersas y de color verde brillante.

\section{Obtención de las semillas}

Las semillas de habas fueron compradas en un comercio local (La Germinadora, Ciudad Autónoma de Buenos Aires) y corresponden a la variedad dulce. Este comercio fue elegido entre un grupo de proveedores de semillas en base a evaluaciones previas realizadas. Estas evaluaciones consistieron en comprar 30 semillas de cada comercio y evaluar su poder 
germinativo y su tendencia a las infecciones fúngicas. Las habas del comercio seleccionado presentaron mayor frecuencia de germinación (mayor al 80\%) y menor tendencia a la contaminación por patógenos fúngicos, cumpliendo los criterios de selección establecidos.

Antes de ser almacenadas a $4^{\circ} \mathrm{C}$ y en bolsas de papel, las semillas fueron seleccionadas a simple vista descartando aquellas muy pequeñas o que denotaran signos de afecciones fúngicas o el ataque de insectos.

\subsubsection{Lactuca Sativa}

\section{Descripción morfológica}

Lactuca sativa, (n.v. lechuga) corresponde a la división Magnoliophyta, clase Magnoliopsida, orden Asterales, familia Asteraceae y género Lactuca.

L. sativa es una planta originaria de la costa sur del Mar Mediterráneo. Los egipcios la comenzaron a cultivar 4500 años antes de Cristo.

Las plantas de lechuga son anuales o bienales, autógamas, de porte erecto y hasta $1 \mathrm{~m}$ de altura, glabras y con tallos ramificados. Las hojas se disponen primariamente en forma de roseta y luego se aprietan formando un cogollo más o menos consistente. Estas hojas varían en tamaño, consistencia, textura y color según el cultivar. El borde de los limbos foliares puede ser liso, ondulado o aserrado. Las plantas de L. sativa poseen raíz pivotante, con un eje principal carnoso y numerosas raíces laterales que desarrollan a poca profundidad. Presenta un tallo muy corto en el período en el cuál la hortaliza es comercialmente importante (etapa vegetativa), mientras que su tallo floral puede alcanzar hasta $1 \mathrm{~m}$ de longitud. Las flores individuales son de color amarillo con cinco estambres y un ovario. Éstas se agrupan en inflorescencias en forma de capítulos en panículas o corimbos. Sus frutos son aquenios obovados con presencia de vilano o papus. Se cultiva por sus hojas que se comen en ensalada y como verdura.

\section{Obtención de organismos}

Las semillas de lechuga fueron adquiridas en un comercio local (Florensa, Luján) y corresponden a la variedad lechuga criolla de verano. Se realizaron ensayos preliminares a fin de obtener el porcentaje de germinación exigido por la norma utilizada. Para ser utilizado en los ensayos, el lote de semillas fue homogeneizado, eliminando selectivamente las semillas de mayor y menor tamaño. Las semillas utilizadas fueron almacenadas a $4^{\circ} \mathrm{C}$ en sobres de papel hasta sus respectivos ensayos. 


\subsubsection{Invertebrados terrestres}

\subsubsection{Lombrices de tierra (Anélidos)}

\section{Descripción morfológica}

El filo Annelida agrupa organismos celomados, protostomados, que presentan segmentación en espiral, desarrollo de tipo mosaico y simetría bilateral. Pertenecen a este grupo unas 15000 especies de organismos con diferentes hábitos de vida. Existen organismos terrestres, acuáticos, tanto marinos como de agua dulce y parásitos. Los anélidos presentan una amplia distribución mundial con especies cosmopolitas. Esta característica hace que muchas especies de este filo sean propuestas como especies centinela en diferentes ambientes. El cuerpo de los anélidos está dividido en segmentos repetitivos (metámeros) a lo largo del eje longitudinal, por lo tanto presentan verdadera metamería.

Los integrantes de este grupo pueden clasificarse en tres clases, los Poliquetos, los Oligoquetos y los Hirudineos.

Los oligoquetos se distinguen por tener pocas quetas en sus segmentos. Comprenden unas 3000 especies, donde están incluidas las lombrices de tierra, pero también organismos de agua dulce y un reducido grupo de organismos marinos. Dentro de este grupo se encuentra Eisenia fetida, la especie utilizada en la presente tesis doctoral y la cual se encuentra estandarizada internacionalmente para diferentes bioensayos. Las lombrices de tierra poseen un cuerpo segmentado, revestido externamente por una cutícula quitinosa, la cual es secretada por el epitelio cilíndrico subyacente. Por debajo de este epitelio se encuentran las fibras musculares dispuestas de manera circular (externa) y longitudinal (internas). Los movimientos alternados y coordinados de ambos grupos musculares permiten el desplazamiento de los organismos en el suelo. Internamente se encuentra la cavidad celómica, llena de líquido, que funciona como un esqueleto hidrostático, dando turgencia al organismo. El líquido celómico, que contiene células especializadas denominadas celomocitos, puede ser expulsado del cuerpo dado que existen poros en el dorso de cada segmento. Esta característica hace de los celomocitos células adecuadas para la determinación de biomarcadores, ya que es sencillo obtenerlas con métodos poco invasivos (Di Marzio et al, 2005).

Entre las células epiteliales, sobre todo en la región anterior y posterior del cuerpo se intercalan células sensitivas, algunas de las cuales son fotosensibles. Existen además células productoras de mucus que permiten mantener húmeda la cutícula. Las lombrices adultas se caracterizan por presentar en el tercio anterior de su cuerpo un engrosamiento anular, el clitelo, cuyas glándulas proveen por un lado la secreción que en contacto con el aire se 
endurece proporcionando la envoltura del cocón, resultante de la cópula; y por otro lado el líquido albuminoideo que provee nutrición a los embriones. Las lombrices de tierra son detritívoras y se alimentan de materia orgánica en descomposición.

Existen unas diez familias de lombrices de tierra que agrupan un número importante de especies. Todas ellas son excavadoras y presentan una amplia distribución geográfica, excepto en los desiertos. Los suelos que mantienen una mayor fauna de oligoquetos son aquellos que contienen una cantidad considerable de materia orgánica. Sin embargo son importantes otros factores propios de suelo en la distribución de las especies terrestres. Los suelos ácidos constituyen hábitats favorables para la mayoría de las lombrices de tierra.

Los oligoquetos terrestres construyen sus galerías forzando su extremo anterior a través de grietas en ingiriendo el suelo. Con los excrementos y el moco que secretan revocan internamente la galería formando un revestimiento característico. El resto del material defecado lo sacan afuera de la galería en forma de heces. Cómo lo demostró Charles Darwin, la actividad excavadora de las lombrices de tierra es beneficioso para el suelo. Las extensas galerías incrementan el drenaje y la aireación del suelo, aunque en un plano mayor de importancia se encuentra en mezclado del mismo. El suelo de las capas profundas es llevado a la superficie en forma de heces y la materia orgánica es trasladada hacia las regiones más profundas.

La mayor parte de las especies de oligoquetos, tanto acuáticas como terrestres son carroñeras y se alimentan de materia orgánica muerta, particularmente vegetación.

El aparato digestivo es recto y relativamente simple. La boca, situada debajo del prostomio se abre en una pequeña cavidad bucal que a su vez se comunica con una faringe más amplia. La pared dorsal de la cámara faríngea es muscular y glandular y se forma un bulbo o cojinete que constituye el principal centro de ingestión. En las lombrices de tierra la faringe actúa como una bomba aspirante. Las glándulas faríngeas producen una secreción salival que contiene sustancias mucosas y enzimas. La faringe desemboca en un estrecho esófago tubular que en las lombrices de tierra esta modificado formando la molleja y el buche. La molleja es utilizada para triturar partículas alimenticias, está revestida por cutícula y es muy muscular. El buche tiene paredes finas y constituye una cámara de almacenamiento.

Como estructuras particulares del aparato digestivo de los oligoquetos se encuentran las glándulas calcíferas en ciertas partes de la pared de esófago. Su principal función es segregar carbonato de calcio en forma de cristales de calcita dentro del esófago. Estos cristales son transportados a lo largo del tubo digestivo y se eliminan con las heces. Las glándulas calcíferas no participan activamente en la digestión y su función es incierta aunque se han 
propuesto algunas hipótesis. Por un lado pueden ser eficaces para la eliminación del $\mathrm{CO}_{2}$ producido durante la respiración celular por vía alimenticia, por otra parte podrían intervenir en la eliminación del exceso de calcio ingerido con el alimento.

El intestino forma el resto del aparato digestivo y se prolonga como un tubo a lo largo del cuerpo con excepción del cuarto anterior. La mitad anterior del intestino es la región más importante de secreción y digestión y la mitad posterior es principalmente un lugar de absorción. El epitelio intestinal de las lombrices de tierra secreta celulasa y quitinasa. Los materiales alimenticios absorbidos pasan a los senos sanguíneos ubicados entre el epitelio y la musculatura intestinal. El área superficial del intestino se incrementa por un pliegue o reborde denominado tiflosol que se proyecta internamente desde la pared medio dorsal. Rodeando el intestino y recubriendo el vaso dorsal de los oligoquetos hay una capa de células peritoneales amarillentas, denominadas células cloragógenas, que juegan un papel vital en el metabolismo intermedio, semejante al del hígado de los vertebrados. El tejido cloragógeno es el principal centro de síntesis y reserva de glucógeno y grasa. En estas células también tiene lugar el almacenamiento y detoxificación de toxinas, síntesis de hemoglobina, catabolismo de proteínas, formación de amoníaco, y síntesis de urea. En las especies terrestres los silicatos obtenidos del material alimenticio y del suelo, se eliminan del cuerpo y depositan en las células cloragógenas como concreciones de desecho.

El intercambio gaseoso se da por difusión de gases a través del tegumento, tanto en organismos terrestres como acuáticos.

El sistema circulatorio de los oligoquetos se encuentra más desarrollado en las lombrices de tierra. Las ramificaciones de los vasos segmentarios envían sangre a los capilares del tegumento irrigando los órganos del segmento correspondiente. Los vasos carecen de endotelio y se encuentran revestidos por la lámina basal del peritoneo. El vaso dorsal es contráctil y es el principal medio de propulsión sanguínea. Los vasos de los oligoquetos, llamados comúnmente corazones, son vasos anteriores comisurales visiblemente contráctiles que funcionan como órganos accesorios para la propulsión sanguínea y varían entre especies por su cantidad.

Los oligoquetos presentan un sistema de excreción metanefridial, con un par de metanefridios por segmento, a excepción de los extremos anterior y posterior.

En cuanto a su sistema nervioso los oligoquetos presentan dos cordones nerviosos ventrales situados por debajo de la pared del cuerpo. El cerebro de los oligoquetos se ha desplazado posteriormente, ubicándose en el tercer segmento. Los oligoquetos presentan axones de gran 
tamaño, siendo particularmente gruesos. El ganglio subfaríngeo es el principal centro de control motor y de reflejos vitales y domina a los demás ganglios presentes.

Los oligoquetos carecen de ojos, no obstante el tegumento está bien dotado de fotorreceptores dispersos situados en la parte interna de la epidermis, especialmente ubicados en el extremo anterior del cuerpo. Poseen además quimiorreceptores encima de la cutícula y concentrados particularmente en la región anterior.

Los oligoquetos son hermafroditas, poseen gónadas diferenciadas y el número de segmentos reproductores se limita a unos pocos. Los segmentos gonadales si sitúan en la mitad anterior del gusano, ubicándose por delante los segmentos femeninos y por detrás los masculinos. Los ovarios y testículos, típicamente pareados se sitúan en la parte inferior del septo, y descargan su contenido en el celoma. Si bien la maduración de los gametos se completa en el celoma, está restringida a los sacos celómicos especiales denominados vesículas seminales y ovisacos. El clitelo es una estructura reproductora característica de los oligoquetos. Está formado por un determinado número de segmentos adyacentes en los que a epidermis está muy engrosada por la presencia de glándulas unicelulares: el clitelo forma un anillo que rodea parcial o totalmente desde el lado dorsal hacia el ventral.

El desarrollo del clitelo varía estacionalmente, pero fundamentalmente coincide con la madurez sexual de los individuos. Las glándulas del clitelo producen sustancias mucosas para la cópula, secretan la pared del cocón y la albúmina en la que se depositan los huevos.

La mayor parte de los oligoquetos se reproducen de manera semicontinua. La cópula es la transferencia mutua y dirigida del esperma. Las superficies ventrales de la pareja de lombrices, se ponen en contacto de manera que la parte anterior de uno de ellos queda dirigida hacia la parte posterior del otro. Pocos días después de la cópula los oligoquetos secretan un capullo para depositar los huevos. Primero se secreta un tubo mucoso alrededor de los segmentos anteriores, incluido el clitelo. Después el clitelo, secreta un material envolvente resistente, parecido a la quitina. La capa más profunda de glándulas clitelares secreta la albúmina que nutrirá a los embriones. Cuando el capullo se encuentra completamente formado se desliza hacia adelante sobre el extremo anterior mientras el oligoqueto tira hacia atrás. Cuando el capullo pasa por los gonoporos femeninos y masculinos colecta gametas femeninas y masculinas respectivamente. En el capullo tiene lugar la fecundación externa. Cuando el capullo se desliza sobre la cabeza de la lombriz el tubo mucoso se desintegra rápidamente y sus extremos se constriñen para sellarse, constituyendo el cocón. Tanto los grupos de oligoquetos terrestres como los acuáticos poseen desarrollo directo, y todo el proceso se da dentro del cocón. 
Eisenia fetida (n.v. lombriz roja californiana) es un oligoqueto que corresponde al orden Haplotaxida, a la familia Lumbricidae. Se trata de una especie epigea ampliamente utilizada para la evaluación de suelos debido a varias características de su biología. Su uso como organismo modelo para la evaluación ecotoxicológica de diversos compuestos ha sido ampliamente difundida.

\section{Obtención y mantenimiento de cultivos}

Los ejemplares de E. fetida utilizados en todos los ensayos fueron adquiridos en un comercio de Lombricultura local (Troli Lumbricultura, Exaltación de la Cruz, Provincia de Buenos Aires). Los organismos fueron trasladados al laboratorio y se aclimataron a las condiciones de cultivo durante el tiempo necesario antes de realizar los ensayos correspondientes.

La optimización del sistema de cultivo adecuado para la obtención de organismos sanos y libres de la potencial influencia de cualquier sustancia química es fundamental para la correcta interpretación de los datos obtenidos en los bioensayos con lombrices de tierra.

Se escogió como sustrato de cultivo suelo fuera de la influencia de actividades antropogénicas. Este suelo fue recogido del campo experimental de la Universidad Nacional de Luján, siendo caracterizado por Di Marzio et al (2007). Para ser utilizado, se recolectaron los primeros $20 \mathrm{~cm}$ de profundidad del suelo, y se separaron manualmente las raíces y la hojarasca presente. Posteriormente, el suelo, fue secado a $105^{\circ} \mathrm{C}$ en estufa, molido en un molinillo industrial y tamizado a $1000 \mu \mathrm{m}$. Para preparar el cultivo, este suelo tamizado, fue hidratado al $75 \%$ de su capacidad de retención de agua y suplementado con un $10 \%$ en peso seco de forraje a base de alfalfa previamente secado a $105^{\circ} \mathrm{C}$ y finamente molido. Todos estos componentes fueron mezclados manualmente hasta llegar a un sustrato homogéneo, que se dejó estabilizar durante $48 \mathrm{~h}$. Los cultivos fueron mantenidos con fotoperiodo de $16 \mathrm{~h}$ luz y 8 h oscuridad, a $22 \pm 2{ }^{\circ} \mathrm{C}$, pH 7,0 $\pm 0,5$ y $60 \%$ de humedad.

$\mathrm{Al}$ arribar al laboratorio los organismos fueron lavados con solución salina $(\mathrm{NaCl}, 0.85 \% \mathrm{~m} / \mathrm{v}$, en agua Milli-Q) para remover los restos del sustrato de cultivo comercial. A fin de optimizar el cultivo para asegurar individuos en buen estado fisiológico, se colocaron 2000 organismos, en una proporción de $60 \%$ de adultos clitelados y 40\% de juveniles, en $10 \mathrm{~kg}$ de sustrato de cultivo descripto con anterioridad. A intervalos regulares de tiempo se calcularon los índices LITA (Lombriz índice Trófico Absoluto), LITAR (Lombriz Índice Trófico Relativo) e ICCT (Índice Corporal de Celomocitos Totales) (Curieses et al, 2011) que se describen en el ítem 2.5.3.3. Los mismos fueron utilizados como criterio de evaluación para determinar el buen estado fisiológico de los organismos a utilizar en las evaluaciones ecotoxicológicas. 


\subsection{Matrices sólidas evaluadas}

Las matrices sólidas seleccionadas para ser evaluadas corresponden a dos tipos:

- Residuos sólidos provenientes de la actividad industrial

- Suelos provenientes de zonas de cultivo de soja

En el caso de los residuos sólidos provenientes de la actividad industrial, estos corresponden, en primer término, a una muestra de arena de fundición generada por la industria metalúrgica y en segundo término a un lodo post-estabilización generado por una industria cosmética.

En el caso de los suelos, se evaluaron muestras ambientales provenientes de zonas de cultivo de soja tomadas durante la fase de post-aplicación del herbicida glifosato y previa a la cosecha post-aplicación del insecticida clorpirifos. También se incluyeron evaluaciones complementarias que involucraron muestras de suelos tratadas artificialmente en el laboratorio con las dosis de aplicación recomendadas de ambos plaguicidas.

\subsubsection{Muestreo y preservación de las muestras}

\subsubsection{Residuos sólidos}

Las muestras de residuos sólidos fueron tomadas de dos áreas industriales correspondientes a la actividad metalúrgica y cosmética, respectivamente.

La muestra de la industria metalúrgica, correspondiente a la arena de fundición, consiste en una muestra compuesta formada por sub-muestras tomadas de manera aleatoria en diferentes tiempos del período de disposición final dentro del área industrial. Este residuo fue preservado a temperatura ambiente en bolsas de polietileno.

En el caso de la muestra de cosmética consiste en una muestra compuesta tomada luego de la deshidratación del lodo secundario proveniente de la planta depuradora industrial. Este residuo fue almacenado para su preservación en recipientes herméticos.

\subsubsection{Suelos}

Los suelos evaluados corresponden a muestras ambientales de suelos tratados con el herbicida glifosato y el insecticida clorpirifos. Complementariamente se evaluaron suelos tratados artificialmente con ambos plaguicidas. 


\subsection{Muestras ambientales}

Las muestras ambientales se colectaron en cultivos de soja ubicados en los alrededores de la ciudad de Saladillo (Coordenadas 3552’00.53“ S 59³8'36.70“ O, elevación 35 m, Provincia de Buenos Aires). Para su obtención se realizaron gestiones con la Asociación Agraria de la ciudad, que permitió conocer el calendario de aplicación de los plaguicidas en los cultivos de soja, de manera de poder coordinar los muestreos de los suelos en los días subsiguientes a la aplicación de los mismos. Estas gestiones también posibilitaron la coordinación con los productores que facilitaron el acceso a los campos de cultivos en los días programados para la recolección de las muestras.

La toma de las muestras también se realizó de manera compuesta, en zonas de cultivo seleccionadas al azar, recolectando los primeros centímetros del suelo tratado con ayuda de una pala. Estos suelos ambientales fueron almacenados a $4^{\circ} \mathrm{C}$ en bolsas de polietileno. $\mathrm{Al}$ momento de ser utilizado el suelo fue desgranado manualmente y se retiraron los restos vegetales (hojarasca y raíces) y animales (artrópodos y oligoquetos) presentes en su matriz

\subsection{Muestras tratadas artificialmente con glifosato y clorpirifos}

Para complementar la evaluación de suelos tratados con plaguicidas, se incluyó una evaluación de suelos tratados artificialmente en el laboratorio, con las dosis de aplicación recomendadas por los fabricantes de ambos plaguicidas, glifosato y clorpirifos. Las dosis de aplicación elegidas fueron 2,5; 4 y $6 \mathrm{~L} /$ ha en el caso del herbicida glifosato; y 1 y $2 \mathrm{~L} / \mathrm{ha}$ para el insecticida clorpirifos.

Este tratamiento artificial se realizó simulando las condiciones de aplicación seguidas por los productores en el campo. Para ello se utilizó una superficie de suelo de 0,04 $\mathrm{m}^{2}$ y con mínimo de espesor, para evitar la dilución por efectos de profundidad. Así $150 \mathrm{~g}$ de suelo molido y tamizado a $1000 \mu \mathrm{m}$ fueron distribuidos en una capa homogénea de $1 \mathrm{~cm}$ de espesor en un recipiente de vidrio de 0,2 $\mathrm{m}$ de lado, y tratados con la cantidad de plaguicida correspondiente según la relación volumen/superficie recomendada por los fabricantes. Los formulados comerciales fueron vehiculizados en agua Milli-Q y aplicados sobre los suelos mediante un rociador comercial.

Una vez tratados con los plaguicidas, los suelos fueron homogeneizados mecánicamente y utilizados de forma inmediata, para evitar pérdidas por volatilización.

Para el tratamiento artificial de los suelos se utilizaron los formulados comerciales de ambos plaguicidas que fueron adquiridos en comercios locales. El formulado comercial del herbicida 
glifosato que se utilizó fue Round-up ${ }^{\circledR}$, cuya fórmula molecular se observa en la Figura 1. El formulado comercial contiene la sal isopropilamina del $\mathrm{N}$-fosfonometil glicina (CAS $\mathrm{N}^{\circ}$ 38641-94-0) en una concentración de $48 \% \mathrm{~m} / \mathrm{v}$. Sus propiedades químicas más relevantes pueden observarse en la Tabla 4.<smiles>O=C(O)CNCP(=O)(O)O</smiles>

Figura 1. Fórmula química del glifosato

Tabla 4. Propiedades químicas del Glifosato

\begin{tabular}{cc}
\hline Propiedades & Valor \\
Masa Molar & $169,1 \mathrm{~g} / \mathrm{mol}$ \\
Log $\mathrm{K}_{\mathrm{OW}}$ & $-3,48$ \\
Solubilidad en agua & $11,6 \mathrm{~g} / \mathrm{L}$ a $25^{\circ} \mathrm{C}$ \\
Solubilidad en tolueno & $0,036 \mathrm{~g} / \mathrm{L}$ \\
Solubilidad en acetona & $0,078 \mathrm{~g} / \mathrm{L}$ \\
Log KoC & 1,27 \\
Presión de vapor & $1,84 \times 10^{-7} \mathrm{~mm} \mathrm{Hg} \mathrm{a} 25^{\circ} \mathrm{C}$, \\
Constante de Henry & $1,44 \times 10-12 \mathrm{~atm} * \mathrm{~m}^{3} / \mathrm{mol}$ \\
\hline
\end{tabular}

El formulado comercial del insecticida clorpirifos utilizado fue $\operatorname{Terfos}^{\circledR}$, que contiene el concentrado emulsionable O,O-dietilfosforotioato de O-3,5,6-tricloro-2-piridilo (CAS $\mathrm{N}^{\circ}$ 2921-88-2) (Figura 2), con una concentración de $48 \%$ m/v. Las propiedades químicas más significativas del mismo se exhiben en el Tabla 5.<smiles>CCOP(=S)(OCC)Oc1nc(Cl)c(Cl)cc1Cl</smiles>

Figura 2. Fórmula Molecular del clorpirifos 
Tabla 5. Propiedades químicas del clorpirifos

\begin{tabular}{|c|c|}
\hline Propiedades & Valor \\
\hline Masa Molar & $350,58 \mathrm{~g} / \mathrm{mol}$ \\
\hline Log $\mathrm{K}_{\mathrm{OW}}$ & 4,8 \\
\hline Solubilidad en agua & $0,4 \mathrm{mg} / \mathrm{L} \mathrm{a} 23^{\circ} \mathrm{c}$ \\
\hline Solubilidad en benceno & $7900 \mathrm{~g} / \mathrm{kg} \mathrm{a} 25^{\circ} \mathrm{c}$ \\
\hline Solubilidad en acetona & $6500 \mathrm{~g} / \mathrm{kg}$ a $25^{\circ} \mathrm{c}$ \\
\hline $\log \mathrm{K}_{\mathrm{OC}}$ & 4,13 \\
\hline Presión de vapor & $2,02 \times 10^{-5} \mathrm{mmHg}$ a $25^{\circ} \mathrm{C}$ \\
\hline Constante de Henry & $2,9 \times 10^{-6} \mathrm{~atm}^{*} \mathrm{~m}^{3} / \mathrm{mol}$ \\
\hline
\end{tabular}

\subsection{Caracterización química de las matrices sólidas}

Se realizó la caracterización química de las matrices sólidas (Residuos y Suelos) en forma entera y de las eluciones preparadas a partir de las mismas. Las determinaciones químicas correspondientes a COT y compuestos orgánicos se realizaron en cooperación con personal del laboratorio Central de la UNLu y del Programa de Investigación en Ecotoxicología.

\subsubsection{Muestras enteras}

Todas las muestras enteras fueron caracterizadas determinando $\mathrm{pH}$, fracción húmeda, sólidos volátiles, CRA y COT (Carter, 1993). Además, en el caso de los residuos industriales se realizó la cuantificación de metales, y se realizó una determinación cualitativa de compuestos orgánicos. Para el residuo correspondiente a la arena de fundición se cuantificaron los Hidrocarburos totales. En el caso de los suelos se clasificaron en cuanto a textura y tipo taxonómico según USDA (2003).

\subsubsection{1. pH}

Para todas las matrices sólidas se determinó el pH utilizando un pHmetro de suelos Kelway ${ }^{\circledR}$. El electrodo fue introducido en la matriz sólida y se registró el valor de $\mathrm{pH}$ una vez estabilizada la lectura. 


\subsubsection{Fracción húmeda}

Para la determinación de la fracción húmeda se utilizó el protocolo 2540 B (APHA, 1998). Según el mismo se pesaron $100 \mathrm{~g}$ de cada matriz sólida y se colocaron en estufa a $105^{\circ} \mathrm{C}$ hasta alcanzar peso constante. La fracción húmeda se calculó cómo la diferencia entre el peso inicial y peso final.

\subsubsection{Sólidos volátiles}

Para determinar la fracción de residuos volátiles presentes en las matrices sólidas suelos se siguió el protocolo 2540 E (APHA, 1998). Siguiendo las indicaciones del mismo, $100 \mathrm{~g}$ de las matrices sólidas son previamente secadas en estufa a $105^{\circ} \mathrm{C}$, durante $24 \mathrm{~h}$, y luego se colocada en la mufla a $550^{\circ} \mathrm{C}$ hasta llegar a peso constante. La determinación de sólidos volátiles se realizó teniendo en cuenta la siguiente ecuación:

$$
\% S V=\frac{(E-M) * 100}{m}
$$

Dónde

E: Es el peso de la muestra luego de ser secada en la estufa

M: Es el peso de la muestra luego de ser calcinada en la mufla

$\mathrm{m}$ : Es el peso de la muestra colocada al inicio

\subsubsection{Capacidad de retención de agua (CRA)}

La capacidad de retención de agua de las matrices sólidas y la arena utilizada como soporte inerte se determinó siguiendo el protocolo de la US EPA (1989). Según el mismo, 100 g del sólido, previamente secado a $105^{\circ}$ durante $24 \mathrm{~h}$, fue colocado en un vaso de precipitado de $250 \mathrm{~mL}$, junto con $100 \mathrm{~mL}$ de agua Milli-Q y se mezclaron con varilla hasta formar una dispersión coloidal homogénea. Por otro lado, se cortó un círculo de $100 \mathrm{~mm}$ de diámetro de papel crepé y se colocó en un embudo. Este conjunto fue humedecido con $9 \mathrm{~mL}$ de agua Milli-Q para generar la adherencia del papel al embudo y se determinó el peso. El valor obtenido, sumado a los $100 \mathrm{~g}$ de suelo colocados anteriormente constituye el peso inicial. El embudo previamente preparado con el papel de filtro húmedo se colocaron, con ayuda de un soporte, sobre un Erlenmeyer de $500 \mathrm{~mL}$ y la mezcla de suelo y agua fue vertida sobre este. Las partículas de suelo que quedan en el vaso fueron lavadas con el menor volumen de agua Milli-Q que sea posible, y el embudo se recubrió con papel aluminio para evitar pérdidas de agua por evaporación. Este sistema se dejó drenar el agua durante $3 \mathrm{~h}$ y se pesó nuevamente, obteniéndose el peso final, correspondiente al embudo, papel crepé y suelo hidratado. La 
capacidad de retención de agua se expresa como $\mathrm{mL}$ de agua/100 g de suelo, y se calcula como la diferencia entre el peso final y el inicial.

\subsubsection{Textura}

En las matrices sólidas correspondiente a los suelos se determinó la textura por método hidrométrico (Bouyoucos). Esta técnica se realizó en cooperación con docentes de la asignatura Edafólogía (UNLu). Básicamente una porción de muestra de suelo fue tratada con dispersante Calgón ${ }^{\circledR}$ durante una noche. La mezcla se colocó en una probeta de litro y se colocó un hidrómetro con escala calibrada de Bouyoucos registrándose lecturas sobre la escala del mismo a los 40 segundos (tiempo para la sedimentación de arena) y 7 horas (tiempo de sedimentación para arcilla). El porcentaje de limo se calculó por diferencia respecto a los $\%$ de los dos primeros.

\subsubsection{Clasificación de suelos según clave taxonómica de USDA}

En las matrices sólidas correspondientes a los suelos se determinó el tipo de suelos en base a la clasificación de USDA (2003).

\subsubsection{Determinación de Carbono Orgánico Total (COT)}

Para la determinación de COT en las matrices sólidas se siguió el método de titulación húmeda redox (Tiessen y Moir, 1993). Siguiendo el mismo, entre 0,2-0,4 g de las matrices sólidas fueron pesadas y colocadas en un tubo de ensayo con $6 \mathrm{~mL}$ de mezcla de digestión. El tubo se incubó durante 45 minutos en una plancha calefactora a $150^{\circ} \mathrm{C}$ y el producto de digestión fue trasvasado a un Erlenmeyer de $150 \mathrm{~mL}$. Se adicionaron $20 \mathrm{~mL}$ de agua Milli-Q, $2 \mathrm{~mL}$ de ácido fosfórico y dos gotas de ferroína. Finalmente se tituló con sulfato amoníacoferroso, hasta el viraje de color verde a rojo.

Para el cálculo de los mg de Carbono presentes en las muestras se siguió la siguiente ecuación:

$$
m g C=(B-T) * M * 0,003 * 1000
$$

Dónde:

B: Valor del blanco de digestión

T: Muestra

M: Molaridad del sulfato amoníaco-ferroso 


\subsubsection{Cuantificación de metales}

La cuantificación de metales en las matrices sólidas correspondientes a los residuos sólidos industriales se llevó a cabo mediante una digestión ácida de los mismos y su posterior análisis por espectroscopia de absorción atómica. Para la digestión de las muestras se siguió el protocolo establecido por la norma "Hazardous Waste Test Methods"/ SW-846, Método 3050B, "Acid Digestion of Sediments, Sludges, and Soils" de US EPA. Siguiendo las indicaciones de la misma se utilizaron $2 \mathrm{~g}$ del residuo de arena de fundición y $1 \mathrm{~g}$ (peso seco en ambos casos) del el residuo de la industria cosmética para la digestión ácida realizada. Esta digestión se realizó por duplicado para cada muestra y utilizando como blanco de digestión los reactivos utilizados sin muestras. Para comenzar se adicionaron a las muestras anteriormente pesadas, $10 \mathrm{~mL}$ de ácido nítrico al 50\% y se calentó a reflujo durante $1 \mathrm{~h}$ a 95 ${ }^{\circ} \mathrm{C}$. Se dejaron enfriar las muestras y se agregaron $5 \mathrm{~mL}$ de ácido nítrico concentrado, calentándose nuevamente a reflujo durante $2 \mathrm{~h}$, repitiéndose el proceso hasta la aparición de vapores blancos. La aparición de vapores blancos indica la finalización de la oxidación, mientras que la aparición de vapores marrones indica que la oxidación no se ha completado. Terminada la oxidación se dejó enfriar la muestra y se agregaron $2 \mathrm{~mL}$ de agua Milli-Q y 3 $\mathrm{mL}$ de $\mathrm{H}_{2} \mathrm{O}_{2}$ al $30 \%$. Si la efervescencia persiste se deben agregar alícuotas de $1 \mathrm{~mL}$ de $\mathrm{H}_{2} \mathrm{O}_{2}$, sin superar los $10 \mathrm{~mL}$ del mismo. Para finalizar, se calentó nuevamente a reflujo a $95^{\circ} \mathrm{C}$ hasta llevar a un volumen aproximado de $5 \mathrm{~mL}$. El producto de digestión para ambas muestras fue diluido a $50 \mathrm{~mL}$ finales con agua Milli-Q y fue utilizado para la cuantificación de los metales elegidos.

Los metales determinados en las matrices sólidas fueron $\mathrm{Fe}, \mathrm{Cu}, \mathrm{Zn}, \mathrm{Ni}, \mathrm{Cd}, \mathrm{Cr}$ y $\mathrm{Pb}$. Los cuatro primeros metales fueron determinados según el método de espectroscopia de absorción atómica de llama (Método \#3111; APHA 1998) y los restantes según el método de espectroscopía de absorción atómica con horno de grafito (Método \#3112B, APHA 1998). Los límites de detección para estos metales fueron de $0.05 \mathrm{mg} / \mathrm{L}$. El porcentaje de recuperación en sólidos artificialmente contaminados fue de $85-110 \%$.

\subsubsection{Determinación de compuestos orgánicos}

La extracción de compuestos orgánicos presentes en las matrices sólidas correspondiente a los residuos industriales se realizó combinando las técnicas ultrasónica (US EPA 3550b) y la utilización de una mezcla de solventes orgánicos. Según las mismas se prepara una solución de extracción que consta de una proporción de 35\% de hexano y 75\% de acetona. Para la 
extracción, 40 gr de cada residuo fueron homogeneizados con 20 gr de sulfato de sodio anhidro para remover la humedad de las muestras. A continuación, esta mezcla se agitó durante una hora a temperatura ambiente con $200 \mathrm{~mL}$ de solución de extracción. Para continuar se realizaron 3 ciclos de sonicación de 5 minutos cada uno a $40 \mathrm{kHz}$. El extracto fue separado del residuo sólido por filtración al vacío con filtro Whatman de a $0.45 \mu \mathrm{m}$ y se concentró en rota vapor hasta un volumen final de $1 \mathrm{~mL}$. Se realizó un barrido cualitativo para la identificación de compuestos orgánicos presentes en los residuos sólidos. A tal fin, se inyectaron $2 \mathrm{~mL}$ en el cromatógrafo gaseoso marca Shimadzu modelo 17 ${ }^{\mathrm{a}}$ V1.3 (Japón), acoplado a un espectrómetro de masa QP 5050 A y con el software MS Solution. Las condiciones experimentales incluyen: una columna capilar de sílice fundida PTE-\% de $30 \mathrm{~m}$ (Supelco, Bellafonte), velocidad linear del gas He (utilizado como fase móvil) de 36,2 cm/s, método de inyección fraccionado con un tiempo de muestreo de 4 minutos y un flujo total de $11,7 \mathrm{~mL} / \mathrm{min}$; el programa de temperatura seguido fue de $100^{\circ} \mathrm{C}$ durante $2 \mathrm{~min}$ hasta una temperatura final de $280^{\circ} \mathrm{C}$ que se mantuvo durante 10 minutos, con una rampa de temperatura de $10^{\circ} \mathrm{C} / \mathrm{min}$, la interfaz de temperaturas entre el inyector y el capilar fue de $280^{\circ} \mathrm{C}$. El MS fue usado en modo de exploración en un rango de 50-350 m/z.

\subsubsection{Determinación de Hidrocarburos}

La determinación de hidrocarburos $(\mathrm{HC})$ en la matriz sólida correspondiente al residuo industrial de arena de fundición se realizó mediante el método "Hydrocarbons", método \#5520F; APHA, 1998) Siguiendo las indicaciones del mismo se colocaron $200 \mathrm{~g}$ de la muestra en una ampolla de decantación y se utilizó hexano como solvente de extracción. Para la misma se llevaron a cabo tres extracciones con $50 \mathrm{~mL}$ del solvente cada una. A continuación, se agregaron $3 \mathrm{~g}$ de sílica gel previamente activado durante $24 \mathrm{~h}$ a $110^{\circ} \mathrm{C}$ y se filtró al vacío utilizando papel de filtro. La solución de extracción obtenida se concentró en el Rota vapor hasta un volumen final aproximado de $2 \mathrm{~mL}$. El concentrado obtenido se transvasó a un tubo de hemólisis perfectamente limpio y seco, prepesado, y se llevó a sequedad bajo campana a temperatura ambiente. El cálculo se realizó teniendo en cuenta la siguiente ecuación

$$
m g H C=\frac{(A-B) * 1000}{200 g}
$$

Donde A corresponde al Peso final del tubo con el residuo y B al peso inicial del tubo limpio. 
Las evaluaciones ecotoxicológicas que se realizaron con las muestras enteras fueron:

- Evaluación de germinación de las semillas y elongación de las raíces en Lactuca sativa.

- Evaluación de cito y genotoxicidad en celomocitos de Eisenia fetida expuestos de manera in vivo.

\subsubsection{Fracciones líquidas- Eluciones}

Las eluciones de las matrices sólidas seleccionadas se prepararon siguiendo las recomendaciones de US EPA (2001). Según este método 250 gr del residuo y/o del suelo fueron agitados, mediante agitador magnético, a temperatura ambiente y oscuridad en 1000 $\mathrm{mL}$ de agua Milli-Q durante $48 \mathrm{~h}$. El sobrenadante de esta extracción acuosa fue utilizado para la determinación de parámetros fisicoquímicos, análisis de la concentración de metales y realización de los bioensayos correspondientes.

Para las eluciones líquidas se determinaron los siguientes parámetros fisicoquímicos: $\mathrm{pH}$, concentración de amonio, metales, DQO y COT.

\subsubsection{1. $\mathrm{pH}$}

El pH de las eluciones de las matrices sólidas evaluadas se determinó utilizando un pH metro de mesa OAKTON, modelo 1100. El mismo fue calibrado con soluciones estándar Biopack ${ }^{\circledR}$ de $\mathrm{pH} 4,7$ y 10. Para las determinaciones, los electrodos de $\mathrm{pH}$ y temperatura fueron introducidos en el seno del líquido y se registró la medición una vez estabilizada la lectura.

\subsubsection{Amonio}

El amonio presente en las eluciones se determinó siguiendo el Método \# 4500 (APHA, 1998). Las muestras líquidas fueron tratadas con $\mathrm{ZnSO}_{4}$ para eliminar interferencias y a continuación se agregaron $2 \mathrm{~mL}$ Reactivo de Nessler. Se mezcló por inversión y se determinó su absorbancia en un espectrofotómetro a $425 \mathrm{~nm}$. La cuantificación de amonio se llevó a cabo mediante la interpolación de los valores en una curva de calibración conocida.

\subsubsection{Determinación de metales}

En las fracciones líquidas se determinaron los siguientes metales: $\mathrm{Fe}, \mathrm{Al}, \mathrm{Cr}, \mathrm{Pb}, \mathrm{As}, \mathrm{Cu}, \mathrm{Zn}$ y Ni. Para su cuantificación en el espectrómetro de absorción atómica las muestras fueron acidificadas con ácido nítrico de grado analítico, y preservadas en envases de plástico. El As fue determinado mediante el método de generación de hidruros (Método \#3114 A; APHA, 
1998), con un límite de detección de $0.1 \mathrm{mg} / \mathrm{L}$. Los metales restantes fueron determinados mediante espectrometría de absorción atómica de llama (Método \# 3111B; APHA, 1998) con un límite de detección de $0.05 \mathrm{mg} / \mathrm{L}$.

\subsubsection{Demanda química de Oxígeno (DQO)}

En la fracción líquida de las matrices sólidas evaluadas se llevó a cabo la determinación de la demanda química de oxígeno mediante el método de bajo rango (Método \# 5220; APHA, 1998). Según las indicaciones del mismo $2 \mathrm{~mL}$ de la elución fueron colocados en un tubo que contiene la solución de digestión, y se mezcló por inversión. A continuación se adicionaron 2 $\mathrm{mL}$ de agua Milli-Q y lo tubos fueron llevados a una plancha calefactora a $150^{\circ} \mathrm{C}$ durante $2 \mathrm{~h}$. Por último los tubos se dejaron enfriar y se determinó su absorbancia en un espectrofotómetro a $420 \mathrm{~nm}$. La cuantificación de la demanda química de oxígeno se llevó a cabo mediante la interpolación de los valores en una curva de calibración conocida.

\subsubsection{Carbono Orgánico Total (COT)}

Los resultados obtenidos para las fracciones líquidas fueron corroborados utilizando un analizador automático de carbono (TOC/TNbAnalyzer ELEMENTAR ${ }^{\circledR}$ ). En este se realiza la cuantificación del Carbono Orgánico Total mediante la combustión de la muestra y comparación con una curva de calibración patrón realizada con ftalato de potasio (SIGMA) como estándar.

Las evaluaciones ecotoxicológicas que se realizaron con la fracción líquida fueron:

- Evaluaciones de biomasa de plántulas y enzimas de estrés oxidativo (Catalasa y Guaiacol Peroxidasa) y peroxidación de lípidos en raíces de Vicia faba.

- Evaluaciones de cito y genotoxicidad en celomocitos de Eisenia fetida expuestos de manera ex vivo.

\subsection{Evaluaciones ecotoxicológicas}

Las muestras de suelos y residuos en estado sólido fueron evaluadas utilizando plantas terrestres y lombrices de tierra. En el caso de las plantas terrestres se utilizó como modelo la especie Lactuca sativa evaluándose los parámetros de inhibición de la germinación de semillas y elongación de las raíces en plantas expuestas y control. En el caso de las lombrices 
de tierra correspondientes a la especie Eisenia fetida se evaluaron parámetros toxicológicos de mortalidad, mediante determinación de la CL50, y genotóxicos, mediante el ensayo cometa. Para las eluciones acuosas (fracción líquida) de los residuos y los suelos se utilizó como organismo de prueba Vicia faba, determinando en raíces de estas plántulas biomasa, enzimas antioxidantes (CAT y GPOD) y el nivel de peroxidación lipídica y Eisenia fétida, determinando efectos cito y genotóxicos en celomocitos expuestos de manera ex vivo.

\subsubsection{Ensayos con semillas de Lactuca sativa}

La evaluación de la fitotoxicidad de las matrices sólidas se llevó a cabo determinando el efecto en la germinación y la elongación de las raíces en L. sativa siguiendo las recomendaciones de los siguientes protocolos: US EPA (1989); US EPA (1996a) y US EPA (1996b).

\subsubsection{Ensayo de germinación en Lactuca sativa}

El ensayo de germinación en Lactuca sativa permitió estimar la toxicidad aguda de las matrices sólidas en semillas de lechuga en un ensayo estático de 120 h de duración.

Previamente a la realización de las evaluaciones se realizaron ensayos de referencia mediante la exposición a DSS (US EPA, 1989). Esta prueba de sensibilidad permitió validar la respuesta obtenida en los bioensayos asegurando la calidad de los resultados y la precisión de los análisis generados a partir de los mismos. Para realizar estos ensayos se agregaron en forma de agua de riego las siguientes concentraciones de DSS: 0,5; 1; 2 y 4 mg/L, respectivamente. Los controles se regaron con agua Milli-Q. Las semillas de sembraron en placas de Petri por duplicado en idénticas condiciones de ensayo que con las matrices sólidas evaluadas. Para la obtención de las distintas concentraciones de DSS se tomaron alícuotas a partir de una solución madre de DSS de $4 \mathrm{mg} / \mathrm{L}$.

\subsection{Preparación del ensayo}

El soporte inerte de los controles y el medio de dilución utilizado en los ensayos con las matrices sólidas correspondió a arena comercial. Esta arena fue secada a $105{ }^{\circ} \mathrm{C}$ en estufa durante 24 h, y tamizada a $2 \mathrm{~mm}$ antes de su utilización.

\subsection{Preparación de los sustratos}

Se evaluaron diferentes concentraciones de las matrices sólidas correspondiente a los residuos industriales. En todos los casos se realizaron ensayos preliminares para determinar el rango de 
toxicidad de las muestras. Para los ensayos definitivos se evaluaron, en el caso de la arena de fundición, las concentraciones de $6 ; 12,5 ; 25 ; 50$ y 100\%. En el caso de la muestra de cosmética, las concentraciones evaluadas correspondieron a 1,$5 ; 3 ; 6 ; 12,5$ y $25 \%$. En el caso de las matrices sólidas correspondientes a las muestras ambientales provenientes de las zonas de cultivo y a los tratados artificialmente con plaguicidas no se realizaron diluciones de los mismos. En estos últimos se probaron diferentes dosis de aplicación recomendadas por los fabricantes de los formulados comerciales de los plaguicidas. Estas dosis evaluadas fueron 2,5; 4 y $6 \mathrm{~L} / \mathrm{ha}$, las cuales se corresponden con concentraciones de 1200; 1920 y $2880 \mathrm{~g}$ de glifosato/ha; y 1 y 2 L/ha que representan 480 y 960 g de clorpirifos/ha. Para la correcta interpretación de los datos obtenidos en este ensayo se utilizaron dos controles, por un lado se utilizó el control con arena comercial como sustrato inerte, y por otro lado se utilizó un suelo control para descartar efectos por la matriz. Este suelo correspondió a un suelo libre de actividades antropogénicas, caracterizado por Di Marzio et al (2007). Una vez preparados, la temperatura de todos los sustratos fue ajustada a $24 \pm 2{ }^{\circ} \mathrm{C}$ mediante una pre-incubación en la cámara de cultivo.

\subsection{Realización del ensayo}

Se colocaron 20 semillas de lechuga en placas Petri de vidrio de $10 \mathrm{~cm}$ de diámetro conteniendo $50 \mathrm{~g}$ de los sustratos preparados anteriormente. Estos sustratos correspondieron a las diferentes diluciones de los residuos a evaluar, los suelos ambientales y tratados artificialmente con los plaguicidas estudiados y a los controles. Las semillas que se encontraban almacenadas a $4^{\circ} \mathrm{C}$ fueron aclimatadas durante una hora a temperatura ambiente, y sometidas a una segunda selección bajo lupa para descartar cubiertas seminales vacías, semillas deshidratadas o semillas contaminadas con patógenos. Para la distribución de las semillas sobre el sustrato, se tuvo como precaución dejar $1 \mathrm{~cm}$ de separación entre las semillas, y entre los bordes de la cápsula y las semillas. Unas vez colocadas en las placas de Petri, las semillas fueron presionadas suavemente contra el sustrato sólido con el fondo de un vaso de precipitado y cubiertas con 45 gr de arena. Por último, la superficie de esta cubierta fue nivelada con una regla y se hidrató cada placa al $85 \%$ de la capacidad de retención de agua de las muestras, según lo recomendado por US EPA (1989).

La cantidad de agua requerida para lograr el $85 \%$ de la capacidad de retención de agua, fue calculada de la siguiente manera:

$$
\text { Agua de Hidratación agregada }\left(\frac{m l}{100 g}\right)=H T D-H E R
$$


Donde

HTD: Hidratación Total Deseada

HER: Hidratación Existente en el Residuo

Los mismos se calculan teniendo en cuenta las siguientes fórmulas:

$$
\begin{gathered}
H T D=P H R \times((P S \times C R A s i)+(P R S \times C R A r)) \\
H E R=((P S \times F H s)+(P R S \times F H r)) \times 100
\end{gathered}
$$

Donde:

PHR: Proporción de Hidratación requerida

PS: Proporción del Sustrato Inerte

CRAsi: Capacidad de Retención de Agua del sustrato inerte

PRS: Proporción del Residuo en el Sustrato

CRAr: Capacidad de Retención de Agua del residuo

FHs: Fracción Húmeda del sustrato

FHR: Fracción Húmeda del residuo

Las placas con el sustrato y las semillas fueron colocadas individualmente en bolsas de poliuretano y cerradas para generar una cámara húmeda que mantenga las condiciones de humedad durante el período de exposición. Cada placa fue preparada por triplicado. Las placas fueron incubadas a oscuridad durante las primeras $48 \mathrm{~h}$ de exposición, y a continuación con fotoperiodo de $16 \mathrm{~h}$ de luz y $8 \mathrm{~h}$ de oscuridad, con una intensidad lumínica de $4300 \pm 430$ lux, hasta culminar el ensayo (72 h). La temperatura se mantuvo constante a $24 \pm 2{ }^{\circ} \mathrm{C}$ durante las $120 \mathrm{~h}$ de exposición.

\subsection{Criterio de aceptabilidad}

El criterio de aceptabilidad para el ensayo fue establecido en un $65 \%$ de germinación en las placas controles, según lo establecido en US EPA (1996).

\subsection{Obtención de los resultados y estimación de Concentración Letal media (CL 50)}

Una vez finalizado el tiempo de exposición del ensayo, se cuantificaron las semillas germinadas en las placas expuestas y controles. Se consideró como criterio de germinación la 
aparición visible de la radícula por fuera de la cubierta seminal. Para cada tratamiento, se calculó el porcentaje de las semillas germinadas en relación al total de semillas colocadas al inicio del ensayo. El porcentaje de germinación para cada tratamiento fue utilizado para la estimación del índice de toxicidad CL50-120 h, definido como la concentración que inhibe la germinación de un 50\% de las semillas expuestas.

\subsubsection{Ensayo de elongación de raíces en Lactuca sativa}

El ensayo de elongación de raíces en Lactuca sativa permitió estimar los efectos sub-letales de matrices sólidas sobre las semillas germinadas de los ensayos descriptos con anterioridad, a las 120 horas de exposición.

\subsection{Determinación de la elongación de raíces}

La determinación de la elongación de raíces fue realizada en las semillas germinadas, mediante la extracción de las mismas de los sustratos de exposición con la ayuda de una pinza. A continuación se enjuagaron con agua Milli-Q en una caja de Petri y se removieron los restos de sustrato con un pincel. Luego, las plántulas, se colocaron en un papel de filtro humedecido y se midió la longitud de la raíz principal. Este parámetro se considera como la distancia desde el punto de transición del hipocotile y la raíz, donde el eje presenta una pequeña curvatura y un diminuto cayo, hasta la punta de la raíz principal (Figura 3).

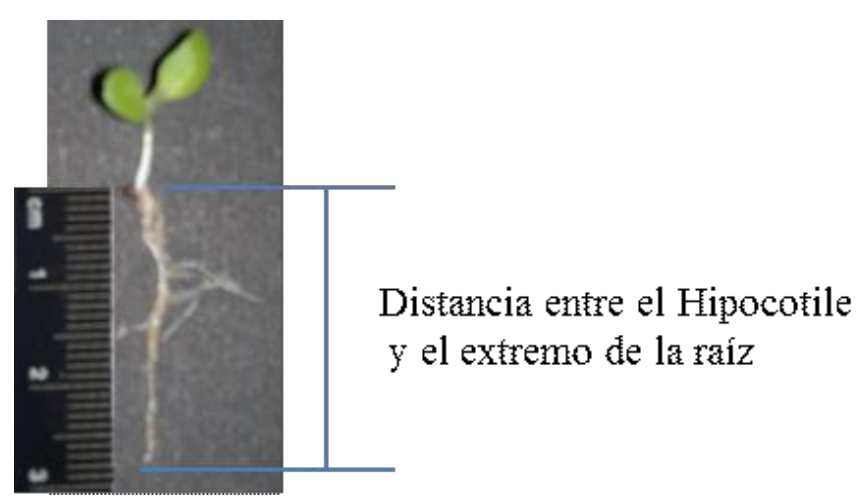

Figura 3. Determinación de la longitud de la raíz en semillas germinadas de L. sativa

\subsection{Criterio de aceptabilidad}

El criterio de aceptabilidad establecido para el ensayo fue una longitud de al menos $2 \mathrm{~cm}$ en las raíces de las plántulas control, de acuerdo a US EPA (1996a). 
2.5.1.2.3. Obtención de los resultados y estimación de la Concentración Efectiva media (CE50)

A partir de la determinación de la elongación de las raíces de las semillas controles y tratadas germinadas se estimó la proporción de efecto para cada tratamiento como:

$$
E=\frac{T-C}{C}
$$

Donde:

$\mathrm{T}$ : longitud media de las raíces en cada tratamiento

C: longitud media de raíces en controles

Los valores de las proporciones de inhibición obtenidas fueron utilizados para la estimación de la CE50-120 h, definida como la concentración que inhibe en un 50\% la elongación de las raíces en los organismos expuestos.

En la Tabla 6 se resumen las condiciones del ensayo de germinación en Lactuca sativa

Tabla 6. Condiciones del ensayo en L. sativa

Tipo de ensayo: Estático

Temperatura: $24 \pm 2$

Calidad de luz: blanca fría

Intensidad de luz: $4300 \pm 430 \mathrm{Lux}$

Fotoperiodo: Inicial: $48 \mathrm{~h}$ a oscuridad/Seguido de $72 \mathrm{~h}$ con fotoperiodo $(16 \mathrm{~h}$

luz/ $8 \mathrm{~h}$ oscuridad

Masa del suelo a evaluar: $50 \mathrm{~g}$

Contenido de humedad del suelo a evaluar: $85 \%$ de la CRA

Sustrato inerte: Arena limpia, $2 \mathrm{~mm}$

$\mathrm{pH}: \geq 4$ pero $\leq 10$

Edad de los organismos: Semillas

Número de organismos por caja de Petri: 20

Número de réplicas: 3

Factor de dilución: 0,5

Duración del ensayo: $120 \mathrm{~h}$

Efecto medido: Germinación

Elongación de las raíces 


\subsubsection{Ensayos con plántulas de Vicia faba}

\subsubsection{Obtención de las plántulas}

Antes de comenzar con el proceso para obtener las plántulas que se utilizaron en los ensayos, las semillas almacenadas a $4^{\circ} \mathrm{C}$ fueron aclimatadas a temperatura ambiente durante $4 \mathrm{~h}$. El procedimiento llevado a cabo se realizó de acuerdo a las recomendaciones generales de la norma AFNOR (2004). Las semillas fueron lavadas con agua Milli-Q para remover restos de plaguicidas utilizados por los comerciantes para evitar infecciones en las semillas. Luego, se colocaron a remojar en agua Milli-Q durante $24 \mathrm{~h}$. Transcurrido este período, se retiraron manualmente las cubiertas seminales, con mucho cuidado de no producir la separación de los cotiledones. Estas semillas sin tegumento, se colocaron para su germinación, entre dos capas de algodones humedecidos con agua Milli-Q y en posición vertical durante 48 horas, en oscuridad a $24^{\circ} \mathrm{C}$. Cuando se observó que la raíz primaria emergía del embrión, se retiró el meristema apical y las semillas se colocaron en suspensión sobre un soporte, en contacto con medio Hoagland aireado (Hoagland y Arnon, 1950) (Tabla 7) a fin de promover el desarrollo de las raíces secundarias. Las plántulas se mantuvieron en este sistema de cultivo hidropónico para asegurar el un buen estado nutricional de las mismas antes de ser expuestas a las sustancias líquidas a evaluar. El cultivo se llevó a cabo con fotoperiodo de 16 horas luz/ 8 horas oscuridad, con una iluminación de $1500 \pm 150$ lux, y a $24^{\circ} \mathrm{C}$, durante 3 o 4 días según el desarrollo de las plántulas (Figura 4), reemplazando diariamente el medio nutricional (AFNOR, 2004; Foltête et al, 2011). Como criterio de selección de las plántulas que fueron utilizadas en las exposiciones, las raíces secundarias debieron de alcanzar entre 1,5 y $3 \mathrm{~cm}$ de longitud.

\subsection{Preparación de las soluciones de prueba}

Las eluciones acuosas de las matrices sólidas correspondientes a los residuos industriales se evaluaron en forma de distintas diluciones. En el caso de las eluciones preparadas a partir de los suelos ambientales de las zonas de cultivo y de los suelos tratados artificialmente con plaguicidas, las evaluaciones se realizaron sin diluir.

Para los residuos industriales correspondientes a la arena de fundición y el residuo de cosmética se prepararon las concentraciones de $6 ; 12,5 ; 25 ; 50$ y $100 \%$. 


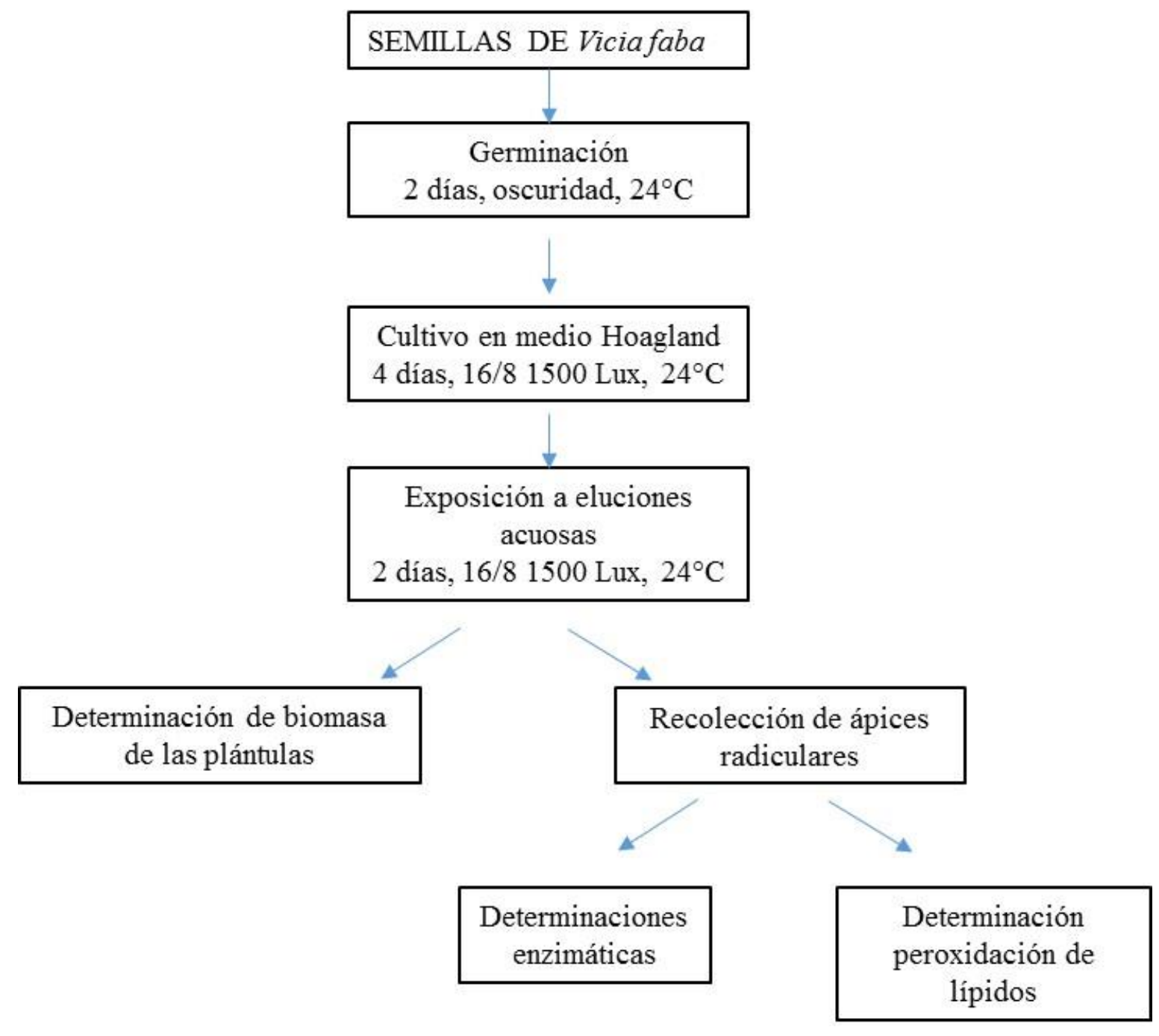

Figura 4. Esquema del procedimiento utilizado en los ensayos de con plántulas de $V$. faba

Como medio de dilución, y como control negativo, en todos los ensayos, fue utilizado el Medio Hoagland (Tabla 7). Para la evaluación de los suelos se utilizó además la elución de un suelo control para descartar efectos debidos a la matriz del suelo.

En los ensayos realizados con el 100\% de la elución y en el caso de todos los suelos tratados con plaguicidas, las soluciones de exposición fueron suplementadas con las sales nutritivas correspondientes al Medio Hoagland. De esta manera se asegura que las plántulas reciban una provisión de nutrientes óptima que permite evaluar una disminución de la biomasa u otros efectos tóxicos debidos exclusivamente a las sustancias presentes en las eluciones y no a la carencia de nutrientes esenciales. 
Tabla 7. Medio nutritivo Hoagland utilizado en los cultivos hidropónicos para la obtención de las plántulas de $V . f a b a$.

\begin{tabular}{cccc}
\hline Sales & $\begin{array}{c}\text { Solución madre } \\
(\mathrm{g} / \mathrm{L})\end{array}$ & $\begin{array}{c}\text { mL de solución } \\
\text { madre/L medio }\end{array}$ & $\begin{array}{c}\text { Concentración final } \\
\mathrm{mM}\end{array}$ \\
\hline $\mathrm{KNO}_{3}$ & $50,5 \mathrm{~g} / \mathrm{L}$ & 10 & 5 \\
$\mathrm{Ca}\left(\mathrm{NO}_{3}\right)_{2} 4 \mathrm{H}_{2} \mathrm{O}$ & $118,0 \mathrm{~g} / \mathrm{L}$ & 10 & 5 \\
$\mathrm{MgSO}_{4} 7 \mathrm{H}_{2} \mathrm{O}$ & $123,2 \mathrm{~g} / \mathrm{L}$ & 10 & 5 \\
$\mathrm{KH}_{2} \mathrm{PO}_{4}$ & $13,6 \mathrm{~g} / \mathrm{L}$ & 10 & 5 \\
Tartrato férrico & $500 \mathrm{mg} / \mathrm{L}$ & 10 & 5 \\
\hline
\end{tabular}

\subsection{Preparación de las experiencias y condiciones de exposición}

Las plántulas de $V$. faba obtenidas y seleccionadas anteriormente, fueron pesadas para la determinación de la biomasa inicial y, divididas, en base a su peso y tamaño, en grupos homogéneos de tres plántulas cada uno. Cada grupo se colocó en vasos de precipitado conteniendo $200 \mathrm{~mL}$ de las eluciones acuosas de todas las matrices sólidas, descriptas anteriormente. Las exposiciones se realizaron en condiciones controladas bajo un fotoperiodo de 16 horas luz y 8 horas oscuridad, a $1500 \pm 150$ lux, a $24^{\circ} \mathrm{C}$ durante $48 \mathrm{~h}$ sin renovación del medio (Radetski et al, 2004; Beraud et al, 2007; Foltête et al, 2011)

Al cabo del tiempo de exposición, las plántulas fueron pesadas para determinar la biomasa final. Se recolectaron alrededor de 6-8 ápices radiculares por cada plántula, dividiéndose en dos grupos, uno de ellos fue utilizado para las determinaciones enzimáticas y el otro para la cuantificación del nivel de peroxidación lipídica (Radetski et al, 2004).

\subsubsection{Determinaciones enzimáticas}

Los ápices radiculares (aproximadamente $10 \mathrm{~mm}$ ) de las plántulas expuestas y controles fueron homogeneizados en un mortero con $2 \mathrm{~mL}$ de buffer fosfato $\mathrm{pH} 7.6\left(4^{\circ} \mathrm{C}\right)$. Estos homogenatos fueron centrifugados a $10000 \times \mathrm{g} \mathrm{y} 4{ }^{\circ} \mathrm{C}$ durante 10 minutos para su clarificación.

Los sobrenadantes obtenidos fueron mantenidos en hielo para ser utilizados en la determinación de la actividad de las enzimas catalasa (CAT), guaiacol peroxidasa (GPOD) y la concentración de proteínas. 
CAT (EC 1.11.1.6)

La actividad de la enzima CAT se determinó siguiendo el método propuesto por Beers y Sizer (1952). En este protocolo se registra la disminución de la absorbancia a $240 \mathrm{~nm}$ debida a la desaparición del peróxido de hidrógeno, sustrato de la enzima. El coeficiente de extinción utilizado fue de $0.036 / \mathrm{mM} / \mathrm{cm}$. Para cuantificar la actividad de la enzima estudiada se colocaron 50-100 $\mu \mathrm{L}$ del extracto enzimático obtenido en el punto 2.5.2.2 en $3 \mathrm{~mL}$ de una mezcla de reacción compuesta por $50 \mathrm{mM}$ de buffer fosfato $\mathrm{pH} 7.6,10 \mathrm{mM}$ de $\mathrm{H}_{2} \mathrm{O}_{2}$. La disminución de la absorbancia se registró a intervalos de $20 \mathrm{~s}$, durante un tiempo total de $80 \mathrm{~s}$. La actividad de la enzima fue expresada como $\mathrm{mM} \mathrm{de} \mathrm{H}_{2} \mathrm{O}_{2} / \mathrm{mg}$ de proteína/min.

\section{GPOX (EC 1.11.1.7)}

La actividad de la enzima GPOX se determinó siguiendo el método de Egert y Tevini (2002). El fundamento de esta determinación es la conversión del guaiacol a tetraguaiacol, producto de color marrón. La oxidación, mediante la peroxidasa que utiliza el guaiacol como donante de electrones, se monitorea mediante el aumento de la absorbancia a $470 \mathrm{~nm}$. Para la determinación de la enzima se colocaron 10-100 $\mu \mathrm{L}$ del extracto enzimático obtenido en el punto 5.2.11 en $3 \mathrm{~mL}$ de una mezcla de reacción compuesta por $50 \mathrm{mM}$ de buffer fosfato $\mathrm{pH}$ 5,5; $10 \mathrm{mM}$ de $\mathrm{H}_{2} \mathrm{O}_{2}$ y $9 \mathrm{mM}$ de guaiacol, y se registró el aumento de la absorbancia a intervalos de $1 \mathrm{~min}$ durante un tiempo total de $4 \mathrm{~min}$. El coeficiente de extinción utilizado fue de $26.6 / \mathrm{mM} / \mathrm{cm}$. La actividad de la enzima fue expresada como $\mathrm{mM}$ de Guaiacol $/ \mathrm{mg}$ de proteína/min.

\section{Preparación de las soluciones de buffer fosfato}

Las soluciones de buffers fosfato de distintos $\mathrm{pH}$ utilizados para la extracción y medición de las actividades enzimáticas en las raíces de Vicia faba fueron preparados a partir de las siguientes soluciones madres (Tabla 8)

Las soluciones A y B fueron almacenadas en frascos opacos y a $4^{\circ} \mathrm{C}$.

Tabla 8. Soluciones para la preparación de buffers fosfato

\begin{tabular}{cc}
\hline Reactivos & Concentración $(\mathrm{g} / \mathrm{L})$ \\
\hline $\mathrm{KH}_{2} \mathrm{PO}_{4}($ Solución A) & 9,073 \\
$\mathrm{Na}_{2} \mathrm{HPO}_{4}$ (Solución B) & 11,87 \\
\hline
\end{tabular}


El buffer fosfato pH 7,6 se preparó colocando 12,8 mL de Solución A y 87,2 mL de Solución B. La solución de buffer fosfato $\mathrm{pH}$ 7,3 se preparó colocando 24,6 mL de Solución A y 75,4 $\mathrm{mL}$ de Solución B. El buffer fosfato $\mathrm{pH}$ 5,5 utilizado en la determinación de la actividad de la GPOX se preparó colocando 96,4 mL de Solución A y 3,6 mL de Solución B con el agregado de $1 \mathrm{~mL}$ de guaiacol.

\section{Concentración de proteínas}

La concentración de proteínas se determinó utilizando el método de Lowry (1956), utilizando los siguientes reactivos:

Reactivo A: $\mathrm{CO}_{3} \mathrm{Na}_{2} 2 \%$ en $\mathrm{NaOH} 0,1 \mathrm{~N}$

Reactivo B: $\mathrm{SO}_{4} \mathrm{Cu} 5 \mathrm{H}_{2} \mathrm{O} 0,5 \%$ en tartrato de $\mathrm{Na}$ o K $1 \%$.

Reactivo C: $49 \mathrm{~mL}$ de A $+1 \mathrm{~mL}$ de B

Reactivo E: Folin Fenol diluido 1:1 en agua desionizada.

Se tomó una muestra del extracto de ítem 2.5.2.2 de $200 \mu \mathrm{l}$, se agregaron $1000 \mu \mathrm{l}$ de reactivo $\mathrm{C}$, se mezcló con vortex y se dejó reposar 10 minutos a temperatura ambiente. Luego se agregó $100 \mu \mathrm{l}$ de reactivo $\mathrm{E}$, se mezcló rápidamente en vortex y se incubó 30 minutos a temperatura ambiente. Por último se midió la absorbancia en espectrofotómetro a $750 \mathrm{~nm}$. Para la cuantificación de proteínas en los extractos de las raíces de las plántulas expuestas y control se realizó una curva de calibración con albúmina bovina como sustancia patrón. Esta curva se realizó a partir de diluciones de una solución patrón de $1 \mathrm{mg} / \mathrm{L}$ de albúmina bovina.

\subsubsection{Determinación la peroxidación lipídica}

Para la determinación de la peroxidación de lípidos de membrana en las raíces de Vicia faba se siguieron los protocolos descriptos por Wu et al (2003) y Gallego et al (1996; 2002). Esta metodología permitió la cuantificación de los metabolitos reactivos del TBA, principalmente MDA, producto generado en la peroxidación de los lípidos. El principio de la reacción colorimétrica observada es la formación de un complejo cromógeno entre el MDA y el TBA a pH ácido (entre 2 y 3 ) detectable a 532 nm en el espectrofotómetro.

Se recolectaron aproximadamente 0,02-0,05 gr de peso fresco de ápices de raíces $(1 \mathrm{~cm})$ de plantas expuestas y control. Este material se maceró en mortero en presencia de $3 \mathrm{~mL}$ de solución de $10 \% \mathrm{~m} / \mathrm{v}$ de TCA y $0,25 \% \mathrm{~m} / \mathrm{v}$ TBA. Luego se incubó a $95^{\circ} \mathrm{C}$ durante $30 \mathrm{~min}, \mathrm{y}$ se detuvo la reacción en hielo. Este homogenato se centrifugó para clarificarlo a 1000 x g 
durante $10 \mathrm{~min}$. La lectura se llevó a cabo en un espectrofotómetro a 532 y a $600 \mathrm{~nm}$. Ésta última medición se realizó para corregir el valor obtenido, ya que se corresponde con las interferencias del método.

Determinación de metabolitos reactivos del ácido tiobarbitúrico - MDA

La determinación del nivel de peroxidación de lípidos en raíces de Vicia faba se realizó mediante la cuantificación de MDA preparando una curva de calibración a partir de diluciones de una solución patrón $0,41 \% \mathrm{~m} / \mathrm{v}$ de MDA. Estas diluciones se realizaron en ácido sulfúrico 1\% preparado en agua Milli-Q. La solución patrón de MDA y sus diluciones fueron preparadas en el momento de la cuantificación.

El resumen con las condiciones de los ensayos con $V$. faba se indican en la Tabla 9

Tabla 9. Condiciones del ensayo en Vicia faba

Tipo de ensayo: Estático

Temperatura: $24 \pm 2$

Calidad de luz: blanca fría

Intensidad de luz: $1500 \pm 150$ Lux

Fotoperiodo: Inicial: $16 \mathrm{~h} \mathrm{luz} / 8 \mathrm{~h}$ oscuridad

Volumen final de la elución: $200 \mathrm{~mL}$

Control y agua de dilución: Medio Hoagland

Edad de los organismos: plántulas de 4 días de germinadas

Número de réplicas: 3

Factor de dilución: 0,5

Duración del ensayo: $48 \mathrm{~h}$

Efecto medido: Biomasa

Enzimas de estrés oxidativo

Peroxidación lipídica

\subsubsection{Ensayos con Eisenia fetida}

\subsubsection{Ensayo de Mortalidad en Eisenia fetida}

El ensayo de toxicidad aguda fue llevado a cabo con organismos de Eisenia fetida siguiendo las recomendaciones generales del protocolo OECD (1984). Los ensayos consistieron en el cultivo de individuos de Eisenia fetida en suelos controles y en las diferentes matrices sólidas durante un tiempo de exposición de 14 días. Para las matrices sólidas correspondientes a los 
residuos industriales, se evaluaron diferentes diluciones, utilizando el suelo control como medio de dilución. La mortalidad de los individuos de E. fetida se cuantificó a los 7 y 14 días. Esta cuantificación permitió la estimación de la CL50-14d para las matrices sólidas ensayadas. Como criterio de validez y aceptabilidad de los resultados, la mortalidad en los controles no debió exceder el 10\% al final del período de exposición de 14 días (OECD, 1984).

\subsection{Preparación del suelo}

El suelo utilizado en los ensayos como control y como medio de preparación de las diferentes concentraciones, fue preparado mezclando el suelo secado a $105^{\circ} \mathrm{C}$, molido y tamizado a $1000 \mu \mathrm{m}$, con agua Milli-Q para lograr un 35\% de humedad. Este procedimiento se llevó a cabo manualmente para lograr una mezcla homogénea de los componentes. Como fue indicado, corresponde a la categoría Molisol, Suborden Argiudol y Subgrupo Argiudol típico, caracterizado por Di Marzio et al (2007).

En la preparación de las diferentes concentraciones de los residuos sólidos, el suelo control fue mezclado primero con la proporción del residuo correspondiente y luego se humedecieron para obtener una mezcla homogénea del residuo. Para los residuos sólidos provenientes de la actividad industrial se eligió un rango de concentraciones de 0 a $100 \%$ con un factor de dilución de 0.5. En el caso de los suelos tratados con plaguicidas la aplicación de los mismos se llevó a cabo utilizando agua Milli-Q como vehículo de los mismos. La cantidad de agua Milli-Q que fue utilizada corresponde a la necesaria para alcanzar un 35\% de humedad, requerida para la correcta realización del ensayo. Las dosis de aplicación recomendadas fueron aplicadas sobre una superficie de suelo determinada $\left(0,04 \mathrm{~m}^{2}\right)$ para imitar las condiciones de aplicación utilizadas por los productores. Una vez aplicados los plaguicidas, el suelo fue homogeneizado manualmente y utilizado en el ensayo.

\subsection{Preparación de los organismos}

Los organismos de Eisenia fetida utilizados en el ensayo fueron aclimatados a las condiciones de laboratorio, en cultivos con el suelo utilizado como control, con alimento de forraje en base de alfalfa, $\mathrm{pH} 6,0 \pm 0.5$, temperatura de $22 \pm 2^{\circ} \mathrm{C}$, y un $35 \%$ de humedad.

Para el ensayo se utilizaron organismos adultos, es decir, con clitelo observable, con un peso entre 300 y 600 mg. Además estos organismos cumplieron con el criterio de selección de 
poseer un índice LITAR mayor o igual a 1,6. El mecanismo de selección utilizado fue mediante la aplicación del algoritmo que se indica a continuación (Figura 5)

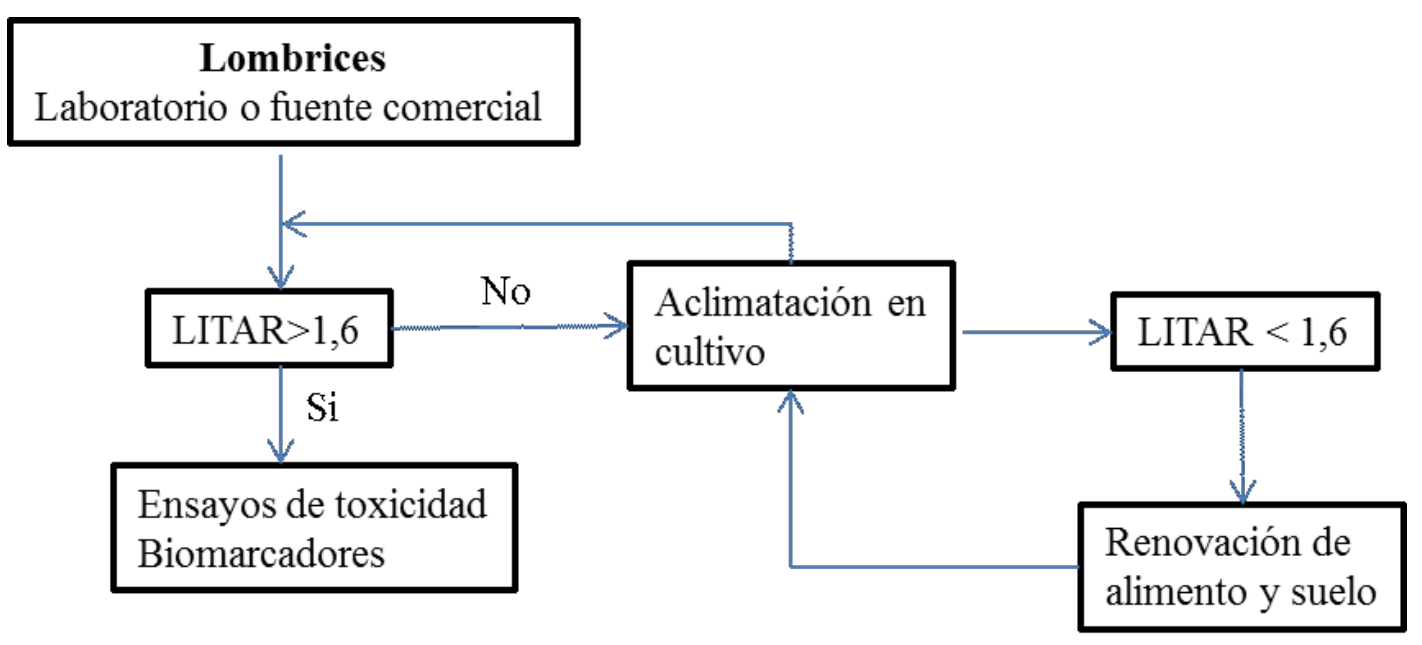

Figura 5: Criterio de selección de los organismos de E. fetida para los bioensayos

\subsection{Evaluación de la sensibilidad de los organismos}

La sensibilidad de los organismos que fueron utilizados en el ensayo se evaluó mediante la exposición a una sustancia de referencia como la cloro acetamida. El rango de toxicidad establecido en el protocolo del ensayo fue de 20-80 mg/kg expresado como la CL-50-14 días.

\subsection{Realización del ensayo}

Los suelos preparados como se describió anteriormente fueron distribuidos en recipientes de plástico inerte. Se pesaron 200 gr de suelo, y se colocaron cuidadosamente 10 organismos de Eisenia fetida en la superficie del mismo. A estos recipientes se les colocó la tapa de plástico correspondiente con pequeñas perforaciones para permitir el intercambio gaseoso pero evitando la pérdida de humedad por evaporación. Cada control y tratamiento fue realizado por triplicado. Las experiencias fueron realizadas en condiciones controladas, a una temperatura de $20 \pm 2{ }^{\circ} \mathrm{C}$ y fotoperiodo de 12 horas luz/12 horas oscuridad durante los 14 días.

La mortalidad fue cuantificada a los 7 y 14 días de exposición, evaluando la reacción de los ejemplares de E. fetida ante estímulos mecánicos.

En la Tabla 10 se resumen las condiciones del ensayo de mortalidad en organismos de $E$. fetida. 
Tabla 10: Resumen de las condiciones del ensayo de mortalidad en E. fetida

Tipo de ensayo: Estático

Duración del ensayo: 14 días

Temperatura: $20 \pm 2{ }^{\circ} \mathrm{C}$

Fotoperiodo: $12 / 12 \mathrm{O} / \mathrm{L}$

Tipo de luz: Blanca fría

Intensidad de luz: 400 lux

Cantidad de sustrato: $100 \mathrm{~g}$ en cada réplica

Cantidad de réplicas: 3

Sustrato artificial: Suelo franco-limoso

Edad de los individuos: adultos con clitelo visible

Peso de los organismos: 300-600 mg de peso fresco

Número de individuos por cámara de ensayo: 10

Régimen de alimentación: sin alimentación

Concentraciones utilizadas para el ensayo: 5 o más

Factor de dilución entre concentraciones: 0,5

Índice de toxicidad obtenido: mortalidad cuantificada como CL50- 14 días.

\subsubsection{2 .Ensayos de cito y genotoxicidad}

Se evaluó la genotoxicidad de las matrices sólidas en forma entera mediante exposición in vivo durante 7 y 14 días de organismos adultos de E. fetida. Asimismo, se evaluaron las fracciones líquidas de las matrices sólidas mediante la exposición ex vivo de celomocitos del mismo organismo. Para la realización de los ensayos ex vivo sobre celomocitos de E. fetida, la fracción líquida de las matrices sólidas (Elución) fue preparada utilizando PBS, pH 7,4; en lugar de agua Milli-Q, para conservar la osmolaridad de las células.

\subsection{Ensayos in vivo}

Para la determinación del efecto genotóxico in vivo se seleccionaron concentraciones de los residuos sólidos en base a los resultados obtenidos de los ensayos de mortalidad. Estas concentraciones correspondieron a la CL50-14d, CL50-14d/2 y CL50-14d/10. En el caso de la arena de fundición estas concentraciones resultaron 26; 13 y 26\% y en el caso del residuo de cosmética las concentraciones fueron $9 ; 4,5$ y $0,9 \%$.

A partir de la extrusión de celomocitos provenientes de los organismos expuestos a 7 y 14 días se determinó: la viabilidad celular, las proporciones de celomocitos, los índices tróficos y 
la genotoxicidad. La viabilidad fue determinada mediante el ensayo de exclusión con Azul de Tripán. Se trata de un colorante utilizado por su capacidad de penetrar células muertas, por lo que se utiliza en la evaluación de viabilidad celular por exclusión ya que es incapaz de penetrar e incorporarse a las células vivas con sus membranas intactas.

Las proporciones celulares fueron establecidas mediante conteos celulares en hematocitómetro de Neubauer. Los índices tróficos fueron calculados según lo explicado en la sección 2.5.3.6. La genotoxicidad fue determinada mediante la realización del ensayo cometa sobre los celomocitos extruidos de los organismos expuestos.

\subsection{Ensayos ex vivo}

Con anterioridad a la determinación de daño genotóxico mediante la aplicación del ensayo cometa fue necesario realizar un ensayo de citotoxicidad para determinar la CL50-1h de las eluciones de las matrices sólidas correspondientes a los residuos industriales. Con este fin se realizó la extrusión de organismos no expuestos de E. fetida para obtener los celomocitos para luego poder ser expuestos de manera ex vivo. La exposición se realizó colocando $1 \times 10^{6}$ células/mL de la dilución correspondiente de las eluciones pertenecientes al residuo arena de fundición y al residuo de cosmética. El rango de diluciones ensayadas para las eluciones de ambos residuos fue de 1,5-100\%. Se utilizó como medio de dilución y control negativo buffer PBS. Las células fueron expuestas durante $1 \mathrm{~h}$ en oscuridad. Al finalizar el período de exposición se cuantificó la viabilidad celular mediante el ensayo de exclusión con Azul de Tripán. A partir de los resultados obtenidos en el ensayo de viabilidad celular se estimó la CL50-1h para las eluciones de ambos residuos industriales. Teniendo en cuenta este índice se evaluó la genotoxicidad en celomocitos expuestos durante una hora a la CL50-1h y CL50$1 \mathrm{~h} / 2$ de las eluciones de ambos residuos industriales.

\subsubsection{Obtención de celomocitos}

La extrusión de los celomocitos se llevó a cabo siguiendo el método no invasivo establecido por Di Marzio et al (2005), utilizando etanol como agente irritante. Este protocolo establece la utilización de un medio de extrusión libre del agente mucolítico éter glicerol guaiacol, ya que la especie E. fetida produce relativamente bajas concentraciones de mucus en el líquido de extrusión.

En el caso de los ensayos ex vivo, los organismos a ser utilizados fueron colocados a depurar durante $24 \mathrm{~h}$ sobre papel de filtro húmedo y en oscuridad. En los organismos expuestos de manera in vivo, la depuración se realizó por masajes manuales sobre papel de filtro 
humedecido con solución salina. En ambos casos, una vez depurados los organismos, fueron lavados con solución salina y se colocaron en grupos de a cinco en tubos de centrifuga a los que se agregó el medio de extrusión, en la proporción de $2 \mathrm{~mL}$ por cada individuo. Los grupos de organismos fueron incubados durante dos minutos a temperatura ambiente, tiempo suficiente para que se produzca la expulsión del fluido celómico y sus celomocitos por los poros dorsales. Las lombrices fueron removidas del medio líquido, lavadas con solución salina y se colocaron en un cultivo con suelo libre de contaminación, suplementado con un $10 \%$ de alimento y una humedad del $60 \%$. La suspensión celular obtenida se centrifugó durante $10 \mathrm{~min}$ a $2000 \mathrm{rpm}$. El pellet celular resultante fue lavado dos veces con $10 \mathrm{~mL}$ de PBS mediante centrifugación (10 $\mathrm{min}, 2000 \mathrm{rpm})$. Por último, las células fueron resuspendidas en $2 \mathrm{~mL}$ de $\mathrm{PBS}$ y mantenidas a $4^{\circ} \mathrm{C}$ para su posterior utilización en el día.

Las soluciones utilizadas en este procedimiento fueron las siguientes:

Solución salina: solución de $\mathrm{NaCl} 0,85 \% \mathrm{~m} / \mathrm{v}$. Se pesó en balanza analítica el soluto y llevando a volumen con agua Milli-Q. La solución fue almacenada a temperatura ambiente.

Buffer PBS: Las soluciones para la preparación del buffer fueron las indicadas en la Tabla 11. Para su preparación cada sal presente en el buffer fue diluida en $150 \mathrm{~mL}$ de agua Milli-Q por separado. A continuación se mezclaron todas las soluciones y se llevó a volumen con agua Milli-Q. Por último se ajustó el pH de la solución a un valor de 7,4.

Tabla 11. Composición del buffer PBS

\begin{tabular}{cc}
\hline Reactivos & Concentración $(\mathrm{g} / \mathrm{L})$ \\
\hline $\mathrm{NaCl}$ & 8 \\
$\mathrm{KCL}$ & 0,2 \\
$\mathrm{Na}_{2} \mathrm{HPO} 4 \mathrm{H}_{2} \mathrm{O}$ & 1,15 \\
$\mathrm{KH}_{2} \mathrm{PO}_{4}$ & 0,2 \\
\hline
\end{tabular}

Solución de extrusión: la solución de extrusión se preparó a partir de las siguientes soluciones (Tabla 12):

Para la preparación de la solución de extrusión se disolvió en primer lugar el $\mathrm{NaCl}$ en agua Milli-Q. Una vez disuelta esta sal se agregó el segundo soluto y se agitó hasta su total disolución. Por último se agregó el alcohol etílico absoluto en el momento de comenzar la 
extrusión. La solución se preparó en todos los casos, en el momento de ser utilizada y no fue almacenada.

Tabla 12: Composición de la solución de extrusión

\begin{tabular}{cc}
\hline Reactivos & Concentración \\
\hline $\mathrm{NaCl}$ & $8,5 \mathrm{~g} / \mathrm{L}$ \\
$\mathrm{Na}_{2}$ EDTA $2 \mathrm{H}_{2} \mathrm{O}$ & $2,5 \mathrm{mg} / \mathrm{mL}$ \\
Alcohol etílico absoluto & $5 \%$ \\
\hline
\end{tabular}

\subsubsection{Ensayo de viabilidad celular}

La viabilidad de todas las células utilizadas para el ensayo del cometa fue evaluada utilizando el ensayo de exclusión con Azul de Tripán al 0,4\%.

Para la determinación de la viabilidad de las células extraídas de organismos expuestos de manera in vivo se mezcló una alícuota de la suspensión celular obtenida con Azul de Tripán al $0,4 \%$ y se colocó en un hematocitómetro de Neubauer. Se contaron la cantidad de células que no incorporan el azul de Tripán (viables) y aquellas que lo incorporan (no viables) para obtener la viabilidad celular. Cada conteo se realizó por sextuplicado.

La solución de Azul de Tripán se preparó al 0,4\% m/v. Esta solución de trabajo fue preparada a partir de una solución stock de $4 \mathrm{~g}$ del colorante en $10 \mathrm{~mL}$ de agua Milli-Q. Esta solución fue almacenada a temperatura ambiente por un período máximo de un mes. Se controló periódicamente que no se formaran precipitados del colorante. Para la preparación de la solución de trabajo se tomaron $100 \mu \mathrm{L}$ de la solución de stock y se colocaron en $10 \mathrm{~mL}$ de PBS. Esta solución fue preparada en el momento de la realización de los ensayos y no fue almacenada.

\subsubsection{Determinación de las proporciones celulares}

La suspensión celular obtenida de las extrusiones en la sección 4.3.3 fue utilizada para la determinación de las proporciones relativas de cada tipo celular presente en el líquido celómico. Las células se clasificaron en tres grupos: amebocitos, eleocitos y granulocitos, según los criterios establecidos en Adamowicz y Wojtaszek (2001) y Adamowicz (2005). Los conteos se realizaron por sextuplicado y se calculó la proporción relativa de los tres tipos celulares tanto en organismos control y expuestos para evidenciar un potencial efecto en la misma debido a la acción de las matrices sólidas en estudio. 


\subsubsection{Determinación de índices tróficos}

Tanto para los organismos expuestos de manera in vivo durante 7 y 14 días como para los celomocitos expuestos de manera ex vivo durante $1 \mathrm{~h}$ se determinaron los índices tróficos LITA, LITAR e ICCT. Los datos del número de células $/ \mathrm{mL}$ y de número de eleocitos $/ \mathrm{mL}$, junto con el valor del peso obtenido para los grupos de individuos fueron utilizados para el cálculo de los índices.

Los índices tróficos establecidos en Curieses et al (2011), podrían indicar cambios en el número de eleocitos con respecto al número total de células, y su relación con el peso de los organismos. Asimismo, podrían indicar cambios subletales tempranos en el estado físiológico de los organismos expuestos.

La determinación de los índices se llevó a cabo mediante las siguientes ecuaciones:

LITA (Lombriz Índice Trófico Absoluto):

$$
\text { LITA }=\frac{N^{\circ} \text { Eleocitos }}{N^{\circ} \text { Celomocitos }}
$$

LITAR (Lombriz Índice Trófico Relativo):

$$
\text { LITAR }=\frac{N^{\circ} \text { Eleocitos }}{N^{\circ} \text { Celomocitos } * \text { phsh }}
$$

ICCT (Índice Corporal de Celomocitos Totales):

$$
I C C T=\log \left(\frac{N^{\circ} \text { celomocitos }}{\text { phsh }}\right)
$$

Donde phsh es el peso húmedo sin heces y expresado en gramos

Como criterio para establecer un buen estado de salud fisiológica para los individuos a ser utilizados en las exposiciones tanto in vivo como ex vivo, se determinó un LITAR mayor o igual a 1,6. Por lo tanto, los organismos fueron mantenidos en las condiciones de cultivo hasta alcanzar este valor, ya que por debajo del mismo no podían ser utilizados en los ensayos ecotoxicológicos.

\subsubsection{Determinación de efectos genotóxicos}

Para la determinación de efectos genotóxicos se utilizó el ensayo de electroforesis en gel de células individuales o ensayo cometa siguiendo el protocolo propuesto por Di Marzio et al 
(2005) en celomocitos de Eisenia fetida. Se siguió el protocolo de la versión alcalina del ensayo propuesto por Singh et al (1988)

\section{Generalidades del protocolo}

El ensayo de cometas consistió de las siguientes etapas (Figura 6):

- Preparación de los portaobjetos: los portaobjetos utilizados para la realización del ensayo del cometa con celomocitos de E. fetida estuvieron constituidos por tres capas de agarosa. Fue importante que las capas de agarosa fueran homogéneas para evitar problemas en la etapa de visualización de las imágenes.

- Lisis: el proceso de lisis celular fue llevado a cabo mediante el uso de detergente no iónico y altas concentraciones salinas para facilitar la desestabilización de las membranas y permitir el desagregado (o desorganización) de los nucleosomas. El tiempo necesario para la lisis celular varía con el tipo de células a utilizar. En el caso de los celomocitos de Eisenia fetida se ha demostrado que el tiempo óptimo para esta etapa en este tipo celular es de 10 min (Di Marzio et al, 2005)

- Desenrrollamiento alcalina (unwinding): esta etapa permitió la expresión de las lesiones de simple cadena del ADN ya que elimina el apareamiento de bases y los sitios álcali-lábiles debido a que se realiza en condiciones fuertemente alcalinas. El tiempo de incubación con la solución de electroforesis para esta etapa fue de 20 min.

- Electroforesis: finalizada la etapa de desenrollamiento alcalino, los geles conteniendo los nucleoides fueron sometidos a la electroforesis en condiciones alcalinas para inducir la migración del ADN dañado de los nucleoides.

- Neutralización: luego de la electroforesis alcalina los geles fueron neutralizados con el buffer adecuado de neutralización.

- Tinción del ADN y visualización de los nucleoides: existen diferentes colorantes fluorescentes que pueden ser utilizados para la visualización de estos nucleoides, tales como el bromuro de etidio, yoduro de propidio, SYBR Green, 4,6-diamino-2fenilindol (DAPI). Sin embargo, también pueden utilizarse técnicas no fluorescentes de tinción basadas en la coloración con nitrato de plata. En nuestros ensayos hemos empleado bromuro de etidio para la visualización microscópica de los nucleoides. 


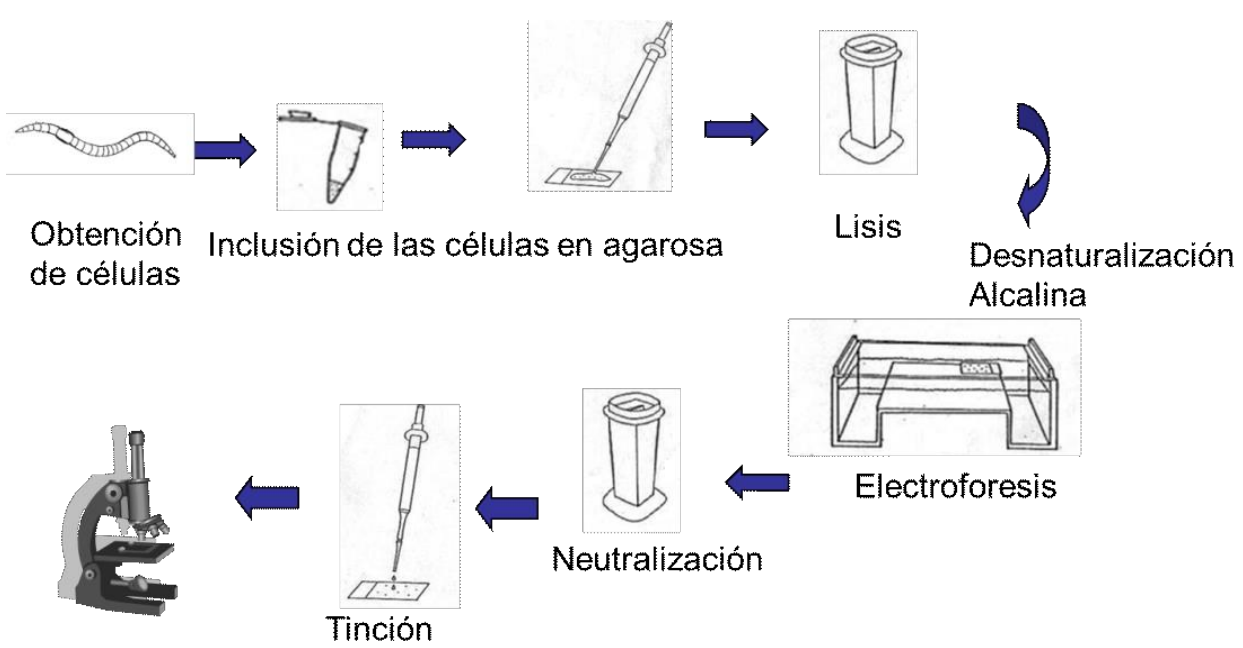

Figura 6: Esquema general del protocolo del ensayo Cometa propuesto por Singh et al (1988)

Controles utilizados en las evaluaciones de genotoxicidad

Como control negativo y control positivo se utilizaron PBS y $\mathrm{H}_{2} \mathrm{O}_{2}$, respectivamente. El peróxido de hidrógeno es un agente genotóxico capaz de producir daño en la molécula de ADN en células expuestas mediante la producción de especies reactivas del oxígeno tales como el radical · OH (Horváthová et al; 1998; Collins 2004). Es particularmente adecuado en la realización de estudios que consideran tiempos de exposición prolongados ya que es altamente reactivo, no sufre fenómenos de precipitación y no posee efectos residuales una vez que el medio ha sido renovado (Chuang et al, 2002; Kruszewski et al, 1994). Ha sido ampliamente utilizado en estudios que detectan el daño al ADN mediante la aplicación del ensayo cometa (Reeves et al, 2008; Oggier et al, 2011). Di Marzio et al (2005) han demostrado que el peróxido de hidrógeno produce un incremento significativo del daño genotóxico determinado como \% de $\mathrm{ADN}$ en la cola, aplicando el ensayo cometa en celomocitos de E. fetida a partir de $37 \mu \mathrm{M}$ de peróxido de hidrógeno, alcanzando un valor asintótico a partir de $100 \mu \mathrm{M}$. Esta última concentración fue la utilizada para los controles positivos de los ensayos cometa.

\section{Densidad celular óptima}

Antes de comenzar los ensayos de genotoxicidad se determinó la densidad celular óptima para la correcta visualización de imágenes. Esto se debe a que a altas densidades celulares la proporción de cometas solapados es mayor y se dificulta el análisis de las imágenes. 
Se realizó un ensayo preliminar utilizando suspensiones celulares de celomocitos de E. fetida con diferentes densidades celulares iniciales. Así los celomocitos extruidos a partir de organismos no expuestos fueron obtenidos como se indica en la sección 4.3.3 y se obtuvieron suspensiones con las siguientes densidades celulares: $2 \times 10^{6}, 1 \times 10^{6}$ y $0,5 \times 10^{6}$ células $/ \mathrm{mL}$. Cada una de estas diluciones se ensayó por duplicado con exposición a PBS y a $\mathrm{H}_{2} \mathrm{O}_{2}$. Con estas suspensiones celulares de diferente densidad celular se realizó el ensayo cometa siguiendo las etapas mencionadas con anterioridad. A partir de la observación de las imágenes se determinó que la densidad celular óptima para la observación de cometas fue de $1 \times 10^{6}$ células/mL. A esta densidad fue posible obtener la menor proporción de cometas solapados, sobre todo en las células expuestas al $\mathrm{H}_{2} \mathrm{O}_{2}$, las cuáles muestran mayores niveles de migración del ADN resultado del daño inducido por el agente.

El procedimiento utilizado para la determinación de efectos genotóxicos en celomocitos de $E$. fetida en los ensayos in vivo e ex vivo se resume en la Figura 7.

Las soluciones utilizadas en el procedimiento indicado fueron las siguientes:

Solución de agarosa regular: la solución de agarosa regular utilizada en el ensayo cometa fue preparada disolviendo $50 \mathrm{mg}$ de agarosa de punto de fusión regular en $10 \mathrm{~mL}$ de PBS. Para lograr la disolución de la agarosa, ésta se calentó en baño termostatizado a $65^{\circ} \mathrm{C}$ hasta lograr su completa disolución.

Solución de Agarosa de bajo punto de Fusión (LMP): la solución de agarosa fue preparada disolviendo $100 \mathrm{mg}$ de agarosa de bajo punto de fusión en buffer $10 \mathrm{~mL}$ de PBS. Para lograr la disolución de la agarosa, ésta se calentó en baño termostatizado a $65^{\circ} \mathrm{C}$ hasta que la misma se observó transparente.

Solución de Peróxido de Hidrógeno: La solución $100 \mu \mathrm{M}$ de $\mathrm{H}_{2} \mathrm{O}_{2}$ fue preparada en PBS para mantener la osmolaridad celular. La solución se preparó en el momento de realizar el ensayo y no fue almacenada.

Solución de lisis: la solución de lisis fue preparada disolviendo los siguientes reactivos en sus respectivas concentraciones (Tabla 13).

Cada reactivo fue disuelto en forma separada y posteriormente el pH de la solución se ajustó a un valor de 10, con lentejas de $\mathrm{NaOH}$. Para mejorar la disolución de las lentejas la solución se calentó suavemente en un agitador provisto de plancha calefactora, teniendo la precaución de que la temperatura no supere $\operatorname{los} 45^{\circ} \mathrm{C}$. A continuación se agregaron $10 \mathrm{~g}$ de $\mathrm{N}$ Laurylsarcosinato y se agitó hasta su completa disolución. Esta solución se almacenó a $4^{\circ} \mathrm{C}$ 
por un período no mayor a 30 días. En el momento de realizar el ensayo cometa se combinaron $89 \%$ de esta solución almacenada con $10 \%$ de DMSO y 1\% de Tritón para la obtención de la Solución de Lisis final. Esta solución fue preparada en el día de la realización del ensayo del cometa y fue mantenida a $4^{\circ} \mathrm{C}$ hasta su utilización.

Tabla 13. Composición de la solución de Lisis

\begin{tabular}{cc}
\hline Reactivos & Concentración \\
\hline $\mathrm{NaCl}$ & $146,1 \mathrm{~g} / \mathrm{L}$ \\
$\mathrm{Na}_{2}$ EDTA $2 \mathrm{H}_{2} \mathrm{O}$ & $37,2 \mathrm{~g} / \mathrm{L}$ \\
TRIS & $1,2 \mathrm{~g} / \mathrm{L}$ \\
\hline
\end{tabular}

Buffer de Electroforesis: el buffer empleado se preparó en el momento de la realización del ensayo a partir de las soluciones indicadas en la Tabla 14.

Tabla 14. Composición del buffer de electroforesis

\begin{tabular}{ccc}
\hline Reactivos & Concentración & $\begin{array}{c}\text { Cantidad }(\mathrm{mL}) \text { necesaria en } \\
\text { 1L de solución }\end{array}$ \\
\hline $\mathrm{NaOH}$ & $400 \mathrm{~g} / \mathrm{L}$ & 30 \\
$\mathrm{Na}_{2}$ EDTA & $74,4 \mathrm{~g} / \mathrm{L}$ & 5 \\
\hline
\end{tabular}

En el momento de realizar el ensayo se prepararon 1,5 L de acuerdo a las proporciones de cada una de las soluciones y se llevó a volumen con agua Milli-Q.

Buffer de Neutralización: se utilizó como solución de neutralización una solución de Tris 484 g/L con pH 7,5. La misma se preparó disolviendo 48,5 g de Tris en agua Milli-Q. Se llevó a volumen final de $1 \mathrm{~L}$ en un matraz aforado, agregándose bajo campana gotas de $\mathrm{HCl}$ puro (36\%) hasta alcanzar un valor de $\mathrm{pH}$ de 7,5 . Esta solución se almacenó a $4{ }^{\circ} \mathrm{C}$ durante un período no mayor a 30 días desde su preparación.

Solución de Bromuro de etidio: la solución con la que se realizó la tinción del ADN para la observación de los cometas se preparó a partir de una solución madre de concentración 10 $\mathrm{mg} / \mathrm{mL}$, utilizando una concentración de trabajo de $20 \mu \mathrm{g} / \mathrm{mL}$ en agua Milli-Q. 


\section{Preparación de los portaobjetos}

Los geles utilizados en el ensayo del cometa fueron realizados con tres capas de agarosa. Para comenzar, los portaobjetos utilizados en el ensayo fueron sumergidos en alcohol durante $24 \mathrm{~h}$. A continuación fueron secados y tratados con tela esmeril de granulometría fina para aumentar la rugosidad del portaobjetos y favorecer la adhesión de la agarosa. La primera capa de agarosa se realizó con agarosa de punto de fusión normal (NMP) al 0,5\% disuelta en PBS. Los portaobjetos fueron sumergidos en solución de agarosa en forma vertical, y se retiró el exceso de agarosa con el borde superior de un vaso de precipitado. La agarosa se dejó solidificar a temperatura ambiente durante $24 \mathrm{~h}$.

La segunda capa de agarosa, en la cual se produjo la inclusión de los celomocitos fue preparada en el momento de comenzar el ensayo. Los celomocitos de E. fetida fueron obtenidos a partir de ejemplares no expuestos en el caso de los ensayos ex vivo, y de organismos expuestos a las diferentes matrices sólidas en el caso de los ensayos in vivo. La extrusión de celomocitos fue realizada como se describió en la sección 4.4.3 y se generó una suspensión celular de la concentración establecida cómo óptima en los ensayos preliminares de $1 \times 10^{6}$ células $/ \mathrm{mL}$.

Para comenzar la inclusión de los celomocitos se tomaron $500 \mu \mathrm{L}$ de la suspensión celular y se mezclaron con $500 \mu \mathrm{L}$ de solución de agarosa de bajo punto de fusión al 1\% en PBS en un tubo de microcentrífuga. A continuación se tomaron $80 \mu \mathrm{L}$ de la mezcla y se colocaron sobre el portaobjetos preparado previamente con la primera capa de agarosa. Esta alicuota fue homogéneamente extendida mediante la colocación de un cubreobjetos. Estos portaobjetos fueron colocados a $4^{\circ} \mathrm{C}$, sobre un soporte de vidrio, para facilitar la solidificación de la agarosa durante $10 \mathrm{~min}$. Luego, se removió cuidadosamente el cubreobjetos por deslizamiento horizontal del mismo y se agregaron $80 \mu \mathrm{L}$ de solución de agarosa de bajo peso molecular al $0,5 \%$ en PBS. Esta capa fue homogéneamente extendida mediante la colocación de un cubreobjetos. Estos portaobjetos fueron colocados nuevamente a $4^{\circ} \mathrm{C}$ sobre un soporte de vidrio para facilitar la solidificación de esta tercera capa de agarosa durante $10 \mathrm{~min}$.

En el caso de los ensayos de exposición in vivo, luego de realizar la inclusión de las células en agarosa sobre los portaobjetos se prosiguió con la lisis celular. En el caso de los ensayos de exposición ex vivo, en este punto, se produjo la exposición de las células a las fracciones líquidas- eluciones de las matrices sólidas estudiadas. Para la realización de esta exposición las eluciones fueron preparadas según lo descripto en la sección 4.2, pero utilizando PBS en 
lugar de agua Milli-Q. Esto se debe a que la utilización de agua Milli-Q no mantiene la osmolaridad celular comprometiendo la viabilidad celular.

Exposición

La exposición de los celomocitos a las eluciones de las matrices sólidas estudiadas y a los controles negativo y positivo, correspondientes a PBS y solución $100 \mu \mathrm{M}$ de $\mathrm{H}_{2} \mathrm{O}_{2}$ fue realizada durante $1 \mathrm{~h}$. A los portaobjetos obtenidos en el paso anterior se les removió cuidadosamente por deslizamiento horizontal el cubreobjetos y fueron sumergidos en las soluciones de exposición.

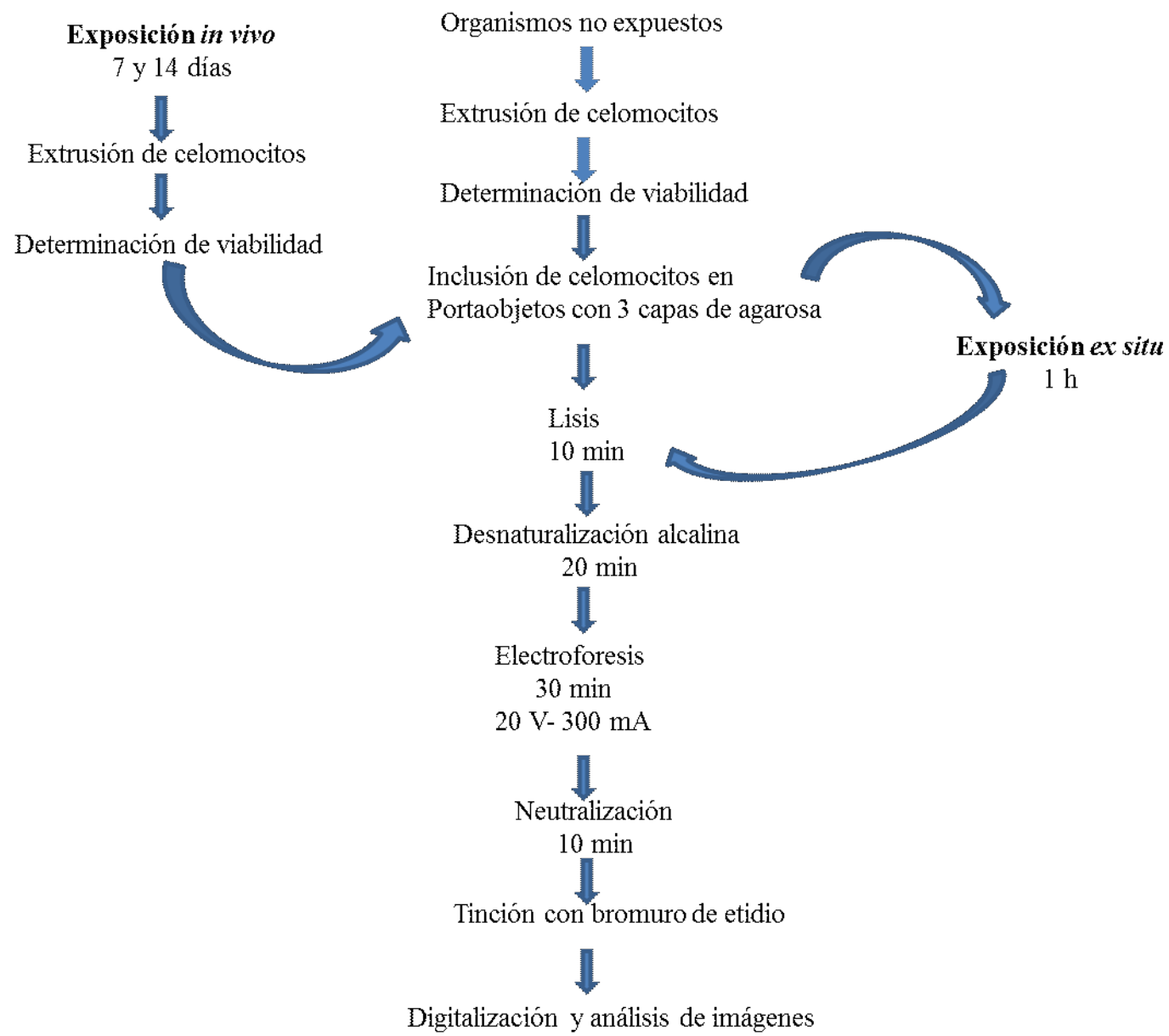

Figura 7: Esquema general del procedimiento utilizado para evaluación de genotoxicidad en las exposiciones in vivo y ex vivo.

\section{Lisis}

Tanto los portaobjetos provenientes de los ensayos in vivo como los del ensayo ex vivo luego de la exposición, se colocaron en solución de lisis fría para la remoción de proteínas y lípidos. Los portaobjetos que contenían los celomocitos incluidos en las tres capas de agarosa fueron 
colocados sin cubreobjetos en la solución final de lisis. La solución final de lisis fue preparada en el día de realización del ensayo y preservada a $4^{\circ} \mathrm{C}$ a fin de asegurar el mantenimiento de la integridad de las capas de agarosa. La lisis de las células celómicas de E fetida e incluidas en las capas de agarosa se llevó a cabo durante $10 \mathrm{~min}$.

\section{Lavado}

Una vez finalizada la lisis celular, los portaobjetos fueron lavados por inmersión rápida en buffer de electroforesis. Este lavado se realizó con la finalidad de remover residuos de sales y detergentes de los portaobjetos. De esta manera, se incrementa la reproducibilidad del ensayo (Tice et al, 2000).

\section{Desnaturalización alcalina}

Los portaobjetos fueron colocados en la cuba electroforética (BIORAD) en forma horizontal y orientados de manera paralela a la dirección de la corriente inmersos en buffer de electroforesis preparado como se indicó con anterioridad e incubados durante 25 minutos a temperatura ambiente para facilitar el proceso de desenrollamiento del ADN.

\section{Electroforesis}

Una vez finalizado el periodo de desnaturalización de ADN se realizó la electroforesis de los portaobjetos. Las condiciones de la electroforesis fueron:

Intensidad de corriente: $300 \mathrm{~mA}$

Tiempo: $30 \mathrm{~min}$

Diferencia de potencial: $1 \mathrm{~V} / \mathrm{cm}$

Neutralización

Los portaobjetos fueron sumergidos en solución de neutralización durante 10 minutos.

\section{Tinción y digitalización de imágenes}

Si bien ha sido demostrado que el secado y posterior rehidratación de los portaobjetos obtenidos a partir del ensayo del cometa no difiere de la observación de los preparados frescos (Woods et al, 1999), las observaciones y digitalización de las imágenes se realizaron una vez finalizado el procedimiento.

La tinción de los portaobjetos se llevó a cabo con una solución $20 \mu \mathrm{g} / \mathrm{mL}$ de bromuro de etidio. Para la tinción se agregaron $30 \mu \mathrm{L}$ de esta solución sobre los portaobjetos. La 
observación de los preparados se realizó con un microscopio Nikon, Eclipse 600, provisto con epifluorescencia (filtro de excitación 541-560 nm y filtro de emisión de $590 \mathrm{~nm}$ ), equipado para la obtención de fotomicrografías mediante una cámara Nikon FDX-35 unido a un sistema de análisis de imágenes (Image Pro Plus, V4.0, Media Cybertnetics, Maryland USA).

Las imágenes fueron digitalizadas a una magnificación de 1000x con aceite de inmersión de baja fluorescencia basal. Se analizaron 300 nucleoides por tratamiento mediante las imágenes digitalizadas según se describe a continuación.

\section{Cuantificación del daño genotóxico mediante análisis de imágenes}

Las imágenes observadas mediante microscopia de epifluorescencia fueron digitalizadas para su posterior análisis utilizando una cámara CCD (charge-coupled device) marca Nikon modelo FDX-35 y el programa Image Pro Plus V4.0 (Media Cybertnetics, MD, USA). Las mismas fueron almacenadas en formatos Join Photograph Expert Group (JPEG) y Tagged Image File Format (TIFF). De acuerdo con Tice et al (2000) los parámetros más comunes que pueden determinarse a partir del desarrollo del ensayo cometa (Figura 8) para cuantificar los efectos genotóxicos son:

- Diámetro del nucleoide o cabeza (DC)

- Largo de la cola del cometa (LC, representa la migración del ADN desde el borde derecho de la cabeza hasta el final de la cola del cometa)

- Relación cabeza/cola

- ADN en la cabeza (medido con densidad óptica o intensidad, porcentaje relativo de ADN en el nucleoide)

- $A D N$ en cola (medido con densidad óptica o intensidad, representa el porcentaje de ADN que migra desde el núcleo en dirección al ánodo expresado como: 100 - \% $\left.\mathrm{ADN}_{\text {cabeza }}\right)$

- Momento extendido de cola (LC * \% ADN Cola)

- Momento de cola de Olive (Lo * \% DNA Cola, Lo: Longitud entre los centros de cabeza y cola. 


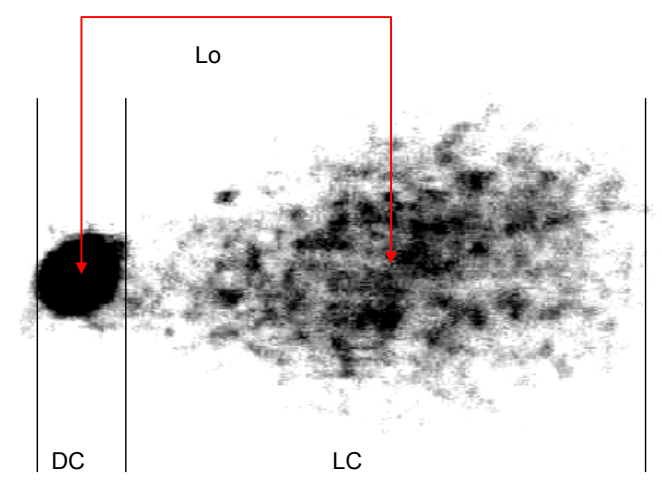

Figura 8: Parámetros para la determinación de daño genotóxico

De estos parámetros, como se explicó anteriormente, se seleccionó el porcentaje relativo de $\mathrm{ADN}$ en la cola del cometa (\% $\mathrm{ADN}$ Cola) al ser la variable más significativa y fácil de conceptualizar (Kumaravel y Jha, 2006). El programa de análisis de imágenes Image Pro-Plus permite la medición de las densidades ópticas de las áreas de interés seleccionadas en las imágenes evaluadas. También selecciona el color de máxima intensidad, de acuerdo con el color del fluorógeno utilizado y la medida de la longitud requerida según el parámetro elegido, generalmente expresada en $\mu \mathrm{m}$, en relación al aumento o magnificación con el cual se ha digitalizado la imagen. Todas las medidas realizadas sobre los cometas obtenidos se llevan a cabo de manera manual. Debido al elevado número de mediciones que deben registrarse por preparado y sus réplicas, por cada dilución o concentración ensayada, sumado a los controles positivos y negativos (300 nucleoides por tratamiento), es conveniente el uso de una herramienta que permita analizar las imágenes de manera automática. En este sentido se trabajó con un programa de acceso público dedicado al estudio de cometas, presentado por Końca et al (2003) denominado CASP, al cual puede accederse desde http://casplab.com/. Sin embargo, antes de decidir sobre su uso definitivo se realizaron determinaciones de ADN en la cola de 300 células empleando ambos programas (manual y automático). Se comprobó, mediante una análisis de regresión lineal, la similitud de las medidas generadas por los mismos $\left(\mathrm{R}^{2}>95 \%\right)$, verificando la confiabilidad del programa computacional propuesto por Końca y sus colaboradores.

\section{Capturas de pantalla de Image Pro-Plus}

En la Figura 9 se muestran las imágenes de un nucleoide control, observando a la izquierda la medida de la densidad óptica o intensidad de la cabeza y a la derecha, el uso de la herramienta de medida. 


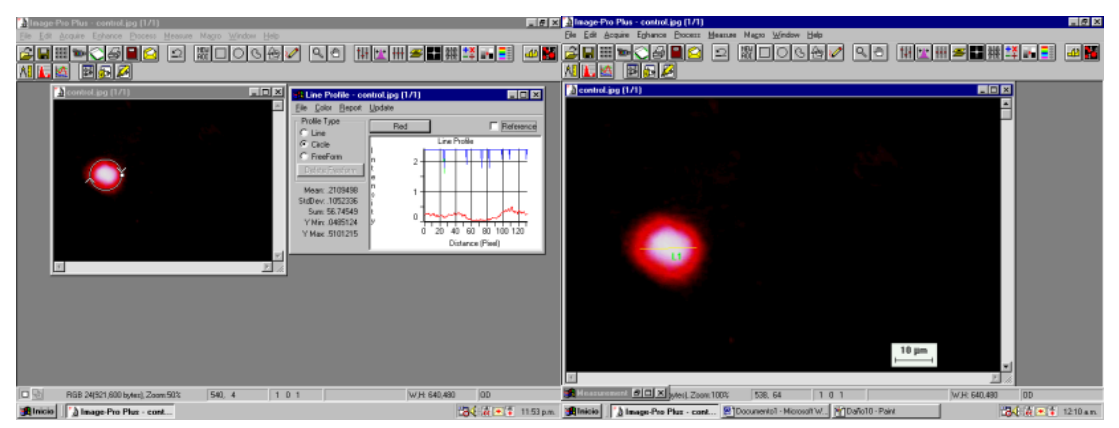

Figura 9: Captura de pantalla del análisis con el programa Image Pro Plus de un nucleoide control.

En la Figura 10 se observa la imagen de un nucleoide con considerable daño genotóxico, donde se indica la medida de la intensidad de la cabeza y la cola, a la izquierda y centro, respectivamente. La imagen de la derecha indica la medida del diámetro de la cabeza y del largo de la cola del cometa.

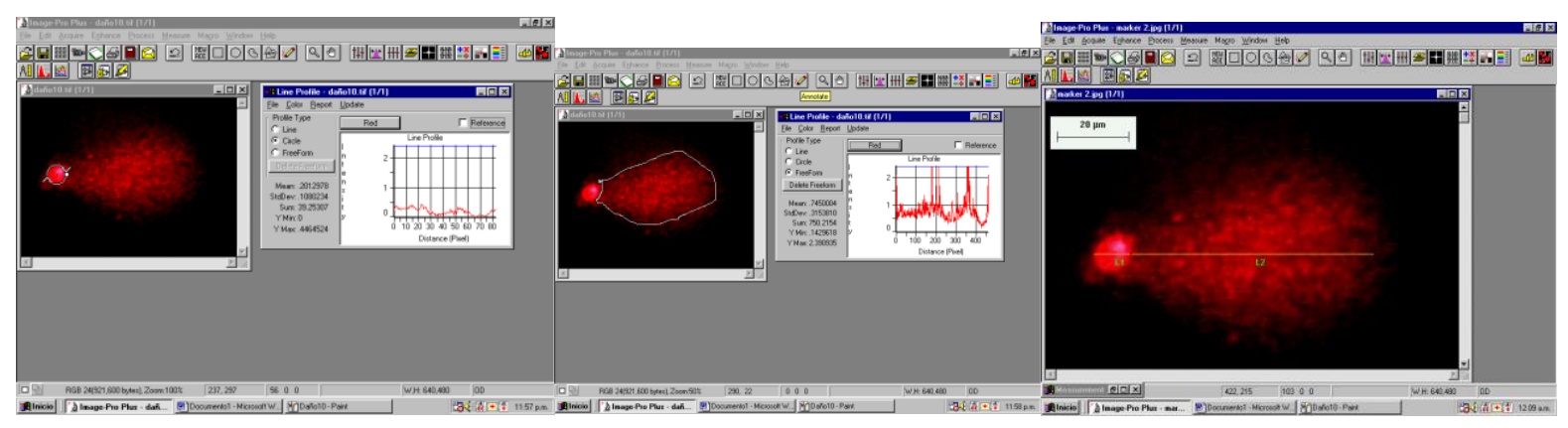

Figura 10: Capturas de pantallas del programa Image Pro Plus para el análisis de un nucleoide con cometa evidente

\section{Capturas de pantalla de CASP en modo medición}

En la Figura 11 se muestra la imagen de un nucleoide control, mostrando sobre la izquierda los rectángulos del área de selección indicando la zona de substracción del background o fondo (superior) y de medida (inferior); sobre la derecha se observa el perfil de intensidad de la cabeza del nucleoide. En la misma, pueden registrarse los valores de los parámetros automatizados una vez terminada la selección. 


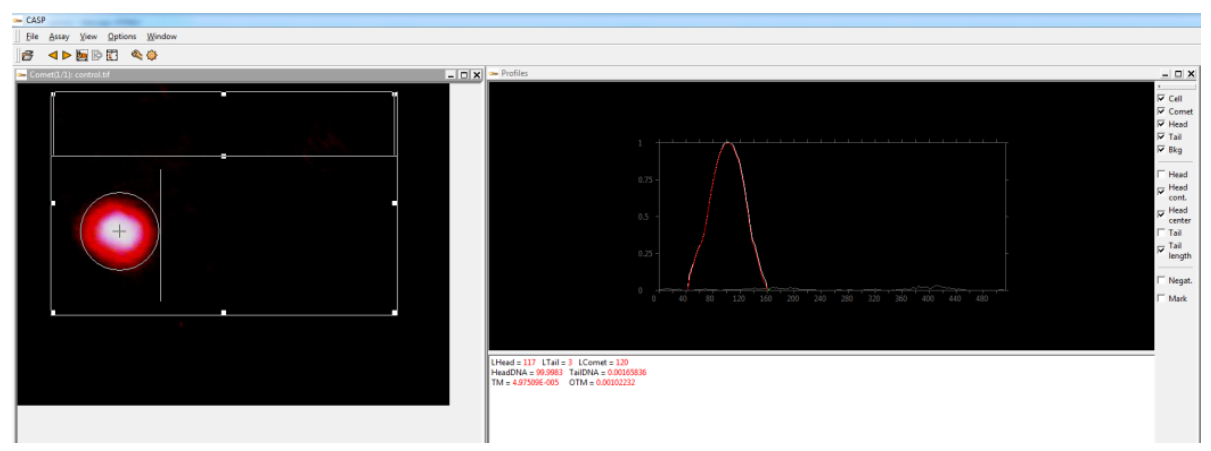

Figura 11: Captura de pantalla de un nucleoide control en el software CASP

La Figura 12 muestra la imagen de un nucleoide con cometa evidente, donde sobre la izquierda puede notarse el límite elegido por el programa para la determinación del largo de la cola (LC). A la derecha se muestra el perfil de intensidad, indicando en verde la cantidad de ADN presente en la cola, que corresponde a un $87 \%$, indicado en el margen inferior de la imagen.

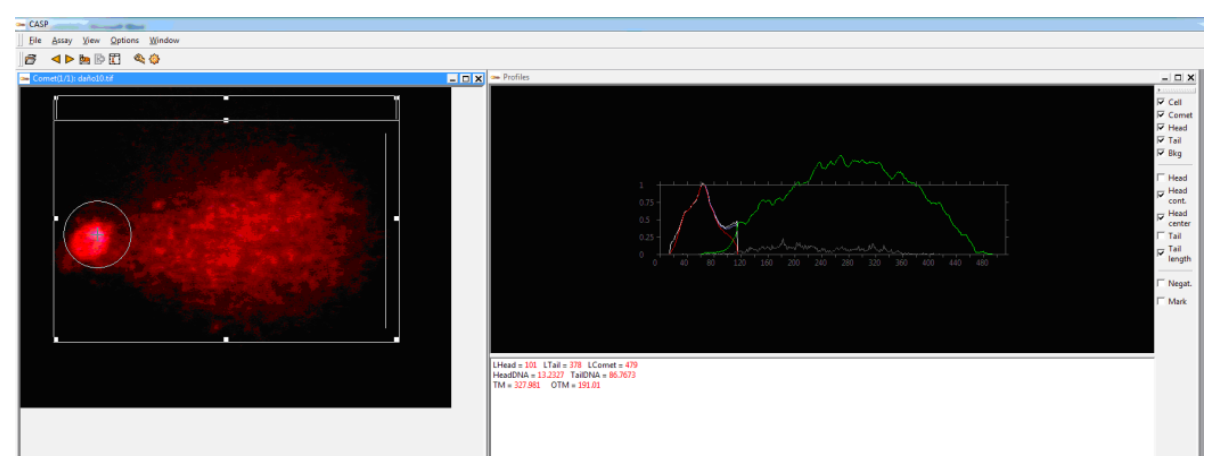

Figura 12: Captura de pantalla de un nucleoide con cometa evidente en el software CASP

\subsection{Análisis estadístico}

Los resultados obtenidos en los diferentes ensayos fueron analizados respecto al cumplimiento de normalidad mediante el test de Bartlett y de homogeneidad de varianzas mediante el test de Shapiro-Wilks. En el caso que los mismos permitieran un tratamiento estadístico paramétrico, el análisis de las diferencias observadas entre los grupos tratados y los controles fue realizado mediante análisis de la varianza (ANOVA) de un factor combinado con los test de comparaciones múltiples Dunnet y Tuckey. Para tal fin se utilizó el programa de computación TOXSTAT V 3.5 (West Inc and Gulley, 1996). En los casos de resultados no-paramétricos se utilizó el ensayo de Kruskal-Wallis, combinado con los test de comparación de medias o test U de Mann-Whitney. Estos últimos análisis estadísticos se realizaron con el programa Statistica Versión 8. Este fue el caso de los resultados obtenidos 
en el ensayo cometa, citotoxicidad e índices celulares. Los índices de toxicidad CE50 y CL50 se determinaron según el método Probit (US EPA 1991) o el de Spearman-Karber (Hamilton et al, 1977) para datos no paramétricos. La estimación del CMEO y CENO se realizó utilizando el test de Dunnet (Sparks 2000, Zar 2010).

Para las muestras ambientales se utilizó la comparación de pares mediante t- student entre las mismas y los organismos control. 
3. RESULTADOS Y DISCUSIÓN 


\subsection{Residuos sólidos}

\subsubsection{Arena de Fundición}

\subsubsection{Muestra entera}

\subsection{Parámetros fisicoquímicos}

Para la muestra entera del residuo industrial, correspondiente a la arena de fundición, se determinaron los siguientes parámetros físicoquímicos: $\mathrm{pH}$, Fracción húmeda, Sólidos volátiles, CRA, COT e Hidrocarburos. Los resultados para estas determinaciones pueden observarse en la Tabla 1.

Tabla 1. Parámetros fisicoquímicos y cuantificación de metales (expresados en $\mathrm{mg} / \mathrm{kg}$ ) del residuo Arena de fundición en su forma sólida (muestra entera). CRA expresada como mLde agua/100 g de muestra. COT expresado como mg C/g. HC expresado como mg HC/g muestra

\begin{tabular}{cc}
\hline Parámetro & Arena de fundición \\
\hline pH & 6,8 \\
Fracción húmeda (\%) & 0,1 \\
Sólidos Volátiles $(\%)$ & 1,3 \\
$\mathrm{CRA}$ & 25,0 \\
$\mathrm{COT}$ & 4,8 \\
$\mathrm{HC}$ & 0,02 \\
$\mathrm{Fe}$ & 2813,7 \\
$\mathrm{Cu}$ & 4,4 \\
$\mathrm{Zn}$ & 38,9 \\
$\mathrm{Ni}$ & 4,2 \\
$\mathrm{Cd}$ & 0,2 \\
$\mathrm{Cr}$ & 6,1 \\
$\mathrm{~Pb}$ & 205,2
\end{tabular}

El residuo proveniente de la arena de fundición presentó un $\mathrm{pH}$ cercano a la neutralidad de 6,8 y un bajo porcentaje de humedad. Asimismo, presentó una proporción de sólidos volátiles del $1,3 \%$ y una baja CRA con un valor de $25 \mathrm{~mL} / 100 \mathrm{~g}$ de muestra. El valor de COT para esta muestra fue de 4,8 $\mathrm{mg}$ de $\mathrm{C} / \mathrm{g}$ de muestra y finalmente, la cuantificación de Hidrocarburos fue de $0,02 \mathrm{mg} \mathrm{HC} / \mathrm{g}$ muestra. 
Para la muestra entera, correspondiente al residuo de arena de fundición, se cuantificaron además los metales presentes. El Fe se encontró en mayor concentración, seguido por el $\mathrm{Pb}$ y el $\mathrm{Zn}$. Entre los metales presentes en menor concentración se encontraron el $\mathrm{Cr}, \mathrm{Cu}$ y $\mathrm{Ni}$, mientras que aquellos aun con menor concentración fueron Al y As (Tabla 1).

El análisis cualitativo de los componentes orgánicos de la muestra correspondiente a la arena de fundición reveló la presencia del compuesto Ácido para-terc-Butilbenzoico (CAS 98-737). El mismo ha sido identificado como agente aglomerante en las resinas alquílicas (Carnin et al, 2012).

\subsection{Ensayos de germinación y elongación de las raíces con L. sativa}

El ensayo de germinación de semillas y elongación de raíces en L. sativa fue utilizado para evaluar los efectos fitotóxicos del residuo de arena de fundición en su forma entera. En el ensayo realizado, el porcentaje de germinación en las placas control fue mayor al $65 \%$ cumpliendo con el requerimiento de la normativa utilizada (US EPA, 1996b).

Las concentraciones del residuo de arena de fundición evaluadas se realizaron con arena inerte, y corresponden a $6 ; 12,5 ; 25 ; 50$ y $100 \% \mathrm{p} / \mathrm{p}$.

El residuo industrial de arena de fundición no mostró ejercer efectos fitotóxicos significativos a las concentraciones correspondientes a 6; 12,5 y $25 \% \mathrm{p} / \mathrm{p}$. Sin embargo, a las concentraciones de 50 y $100 \%$ p/p, el residuo provocó una inhibición estadísticamente significativa $(\mathrm{p}<0,01)$ con respecto al control en la germinación de semillas de L. sativa con valores de inhibición de la germinación de 40,4 y 72\%, respectivamente (Tabla 2). El valor de CL50-120h derivado de este parámetro fue una concentración del 59,8\% p/p, siendo su intervalo de confianza del 95\% de 21,2-105,3\%.

El ensayo de germinación en L. sativa permitió evaluar las respuestas sinérgicas, antagónicas $\mathrm{y}$ aditivas que las matrices sólidas pueden generar en las funciones fisiológicas o bioquímicas de los organismos de prueba (US EPA, 1989; 1996). Los resultados obtenidos en el ensayo de germinación con el residuo de arena de fundición evidenciaron que el mismo ejerció un efecto fitotóxico que se corresponde con una relación dosis-respuesta positiva. Estudios previos han demostrado que la presencia de metales pasados ha sido capaz de inducir una inhibición en la germinación de semillas de lechuga (Ferrari et al, 1999). Estos autores evaluaron un residuo de cenizas proveniente del incinerador municipal el cuál contenía compuestos orgánicos y metales pesados tales como $\mathrm{Fe}$ (en mayor concentración), $\mathrm{Cu}$ y $\mathrm{Pb}$, mediante una batería de organismos y bioensayos. En el caso del ensayo de germinación de semillas, se utilizaron tres especies de plantas tales como Avena sativa, Brassica campestris y L. sativa para la 
evaluación de los residuos en fase sólido. Los resultados indicaron que $L$. sativa fue la especie más sensible para la detección de efectos fitotóxicos originados por el residuo (Ferrari et al, 1999). Por su parte, Saterbak et al (1999) reportaron en sus estudios que suelos contaminados con hidrocarburos causaron una inhibición en la germinación de semillas en L. sativa y $B$. rapa luego de 14 días de exposición. Asimismo, se ha demostrado que la presencia de $\mathrm{Pb}$ en suelo ejerce una inhibición en la germinación de semillas de Avena sativa y L. sativa y de dos especies de pasturas locales (Chang et al, 1997).

Tabla 2. Efecto fitotóxico del residuo de arena de fundición sobre la germinación de las semillas y la elongación de las raíces en L. sativa

\begin{tabular}{|c|c|c|c|c|}
\hline $\begin{array}{l}\% \mathrm{p} / \mathrm{p} \text { del residuo de } \\
\text { arena de fundición }\end{array}$ & $\begin{array}{c}\text { Semillas } \\
\text { germinadas/semillas } \\
\text { expuestas }\end{array}$ & $\begin{array}{c}\text { Inhibición } \\
\text { Germinación } \\
(\%)\end{array}$ & $\begin{array}{l}\text { Elongación de } \\
\text { raíces }(\mathrm{cm})\end{array}$ & $\begin{array}{l}\text { Inhibición } \\
\text { elongación de } \\
\text { raíces }(\%)\end{array}$ \\
\hline 0 (Control) & $16 / 20$ & 0 & 2,8 & - \\
\hline 6 & $17 / 20$ & 0 & 2,8 & 0 \\
\hline 12,5 & $15 / 20$ & 8 & 2,6 & 7 \\
\hline 25 & $13 / 20$ & 16,9 & 2.0 & $28 * *$ \\
\hline 50 & $9 / 20$ & $40,4^{*}$ & 1,8 & $35^{* *}$ \\
\hline 100 & $4 / 20$ & $72 *$ & 1,6 & $42 * *$ \\
\hline
\end{tabular}

* Diferencias estadísticamente significativas con el control, $\mathrm{p}<0,01$

** Diferencias estadísticamente significativas con el control, $\mathrm{p}<0,05$

Además de los metales pesados, otras matrices complejas han sido evaluadas mediante el ensayo de germinación en L. sativa. Este ha sido el caso de efluentes ricos en materia orgánica, provenientes de digestores anaeróbicos. Estudios previos indican que estos residuos han demostrado inducir fitotoxicidad en semillas de L. sativa (Young et al, 2012). Schultz et al (2002) han observado una marcada inhibición de la germinación de semillas de L. sativa expuestas a residuos industriales con presencia de compuestos orgánicos. 
El ensayo de germinación en L. sativa ha permitido, además, determinar de manera sensible la toxicidad matrices líquidas. Valerio et al (2007) han utilizado el mencionado ensayo para la detección de la toxicidad de lixiviados de suelos sobre semillas de lechuga. Andrade et al (2010) observaron una disminución de la germinación de semillas de L. sativa expuestas a los lixiviados de residuos sólidos generados en la industria metalúrgica.

Coincidiendo con estos estudios previos, el ensayo de germinación de L. sativa ha sido sensible para detectar el efecto fitotóxico inducido por el residuo de arena de fundición, el cual presentó metales pesados tales como el $\mathrm{Fe}, \mathrm{Pb}$ y Al.

Diferentes mecanismos han sido propuestos para explicar la inhibición de las semillas expuestas a metales pesados. Por un lado, ha sido propuesto un mecanismo de toxicidad global causado por un efecto directo del metal en el metabolismo del embrión con una consecuente depleción en la viabilidad. Al germinar, las semillas sufren cambios rápidos en el metabolismo, transporte de nutrientes y división celular, por lo que pueden ser sensibles al estrés ambiental y verse afectadas en su viabilidad (Wang, 1987). Por otro lado, otra hipótesis plantea que algunos metales podrían interferir con el ingreso de agua a las semillas por modificación de la permeabilidad de la cubierta seminal (Kranner y Colville, 2011). La absorción de agua a través de la cubierta seminal es el primer paso fundamental en el proceso germinativo. El potencial de agua del embrión debe alcanzar el valor crítico para hacer posible el proceso germinativo. La entrada de agua a través de los tejidos seminales activa diversos procesos metabólicos que son necesarios para la germinación (Heldt, 2005). Las cubiertas seminales actúan como una barrera selectiva para el pasaje de sustancias necesarias en el proceso. La presencia de metales pesados puede afectar la permeabilidad de estas barreras evitando el flujo de agua necesario para el normal desarrollo del proceso germinativo, provocando una inhibición de la germinación en semillas expuestas (Kranner y Colville, 2011).

En cuanto al parámetro de elongación de la raíz, el residuo ejerció un efecto inhibitorio con respecto al control. Las concentraciones del residuo de arena de fundición correspondientes al 6 y $12,5 \%$ p/p no evidenciaron efectos estadísticamente significativos sobre la elongación de las raíces. Sin embargo, las concentraciones de 25,50 y $100 \%$ p/p revelaron una disminución estadísticamente significativa $(\mathrm{p}<0,05)$ en el parámetro evaluado, con valores de inhibición del 28,3 y 42\%, respectivamente (Tabla 2). El valor de la CE50-120h para la elongación de las raíces en L. sativa no pudo ser estimado ya que la mayor concentración evaluada de la muestra produjo menos del 50\% de la inhibición de la elongación de la raíz (42\%) (Tabla 9). 
La evaluación de la elongación de las raíces permitió determinar los efectos subletales ejercidos por las matrices sólidas estudiadas en las semillas expuestas (US EPA 1989; 1996a). En el caso del residuo de arena de fundición se ha observado que la longitud de las raíces disminuyó conforme se incrementó la concentración del residuo. Por lo tanto, el efecto fitotóxico se manifestó como una inhibición de la elongación de las raíces en las semillas expuestas durante $120 \mathrm{~h}$. Estos resultados son concordantes con los resultados obtenidos por otros autores. Chang et al (1997) han observado una inhibición de la elongación de las raíces de semillas de L. sativa expuestas durante $120 \mathrm{~h}$ a suelos contaminados con $\mathrm{Pb}$. Di Salvatore et al (2008) expusieron semillas de diferentes especies vegetales sugeridas por normativas internacionales a diferentes concentraciones de diversos metales, entre los cuales se encontraba el $\mathrm{Cd}, \mathrm{Pb}, \mathrm{Ni}$ y $\mathrm{Cu}$. Estos autores observaron que la elongación de las raíces resultó inhibida para las mayores concentraciones de los metales evaluados (Di Salvatore et al, 2008).

La CMEO para el ensayo de germinación de semillas en L. sativa resultó ser del $50 \%$ p/p, mientras que la CMEO del parámetro de elongación de la raíz fue del $25 \%$ p/p. Esta mayor sensibilidad del parámetro de elongación de raíces es coincidente con lo encontrado con otros autores al comparar ambos parámetros (Wang, 1987; Chang et al, 1997; Di Salvatore et al, 2008) (Tabla 9).

\subsection{Ensayos de cito y genotoxicidad en celomocitos de E. fetida in vivo}

El efecto letal ejercido por el residuo de arena de fundición fue evaluado mediante el ensayo de exposición aguda de ejemplares de E. fetida siguiendo el protocolo propuesto por la normativa internacional (OECD, 1984).

A partir de los resultados de mortalidad con organismos expuestos durante 14 días se determinó la CL50-14d para la realización de los ensayos de genotoxicidad. El valor de la CL50 para el residuo de arena de fundición fue de 26\% p/p (rango 15,7-26,21).

Los ensayos de laboratorio poseen un rol fundamental en la evaluación del riego asociado a la exposición de productos químicos. La prueba de toxicidad aguda en E. fetida es un ensayo internacionalmente estandarizado (OECD, 1984) y con un papel fundamental en el asesoramiento de riesgo dentro de la Comunidad Europea (Kula, 1997). Este bioensayo es uno de los que poseen mayor relevancia para la evaluación de suelos en condiciones de laboratorio (OECD, 1984). Sobre todo, esta relevancia se debe a su alta reproducibilidad y aplicabilidad para ser implementado con propósitos legislativos (Kula, 1996). Sin embargo, la información obtenida por el mismo no permite elucidar los mecanismos de acción de los tóxicos en los 
organismos expuestos. Por lo tanto, es importante complementar el bioensayo con otros biomarcadores para comprender los mecanismos de toxicidad asociados a las matrices sólidas. Por esta razón, se evaluó en forma paralela la acción cito y genotóxica de las matices sólidas estudiadas con el ensayo de mortalidad.

\section{Efectos en la viabilidad celular}

A partir de los resultados obtenidos en el ensayo de mortalidad aguda en E. fetida se seleccionaron las concentraciones que fueron evaluadas en el ensayo de cito y genotoxicidad. En el caso del residuo de arena de fundición las diluciones ensayadas correspondieron a la CL50, CL50/2 y CL50/10, con valores de 26; 13 y 2,6\% p/p, respectivamente.

La citotoxicidad de las diferentes concentraciones del residuo de arena de fundición fue determinada mediante la extrusión de los celomocitos de organismos expuestos durante 7 y 14 días y el posterior ensayo de exclusión con Azul de Tripán.

Los resultados de este ensayo se expresan en la Tabla 3. A los 7 días de exposición sólo la concentración más elevada de $26 \%$ p/p evidenció una citotoxicidad que difiere estadísticamente con la misma en los celomocitos de organismos control $(\mathrm{p}<0,05)$. A los 14 días de exposición, las concentraciones del residuo de arena de fundición correspondientes a 13 y $26 \%$ p/p revelaron un incremento estadísticamente significativo en la citotoxicidad celular $(\mathrm{p}<0,05)$ con valores de 36 y 46\% de células que incorporan Azul de Tripán, respectivamente.

Tabla 3. Citotoxicidad en celomocitos de organismos de E. fetida expuestos de manera in vivo durante 7 y 14 días al residuo de arena de fundición. Valores expresados como \% de células no viables

\begin{tabular}{ccc}
\hline$\% \mathrm{p} / \mathrm{p}$ & 7 días & 14 días \\
\hline 0 (control) & 9 & 9 \\
2,6 & 13 & 18 \\
13 & 19 & $36^{* *}$ \\
26 & $25^{* *}$ & $46^{* *}$ \\
\hline
\end{tabular}

** Diferencias estadísticamente significativas con el control, $\mathrm{p}<0,05$ 


\section{Índices tróficos}

A partir de los mismos organismos expuestos durante 7 y 14 días de manera in vivo se determinaron los índices tróficos LITA, LITAR e ICCT, los cuales se muestran en la Tabla 4.

Tabla 4. Índices tróficos con su desviación estándar (entre paréntesis) en organismos de $E$. fetida expuestos de manera in vivo al residuo de arena de fundición (\%)

\begin{tabular}{ccccccc}
\hline$\% \mathrm{p} / \mathrm{p}$ & \multicolumn{3}{c}{ Día 7} & & \multicolumn{3}{c}{ Día 14} \\
& LITA & LITAR & ICCT & LITA & LITAR & ICCT \\
\hline 0 & 0,59 & 1,59 & 6,13 & 0,59 & 1,59 & 6,13 \\
& $(0,03)$ & $(0,12)$ & $(0,02)$ & $(0,03)$ & $(0,12)$ & $(0,02)$ \\
2,6 & $0,65^{*}$ & 1,56 & 6,11 & 0,56 & $1,21^{*}$ & 6,12 \\
& $(0,01)$ & $(0,37)$ & $(0,09)$ & $(0,03)$ & $(0,12)$ & $(0,02)$ \\
\multirow{2}{*}{13} & $0,56^{*}$ & 1,35 & 6,08 & 0,56 & 1,38 & 6,08 \\
& $(0,015)$ & $(0,12)$ & $(0,03)$ & $(0,013)$ & $(0,11)$ & $(0,03)$ \\
& $0,52^{*}$ & $1,31^{*}$ & 6,03 & $0,52^{*}$ & $1,22^{*}$ & $6,01 *$ \\
& $(0,023)$ & $(0,18)$ & $(0,08)$ & $(0,019)$ & $(0,044)$ & $(0,05)$
\end{tabular}

* Diferencias estadísticamente significativas con respecto al control, $\mathrm{p}<0,001$

Para el LITA en el día 7 de exposición con el residuo de arena de fundición se observó un incremento estadísticamente significativo $(\mathrm{p}<0,001)$ del mismo para la menor concentración del residuo ensayada $(2,6 \% \mathrm{p} / \mathrm{p})$. Por el contrario, para las mayores concentraciones evaluadas (13 y 26\% p/p) se observó una disminución estadísticamente significativa $(\mathrm{p}<0,001)$ para el valor del índice. Para el día 14 de exposición, este índice se redujo al aumentar la concentración del residuo, siendo esta variación estadísticamente significativa $(p<0,001)$ para la concentración del $26 \%$ p/p. El Índice LITAR para las lombrices expuestas al mismo residuo exhibió una tendencia similar. Para el día 7 se acrecentó de manera estadísticamente significativa $(\mathrm{p}<0,001)$ con respecto al control y disminuyó su valor para las concentraciones mayores evaluadas. En cuanto al día 14 de exposición, se observó una disminución del valor del índice en todas las concentraciones evaluadas. Al respecto, es importante recordar que los Índices LITA y LITAR consideran la relación entre el número total de eleocitos y el número total de celomocitos. Por lo que, una disminución en el valor de ambos Índices estuvo acompañada por un descenso en la proporción de eleocitos para las mayores concentraciones y tiempo de exposición al residuo de arena de fundición. Este efecto es capaz de generar una 
menor disponibilidad de células con funciones nutricias en los tejidos internos de los organismos expuestos. En concordancia con estos resultados, Plytycz et al (2011) han encontrado que el número de celomocitos disminuye en organismos de las especies de lombrices de tierra Allolobophora chlorotica y Dendrobaena veneta expuestas a diferentes metales.

El Índice ICCT, que considera el número total de celomocitos, no evidenció alteraciones estadísticamente significativas en ninguna de las concentraciones ensayadas a 7 días de exposición. Por el contrario, para el día 14 de exposición, los organismos mostraron una disminución en el mismo, siendo esta tendencia estadísticamente significativa $(p<0,001)$ para la mayor concentración $(26 \% \mathrm{p} / \mathrm{p})$.

\section{Proporciones celulares}

Las proporciones de los diferentes tipos de celomocitos para los organismos de E. fetida fueron calculados en organismos expuestos in vivo durante 7 y 14 días al residuo de arena de fundición (Figura 1 y Figura 2). La proporción de granulocitos se mantuvo constante en todas las concentraciones del residuo de arena de fundición evaluadas y para ambos tiempos de exposición. Sin embargo, la proporción relativa de eleocitos reveló una disminución estadísticamente significativa $(\mathrm{p}<0,001)$ para las mayores concentracuibes y para el período de exposición de 14 días. Contrariamente, la relación de amebocitos se incrementó tanto a mayores concentraciones como a tiempos de exposición. Esta reducción en la proporción de eleocitos es coincidente con la disminución en los Índices LITA y LITAR, los cuales están relacionados al estado nutricional y fisiológico del organismo.

Este cambio en la proporción de los diferentes tipos de celomocitos podría ser comprendido como una respuesta fisiológica al estrés químico provocado por la exposición al residuo. Ha sido observado que la proporción eleocitos del oligoqueto $D$. veneta disminuyó en organismos sometidos a exposición dérmica durante tres días a $\mathrm{Cd}$ y $\mathrm{Cu}$ (Olchawa et al, 2006). Asimismo, otros autores han demostrado que la relación entre los distintos tipos de celomocitos en diferentes especies de oligoquetos se correlaciona con el estado físiológico del organismo, su edad y su estado nutricional (Eyambe et al, 1991; Di Marzio et al, 2005). 


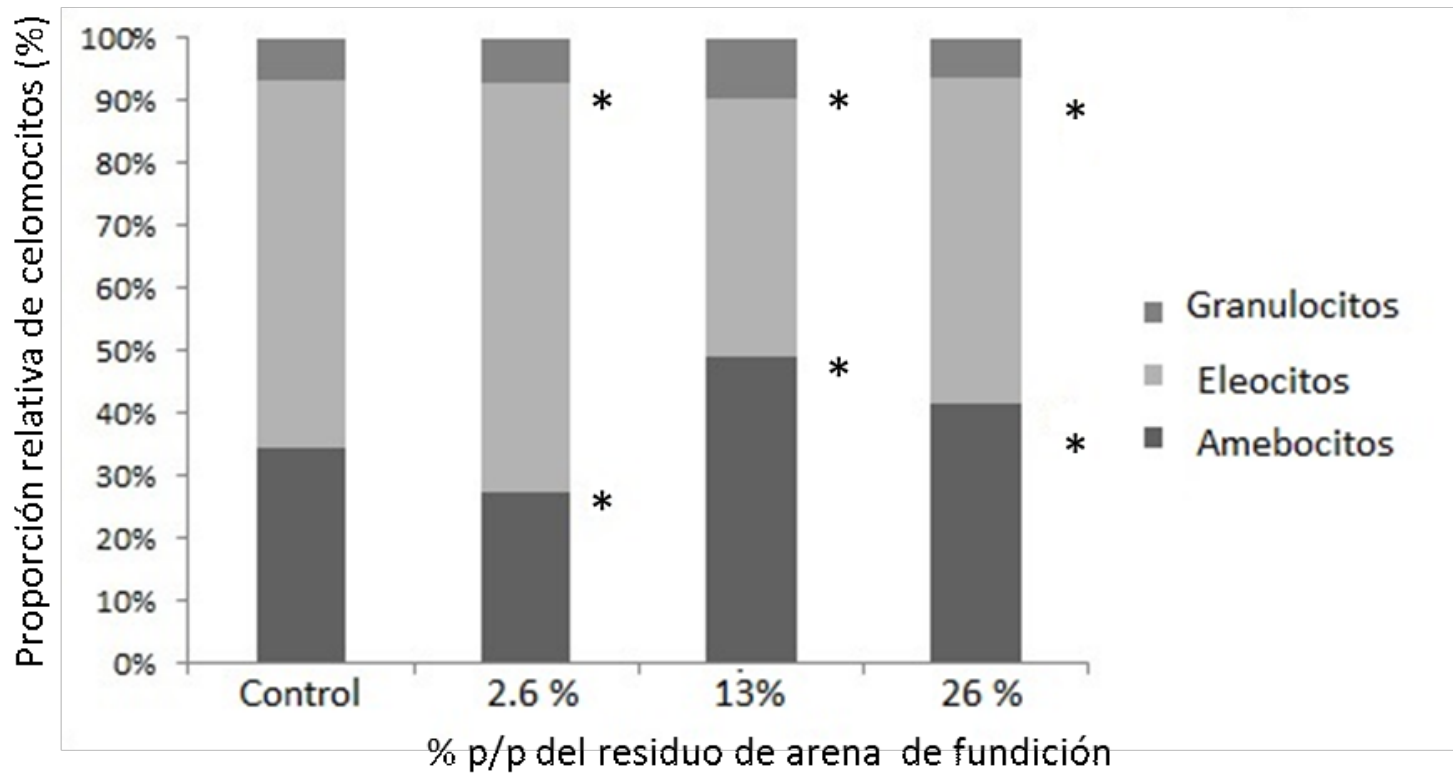

Figura 1. Proporciones celulares de los celomocitos de E. fetida expuestos in vivo al residuo de arena de fundición durante 7 días. * Diferencias estadísticamente significativas con respecto al control, $\mathrm{p}<0,001$

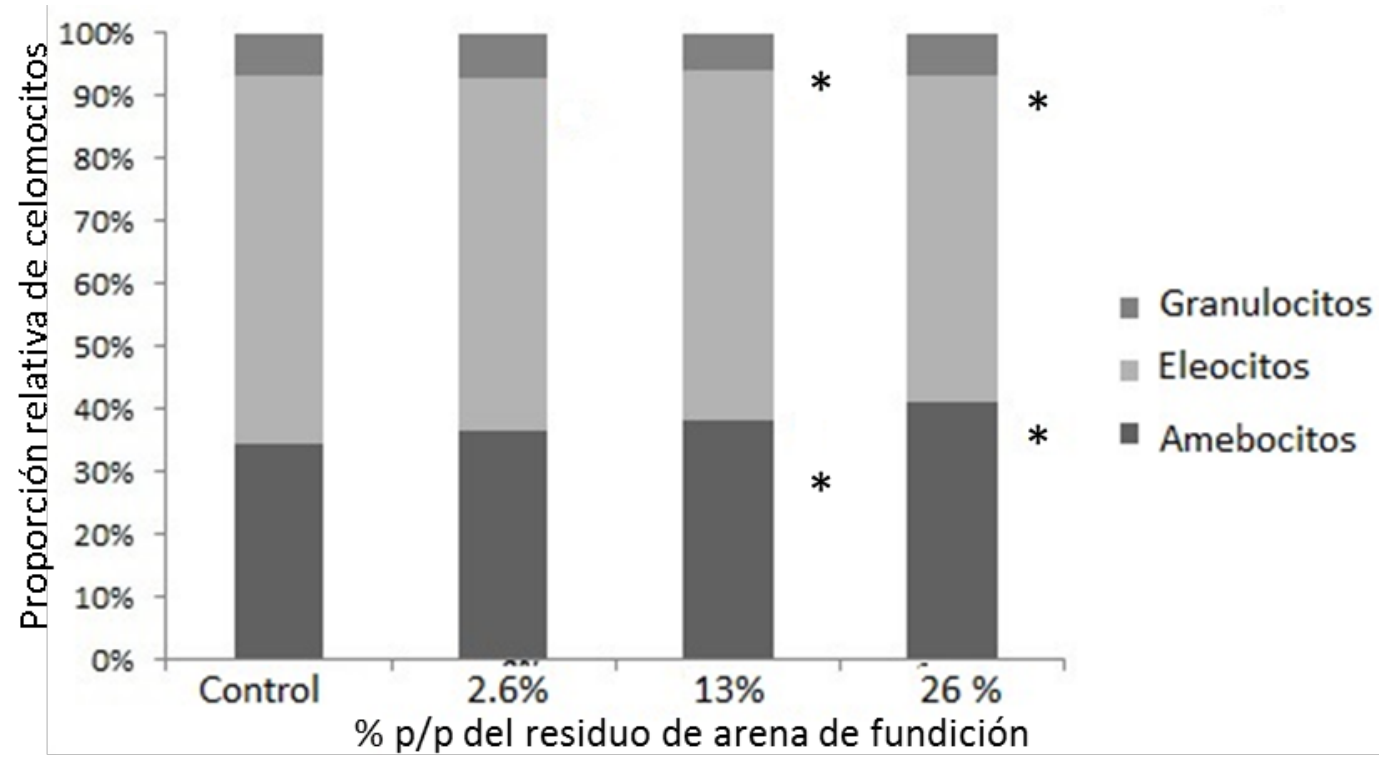

Figura 2. Proporciones celulares de los celomocitos de E. fetida expuestos in vivo al residuo de arena de fundición durante 14 días. * Diferencias estadísticamente significativas con respecto al control, $\mathrm{p}<0,001$ 
Genotoxicidad sobre celomocitos de E. fetida in vivo

La genotoxicidad del residuo industrial correspondiente a la arena de función fue evaluada mediante el ensayo cometa. Los resultados correspondientes a los tiempos de exposición de 7 y 14 días pueden observarse en la Figura 3 y Figura 4, respectivamente.

A los 7 días de exposición al residuo de arena de fundición, el daño al ADN se incrementó de manera estadísticamente significativa en todas las concentraciones ensayadas con respecto al control $(\mathrm{p}<0,001)$. En el caso de los organismos de E. fetida expuestos durante 14 días, aquellos que sobrevivieron a la exposición exhibieron una elevada tasa de citotoxicidad en sus celomocitos (Tabla 3). A raíz de este hecho, sólo fue posible la determinación de genotoxicidad en la menor concentración del residuo correspondiente a 2,6\% p/p. La migración del ADN resultó ser mayor y estadísticamente significativa $(p<0,001)$ en los organismos expuestos comparados con los organismos del grupo control.

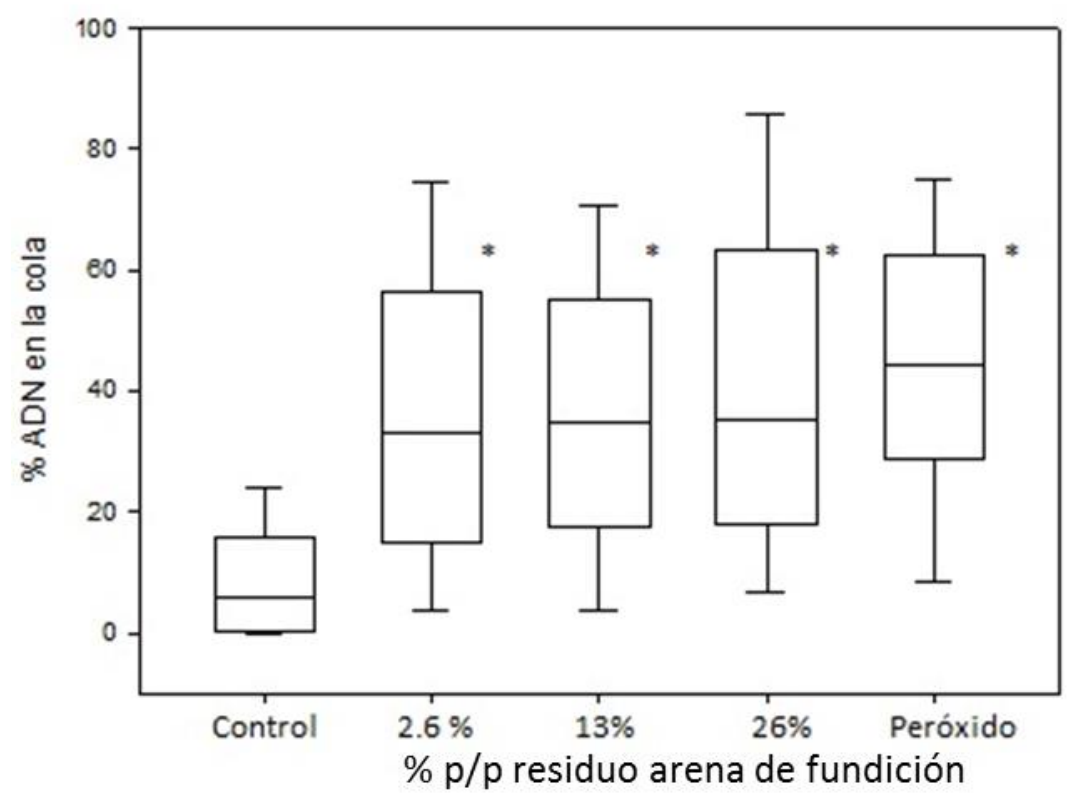

Figura 3. Genotoxicidad del residuo de arena de fundición en celomocitos de E. fetida expuestos durante 7 días de manera in vivo. Los límites del "boxplot" representan los cuartiles $25 \%$ y $75 \%$, mientras que la línea central corresponde a la mediana de los valores. Las barras indican los valores mínimos y máximos.* Diferencias estadísticamente significativas con el control, $\mathrm{p}<0,001$ 


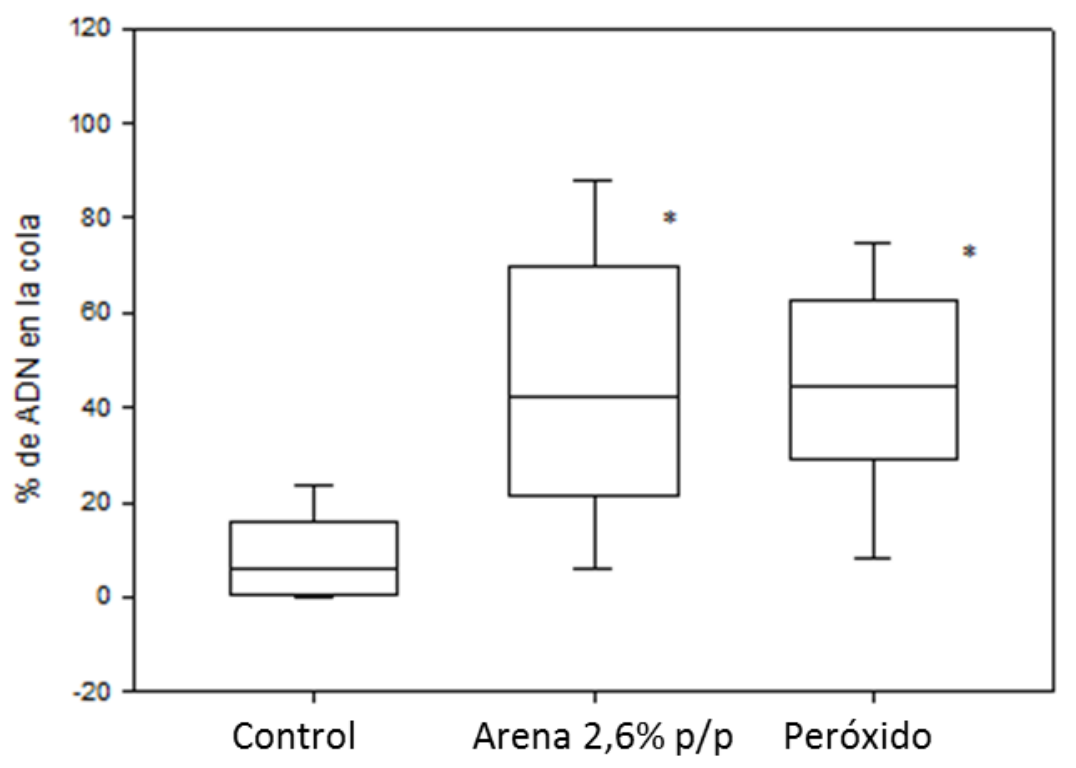

Figura 4. Genotoxicidad del residuo de arena de fundición en celomocitos de E. fetida expuestos durante 14 días de manera in vivo. Los límites del "boxplot" representan los cuartiles $25 \%$ y $75 \%$, mientras que la línea central corresponde a la mediana de los valores.

Las barras indican los valores mínimos y máximos. *Diferencias estadísticamente significativas con el control, $\mathrm{p}<0,001$

Muchos contaminantes con acción genotóxica pueden ser introducidos en el suelo mediante actividades antropogénicas, tales como la inadecuada disposición de residuos industriales, entre otras (Chen et al, 2004). Dichos compuestos pueden no sólo inducir carcinogénesis, teratogénsis y embriotoxicidad en animales sino que, fundamentalmente, pueden alterar la salud del ecosistema (Quiao et al, 2007). Dentro de este grupo de compuestos podemos encontrar a los metales pesados. El Cd ha demostrado ser genotóxico para los vertebrados (Hartwig, 1995). Se ha comprobado su efecto mutagénico y carcinógeno en diferentes modelos celulares y animales (WHO, 1992) y ha sido clasificado como cancerígeno para humanos y mamíferos por la IARC (1993). El Cr y el Ni también han sido reconocidos como carcinógenos para la misma entidad (IARC, 1990). Estudios previos conducidos por la Organización Mundial de la Salud han manifestado la acción genotóxica del Cr en diferentes sistemas in vitro e in vivo, enfatizando la vinculación entre la genotoxicidad del mismo y su estado de oxidación (WHO, 1988). En el caso del Pb también ha sido demostrada su capacidad de inducir genotoxicidad en modelos in vivo e in vitro (WHO, 1995).

En el caso de ejemplares de E. fetida expuestos in vivo para la detección del daño genotóxico inducido por diferentes metales utilizando el ensayo cometa, éste ha revelado ser una 
herramienta sensible para la identificación y cuantificación de la genotoxicidad tal como fuera observado previamente (Faust et al, 2004; Quiao et al, 2007; Bonnard et al, 2009). La aplicación de este ensayo permite detectar niveles bajos de daño en el material genético (Tice et al, 2000) por lo que su vinculación con los efectos observados a niveles supraindividuales es una poderosa herramienta en la evaluación de matrices complejas (Cotelle y Ferard, 1999; Jha, 2008; Collins et al, 2008).

Así, el ensayo cometa ha sido una herramienta utilizada para la detección de daño genotóxico inducida por metales. Su aplicación en celomocitos de oligoquetos es relevante debido a que por tratarse de células en suspensión en el fluido celómico, las mismas reflejan una exposición integral del organismo (Adamowiz, 2005; Manerikar et al, 2011; Di Marzio y Sáenz, 2013). En este aspecto, la evaluación de genotoxicidad aplicando el ensayo cometa en celomocitos de E. fetida ha mostrado ser una herramienta sensible para la detección de daño genotóxico originado por diferentes metales. Fourie et al (2007) han comprobado que de las especies potenciales a ser aplicadas para la determinación de genotoxicidad en suelos, E. fetida es la más sensible. En este estudio se comparó la inducción de daño genotóxico mediante el ensayo cometa en cinco especies de lombrices de tierra Amynthasdy fringens, Aporrectodea caliginosa, Dendodrilus rubidus, E. fetida y Microchaetus benhami expuestas a Cd.

Bigorne et al (2010) observaron un incremento en el daño genotóxico inducido por exposición de organismos de E. fetida durante 2 y 4 días a diferentes concentraciones de $\mathrm{Cr}$ (III) y $\mathrm{Cr}$ (IV) en suelo artificial OECD. Wu et al (2012) han demostrado que tanto el $\mathrm{Pb}$ como el $\mathrm{Cd}$ son capaces de inducir daño genotóxico, evaluado mediante el ensayo cometa en celomocitos de E. fetida expuestos durante 7 días. Voua Otomo et al (2014) han demostrado la existencia de un incremento de la genotoxicidad inducido por Cd y $\mathrm{Zn}$ y su mezcla en organismos de $E$. andrei expuestos en suelo artificial OECD durante 28 días.

Li et al (2009) advirtieron un incremento en el daño genotóxico en celomocitos de E. fetida expuestos durante 7 días a suelos artificialmente contaminados con $\mathrm{Pb}$ y $\mathrm{Cd}$ evidenciado mediante el ensayo cometa.

Los resultados obtenidos coinciden con diferentes estudios, ya que la exposición a la matriz sólida correspondiente al residuo arena de fundición incrementa la migración del material genético de los celomocitos de E. fetida expuestos durante 7 y 14 días. Este residuo, especialmente, se caracteriza por la presencia de metales tales como el $\mathrm{Fe}, \mathrm{Pb}, \mathrm{Zn}, \mathrm{Cr}, \mathrm{y} \mathrm{Ni}$ (Tabla 1). 


\subsubsection{Fracción líquida-Elución}

\subsection{Parámetros fisicoquímicos}

La elución acuosa del residuo de arena de fundición fue químicamente caracterizada por la determinación de los siguientes parámetros: $\mathrm{pH}$, contenido de amonio, COT, DQO y la cuantificación de los siguientes metales: $\mathrm{Fe}, \mathrm{Al}, \mathrm{Cr}, \mathrm{Pb}, \mathrm{As}, \mathrm{Zn}, \mathrm{Cu}$ y Ni. Los valores obtenidos para estas determinaciones se encuentran expresados en la Tabla 5. La medición de pH de la elución acuosa del residuo de arena de fundición reveló un carácter ácido de la misma. La concentración de $\mathrm{N}$ analizada como $\mathrm{NH}_{3}-\mathrm{N}$ en la elución acuosa del residuo de arena de fundición resultó ser de 16,4 mg/L. El análisis de los parámetros DQO y COT arrojó resultados de 299 y 13,7 g/L, respectivamente. La cuantificación de metales en la elución acuosa evidenció que el metal presente en mayor proporción es el $\mathrm{Pb}$ con una concentración de $5 \mathrm{mg} / \mathrm{L}$ seguido por el Fe con una concentración de 1,2 mg/L. Otros metales fueron cuantificados en bajas concentraciones tales como el Al, As y Zn, Cu, Cr y Ni.

Tabla 5. Parámetros fisicoquímicos de la elución acuosa del residuo de arena de fundición. Valores expresados en $\mathrm{mg} / \mathrm{L}$

\begin{tabular}{cc}
\hline & Arena de Fundición \\
\hline $\mathrm{pH}$ & 4,3 \\
$\mathrm{NH}_{3}-\mathrm{N}$ & 16,4 \\
$\mathrm{NH}_{4}$ & 21,2 \\
$\mathrm{NH}_{3}$ & 20 \\
$\mathrm{COT}$ & 13,7 \\
$\mathrm{DQO}$ & 299 \\
$\mathrm{Fe}$ & 1,2 \\
$\mathrm{Al}$ & 0,3 \\
$\mathrm{Cr}$ & 0,05 \\
$\mathrm{~Pb}$ & 5 \\
$\mathrm{As}$ & 0,1 \\
$\mathrm{Zn}$ & 0,1 \\
$\mathrm{Cu}$ & 0,09 \\
$\mathrm{Ni}$ & 0,04 \\
\hline
\end{tabular}




\subsection{Ensayos con plántulas de $V$. faba}

Las plántulas de $V$. faba fueron expuestas durante $48 \mathrm{~h}$ a diferentes concentraciones de la elución acuosa del resido de arena industrial correspondientes a $6 ; 12,5 ; 25,50$ y $100 \% \mathrm{v} / \mathrm{v}$ y al Medio Hoagland, utilizado como control negativo. Tanto en las plántulas expuestas cómo en las plántulas control se determinó la biomasa. En forma conjunta, en las raíces de estas plántulas se cuantificó, por un lado, el nivel de actividad de dos enzimas relacionadas al estrés oxidativo, CAT y GPOD, y por otro lado, el nivel de peroxidación de lípidos.

\section{Efectos sobre la biomasa}

El efecto sobre la biomasa de las plántulas de $V$. faba expuestas durante $48 \mathrm{~h}$ a las diferentes concnetraciones de la elución acuosa del residuo de arena de fundición se presenta en la Tabla 6. Ninguna de las concentraciones de la elución utilizadas provocaron un cambio estadísticamente significativo en la biomasa de las plántulas expuestas comparadas con el control ( $\mathrm{p}>0,05)$. El efecto observado, cuando se considera la biomasa como parámetro, evidenció una baja sensibilidad relativa cuando se compara con otros biomarcadores, a pesar de su alta significancia ecológica. Este patrón de resultados también fue observado por otros autores al exponer plántulas de $V$. faba a soluciones con diferentes concentraciones de $\mathrm{Cd}$ (Cordova Rosa et al, 2003).

\section{Efectos sobre enzimas del estrés oxidativo CAT y GPOD}

Se evaluó el nivel de actividad de dos enzimas relacionadas al estrés oxidativo: CAT y GPOD luego de $48 \mathrm{~h}$ de exposición de las plántulas de $V$. faba a todas las concentraciones de la elución del residuo de arena de fundición. Los resultados obtenidos para la cuantificación de la actividad enzimática se presentan en la Tabla 6.

La actividad de la enzima CAT fue inhibida de manera estadísticamente significativa $(\mathrm{p}<0,05)$ sólo a la concentración correspondiente al 100\% v/v de la elución, con un $65 \%$ de inhibición con respecto a las plantas control. A las concentraciones correspondientes al 25 y $50 \% \mathrm{v} / \mathrm{v}$ se observó una tendencia a la pérdida de la actividad de esta enzima. Al 6\% v/v de la elución se observó una inducción del $53 \%$ en la actividad de la misma, sin ser este fenómeno estadísticamente significativo con respecto al control ( $p>0,05)$. 
Tabla 6. Efectos expresados como media y desviación estándar (entre paréntesis), sobre la biomasa ( $\mathrm{g}$ de peso fresco), actividad enzimática ( $\mathrm{mM}$ de $\mathrm{H}_{2} \mathrm{O}_{2} / \mathrm{mg}$ proteína/min) y peroxidación lipídica ( $\mu \mathrm{mol} \mathrm{MDA/g} \mathrm{de} \mathrm{peso} \mathrm{fresco)} \mathrm{de} \mathrm{la} \mathrm{elución} \mathrm{acuosa} \mathrm{del} \mathrm{residuo} \mathrm{de} \mathrm{arena} \mathrm{de}$ fundición en plántulas de $V$. faba.

\begin{tabular}{lcccccc}
\hline Biomarcador & & \multicolumn{5}{c}{$\%$ v/v Elución } \\
\cline { 3 - 7 } & Control & 6 & 12,5 & 25 & 50 & 100 \\
\hline Biomasa & 1,19 & 1,41 & 1,13 & 1,05 & 1,39 & 1,02 \\
& $(0,06)$ & $(0,35)$ & $(0,45)$ & $(0,13)$ & $(0,31)$ & $(0,19)$ \\
CAT & 13,21 & 20,04 & 13,33 & 6,00 & 8,33 & $4,66^{* *}$ \\
& $(6,74)$ & $(4,76)$ & $(1,00)$ & $(1,06)$ & $(0,57)$ & $(0,57)$ \\
GPOD & 3,17 & 2,92 & 4,37 & 2,40 & 2,89 & 2,33 \\
& $(1,26)$ & $(0,53)$ & $(1,20)$ & 1,00 & $(0,52)$ & $(1,23)$ \\
MDA & 30,28 & 28,54 & 24,74 & 35,49 & 23,96 & 21.23 \\
& $(3,13)$ & $(5,06)$ & $(8,18)$ & $(12,62)$ & $(8,3)$ & $(6,63)$ \\
\hline
\end{tabular}

** Diferencias estadísticamente significativas con el control, $\mathrm{p}<0,05$

Es conocido que la acción de algunos metales modifica la acción de enzimas asociadas al estrés oxidativo. Esta afirmación se basa en estudios que demuestran que un grupo de metales tales como el $\mathrm{Fe}, \mathrm{Cu}, \mathrm{Cr}$ y $\mathrm{V}$, entre otros, presentan actividad pro-oxidante, siendo su mecanismo de acción la producción de ERO (Di Marzio y Sáenz, 2013).

H.J.H Fenton descubrió en 1894 que varios metales tienen la propiedad especial de transferir oxígeno actuando como agentes catalíticos en una reacción de descomposición del peróxido de hidrógeno, generando especies altamente reactivas como radicales hidroxilos y aniones hidróxidos. Esta reacción se llamó reacción de Fenton y está representada por la siguiente ecuación:

$\mathrm{Fe}^{2+}+\mathrm{H}_{2} \mathrm{O}_{2} \rightarrow \mathrm{Fe}^{3+}+\mathrm{OH} \cdot+\mathrm{OH}^{-}$

$\mathrm{El} \mathrm{Fe}^{2+}$ es oxidado por el peróxido de hidrógeno a $\mathrm{Fe}^{3+}$, con la formación de radical hidroxilo $\mathrm{y}$ anión hidroxilo.

Posteriormente, el $\mathrm{Fe}^{3+}$ es reducido nuevamente por el peróxido de hidrógeno a $\mathrm{Fe}^{2+}$ y la producción de radical peróxido y liberación de un protón libre, tal como se indica a continuación.

$\mathrm{Fe}^{3+}+\mathrm{H}_{2} \mathrm{O}_{2} \rightarrow \mathrm{Fe}^{2+}+\mathrm{OOH} \cdot+\mathrm{H}^{+}$ 
La reacción de Fenton fue descripta para el $\mathrm{Fe}$ y las especies que participan son $\mathrm{Fe}^{2+} / \mathrm{Fe}^{3+}$. Cuando otros metales de transición actúan como catalizadores (las reacciones llamadas tipo Fenton), las parejas redox propuestas son: $\mathrm{Cu}^{1+} / \mathrm{Cu}^{2+}, \mathrm{Cr}^{2+} / \mathrm{Cr}^{3+}, \mathrm{Cr}^{5+} / \mathrm{Cr}^{6+} \mathrm{y} \mathrm{V}^{4+} / \mathrm{V}^{5+}(\mathrm{Schröder}$ y Krutmann, 2005).

El Fe es el metal que se encontró en mayor concentración en la elución del residuo de arena de fundición. Si bien se desconoce el estado de oxidación del Fe en la muestra evaluada, esta reacción podría explicar la estimulación de la enzima CAT dada por el 100\% v/v de la elución.

La actividad de la enzima GPOD no evidenció efectos inhibitorios o estimulatorios en ninguna de las concentraciones ensayadas respecto a la actividad en las raíces de las plántulas control $(\mathrm{p}>0,05)$.

Las enzimas peroxidasas se encuentran ampliamente distribuidas en diferentes reinos. En plantas, las peroxidadas están involucradas en varios procesos metabólicos tales como como la biosíntesis de lignina, biosíntesis de etileno, actúan como funguicidas y bactericidas, y en la depuración de $\mathrm{H}_{2} \mathrm{O}_{2}$, entre otras funciones (Mullineaux et al, 2008). En este sentido, estas enzimas pueden ser consideradas menos específicas debido a su participación en diferentes procesos metabólicos. Debido a este hecho, podría considerarse que estas enzimas podrían ser menos sensibles a la exposición de sustancias tóxicas. En coincidencia con nuestros hallazgos, Chaoui et al (1997) observaron que la actividad enzimática de la peroxidasa en raíces de Phaseolus vulgaris expuestas a Cd y Zn no fue modificada.

Los resultados obtenidos indicaron que los marcadores bioquímicos, tales como las enzimas de estrés oxidativo pueden ser utilizados para detectar alteraciones tempranas en plantas antes de que se evidencie una disminución apreciable en la biomasa.

\section{Efectos sobre peroxidación lipídica}

Los niveles de MDA en raíces de las plántulas expuestas a diferentes concentraciones de la elución del residuo de arena de fundición se muestran en la Tabla 6. La elución del residuo de arena no provocó una modificación estadísticamente significativa $(\mathrm{p}>0,05)$ en el contenido de MDA en comparación con el control, independientemente de las concentraciones ensayadas. Respecto a la falta de respuesta del biomarcador de peroxidación de lípidos en nuestras condiciones de ensayo cabe aclararse que las plántulas de $V$. faba estuvieron expuestas durante $48 \mathrm{~h}$, mientras que otros autores encontraron un incremento en este biomarcador a mayores tiempos de exposición. Wang et al (2008), observaron un incremento en la peroxidación de lípidos en plántulas de $V$. faba expuestas durante 30 días a concentraciones 
de $\mathrm{Pb}$ de $125 \mathrm{mg} / \mathrm{kg}$ en suelo artificialmente contaminado. Wu et al (2003) estudiaron el nivel de peroxidación de lípidos en cuatro genotipos de cebada encontrando resultados positivos luego de 30 días de exposición a concentraciones de Cd de 1 y $5 \mu \mathrm{M}$.

\subsection{Ensayos de cito y genotoxicidad en celomocitos de E. fetida ex vivo}

La toxicidad de la elución del residuo de arena de fundición fue evaluada sobre celomocitos de E. fetida expuestos de manera ex vivo durante $1 \mathrm{~h}$ mediante la determinación de citotoxicidad, índices tróficos, proporciones celulares y genotoxicidad.

\section{Citotoxicidad}

La citotoxicidad de la elución acuosa del residuo de arena de fundición fue determinada mediante el ensayo con Azul de Tripán. Los resultados de este indicador inducidos por las diferentes diluciones de la elución son presentados en la Tabla 7. Todas las concentraciones ensayadas provocaron un incremento estadísticamente significativo $(p<0,05)$ en la citotoxicidad de los celomocitos expuestos ex vivo durante $1 \mathrm{~h}$. El análisis de los datos reveló que los mismos pueden dividirse en cuatro grupos diferenciales $(\mathrm{p}<0,05)$. Las concentraciones correspondientes a 1,$5 ; 3$ y $12,5 \% \mathrm{v} / \mathrm{v}$ constituyeron el primer grupo, mientras que el segundo grupo se formó por las concentraciones correspondientes a 6 y $50 \% \mathrm{v} / \mathrm{v}$. En tanto las concentraciones de 25 y $100 \% \mathrm{v} / \mathrm{v}$ se separaron en forma independiente.

Tabla 7. Citotoxicidad inducida por la elución del residuo de arena de fundición en celomocitos de E. fetida expuestos de manera ex vivo durante $1 \mathrm{~h}$. Valores expresados como $\%$ de células no viables

\begin{tabular}{cc}
\hline$\% \mathrm{v} / \mathrm{v}$ & Citotoxicidad $(\%)$ \\
\hline 0 & 13 \\
1,5 & $48^{* *}$ \\
3 & $52^{* *}$ \\
6 & $70^{* *}$ \\
12,5 & $54^{* *}$ \\
25 & $79^{* *}$ \\
50 & $70^{* *}$ \\
100 & $85^{* *}$
\end{tabular}

**Diferencias estadísticamente significativas, $\mathrm{p}<0,05$ 
A partir de los resultados de la citotoxicidad inducida por las eluciones se estimó la CL50-1h para los celomocitos, la cual resultó ser de $2,12 \% \mathrm{v} / \mathrm{v}$ con un intervalo de confianza del $95 \%$ de 0,62-7,22. La CMEO para la viabilidad celular resultó ser de 1,5\% v/v.

La viabilidad de los celomocitos de E. fetida podría verse afectada por la presencia de metales en la elución acuosa. Antes de la acción citotóxica por parte de la elución, la célula puede verse comprometida por alteración de la permeabilidad de su sistema de membranas. En este aspecto, un biomarcador utilizado frecuentemente para evaluar la viabilidad celular es la retención del colorante rojo neutro en la membrana lisosomal (Svendsen et al, 1997). Este ensayo permite cuantificar el daño celular ya que sólo los lisosomas íntegros pueden retener el colorante supravital, así la estabilidad de la membrana decrece en respuesta al estrés, incrementando la permeabilidad de membrana (Weeks y Svendsen, 1996).

Maboeta et al (2004) han observado que funguicidas basados en $\mathrm{Cu}$ ocasionaron una pérdida de la estabilidad de la membrana lisosomal en organismos de E. fetida expuestos de manera in vivo. Gastaldi et al (2007) han observado un incremento en la permeabilidad de la membrana lisosomal en respuesta a la exposición de organismos de E. andrei a $\mathrm{Cu}$.

Coincidente con estos resultados, la viabilidad de los celomocitos de E. fetida expuestos a la elución del residuo de arena de fundición, el cual presentó diferentes metales, se observó disminuida para todas las concentraciones evaluadas.

\section{Índices tróficos}

Los índices tróficos para los celomocitos expuestos de manera ex vivo pueden observarse en la Tabla 8.

El índice LITA tiende a decrecer de manera estadísticamente significativa con respecto al control $(\mathrm{p}<0,001)$ a todas las concentraciones evaluadas. En concordancia, el Índice LITAR también presenta una disminución estadísticamente significativa $(\mathrm{p}<0,001)$ a todas las concentraciones de exposición ensayadas. El índice ICCT se comporta como el biomarcador menos sensible ya que se modifica de manera estadísticamente significativa $(p<0,001)$ a partir de la concentración correspondiente al $6 \%$ v/v de la elución. Debido a la sensibilidad de los Índices LITA y LITAR (CENO 1,5\% v/v) y del corto tiempo de ensayo para la obtención de estos biomarcadores ( $1 \mathrm{~h}$ de exposición), estos índices, junto con la evaluación de la citotoxicidad, podrían ser recomendados como biomarcadores de efecto para ser incluidos en protocolos técnicos contemplados en las normativas ambientales. 
Tabla 8. Índices tróficos con su desviación estándar (entre paréntesis) para la elución del residuo de arena de fundición en celomocitos de E. fetida expuestos ex vivo durante $1 \mathrm{~h}$

\begin{tabular}{cccc}
\hline $\begin{array}{c}\text { Elución de arena de } \\
\text { fundición }(\% \mathrm{v} / \mathrm{v})\end{array}$ & LITA & LITAR & ICCT \\
\hline 0 & 0,59 & 1,8 & 6,1 \\
& $(0,04)$ & $(0,08)$ & $(0,05)$ \\
1,5 & $0,52^{* *}$ & $1,12^{* *}$ & 6,0 \\
& $(0,01)$ & $(0,02)$ & $(0,02)$ \\
3 & $0,53^{* *}$ & $1,27^{* *}$ & 5,98 \\
& $(0,01)$ & $(0,02)$ & $(0,02)$ \\
\multirow{2}{*}{6} & $0,52^{* *}$ & $1,26^{* *}$ & $5,88^{* *}$ \\
& $(0,03)$ & $(0,05)$ & $(0,02)$ \\
12,5 & $0,51^{* *}$ & $1,23^{* *}$ & 5,92 \\
& $(0,02)$ & $(0,05)$ & $(0,03)$ \\
25 & $0,54^{* *}$ & $1,16^{* *}$ & $5,62^{* *}$ \\
& $(0,02)$ & $(0,04)$ & $(0,04)$ \\
50 & $0,53^{* *}$ & $1,20^{* *}$ & $5,80^{* *}$ \\
& $(0,03)$ & $(0,07)$ & $(0,03)$ \\
& $0,43^{* *}$ & $0,94^{* *}$ & $5,66^{* *}$ \\
& $(0,02)$ & $(0,05)$ & $(0,02)$ \\
& & &
\end{tabular}

**Diferencias estadísticamente significativas, $\mathrm{p}<0,05$

\section{Proporciones celulares}

Se determinaron las proporciones celulares de los celomocitos de E. fetida expuestos ex vivo durante $1 \mathrm{~h}$ a la elución del residuo de arena de fundición. Los resultados de los mismos pueden observarse en la Figura 5. La proporción de eleocitos disminuyó de manera estadísticamente significativa $(\mathrm{p}<0,001)$ a medida que crecieron las concentraciones de exposición a la elución. Contrariamente, los amebocitos incrementaron su proporción de manera estadísticamente significativa $(\mathrm{p}<0,001)$ a concentraciones mayores al $6 \% \mathrm{v} / \mathrm{v}$ de la elución. Los granulocitos sufrieron un aumento estadísticamente significativo $(p<0,001)$ en su proporción sólo a la concentración correspondiente al 100\% v/v de la elución. Estos cambios en las proporciones celulares en un tiempo corto de exposición podrían revelar cambios 
fisiológicos tempranos que evidencian efectos tóxicos producidos por la elución del residuo de arena de fundición.

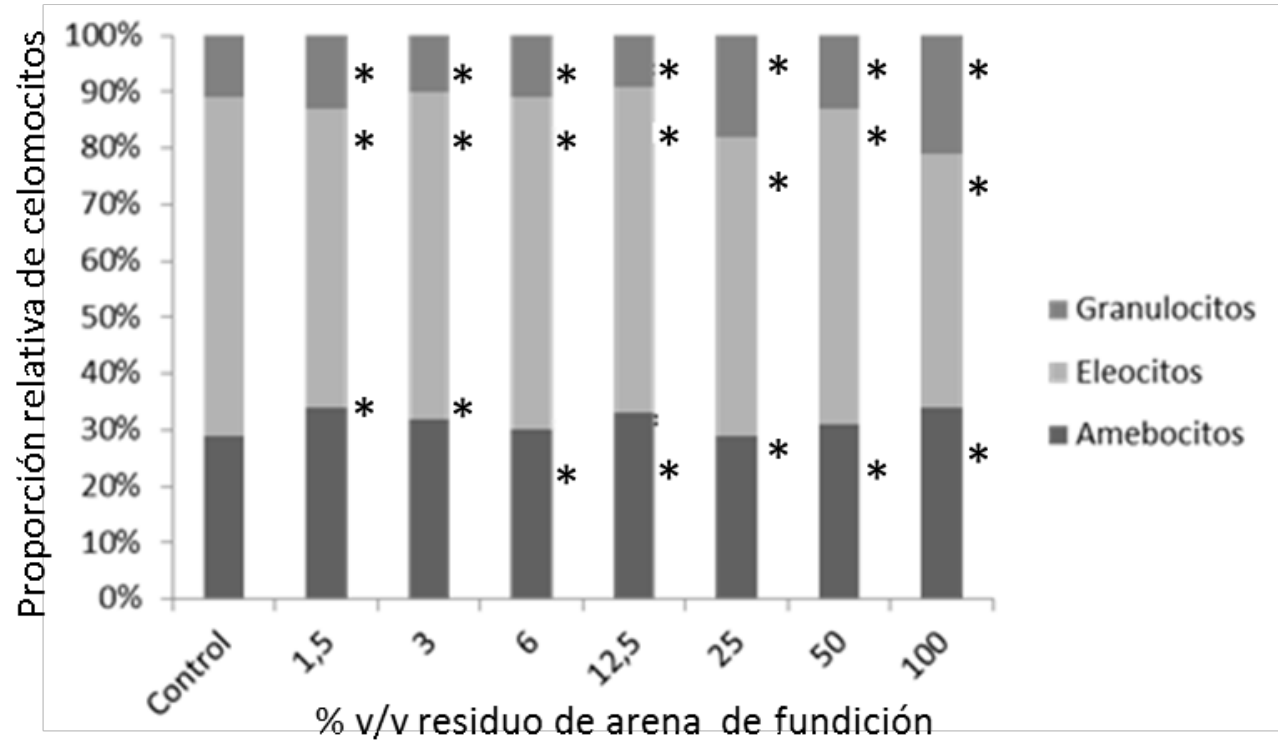

Figura 5. Proporciones celulares de celomocitos de E. fetida expuestos ex vivo durante $1 \mathrm{~h}$ a la elución del residuo de arena de fundición. * Diferencias estadísticamente significativas con respecto al control, $\mathrm{p}<0,001$

Genotoxicidad en celomocitos de E. fetida ex situ

A partir de los resultados obtenidos en el ensayo de citotoxicidad y de la estimación de la CL50-1h, se evaluó el efecto genotóxico para dos concentraciones de la elución del residuo de arena de fundición. Estas concentraciones correspondieron a la CL50-1h y CL50-1h/2 con valores de 2,12 y $1,06 \% \mathrm{v} / \mathrm{v}$, respectivamente. Los resultados para la cuantificación del daño genotóxico mediante el ensayo cometa se presentan en la Figura 6. Ambas concentraciones ensayadas ejercieron un efecto genotóxico estadísticamente significativo $(p<0,001)$ en celomocitos de E. fetida expuestos ex vivo durante $1 \mathrm{~h}$.

Los valores de las medianas de la variable \% de ADN en cola, es decir, el ADN presente en la cola del cometa, resultaron ser de 45,2 y $31,9 \%$ para las concentraciones de 1,06 y $2,12 \% \mathrm{v} / \mathrm{v}$ de la elución, respectivamente. Este mayor efecto observado a la menor concentración de la elución ensayada podría ser explicado por el fenómeno de hormesis (Calabrese y Baldwin, 2001; Calabrese, 2001; 2005). Estos resultados son concordantes con las respuestas halladas en estudios previos en ejemplares de E. fetida expuestos a metales (Spurgeon et al, 2004; Zhang et al, 2009). En estos trabajos se observó una mayor respuesta tóxica a bajas 
concentraciones de exposición a metales pesados tales como $\mathrm{Cd}$ y $\mathrm{Cu}$, proponiendo una respuesta del tipo hormética como la por nosotros sugerida.

Estos resultados evidenciaron la importancia de la evaluación de la genotoxicidad de las eluciones acuosas de los residuos debido a que esta fracción representa la movilidad de las sustancias potencialmente peligrosas. Así, las sustancias presentes en los residuos que son depositados en los suelos (Newman y Clements, 2008) pueden migrar a otros compartimentos ambientales llegando a aguas subterráneas por infiltración, o a cuerpos de agua por escorrentía superficial (Moriarty, 1985; Widziewicz et al, 2011). Di Marzio et al (2007) han demostrado el efecto genotóxico de las eluciones acuosas de suelos industrialmente contaminados mediante la aplicación del ensayo cometa en celomocitos de E. fetida.

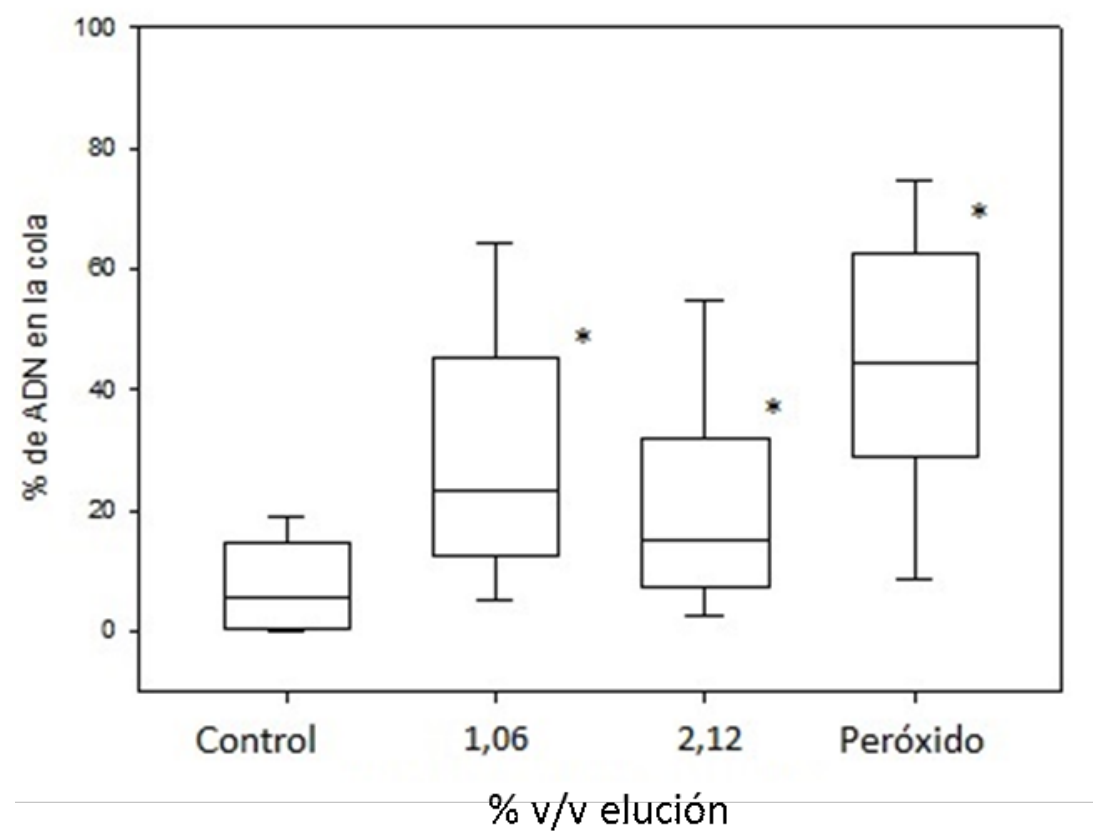

Figura 6. Genotoxicidad de la elución del residuo de arena de fundición en celomocitos de $E$. fetida expuestos ex vivo durante $1 \mathrm{~h}$. Los límites del "boxplot" representan los cuartiles $25 \% \mathrm{y}$ $75 \%$, mientras que la línea central corresponde a la mediana de los valores. Las barras indican los valores mínimos y máximos. * Diferencias estadísticamente significativas con el control,

$$
\mathrm{p}<0,001
$$

Las arenas de fundición son producidas en grandes cantidades en la República Argentina. Habitualmente en la ciudad de Tandil (Buenos Aires, Argentina) dónde estos residuos son generados en grandes cantidades, son depositados en canteras o cavas abandonadas. Estas cavas de cantera están formadas por rocas de origen ígneo, con un basamento cristalino 
granítico. Estas rocas se presentan diaclasadas lo que hace posible que cualquier elemento químico pueda lixiviar de las arenas usadas de moldeo y circular en el medio. El mayor grado de diaclasamiento o la presencia de fisuras provocadas por la actividad minera aumentan la permeabilidad propia del basamento cristalino, permitiendo al agua infiltrar más velozmente (Miguel et al, 2006).

Los resultados de las determinaciones fisicoquímicas evidenciaron la presencia de metales que deben quedar sujetos a evaluación según lo establecido en el Anexo I de la Ley Nacional $\mathrm{N}^{\circ}$ 24.051. Dentro de este Anexo se encuentran incluidos los metales $\mathrm{Cr}, \mathrm{Cu}, \mathrm{Zn}$ y $\mathrm{Pb}$ en las categorías Y21, Y22, Y23, Y31, todos presentes en la muestra entera del residuo industrial correspondiente a la arena de fundición. Sin embargo, las concentraciones medidas no explicarían el grado de toxicidad que manifestó la muestra (Tabla 9). Los resultados obtenidos demuestran que caracterizar toxicológicamente un residuo solamente mediante el análisis químico resulta inadecuado ya que no permite estimar su toxicidad real cuando es tratado como una muestra que representa una mezcla de sustancias que interactúan con la matriz que las incluye (Ferrari et al, 1999; Wilke et al, 2008; Pandard y Römbke, 2013). Así las observaciones realizadas en el presente trabajo avalan que resulta de fundamental importancia evaluar en conjunto los análisis químicos de las matrices sólidas estudiadas y las respuestas biológicas antes de definir su disposición final en el ambiente, en concordancia con otros autores (Moser y Römbke, 2005). 
Tabla 9. Resumen de los parámetros evaluados para el residuo de arena de fundición (Nd:no determinado)

\begin{tabular}{ccc}
\hline Variable & CMEO & CE/CL50 (IC 95\%) \\
\hline Muestra sólida & $\% \mathrm{p} / \mathrm{p}$ & $59,8(21,9-105,3)$ \\
Germinación en L. sativa & 50 & $\mathrm{Nd}$ \\
Elongación de raíces en L. sativa & 25 & $26(15,7-26,21)$ \\
Mortalidad en E. fetida & & \\
LITA 14 d & 26 & \\
LITAR 14 d & 2,6 & \\
ICCT 14 d & 26 & \\
Proporciones celulares 14 d & 2,6 & \\
Genotoxicidad 14 d & 2,6 & \\
Elución & $\% \mathrm{v} / \mathrm{v}$ & \\
Biomasa en plántulas de $V$. faba & $\mathrm{Nd}$ & \\
CAT & 100 & \\
GPOD & $\mathrm{Nd}$ & \\
Peroxidación de lípidos & $\mathrm{Nd}$ & \\
Citotoxicidad en celomocitos & 1,5 & \\
LITA 1h & 1,5 & \\
LITAR 1h & 1,5 & \\
Proporciones celulares $1 \mathrm{~h}$ & 6 & \\
Genotoxicidad 1h & $6,22)$ \\
\hline
\end{tabular}




\subsubsection{Residuo de cosmética}

\subsubsection{Muestra entera}

\subsection{Parámetros fisicoquímicos}

Para la muestra entera del residuo industrial correspondiente a la industria cosmética se determinaron los siguientes parámetros físicoquímicos: $\mathrm{pH}$, Fracción húmeda, Sólidos volátiles, CRA y COT. Los resultados para estas determinaciones pueden observarse en la Tabla 10. El residuo proveniente de la industria cosmética presentó un $\mathrm{pH}$ de 6,0, evidenciando un carácter ligeramente ácido y un elevado porcentaje de humedad. En cuanto a la proporción de sólidos volátiles, el residuo mostró un 9,1\% y una elevada CRA con un valor de $61,8 \mathrm{~mL} / 100 \mathrm{~g}$ de muestra. El valor de COT para esta muestra fue de 73,3 $\mathrm{mg}$ de $\mathrm{C} / \mathrm{g}$ de muestra.

Tabla 10. Parámetros fisicoquímicos y cuantificación de metales (expresados en $\mathrm{mg} / \mathrm{kg}$ ) del residuo de industria cosmética (muestra entera). CRA expresada como $\mathrm{mL}$ de agua/100 g de muestra. COT expresado como $\mathrm{mg} \mathrm{C/g}$

\begin{tabular}{cc}
\hline Parámetro & Residuo de Cosmética \\
\hline pH & 6,0 \\
Fracción húmeda (\%) & 79,8 \\
Sólidos Volátiles (\%) & 9,1 \\
$\mathrm{CRA}$ & 61,8 \\
$\mathrm{COT}$ & 73,3 \\
$\mathrm{Fe}$ & 86,5 \\
$\mathrm{Cu}$ & 12,8 \\
$\mathrm{Zn}$ & 394,5 \\
$\mathrm{Ni}$ & 22,1 \\
$\mathrm{Cd}$ & 0,2 \\
$\mathrm{Cr}$ & 6,2 \\
$\mathrm{~Pb}$ & 3,4 \\
\hline
\end{tabular}

El análisis cualitativo de los componentes orgánicos de la muestra correspondiente al residuo de cosmética reveló la presencia de diversos compuestos los cuáles se presentan en la Tabla 11. Esta diversidad de sustancias podría ejercer efectos tóxicos por narcosis polar y no polar (Rand, 1995). Los compuestos orgánicos que fueron encontrados en el residuo de la industria 
cosmética se encuentran incluidos en el grupo de los productos farmacéuticos y de cuidado personal (PFCP). Se trata de drogas e ingredientes de la industria cosmética que han revelado ejercer toxicidad sobre los humanos y el ambiente (Reif et al, 2008; Volpe et al, 2012; FattaKasinos et al, 2011; Esplugas et al, 2012). Los PFCP incluyen tanto compuestos orgánicos como inorgánicos. Dentro de los compuestos orgánicos se encuentran hidrocarburos, proteínas, éteres, ésteres, aldehídos, cetonas, alcoholes, ácidos carboxílicos, y algunos derivados complejos producidos por transformaciones bioquímicas (Bogacki et al, 2011). Los compuestos inorgánicos incluyen ácidos, hidróxidos, sales, óxidos y compuestos con metales pesados (Kasprzyk-Hordern et al, 2009). Sustancias tales como grasas, aceites minerales, colorantes orgánicos y sufractantes, también son comúnmente hallados en residuos provenientes de la industria cosmética (Fatta-Kassinos et al, 2011).

Tabla 11. Compuestos orgánicos presentes en el residuo de Cosmética

\begin{tabular}{|c|c|c|c|c|c|}
\hline Compuesto & Kow & Koc & $\begin{array}{c}\mathrm{H} \\
\left(\mathrm{atm} * \mathrm{~m}^{3} * \mathrm{~mol}^{-1}\right)\end{array}$ & CAS & $\begin{array}{c}\text { CL } 50 \\
\text { lombrices } \\
(\mathrm{mg} / \mathrm{kg})\end{array}$ \\
\hline Alcohol diacetona & $-0,34$ & 1,1 & $1,38 \times 10^{-9}$ & $123-42-2$ & 3556,486 \\
\hline $\begin{array}{c}\text { 6,10,14-trimetil-2- } \\
\text { Pentadecanona }\end{array}$ & 6,91 & $1,3 \times 10^{4}$ & $1,23 \times 10^{-2}$ & $502-69-2$ & 50,774 \\
\hline Dodecilciclohexanol & 7,49 & $1,08 \times 10^{4}$ & $1,51 \times 10^{-4}$ & & 33,651 \\
\hline $\begin{array}{c}\text { Propanal } \\
\text { Nonadecano }\end{array}$ & 0,3252 & 2,75 & $8,48 \times 10^{-5}$ & $123-38-6$ & \\
\hline 1-tetradecanol & 5,75 & 1113 & $3,08 \times 10^{-4}$ & $000112-72-2$ & 92,303 \\
\hline Ácido octadecanoinco & & & $4,76 \times 10^{-3}$ & $57-11-4$ & \\
\hline Decametilciclopentasiloxano & 5,71 & $1,45 \times 10^{5}$ & $1,20 \times 10^{-1}$ & $000541-02-6$ & 164,222 \\
\hline Oxaciclohexadecan-2-ona & 6,15 & 5994 & $8,10 \times 10^{-4}$ & $106-02-5$ & \\
\hline
\end{tabular}

\subsection{Ensayos de germinación y elongación de las raíces con L. sativa}

El ensayo de germinación de semillas y elongación de raíces en L. sativa fue utilizado para evaluar los efectos fitotóxicos del residuo de industria cosmética en su forma entera. Las concnetraciones del residuo de cosmética se realizaron con arena inerte de 1,5; 3, 6; 12,5 y $25 \% \mathrm{p} / \mathrm{p}$, dado que ensayos preliminares evidenciaron una inhibición de la germinación del 100\% para las diluciones del 50 y 100\% p/p de la misma.

Los resultados obtenidos en el ensayo de germinación realizados con el residuo de industria cosmética manifestaron que el mismo ejerció un efecto fitotóxico sobre las semillas de $L$. 
sativa. La menor concentración evaluada $(1,5 \% \mathrm{p} / \mathrm{p})$ no provocó efectos estadísticamente significativos $(\mathrm{p}>0,05)$ en la germinación de las semillas expuestas respecto al control. Contrariamente, la concentración correspondiente al 3\% p/p del residuo redujo la germinación de las semillas en un 50\% (p<0,05). Para las concentraciones de $6 ; 12,5$ y $25 \% \mathrm{p} / \mathrm{p}$ del residuo se observó un incremento en la inhibición de la germinación de las semillas estadísticamente significativo $(p<0,05)$ con valores de inhibición de 41,7; 70,8 y 87,5\%, respectivamente (Tabla 12).

Tabla 12. Efecto fitotóxico del residuo de cosmética sobre la germinación de las semillas y la elongación de las raíces en L. sativa

\begin{tabular}{ccccc}
\hline $\begin{array}{c}\text { \% p/p del residuo de } \\
\text { cosmética }\end{array}$ & $\begin{array}{c}\text { Semillas } \\
\text { germinadas/semillas } \\
\text { expuestas }\end{array}$ & $\begin{array}{c}\text { Inhibición } \\
\text { Germinación } \\
(\%)\end{array}$ & $\begin{array}{c}\text { Elongación de } \\
\text { raíces }(\mathrm{cm})\end{array}$ & $\begin{array}{c}\text { Estimulación } \\
\text { elongación de } \\
\text { raíces }(\%)\end{array}$ \\
\hline 0 (Control) & $16 / 20$ & 0 & 2,2 & \\
1,5 & $14 / 20$ & 14,6 & 4,1 & $86,7^{* *}$ \\
3 & $8 / 20$ & $50^{* *}$ & 4,7 & $114,2^{* *}$ \\
6 & $9 / 20$ & $41,7^{* *}$ & 4,1 & $87,7^{* *}$ \\
12,5 & $5 / 20$ & $70,8^{* *}$ & 3,9 & $42^{* *}$ \\
25 & $2 / 20$ & $87,5^{* *}$ & 2,2 & - \\
\hline
\end{tabular}

** Diferencias estadísticamente significativas con el control, $\mathrm{p}<0,05$

Como ya ha sido descripto, estudios previos demostraron que la presencia de metales pasados es capaz de inducir una inhibición en la germinación de semillas de lechuga (Ferrari et al, 1999; Saterbak et al 1999; Chang et al, 1997; Valerio et al, 2007; Andrade et al, 2010). Además de los metales pesados, otras matrices complejas han sido evaluadas mediante el ensayo de germinación en L. sativa. Schultz et al (2002) han observado una marcada inhibición de la germinación de semillas de L. sativa expuestas a residuos industriales con presencia de compuestos orgánicos. Otras investigaciones han demostrado que algunos miembros del grupo de PFCP, tales como triclosan y galaxolide, fueron capaces de ejercer efectos inhibitorios en la germinación de semillas de la especie Triticum aestivum L (An et al, 2009). De manera similar a estos estudios previos, los resultados obtenidos para el ensayo de germinación en L. sativa posibilitaron detectar el efecto fitotóxico inducido por el residuo de 
industria cosmética. El análisis químico de este residuo evidenció la presencia de metales pesados tales como Zn, Fe y Ni y compuestos orgánicos de la familia de PFCP tales como, alcohol diacetona, dodecilciclohexanol, propanal, nonadecano, ácido octadecanoinco, entre otros.

Los mecanismos propuestos actualmente para explicar la inhibición de las semillas por parte de los metales pesados ya han sido detallados con anterioridad en la sección 3.1.1.1.2 (Wang, 1987; Heldt, 2005; Kranner y Colville, 2011).

En cuanto al parámetro de elongación de la raíz, el residuo ejerció un efecto estimulatorio en la longitud de las raíces con respecto a las plántulas control. Este incremento en la elongación de raíces fue observado a bajas concentraciones de exposición del residuo dentro del rango de 1,5-12,5\% p/p, el que podría ser explicado por el fenómeno de hormesis (Calabrese, 2005, 2013). Este modelo ha sido utilizado para explicar una respuesta adaptativa a bajos niveles de estrés o daño, la cual resulta en un aumento de la aptitud de algún sistema fisiológico por un periodo de tiempo finito (Calabrese y Baldwin, 2002). De esta manera, bajas concentraciones de metales pasados, podrían generar un desbalance celular, produciendo una estimulación de diferentes procesos que se constituyen en el primer signo de injuria de diversos procesos biológicos. A mayores concentraciones, el daño producido por los metales es más drástico, causando una inhibición de la longitud de las raíces. Los conceptos clave en los efectos horméticos es la disrupción de la homeostasis, la activación de mecanismos de sobrecompensación para el restablecimiento de la homeostasis, y la naturaleza adaptativa del proceso. Este efecto ha sido reportado en diversas especies de algas y plantas por varios autores (Cedergreen et al, 2007; Sáenz et al, 2012). Particularmente, el efecto hormético ha sido observado en semillas de L. sativa expuestas a diferentes tóxicos, los cuáles produjeron un incremento en la elongación de las raíces a bajas concentraciones del xenobiótico (Belz et al, 2008). De igual forma, este efecto ha sido observado en la elongación de raíces de semillas de L. sativa, Raphanus sativus y P. vulgaris expuestas a bajas concentraciones de PFCP (Fatta-Kassinos et al, 2011).

La CMEO para el ensayo de germinación de semillas en L. sativa resultó ser del 3\% p/p, mientras que la CMEO del ensayo de elongación de la raíz fue del 1,5\% p/p. Esta mayor sensibilidad del parámetro de elongación de raíces coincide con los resultados obtenidos para el residuo de arena de fundición y coincidió con lo encontrado por otros autores al comparar ambos parámetros (Wang, 1987; Chang et al, 1997; Di Salvatore et al, 2008). 


\subsection{Ensayos de cito y genotoxicidad en celomocitos de E. fetida in vivo}

El efecto letal ejercido por el residuo de industria cosmética en invertebrados terrestres fue evaluado mediante el ensayo de exposición aguda de ejemplares de E. fetida siguiendo el protocolo establecido por OECD (1984).

A partir de los resultados de mortalidad con organismos expuestos durante 14 días se determinó la CL50-14d para la realización de los ensayos de genotoxicidad. El valor de la CL50 para el residuo de industria cosmética reveló un valor del $9 \%$ p/p con un intervalo de confianza del 95\% de 7,01-11,23.

\section{Efectos en la viabilidad celular}

A partir de los resultados obtenidos en el ensayo de mortalidad aguda en E. fetida se seleccionaron las concentraciones que fueron estudiadas en el ensayo de cito y genotoxicidad. Para el residuo de cosmética las concentraciones ensayadas correspondieron a la CL50, CL50/2 y CL50/10 con valores de 9, 4,5 y 0,9\% p/p, respectivamente.

La citotoxicidad de las diferentes diluciones del residuo de cosmética fue determinada mediante la extrusión de los celomocitos de organismos de E. fetida expuestos durante 7 y 14 días mediante el ensayo de exclusión con Azul de Tripán. Los resultados de este ensayo se expresan en la Tabla 13.

Tabla 13. Citotoxicidad en celomocitos de organismos de E. fetida expuestos de manera in vivo durante 7 y 14 días. Valores expresados como \% de células no viables.

\begin{tabular}{|c|c|c|}
\hline $\begin{array}{c}\% \mathrm{p} / \mathrm{p} \text { del residuo de } \\
\text { cosmética }\end{array}$ & 7 días & 14 días \\
\hline 0 (control) & 10 & 11 \\
\hline 0,9 & 16 & 19 \\
\hline 4,5 & 24 & $42 * *$ \\
\hline 9,0 & $32 * *$ & $55 * *$ \\
\hline
\end{tabular}

**Diferencias estadísticamente significativas con el control, $\mathrm{p}<0,05$

Para los organismos expuestos durante 7 días se observó un incremento de la toxicidad en concordancia con el incremento de las concentraciones del residuo de cosmética. Esta mayor citotoxicidad resultó estadísticamente significativa $(\mathrm{p}<0,05)$ para la mayor concentración evaluada. Para los organismos expuestos durante 14 días la citotoxicidad se acrecentó de 
manera significativa $(\mathrm{p}<0,05)$ para las concentraciones correspondientes a 4,5 y $9 \% \mathrm{p} / \mathrm{p}$, alcanzando valores de 42 y 55\% de células, respectivamente.

\section{Índices tróficos}

A partir de los mismos organismos expuestos in vivo durante 7 y 14 días se determinaron los índices tróficos LITA, LITAR e ICCT, los cuales se muestran en la Tabla 14.

Tabla 14. Índices tróficos con sus desviaciones estándar (entre paréntesis) en organismos de E. fetida expuestos in vivo al residuo de cosmética.

\begin{tabular}{ccccccc}
\hline & & Día 7 & & \multicolumn{3}{c}{ Día 14} \\
$\% \mathrm{p} / \mathrm{p}$ & LITA & LITAR & ICCT & LITA & LITAR & ICCT \\
\hline 0 & 0,62 & 1,46 & 6,11 & 0,59 & 1,49 & 6,11 \\
& $(0,01)$ & $(0,02)$ & $(0,02)$ & $(0,03)$ & $(0,12)$ & $(0,02)$ \\
0,9 & $0,66^{*}$ & 1,48 & 6,06 & 0,56 & $1,21^{*}$ & 6,08 \\
& $(0,03)$ & $(0,06)$ & $(0,03)$ & $(0,03)$ & $(0,12)$ & $(0,02)$ \\
4,5 & $0,65^{*}$ & $1,25^{*}$ & 6,09 & 0,56 & 1,38 & $6,05^{*}$ \\
& $(0,03)$ & $(0,06)$ & $(0,12)$ & $(0,01)$ & $(0,11)$ & $(0,03)$ \\
& $0,53^{*}$ & 1,41 & 6,09 & $0,52^{*}$ & $1,22^{*}$ & $6,01^{*}$ \\
& $(0,02)$ & $(0,09)$ & $(0,02)$ & $(0,02)$ & $(0,04)$ & $(0,02)$
\end{tabular}

* Diferencias estadísticamente significativas con respecto al control $(\mathrm{p}<0,001)$

Para el Índice LITA se observó un aumento estadísticamente significativo $(\mathrm{p}<0,001)$ del mismo en los organismos expuestos durante 7 días a las concentraciones de 0,9 y $4,5 \% \mathrm{p} / \mathrm{p}$. Por el contrario, el índice disminuyó de manera significativa $(\mathrm{p}<0,001)$ para la mayor concentración ensayada. Para el día 14 de exposición, el índice disminuyó con las concentraciones crecientes de exposición, siendo estadísticamente significativo $(\mathrm{p}<0,001)$ para la mayor concentración de exposición. El índice LITAR disminuyó según aumentaron las concentraciones y los tiempos de exposición. Esta disminución fue estadísticamente significativa $(\mathrm{p}<0,001)$ para las concentraciones de 4,5\% p/p al día 7 de exposición y $0,9 \%$ $\mathrm{p} / \mathrm{p}$ para el día 14 de exposición. El índice ICCT fue estadísticamente significativo $(\mathrm{p}<0,001)$ para las mayores concentraciones de exposición al residuo de cosmética durante 14 días. Éste índice, que considera el número total de celomocitos, disminuyó sólo en las mayores 
concentraciones y luego de 14 días de exposición, coincidiendo con la mayor citotoxicidad observada en celomocitos, como hemos descripto anteriormente.

\section{Proporciones celulares}

Las proporciones de los diferentes tipos de celomocitos para los organismos de E. fetida expuestos in vivo fueron calculados en los organismos expuestos durante 7 y 14 días al residuo de cosmética. Para el día 7 de exposición los resultados se presentan en la Figura 7 mientras que para el día 14, se presentan en la Figura 8.

Los granulocitos no sufrieron cambios estadísticamente significativos $(p>0,05)$ en cuanto a su proporción, independientemente de las concentraciones y los tiempos de exposición ensayados.La proporción de eleocitos aumentó de manera estadísticamente significativa $(\mathrm{p}<0,001)$ al día 7 de exposición para las concentraciones correspondientes a 0,9 y $4,5 \% \mathrm{p} / \mathrm{p}$, y la misma disminuyó cuando los ejemplares fueron expuestos a concentraciones equivalentes al 9\%. Para el día 14, la proporción de eleocitos reveló una disminución significativa $(\mathrm{p}<0,001)$ a las mayores concentraciones de exposición.

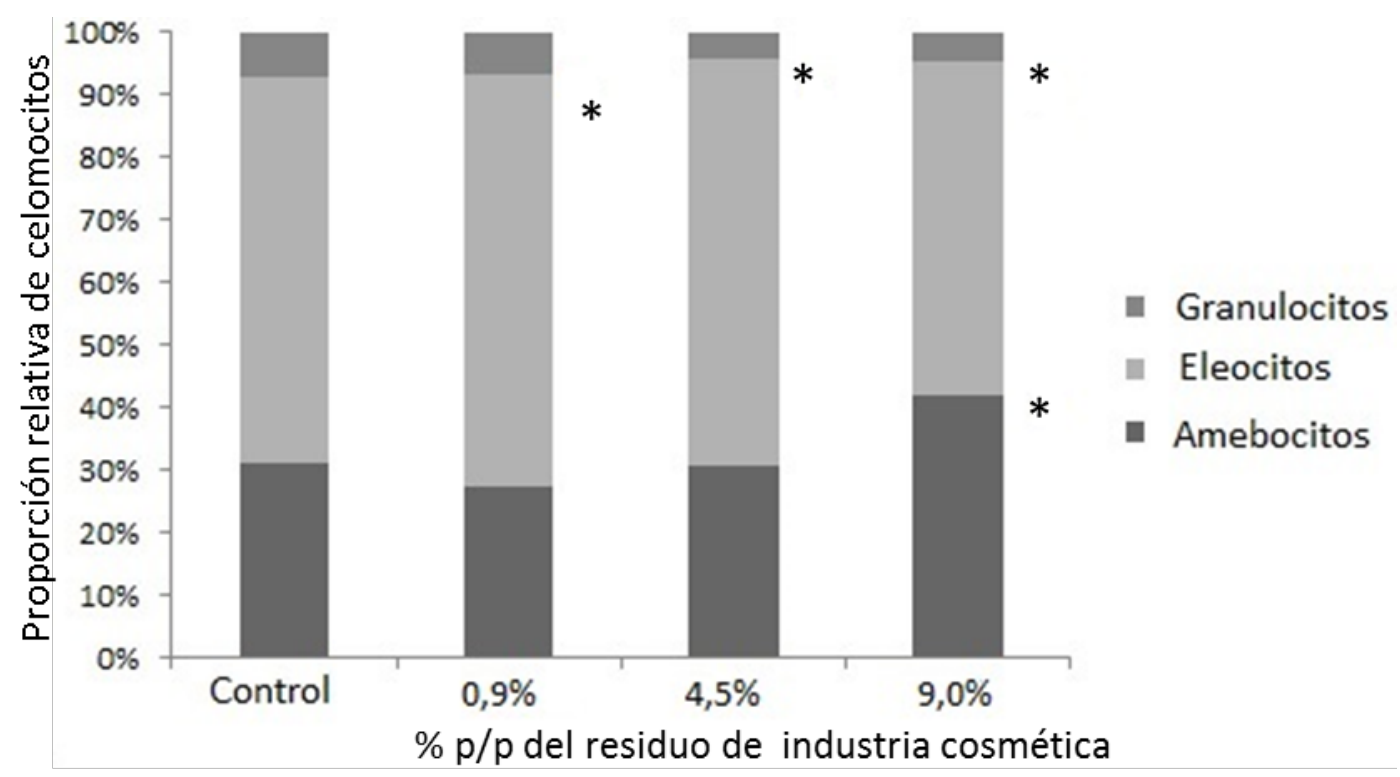

Figura 7. Proporciones celulares de los celomocitos de E. fetida expuestos de manera in vivo al residuo de cosmética durante 7 días. * Diferencias estadísticamente significativas con respecto al control, $\mathrm{p}<0,001$ 


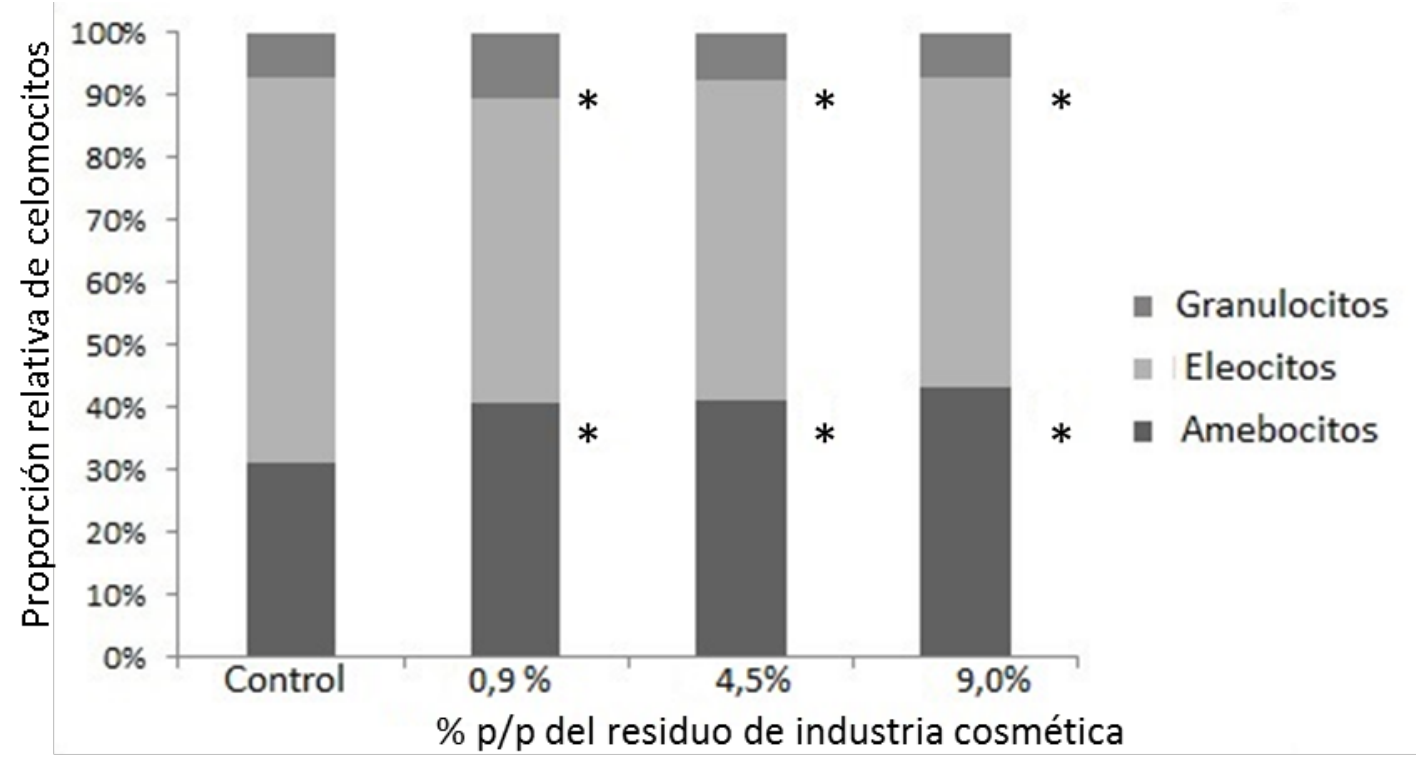

Figura 8. Proporciones celulares de los celomocitos de E. fetida expuestos de manera in vivo al residuo de cosmética durante 14 días. * Diferencias estadísticamente significativas con respecto al control, $\mathrm{p}<0,001$

Estos cambios en la proporción de los mismos fueron concordantes con las observaciones realizadas para los índices LITA y LITAR que correlacionan el número de eleocitos con el número total de celomocitos.

La proporción de amebocitos se incrementó significativamente $(\mathrm{p}<0,001)$ luego de 7 días de exposición. De igual manera, para los organismos expuestos durante 14 días se observó un incremente de la proporción relativa de amebocitos estadísticamente significativo $(\mathrm{p}<0,001)$ a todas las concentraciones evaluadas en relación a los valores controles.

\section{Genotoxicidad sobre celomocitos de E. fetida in vivo}

Los resultados correspondientes a los tiempos de exposición de 7 y 14 días pueden observarse en la Figura 9 y Figura 10, respectivamente.

A los 7 días de exposición al residuo de cosmética, el daño al ADN se incrementó de manera estadísticamente significativa en todas las concentraciones ensayadas con respecto al control $(\mathrm{p}<0,001)$. Los valores de $\%$ ADN cola son de 26,$7 ; 37,2$ y $28,9 \%$ para las concentraciones correspondientes al 0,$9 ; 4,5$ y $9 \% \mathrm{p} / \mathrm{p}$, respectivamente. 


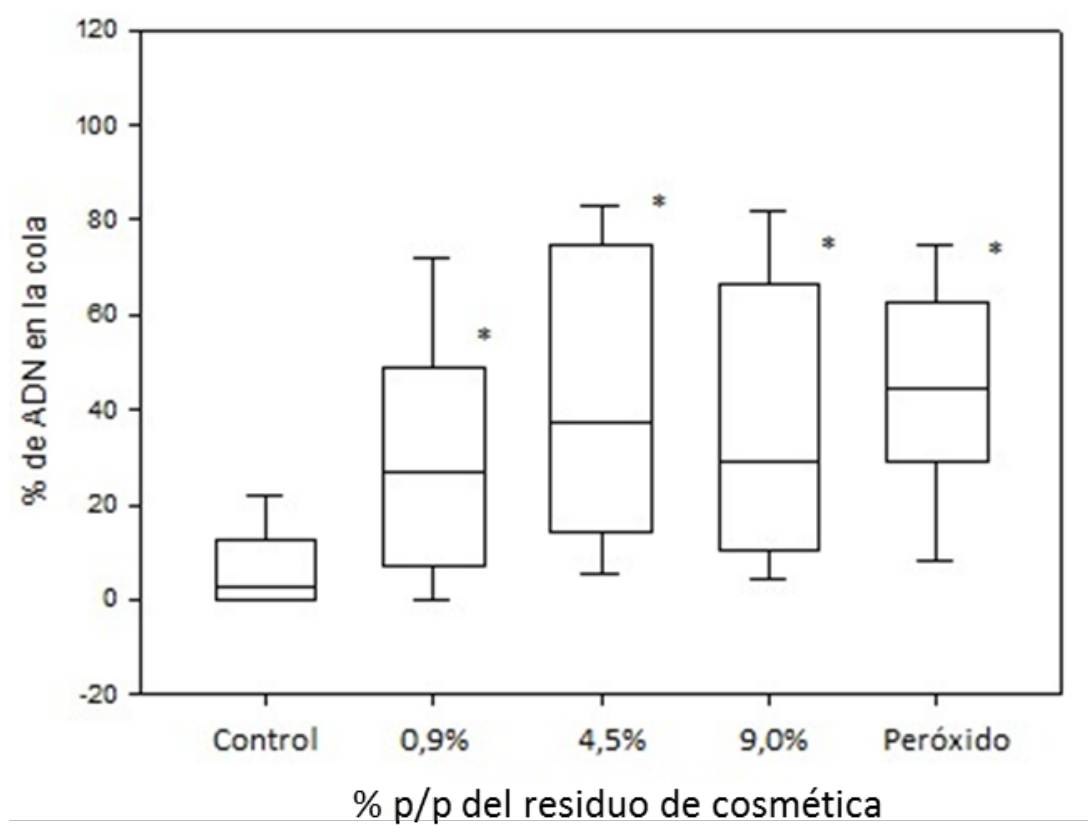

Figura 9. Genotoxicidad del residuo de cosmética en celomocitos de E. fetida expuestos in vivo durante 7 días. . Los límites del "boxplot" representan los cuartiles $25 \%$ y $75 \%$, mientras que la línea central corresponde a la mediana de los valores. Las barras indican los valores mínimos y máximos. *Diferencias estadísticamente significativas con el control, $p<0,001$

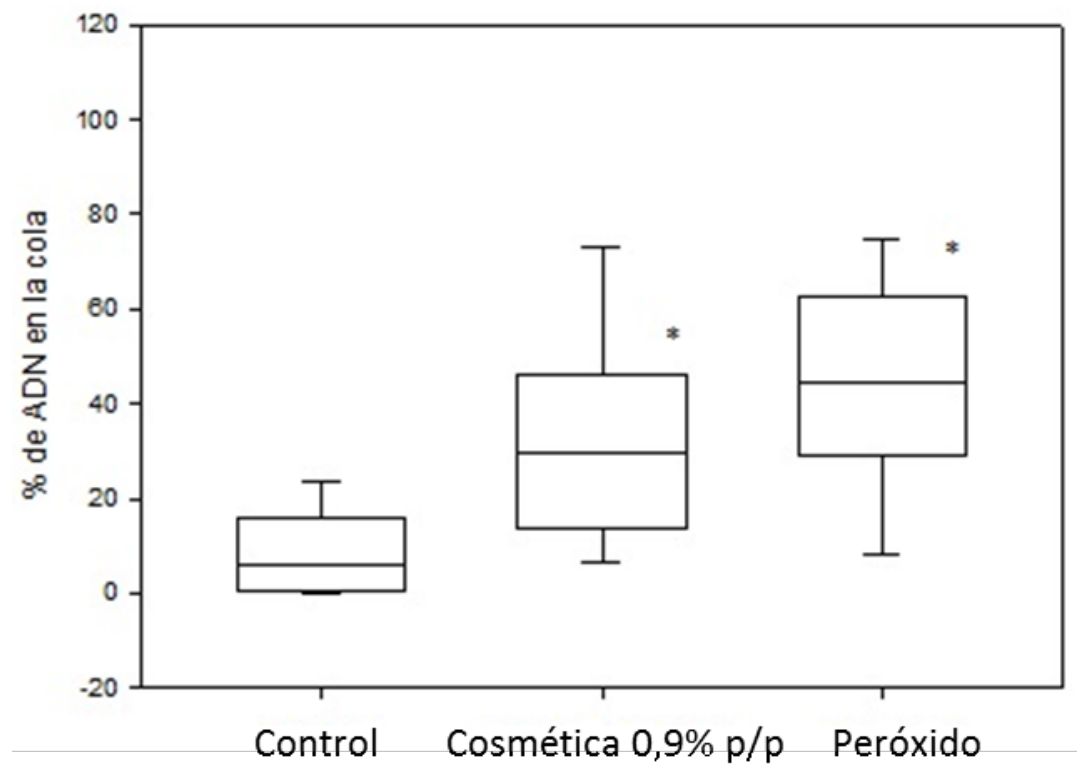

Figura 10. Genotoxicidad del residuo de cosmética en celomocitos de E. fetida expuestos in vivo durante 14 días. Los límites del "boxplot” representan los cuartiles $25 \%$ y $75 \%$, mientras que la línea central corresponde a la mediana de los valores. Las barras indican los valores mínimos y máximos. * Diferencias estadísticamente significativas con el control, $p<0,001$ 
En el caso de los ejemplares de E. fetida expuestos durante 14 días, aquellos que sobrevivieron a la exposición exhibieron una elevada tasa de citotoxicidad en sus celomocitos (Tabla 13). A raíz de este hecho, sólo fue posible la determinación de genotoxicidad en la menor concentración del residuo, correspondiente a una concentración del 0,9\% p/p. Para la misma, el daño al ADN, evidenciado como la migración del mismo, resultó ser mayor y estadísticamente significativa $(\mathrm{p}<0,001)$ en los organismos expuestos comparados con los organismos del grupo control.

La presencia de sustancias genotóxicas en suelos presenta un riesgo no sólo para los organismos que habitan el ecosistema terrestre, sino también para los seres humanos (Römbke y Neumann-Hensel, 2005). Sin embargo, la genotoxicidad de las matrices sólidas correspondientes a residuos industriales que son depositados en el ambiente es pocas veces estudiada. Dentro de los contaminantes, presentes en estos residuos, de conocida acción genotóxica podemos encontrar a los metales pesados. Algunos de ellos, tales como el $\mathrm{Cd}, \mathrm{Cr}$, $\mathrm{Pb}$ y Ni, ya han sido anteriormente descriptos por sus efectos genotóxicos. Con respecto al $\mathrm{Al}$, estudios previos han demostrado que el Al puede interaccionar con el ADN formando complejos con el mismo y con proteínas cromosómicas por lo que podría inducir daño genotóxico (WHO, 1997). En el caso del Zn, existen evidencias de su genotoxicidad en diferentes sistemas biológicos (WHO, 2001). Otros compuestos que pertenecen al grupo de contaminantes emergentes, también podrían ser causante de efectos genotóxicos debido a la presencia de grupos funcionales electrofílicos (Preston y Hoffmann, 2008).

Así, los resultados observados en el presente trabajo de Tesis son concordantes con estos estudios previos que evalúan la actividad genotóxica de los metales pesados y los contaminantes emergentes.

Cómo fue anteriormente expresado, el ensayo cometa ha resultado un estimador sensible para la cuantificación de daño genotóxico originado por matrices complejas (Faust et al, 2004; Quiao et al, 2007; Bonnard et al, 2009; Bigorne et al, 2010; Wu et al, 2012; Voua Otomo et al, 2014; Li et al, 2009).

Los resultados obtenidos coinciden con los obtenidos por diferentes estudios, ya que la exposición a la matriz sólida correspondiente al residuo de industria cosmética incrementa la migración del material genético de los celomocitos de E. fetida expuestos durante 7 y 14 días. Este residuo se caracteriza por la presencia de metales tales como $\mathrm{Al}, \mathrm{Pb}, \mathrm{Zn}$ y $\mathrm{Cu}$, sumados a la presencia de compuestos orgánicos, que podrían actuar de manera sinérgica, los que podrían explicar la mayor toxicidad del residuo de industria cosmética comparado con el residuo de arena de fundición. 


\subsubsection{Fracción líquida-Elución}

\subsection{Parámetros fisicoquímicos de la Fracción líquida-Elución}

La elución acuosa del residuo de industria cosmética fue químicamente caracterizada por la determinación de los siguientes parámetros: $\mathrm{pH}$, contenido de amonio, COT, DQO y la cuantificación de los siguientes metales: $\mathrm{Fe}, \mathrm{Al}, \mathrm{Cr}, \mathrm{Pb}, \mathrm{As}, \mathrm{Zn}, \mathrm{Cu}$ y $\mathrm{Ni}$. Los valores obtenidos para estas determinaciones se encuentran expresados en la Tabla 15. La medición de $\mathrm{pH}$ de la elución acuosa del residuo cosmética reveló un carácter ligeramente alcalino de la misma (7,7). La concentración de las tres especies de $\mathrm{N}$ analizadas resultó ser elevada $\mathrm{y}$ semejante en la elución acuosa con valores de 175, 212 y $225 \mathrm{mg} / \mathrm{L}$ para $\mathrm{NH}_{3}-\mathrm{N}, \mathrm{NH}_{4}$ y $\mathrm{NH}_{3}$, respectivamente. El análisis de los parámetros DQO y COT arrojó resultados de 1157,5 y $722,4 \mathrm{~g} / \mathrm{L}$, respectivamente.

La cuantificación de metales en la elución acuosa evidenció que el metal presente en mayor proporción es el Al, con una concentración de $9 \mathrm{mg} / \mathrm{L}$, seguido por el $\mathrm{Zn}$, con una concentración de $3.0 \mathrm{mg} / \mathrm{L}$. Otros metales fueron cuantificados en bajas concentraciones tales como el Cr (0,5 mg/L), Ni (0,3 mg/L), Cu y Fe (0,2 mg/L), Pb (0,2 mg/L) y As (0,1 mg/L).

Tabla 15. Parámetros fisicoquímicos de la elución acuosa del residuo de cosmética. Valores expresados en $\mathrm{mg} / \mathrm{L}$

\begin{tabular}{cc}
\hline Parámetros & Residuo de cosmética \\
\hline $\mathrm{pH}$ & 7,7 \\
$\mathrm{NH}_{3}-\mathrm{N}$ & 175 \\
$\mathrm{NH}_{4}$ & 212 \\
$\mathrm{NH}_{3}$ & 225 \\
$\mathrm{COT}$ & 722,4 \\
$\mathrm{DQO}$ & 1157,5 \\
$\mathrm{Fe}$ & 0,2 \\
$\mathrm{Al}$ & 9,0 \\
$\mathrm{Cr}$ & 0,5 \\
$\mathrm{~Pb}$ & 0,2 \\
$\mathrm{As}$ & 0,1 \\
$\mathrm{Zn}$ & 3,0 \\
$\mathrm{Cu}$ & 0,2 \\
$\mathrm{Ni}$ & 0,3 \\
\hline
\end{tabular}




\subsection{Ensayos con plántulas de $V$. faba}

Las plántulas de $V$. faba fueron expuestas durante $48 \mathrm{~h}$ a las diferentes concentraciones de la elución acuosa del resido de cosmética correspondientes a 6, 12,5; 25, 50 y 100\% v/v y al Medio Hoagland utilizado como control negativo. Tanto en las plántulas expuestas cómo en las plántulas control se determinó en primer lugar la biomasa. En forma conjunta en las raíces de estas plántulas se cuantificó por un lado el nivel de actividad de dos enzimas relacionadas al estrés oxidativo (CAT y GPOD) y por otro lado el nivel de peroxidación de lípidos.

\section{Efectos sobre la biomasa}

El efecto sobre la biomasa de las plántulas de $V$. faba expuestas durante $48 \mathrm{~h}$ a las diferentes concentraciones de la elución acuosa del residuo de industria cosmética puede observarse en la Tabla 16. La biomasa evidenció una reducción estadísticamente significativa $(\mathrm{p}<0,05)$ para la concentración correspondiente al 100\% v/v de la elución del residuo de cosmética.

Tabla 16. Efectos expresados como media y desviación estándar (entre paréntesis) sobre la biomasa ( $\mathrm{g}$ de peso fresco), actividad enzimática ( $\mathrm{mM}$ de $\mathrm{H}_{2} \mathrm{O}_{2} / \mathrm{mg}$ proteína/min) y peroxidación lipídica ( $\mu$ mol $\mathrm{MDA} / \mathrm{g}$ de peso fresco) de la elución acuosa del residuo de industria cosmética en plántulas de $V$. faba.

\begin{tabular}{ccccccc}
\hline Biomarcador & & \multicolumn{5}{c}{$\%$ v/v Elución } \\
\cline { 3 - 7 } & Control & 6 & 12,5 & 25 & 50 & 100 \\
\hline Biomasa & 0,88 & 0,87 & 0,98 & 0,64 & 0,20 & $0,18^{*}$ \\
& $(0,26)$ & $(0,28)$ & $(0,17)$ & $(0,11)$ & $(0,30)$ & $(0,27)$ \\
\multirow{2}{*}{ CAT } & 44,86 & $13,16^{*}$ & $11,89^{*}$ & $5,90^{*}$ & $5,27^{*}$ & $15,71^{*}$ \\
& $(6,84)$ & $(4,76)$ & $(3,62)$ & $(3,38)$ & $(2,09)$ & $(3,97)$ \\
\multirow{2}{*}{ GPOD } & 3,12 & 3,88 & 5,16 & 5,55 & $9,09^{* *}$ & $0,22^{* *}$ \\
& $(0,06)$ & $(2,92)$ & $(0,69)$ & $(2,79)$ & $(0,97)$ & ) $0,06)$ \\
\multirow{2}{*}{ MDA } & 11,34 & 1,89 & 16,69 & 8,25 & 11,58 & 11,94 \\
& $(2,82)$ & $(0,43)$ & $(3,25)$ & $(1,09)$ & $(0,80)$ & $(0,09)$ \\
\hline
\end{tabular}

*Diferencias estadísticamente significativas con respecto al control, $\mathrm{p}<0,01$

**Diferencias estadísticamente significativas con respecto al control, $\mathrm{p}<0,05$ 


\section{Efectos sobre enzimas del estrés oxidativo CAT y GPOD}

Se evaluó el nivel de actividad de dos enzimas relacionadas al estrés oxidativo: CAT y GPOD luego de $48 \mathrm{~h}$ de exposición de las plántulas de $V$. faba a todas las concentraciones de la elución del residuo de arena de fundición. Los resultados obtenidos para la cuantificación de la actividad enzimática se presentan en la Tabla 16.

La actividad de la enzima CAT fue inhibida de manera estadísticamente significativa $(p<0,01)$ por todas las concentraciones de exposición evaluadas. La actividad de la enzima GPOD manifestó un efecto estimulatorio de manera estadísticamente significativa $(p<0,05)$ a la concentración correspondiente al $50 \% \mathrm{v} / \mathrm{v}$ de la elución en un 191\%. Contrariamente, al 100\% de la elución la actividad de esta enzima se encontró inhibida de manera significativa $(p<0,05)$ en un $93 \%$.

Como ha sido explicado anteriormente, la presencia de algunos metales modifica la acción de enzimas asociadas al estrés oxidativo (Di Marzio y Sáenz, 2013).

En el caso de la elución del residuo de cosmética, el metal presente en mayor concentración resultó ser el Al (9 mg/L). Diferentes autores han informado que este metal es capaz de irrumpir en diferentes procesos celulares generando la pérdida de la estructura y/o funciones de la pared celular, membrana plasmática, procesos de transducción de señal y homeostasis del Ca (Achary et al, 2013). Asimismo, se observó que este metal originó una disminución en el crecimiento de plantas de Pinus nigra debido a una reducción de la captación de nutrientes (Boxman et al, 1991). En el caso de Zn, existen reportes que indicaron una acción fitotóxica del metal en diferentes procesos fisiológicos de plantas tales como fotosíntesis, respiración, transpiración y desarrollo general (Van Assche y Clijters, 1986; Chaney et al, 1993; Vangronsveld y Clijsters, 1994). Van Assche et al (1988) han observado una inhibición del crecimiento y una inducción de enzimas de estrés oxidativo en plantas de $P$. vulgaris expuestas a $\mathrm{Zn}$. El Pb, presente en la elución del residuo de cosmética, ha mostrado ejercer efectos adversos en el metabolismo y crecimiento de plantas. En plantas de Orizia sativa, el $\mathrm{Pb}$ incrementó la actividad de enzimas antioxidantes (Verma y Dubey, 2003). Asimismo, suelos contaminados artificialmente con $250 \mathrm{mg} / \mathrm{kg}$ de $\mathrm{Pb}$ han demostrado inhibir la actividad de la enzima CAT y estimular la actividad de GPOD en hojas de $V$. faba (Wang et al, 2008).

El incremento de la presencia y concentración de metales pesados en la elución del residuo de cosmética podría llevar a una pérdida de la capacidad antioxidante de las enzimas asociadas este proceso. Esta pérdida de actividad podría estar relacionada con el bloqueo de grupos 
funcionales esenciales para las reacciones biológicas, como ha sido propuesto anteriormente (Di Marzio y Sáenz, 2013).

Los resultados obtenidos en el presente trabajo podrían indicar la existencia de efectos sinérgicos debido a la presencia de metales, compuestos orgánicos y la elevada concentración de amonio no ionizado, la forma más tóxica del amonio. A favor de lo expresado anteriormente, sumado a estos factores, elevados niveles de DQO y amonio no ionizado han sido relacionados con la toxicidad de lixiviados en diferentes organismos (Clément et al, 1997).

De este modo, la composición química podría ser el factor clave para explicar la elevada toxicidad del residuo de Cosmética. Esta toxicidad queda evidenciada en la pérdida de la biomasa y las modificaciones de las actividades enzimáticas observadas en las plántulas de $V$. faba expuestas a las diferentes concentraciones de la elución. Los resultados del presente trabajo coinciden con las observaciones realizadas por otras investigaciones.

Los resultados obtenidos indican que el análisis conjunto de marcadores, tales como la biomasa y la actividad de las enzimas de estrés oxidativo, podrían ser utilizados para la detección de alteraciones tempranas, al menos, en plantas.

\section{Efectos sobre peroxidación lipídica}

Los niveles de MDA en raíces de las plántulas expuestas a diferentes concentraciones de la elución del residuo de industria cosmética pueden observarse en la Tabla 16. La elución del residuo de cosmética no provocó una alteración estadísticamente significativa $(p>0,05)$ en el contenido de MDA en comparación con el control, independientemente de las concentraciones ensayadas. Como ha sido anteriormente explicado, la ausencia de respuesta de este biomarcador en nuestras condiciones de ensayo podría ser causada por el corto período de exposición utilizado en el presente Trabajo de Tesis.

\subsection{Ensayos de cito y genotoxicidad en celomocitos de E. fetida ex vivo}

La toxicidad de la elución del residuo de cosmética fue evaluada sobre celomocitos de $E$. fetida expuestos ex vivo durante $1 \mathrm{~h}$ mediante la determinación de citotoxicidad, índices tróficos, proporciones celulares y genotoxicidad.

\section{Citotoxicidad}

La citotoxicidad de la elución acuosa del residuo de industria cosmética fue determinada mediante el ensayo con Azul de Tripán. El rango de concentraciones evaluadas correspondió 
a $1,5-25 \%$ v/v ya que, ensayos preliminares evidenciaron una citotoxicidad total a concentraciones superiores.

Los resultados de la citotoxicidad inducida por las diferentes diluciones de la elución son presentados en la Tabla 17.

Tabla 17. Citotoxicidad inducida por la elución del residuo de industria cosmética en celomocitos de E. fetida expuestos ex vivo durante $1 \mathrm{~h}$. Resultados expresados como \% de células no viables

\begin{tabular}{cc}
\hline$\% \mathrm{v} / \mathrm{v}$ Elución & Citotoxicidad $(\%)$ \\
\hline 0 & 12 \\
1,5 & $26^{* *}$ \\
3 & $33^{* *}$ \\
6 & $37^{* *}$ \\
12,5 & $55^{* *}$ \\
25 & $81^{* *}$ \\
\hline
\end{tabular}

**Diferencias estadísticamente significativas, $\mathrm{p}<0,05$

Todas las diluciones ensayadas provocaron un incremento estadísticamente significativo $(\mathrm{p}<0,05)$ en la citotoxicidad de los celomocitos expuestos ex vivo durante $1 \mathrm{~h}$. A partir de los resultados de la citotoxicidad inducida por las eluciones, se estimó la CL50-1h para los celomocitos la cual resultó ser de 9,15\% v/v con un intervalo de confianza del 95\% de 6,911,9. La CENO para la viabilidad celular resultó ser de 1,5\% v/v.

Al igual que en caso del residuo de arena de fundición la viabilidad de los celomocitos de $E$. fetida podría verse afectada por la presencia de metales en la elución acuosa

\section{Índices tróficos}

Conjuntamente con la citotoxicidad se determinaron los índices tróficos para los celomocitos expuestos ex vivo durante $1 \mathrm{~h}$ a la elución del residuo de cosmética, los cuales pueden observarse en la Tabla 18.

En el mismo pudo observarse que el índice LITA disminuyó conforme se incrementó la concentración de exposición a la elución. Este descenso fue estadísticamente significativo con respecto al control $(\mathrm{p}<0,001)$ a las concentraciones mayores al 3\% v/v. El índice LITAR también presentó una disminución significativa $(\mathrm{p}<0,001)$ en todas las concentraciones de 
exposición ensayadas. El índice ICCT se comportó nuevamente como el biomarcador menos sensible, dado que se modificó de manera estadísticamente significativa $(\mathrm{p}<0,001)$ para las concentraciones de 12,5 y $25 \%$ v/v de la elución.

Tabla 18. Índices tróficos con su desviación estándar (entre paréntesis) para el residuo de cosmética en celomocitos de E. fetida expuestos durante $1 \mathrm{~h}$

\begin{tabular}{cccc}
\hline$\%$ v/v Elución & LITA & LITAR & ICCT \\
\hline 0 & 0,6 & 1,60 & 6,11 \\
& $(0,01)$ & $(0,01)$ & $(0,02)$ \\
1,5 & 0,56 & $1,28^{*}$ & 6,08 \\
& $(0,01)$ & $(0,02)$ & $(0,02)$ \\
3 & $0,55^{*}$ & $1,28^{*}$ & 6,04 \\
& $(0,02)$ & $(0,02)$ & $(0,01)$ \\
\multirow{2}{*}{6} & $0,54^{*}$ & $1,22^{*}$ & 6,06 \\
& $(0,02)$ & $(0,02)$ & $(0,02)$ \\
\multirow{2}{*}{12} & $0,53^{*}$ & $1,23^{*}$ & $6,02^{*}$ \\
& $(0,02)$ & $(0,06)$ & $(0,02)$ \\
25 & $0,51^{*}$ & $1,10^{*}$ & $5,62^{*}$ \\
& $(0,04)$ & $(0,08)$ & $(0,06)$ \\
\hline
\end{tabular}

*Diferencias estadísticamente significativas, $\mathrm{p}<0,001$

\section{Proporciones celulares}

Se determinaron las proporciones celulares de los celomocitos de E. fetida expuestos ex vivo durante $1 \mathrm{~h}$ a la elución del residuo de cosmética. Los resultados de los mismos pueden observarse en la Figura 11.

La proporción de eleocitos disminuyó de manera estadísticamente significativa $(p<0,001)$ a medida que se incrementaron las concentraciones de exposición de la elución. Los granulocitos presentaron un ascenso estadísticamente significativo $(\mathrm{p}<0,001)$ sólo a la concentración de $100 \% \mathrm{v} / \mathrm{v}$ de la elución. Los amebocitos incrementaron su proporción de manera significativa $(\mathrm{p}<0,001)$ a concentraciones mayores al 6\% de la elución. 


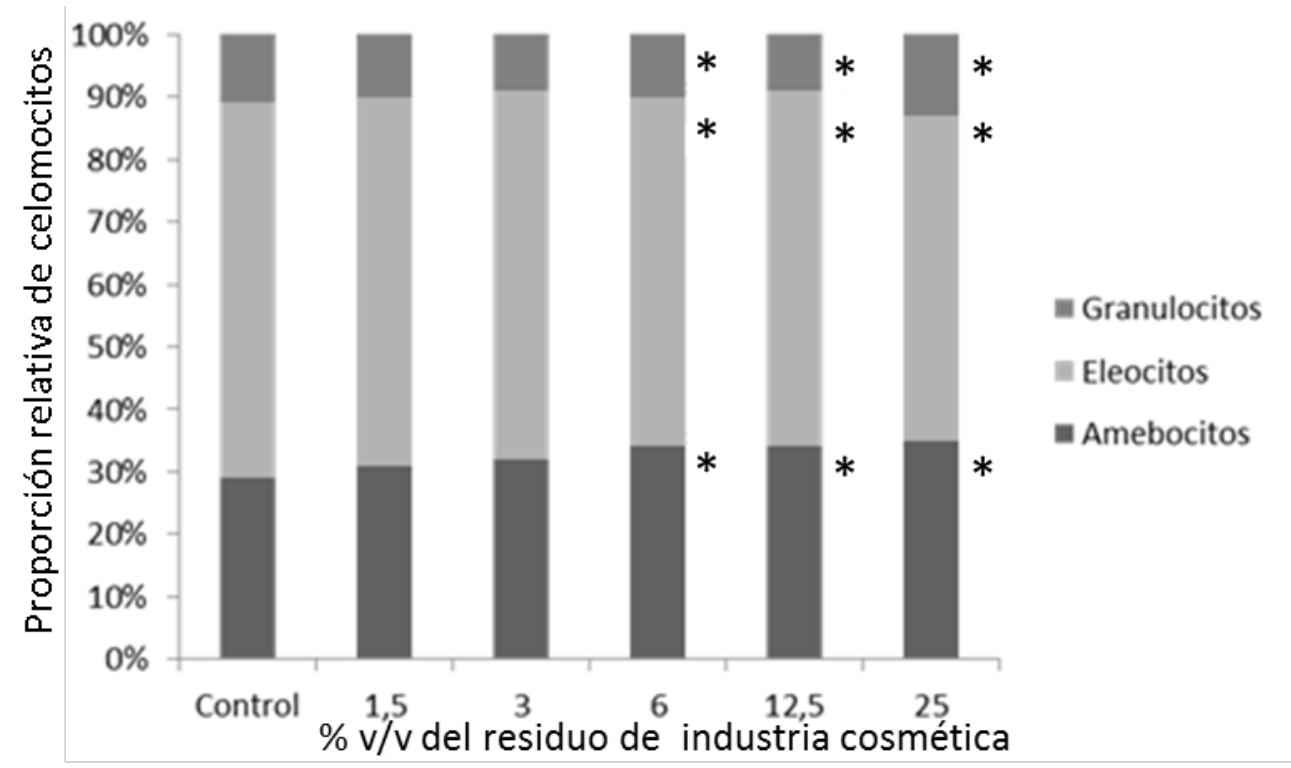

Figura 11. Proporciones celulares de celomocitos de E. fetida expuestos de manera ex vivo durante $1 \mathrm{~h}$ a la elución del residuo de industria cosmética. * Diferencias estadísticamente significativas con respecto al control, $\mathrm{p}<0,001$

Genotoxicidad en celomocitos de E. fetida expuestos ex vivo

A partir de los resultados obtenidos en el ensayo de citotoxicidad y la estimación de la CL501h se determinó el efecto genotóxico de dos concentraciones de la elución del residuo de industria cosmética. Estas concentraciones correspondieron a la CL50-1h y CL50-1h/2, equivalentes a 9 y 4,5\% v/v, respectivamente. Los resultados para la cuantificación del daño genotóxico mediante el ensayo cometa se presentan en la Figura 12. Ambas diluciones ensayadas ejercieron un efecto genotóxico estadísticamente significativo $(p<0,001)$ en celomocitos de E. fetida expuestos ex vivo durante $1 \mathrm{~h}$.

Los valores de las medianas del \% de ADN cola resultaron ser de 7,8 y 19,8\% para las concentraciones de 4,5 y 9\% v/v de la elución, respectivamente.

Estos resultados evidencian la importancia de la evaluación de la genotoxicidad de las eluciones acuosas de los residuos debido a que esta fracción representa la movilidad de las sustancias potencialmente peligrosas. Así las sustancias presentes en los residuos que son depositados en los suelos (Newman y Clements, 2008) pueden migrar a otro compartimento ambiental, llegando a aguas subterráneas por infiltración o llegar a cuerpos de agua por escorrentía superficial (Moriarty 1985; Widziewicz et al, 2011). Di Marzio et al (2007) han demostrado el efecto genotóxico de las eluciones acuosas de suelos industriales mediante la aplicación del ensayo cometa en celomocitos de E. fetida. 


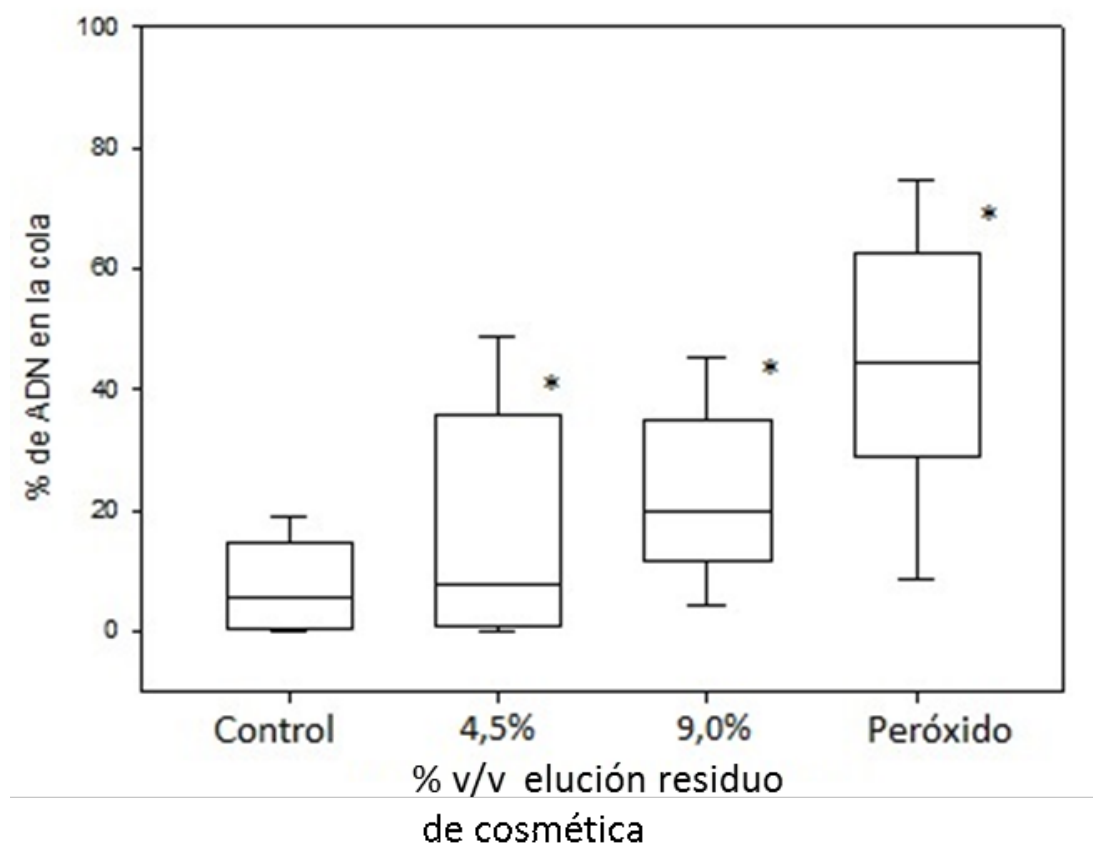

Figura 12. Genotoxicidad de las eluciones del residuo de cosmética en celomocitos de $E$. fetida expuestos ex vivo durante $1 \mathrm{~h}$. Los límites del "boxplot" representan los cuartiles $25 \%$ y $75 \%$, mientras que la línea central corresponde a la mediana de los valores. Las barras indican los valores mínimos y máximos. * Diferencias estadísticamente significativas con el control,

$$
\mathrm{p}<0,001
$$

Los resultados de los ensayos biológicos realizados en el presente Trabajo de Tesis ponen de manifiesto la necesidad de llevar a cabo una batería de bioensayos y biomarcadores en diferentes organismos para lograr una mejor caracterización de un xenobiótico desde el punto de vista ecotoxicológico. La vinculación entre la composición química y las respuestas biológicas provocadas por el residuo de cosmética, permite evidenciar una mayor toxicidad por parte del residuo de cosmética con respecto al residuo de arena de fundición. La presencia de contaminantes emergentes, tales como los compuestos pertenecientes al grupo de los PFCP, pueden generar efectos teratogénicos, genotóxicos, o incluso de disrupción endócrina (Fatta-Kassinos et al, 2011). Todos los elementos y compuestos químicos presentes en el residuo de cosmética podrían actuar de manera sinérgica sobre los diferentes organismos de prueba utilizados en el presente trabajo. Estos fenómenos de sinergia podrían explicar la mayor toxicidad evidenciada por el residuo de industria cosmética con respecto al residuo de arena de fundición. 
Tabla 19. Resumen de los parámetros evaluados para el residuo de industria cosmética. (Nd: no determinado)

\begin{tabular}{lcc}
\hline Variable & CMEO & CE/CL50 (IC 95\%) \\
\hline Muestra sólida & $\% \mathrm{p} / \mathrm{p}$ & $8,5(1,5-27,8)$ \\
Germinación en L. sativa & 3 & $34,8(34,1-35,5)$ \\
Elongación de raíces en L. sativa & 1,5 & $9(6,25-12,5)$ \\
Mortalidad en E. fetida & & \\
LITA 14 d & 9,9 & \\
LITAR 14 d & 9 & \\
ICCT 14 d & 0,9 & \\
Proporciones celulares 14 d & 0,9 & \\
Genotoxicidad 14 d & $\% \mathrm{v} / \mathrm{v}$ \\
\hline Elución & 100 & \\
Biomasa en plántulas de $V$. faba & 6 & \\
CAT & 50 & \\
GPOD & $\mathrm{Nd}$ & \\
Peroxidación de lípidos & 1,5 & \\
Citotoxicidad en celomocitos & 3,5 & \\
LITA 1h & 1,5 & \\
LITAR 1h & 12 & \\
PCCT 1h & & \\
Genoporciones celulares $1 \mathrm{~h}$ & & \\
\hline
\end{tabular}




\subsubsection{Evaluación integrada de los residuos sólidos estudiados}

Por medio de los ensayos realizados se determinó la toxicidad asociada a los dos residuos industriales evaluados. La evaluación del residuo sólido en su fase entera como la fracción líquida-elución, permitió manifestar de manera integral los efectos deletéreos y la movilidad de los contaminantes en el ecosistema.

El residuo de cosmética evidenció una mayor toxicidad tanto en su forma entera como su elución con respecto al residuo de arena de fundición.

Para el residuo de arena de fundición en su forma entera, tanto la germinación de semillas como la elongación de las raíces en $L$. sativa evidenciaron de manera efectiva la fitotoxicidad del mismo en un tiempo de exposición de 120 h. Para ejemplares de E. fetida expuestos durante 14 días al residuo en su forma entera, los bioensayos pusieron en evidencia el efecto deletéreo, cito y genotóxico del mismo. En el caso de la evaluación de la ecotoxicidad de la elución del residuo de arena de fundición, los ensayos con $V$. faba expuesta durante $48 \mathrm{~h}$, indicaron una baja toxicidad del mismo comparado con los efectos observados en celomocitos de E. fetida expuestos ex vivo durante $1 \mathrm{~h}$.

En el caso del residuo de cosmética en su forma entera, tanto la germinación de semillas como la elongación de raíces en $L$. sativa evidenciaron una mayor fitotoxicidad del mismo en un período de exposición de $120 \mathrm{~h}$. Para los organismos expuestos durante 14 días, este residuo también resultó más tóxico que el residuo de arena de fundición. En el caso de la elución de este residuo, los ensayos con $V$. faba evidenciaron una mayor toxicidad de la misma, ya que se modificaron las actividades enzimáticas y es destacable la disminución de la biomasa en las plántulas expuestas a una concentración del 100\%. Nuevamente, los parámetros determinados luego de $1 \mathrm{~h}$ de exposición ex vivo de los celomocitos evidenciaron una alta toxicidad del residuo.

Vinculando las respuestas tóxicas provocadas por los residuos con el análisis químico de las matrices, podríamos establecer que la mayor diversidad y concentración de compuestos químicos en el residuo de cosmética fuera la responsable del mayor grado de toxicidad provocado por el mismo. Es de destacar que los ensayos de germinación y elongación de las raíces sobre $L$. sativa y los ensayos de cito y genotoxicidad en celomocitos de E. fetida expuestos ex vivo son poderosas herramientas para la evaluación ecotoxicológica de residuos. Debido a su simplicidad, repetitividad, sensibilidad y al corto tiempo de exposición para la obtención de resultados, estos biomarcadores podrían ser utilizados para la determinación de toxicidad de manera rápida y sencilla para fines regulatorios. Los ensayos con V. faba, si bien 
son menos sensibles, aportan un conocimiento más integral acerca de la toxicidad de matrices con mayor grado de contaminación. Sin embargo, los mismos podrían considerarse como complementarios a la hora de elegir una batería de ensayos con fines regulatorios. De forma semejante, los ensayos de exposición in vivo en E. fetida permiten comprender diferentes mecanismos activos en los organismos expuestos para una mejor decisión en el manejo de los residuos. A pesar de ello, los efectos genotóxicos pueden evidenciarse en un período corto de exposición de 1 h en los ensayos ex situ.

Se puede afirmar que si bien, a fines de comprender la toxicidad global de un residuo y su posible movilidad entre los compartimentos del ecosistema, es necesario evaluar un amplio número de variables de respuesta sobre diferentes organismos. Cuando se plantean objetivos regulatorios, serán preferibles aquellos ensayos y/o variables de respuesta que permitan determinar la ecotoxicidad de un residuo en menores tiempos de ensayo.

\subsubsection{Conjunto de variables seleccionadas para la evaluación ecotoxicológica de residuos sólidos}

Para la evaluación de las matrices sólidas correspondientes a residuos industriales es posible seleccionar un conjunto de variables de mayor sensibilidad para determinar la ecotoxicidad de los mismos (Tabla 20). Esta determinación de la sensibilidad relativa se llevó a cabo eligiendo el parámetro más sensible en cada residuo en base a su menor CMEO, la cito y genotoxicidad de celomocitos expuestos ex vivo durante $1 \mathrm{~h}$; para el residuo de arena de fundición y en el caso del residuo de industria cosmética, el parámetro fue la genotoxicidad determinada en organismos expuestos in vivo durante 14 días. A partir de estos parámetros elegidos se estimó la sensibilidad con respecto al mismo para cada variable de respuesta.

Para el residuo de arena de fundición, los ensayos más sensibles resultaron ser la citotoxicidad determinada en celomocitos expuestos ex vivo durante $1 \mathrm{~h}$ de exposición, la genotoxicidad en las mismas condiciones de ensayo, la determinación de proporciones celulares en organismos expuestos in vivo durante 14 días y la elongación de raíces en $L$. sativa expuestas durante $120 \mathrm{~h}$. En este caso, estos ensayos evidenciaron de manera sensible la toxicidad del residuo evaluado. En cuanto al tiempo de ensayo podemos afirmar que ensayos que brinden información de la toxicidad de los residuos a menores tiempos de exposición son preferibles a aquellos con períodos más prolongados. Así, la determinación de cito y genotoxicidad en celomocitos de E. fetida expuestos ex vivo se convierte en una poderosa herramienta para la evaluación de residuos. No sólo por la sensibilidad del ensayo y 
su corto tiempo de exposición sino porque, además, permite determinar los efectos genotóxicos de mezclas complejas. Estos efectos podrían vincularse con el riesgo potencial que representan estos residuos a niveles supra-individuales como así también los riesgos para la salud humana. En el caso de la determinación de proporciones celulares a 14 días de exposición, si bien el ensayo es simple, el tiempo de exposición para determinar la toxicidad es mayor, por lo que a fines regulatorios resulta más conveniente contar con ensayos que brindaran resultados a tiempos más acotados. La elongación de raíces en L. sativa es el biomarcador más sensible para la evaluación de fitotoxicidad por lo cual debe ser incluido necesariamente en una batería de ensayos ecotoxicológicos para la determinación de este punto final en diferentes niveles tróficos. Este ensayo se preferirá antes que la determinación de proporciones celulares a 14 días debido al mayor tiempo de exposición del último.

El parámetro menos sensible para ambos residuos resultó ser la peroxidación de lípidos ya que no evidenció modificaciones independientemente de los residuos ensayados. De aquellos parámetros que experimentaron alteraciones en sus valores con respecto al control, los menos sensibles fueron la actividad de la enzima CAT, la germinación en $L$. sativa y la determinación de índices tróficos en organismos expuestos durante 14 días. Estos parámetros fueron 66,$6 ; 33,3$ y 17,3 veces menos sensibles que el parámetro de mayor sensibilidad considerado como referencia, respectivamente.

Si se calcula la sensibilidad relativa de todas las variables de respuesta evaluadas para el residuo de industria cosmética, como se detalló anteriormente, podemos concluir cuáles son los parámetros más sensibles para la caracterización ecotoxicológica del residuo. El parámetro más sensible tomado como referencia fue la genotoxicidad a los 14 días de exposición in vivo. En el caso del residuo de industria cosmética, los ensayos más sensibles resultaron ser la genotoxicidad y las proporciones celulares en celomocitos expuestos in vivo durante 14 días, la elongación de raíces en L. sativa y la citotoxicidad en celomocitos expuestos ex vivo por un período de exposición de $1 \mathrm{~h}$.

En cuanto a los ensayos menos sensibles se encuentran la biomasa, la actividad de la GPOD en raíces de $V$. faba y las proporciones celulares a diferentes tiempos de exposición, siendo estos parámetros 111,$1 ; 55,5$ y unas 10 veces menos sensibles respectivamente que el parámetro tomado como referencia, respectivamente.

Dentro de la batería de bioensayos empleados, los nuevos biomarcadores correspondientes a los índices LITA y LITAR, propuestos en el presente trabajo constituyen herramientas útiles para la evaluación ecotoxicológica de matrices sólidas. Es para remarcar, que los índices LITA y LITAR resultaron, en ambos residuos, ser más sensibles que el índice ICCT. 
Siguiendo con la evaluación de la sensibilidad de nuevos biomarcadores propuestos, los cambios en las proporciones celulares se comportan de manera sensible, por lo que pueden ser incorporados de manera satisfactoria como biomarcadores de estrés ambiental debido a su simplicidad.

Puede observarse que la elección de ensayos depende de la matriz sólida evaluada. En el caso del residuo de cosmética, éste evidenció su mayor toxicidad para 14 días de exposición. Sin embargo a los fines prácticos, el ensayo de elongación de raíces con una duración de $120 \mathrm{~h}$ y la determinación de citotoxicidad en celomocitos expuestos de manera ex vivo serían recomendados fuertemente con fines regulatorios.

Para el residuo de cosmética, los resultados evidencian que a medida que se incrementa el tiempo de exposición se evidencia una mayor toxicidad del mismo, confirmando la respuesta ecotóxica del mismo. Para el caso de la arena de fundición no se puede realizar la misma afirmación, ya que, la mayor toxicidad del residuo se presenta para el período de exposición correspondiente a 7 días, por lo que si sólo se utilizara este tiempo de exposición estaríamos sobreestimando la ecotoxicidad del residuo. Para el día 14 de exposición, la toxicidad del residuo se redujo, lo que parece indicar un proceso adaptativo de los organismos. De esta manera se puede observar que tiempos de exposición más prolongados es posible evaluar mecanismos adaptativos o de defensa ante la presencia de sustancias tóxicas. Estos estudios si bien contribuyen a la elucidación de los efectos integrales provocados por las matrices complejas, no son tan útiles a los fines regulatorios.

Tanto la determinación de cito y genotoxicidad en celomocitos de E. fetida expuestos de manera ex vivo como la elongación de raíces en L. sativa son bioensayos que no deberían faltar en la caracterización ecotoxicológica con fines regulatorios de matrices sólidas correspondientes a residuos industriales. Sin embargo, ensayos que consideren la toxicidad del residuo en un período de 14 días de exposición serían necesarios a fin de comprender la toxicidad de manera más integral. 
Tabla 20. Sensibilidad relativa de los parámetros evaluados para las matrices sólidas correspondientes a los residuos industriales. ( $\mathrm{Nd}$ : no determinado)

\begin{tabular}{|c|c|c|}
\hline Variable & Arena & Cosmética \\
\hline \multicolumn{3}{|l|}{ Muestra sólida } \\
\hline Germinación en L. sativa & 33,3 & 3,3 \\
\hline Elongación de raíces en $L$ sativa & 16,6 & 1,6 \\
\hline LITA $14 \mathrm{~d}$ & 17,3 & 10 \\
\hline LITAR $14 \mathrm{~d}$ & 1,7 & 1 \\
\hline ICCT $14 \mathrm{~d}$ & 17,3 & 10 \\
\hline Proporciones celulares $14 \mathrm{~d}$ & 1,7 & 1 \\
\hline Genotoxicidad $14 \mathrm{~d}$ & 1,7 & 1 \\
\hline \multicolumn{3}{|l|}{ Elución } \\
\hline Biomasa en plántulas de $V$. faba & $\mathrm{Nd}$ & 111,1 \\
\hline CAT & 66,6 & 6,6 \\
\hline GPOD & $\mathrm{Nd}$ & 55,5 \\
\hline Citotoxicidad en celomocitos & 1 & 1,6 \\
\hline LITA $1 \mathrm{~h}$ & 1 & 3,3 \\
\hline LITAR $1 \mathrm{~h}$ & 1 & 1,6 \\
\hline ICCT $1 \mathrm{~h}$ & 4 & 13,3 \\
\hline Proporciones celulares $1 \mathrm{~h}$ & 4 & 1,6 \\
\hline Genotoxicidad $1 \mathrm{~h}$ & 0,7 & 5 \\
\hline
\end{tabular}




\subsection{Suelos}

\subsubsection{Muestras ambientales de suelos post aplicación de plaguicidas}

\subsubsection{Post-aplicación de glifosato}

\subsection{Muestra entera}

\subsection{Ensayos de germinación y elongación de las raíces con L. sativa}

Se determinó la fitotoxicidad de una muestra ambiental proveniente de una zona de cultivo intensivo de soja, post-aplicación del herbicida glifosato. Se utilizó con este fin el ensayo de germinación y elongación de raíces en L. sativa. Los resultados para ambos parámetros se presentan en la Tabla 21. El suelo ambiental post-aplicación de glifosato evidenció una inhibición del $68,9 \%$ en la germinación de las semillas. Este valor resultó estadísticamente significativo $(\mathrm{p}<0,05)$ con respecto al control.

Para el parámetro de elongación de raíces se observó una disminución estadísticamente significativa $(\mathrm{p}<0,05)$ en la longitud de las mismas para organismos expuestos al suelo ambiental post-aplicación de glifosato.

El contacto directo de los herbicidas con organismos vegetales no blanco puede originar efectos perjudiciales sobre los mismos (Carlile, 2006). En general, estos efectos pueden ser originados por la deriva de los plaguicidas fuera de los límites de la zona de cultivo o debido a la persistencia del plaguicida en el suelo. En el caso del glifosato, ha sido demostrado que posee una baja persistencia en el suelo, posee baja movilidad y no es bioacumulable ni biomagnificable a lo largo de la cadena trófica (WHO, 1994; Giesy et al, 2000; Williams et al, 2000).

Como consecuencia de la aplicación de este herbicida, parte del producto se encontraría en contacto con el suelo. Una vez allí, hay diferentes interacciones que determinarán su destino final y reactividad. El glifosato puede formar complejos con cationes de $\mathrm{Ca}^{2+} \mathrm{y} \mathrm{Mg}^{2+} \mathrm{O}$ adsorberse fuertemente en las partículas del suelo (WHO, 1994), ser degradado por microorganismos del suelo (Sprankle et al, 1975) y ser arrastrado por escorrentía e infiltración hacia distintos cuerpos de agua (Williams et al, 2000). La movilidad del plaguicida en el suelo está determinada por su alta adsorción a las partículas del mismo, limitando su capacidad de lixiviación hacia otros compartimentos ambientales (Carlile, 2006). Sin embargo, la composición química del suelo puede afectar esta adsorción facilitando la movilidad del plaguicida a la fase acuosa. La presencia de metales o el contenido de sustancias húmicas puede facilitar su migración (Picolo y Celano, 1994; Welten, 2000). 
Martin y Ronco (2006) han encontrado, en estudios previos, un incremento en la toxicidad del formulado comercial de glifosato en semillas de L. sativa. Un formulado comercial del herbicida glifosato provocó una inhibición en la germinación de las semillas de esta especie no blanco y además generó una disminución en la inhibición de las raíces de las mismas (Martin y Ronco, 2006). Los resultados obtenidos con L. sativa han manifestado la fitotoxicidad inducida por el herbicida glifosato en esta especie no blanco del herbicida.

Tabla 21. Efecto fitotóxico de los suelos naturales post-aplicación de glifosato sobre la germinación de las semillas y la elongación de las raíces en $L$. sativa

\begin{tabular}{ccccc}
\hline Muestra & $\begin{array}{c}\text { Semillas germinadas/ } \\
\text { semillas expuestas }\end{array}$ & $\begin{array}{c}\text { \% Inhibición } \\
\text { Germinación }\end{array}$ & $\begin{array}{c}\text { Elongación de } \\
\text { raíces }(\mathrm{cm})\end{array}$ & $\begin{array}{c}\text { \% Inhibición } \\
\text { elongación de raíces }\end{array}$ \\
\hline Control & $15 / 20$ & 0 & 2,8 & 0 \\
Suelo ambiental & $5 / 20$ & $68,9^{*}$ & 1,3 & $54,3^{*}$
\end{tabular}

*Diferencias estadísticamente significativas con respecto al control, $\mathrm{p}<0,001$.

\subsection{Ensayos de cito y genotoxicidad en celomocitos de E. fetida in vivo}

La muestra ambiental de suelo proveniente de la zona de cultivo intensivo de soja no evidenció efectos significativos ( $>0,05$ ) en la mortalidad de organismos de E. fetida luego de 14 días de exposición.

\section{Citotoxicidad}

Los resultados obtenidos sobre la citotoxicidad de los suelos ambientales post-aplicación del plaguicida glifosato sobre celomocitos de organismos de E. fetida expuestos durante 7 y 14 días pueden observarse en la Tabla 22.

Tabla 22. Citotoxicidad inducida por una muestra ambiental post-aplicación de glifosato en celomocitos de E. fetida expuestos de manera in vivo durante 7 y 14 días. Resultados expresados como \% de células no viables

\begin{tabular}{ccc}
\hline Muestra & 7 días & 14 días \\
\hline Control & 10,4 & 12,5 \\
Muestra ambiental & $16,5^{* *}$ & $21,4^{* *}$
\end{tabular}

$* * \overline{\text { Diferencias estadísticamente significativas con respecto al control, } \mathrm{p}<0,05}$ 
Para ambos tiempos de exposición el suelo ambiental ejerció un efecto citotóxico estadísticamente significativo $(\mathrm{p}<0,05)$ en los celomocitos de organismos expuestos.

\section{Índices tróficos}

A partir de los mismos organismos expuestos in vivo a las muestras ambientales postaplicación de glifosato durante 7 y 14 días se determinaron los índices tróficos LITA, LITAR e ICCT, los cuales se muestran en la Tabla 23.

Al cabo de 7 de exposición los índices LITA y LITAR evidenciaron un descenso estadísticamente significativo $(\mathrm{p}<0,001)$. Asimismo, el índice ICCT se incrementó de manera significativa $(\mathrm{p}<0,05)$ con respecto a los organismos controles. A los 14 días de exposición, los índices LITA y LITAR disminuyeron su valor de manera estadísticamente significativa $(p<0,001)$, contrariamente el índice ICCT el que aumentó su valor de manera significativa con respecto a los organismos control.

Tabla 23. Índices tróficos con su desviación estándar (entre paréntesis) en organismos de $E$. fetida expuestos de manera in vivo a un suelo ambiental post-aplicación de glifosato.

\begin{tabular}{ccccccc}
\hline Muestra & \multicolumn{3}{c}{ Día 7} & & & Día 14 \\
& LITA & LITAR & ICCT & LITA & LITAR & ICCT \\
\hline Control & 0,69 & 1,61 & 6,00 & 0,69 & 1,61 & 6,00 \\
& $(0,02)$ & $(0,05)$ & $(0,03)$ & $(0,02)$ & $(0,05)$ & $(0,03)$ \\
Muestra & $0,61^{*}$ & 1,25 & $6,10^{*}$ & $0,59^{*}$ & $1,10^{*}$ & $6,14^{*}$ \\
ambiental & $(0,02)$ & $(0,04)$ & $(0,04)$ & $(0,01)$ & $(0,05)$ & $(0,03)$
\end{tabular}

$*$ Diferencias significativas con respecto al control, $\mathrm{p}<0,001$

\section{Proporciones celulares}

Las proporciones de los diferentes tipos de celomocitos para los organismos de E. fetida expuestos in vivo durante 7 y 14 días se grafican en la Figura 13. Para ambos tiempos de exposición evaluados se observó una disminución significativa $(\mathrm{p}<0,05)$ en la proporción relativa de eleocitos. 


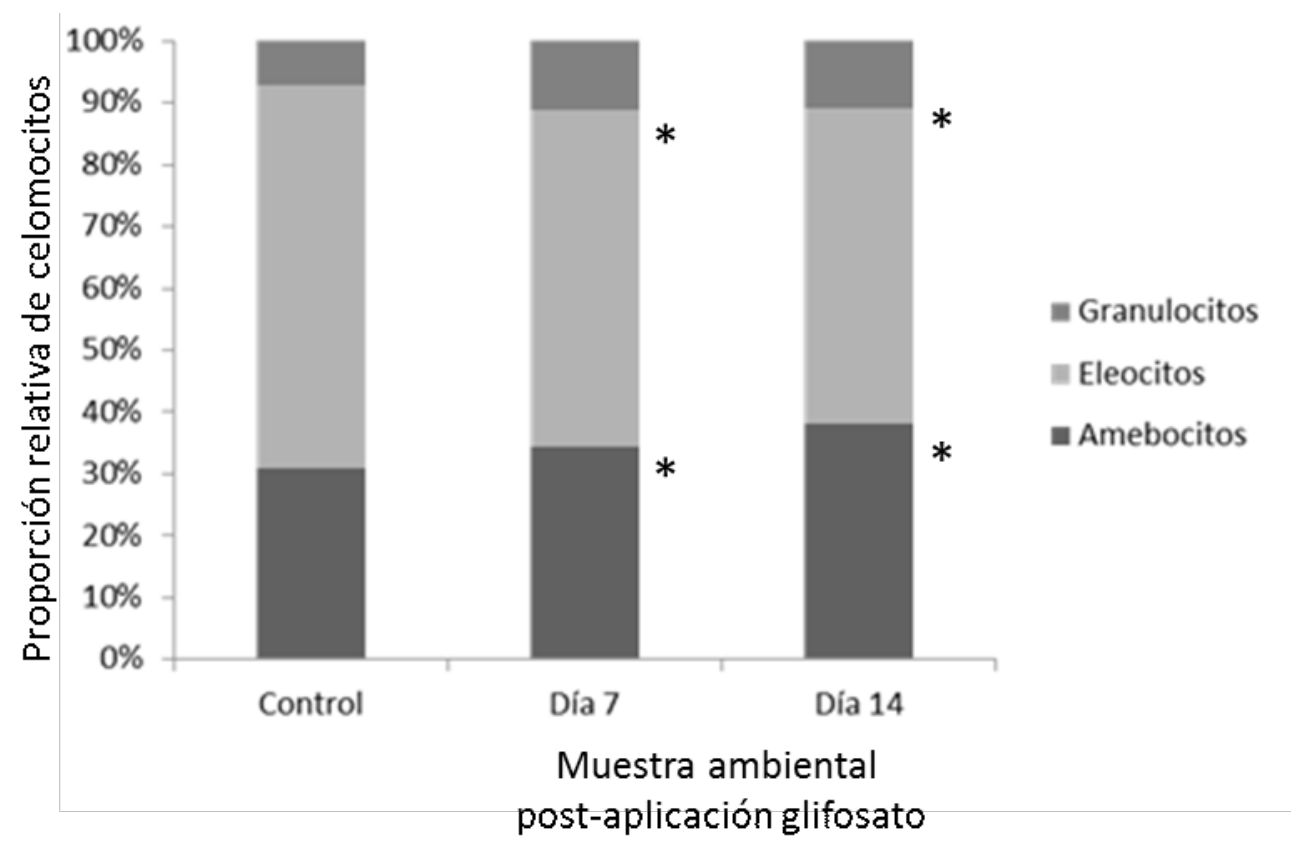

Figura 13. Proporciones celulares de organismos de E. fetida expuestos de manera in vivo a muestras ambientales post-aplicación de glifosato durante 7 y 14 días. *Diferencias estadísticamente significativas con respecto al control, $\mathrm{p}<0,05$

\section{Genotoxicidad en celomocitos de E. fetida in vivo}

Los resultados correspondientes a los tiempos de exposición de 7 y 14 días se presentan en la Figura 14. La exposición de organismos de E fetida al suelo ambiental post-aplicación de glifosato generó un incremento significativo $(\mathrm{p}<0,001)$ del daño genotóxico en los celomocitos al término de ambos períodos de exposición. Los valores de \% ADN cola resultaron 12,9 y 29,1\% para los días 7 y 14 de exposición, respectivamente.

En los ecosistemas terrestres, los microorganismos e invertebrados están involucrados en procesos bioquímicos y biológicos que juegan un papel preponderante en los ciclos geoquímicos de diversos nutrientes y en la descomposición de la materia orgánica. Estas transformaciones son sumamente importantes para los ecosistemas, específicamente para las actividades agrícolas, ya que estos procesos están relacionados con los requerimientos nutricionales de las plantas. Actividades antropogénicas, como el uso de plaguicidas, pueden afectar los suelos provocando desbalances en la comunidad terrestre comprometiendo la sustentabilidad del sistema (Cortet et al, 1999). 


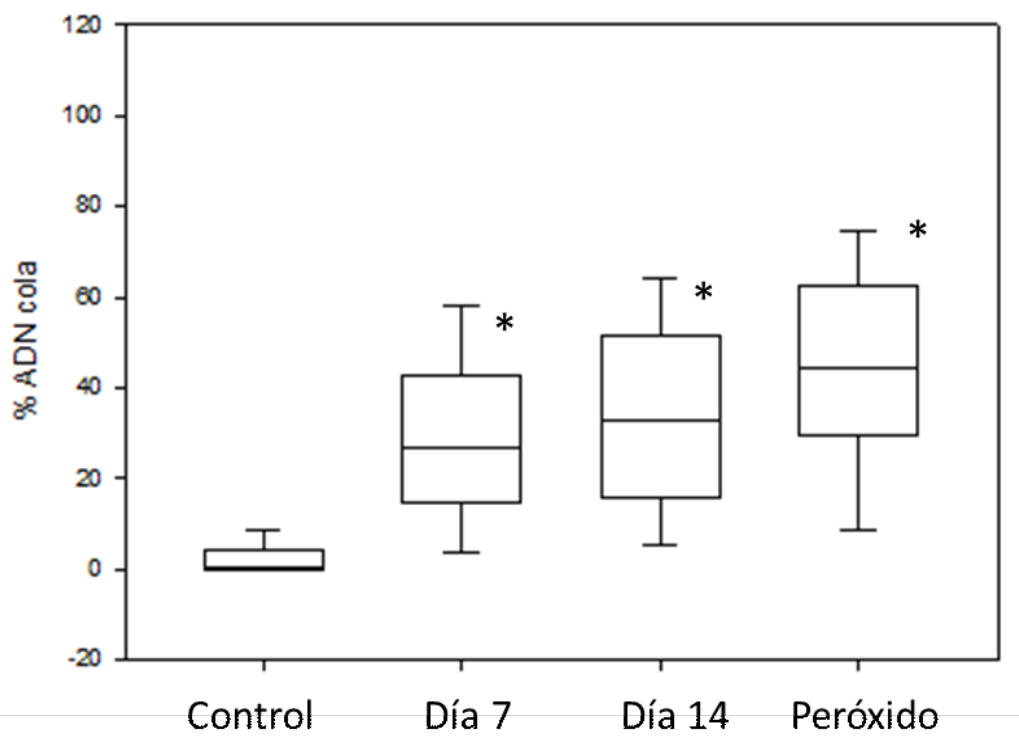

Figura 14. Genotoxicidad de la muestra ambiental post-aplicación de glifosato en celomocitos de E. fetida expuestos ex vivo durante 7 y 14 días. Los límites del "boxplot" representan los cuartiles $25 \%$ y $75 \%$, mientras que la línea central corresponde a la mediana de los valores.

Las barras indican los valores mínimos y máximos. * Diferencias estadísticamente significativas con el control, $\mathrm{p}<0,001$

Han sido observados diversos efectos adversos sobre invertebrados terrestres expuestos al formulado comercial del plaguicida glifosato. En el insecto Chrysoperla externa (Neuropthera, Chrysoperla), el glifosato ha reducido la fertilidad y fecundidad de adultos provenientes de huevos tratados, además de tumores en costes histológicos de adultos (Scheneider et al, 2009). Casabe et al (2007) han registrado una reducción significativa en la viabilidad de los cocones de E. fetida. Bakry et al (2015) han demostrado diversos efectos a nivel celular, molecular y fisiológico en la especie Bulinus truncatus (Mollusca, Planoboirdea). Incluso estos autores han observado efectos genotóxicos y citotóxicos en hemocitos de esta especie. Otros trabajos, evidenciaron la genotoxicidad del glifosato en especies acuáticas tales como el pez Cnesterodon decemmaculatus (Pisces, Poeciliidae) utilizando el ensayo cometa (Vera-Candioti et al, 2013 a; 2013 b). Clements et al (1997) han reportado la inducción de daño en el ADN, mediante la aplicación del ensayo cometa, en eritrocitos de renacuajo de la especie Rana catesbeiana (Amphibia, Ranidae) expuesta a glifosato. Poletta et al (2009) han evidenciado el efecto genotóxico del glifosato en eritrocitos de Caiman latirostris (Reptilia, Alligatoridae) expuestos in ovo mediante la utilización del ensayo cometa. 
Asimismo, Mañas et al (2009) evidenciaron el efecto genotóxico del glifosato en células de la línea celular HepG2 originada de un carcinoma hepatocelular humano mediante el ensayo cometa, y en ratones de la cepa Balb-C mediante el ensayo de micronúcleos. Siguiendo, Bolognesi et al (1997) han observado efectos genotóxicos en linfocitos de sangre periférica de humanos evidenciados por el intercambio de cromátides hermanas, y una inducción de micronúcleos en médula ósea de ratones.

En forma similar, los resultados obtenidos en este trabajo de Tesis han demostrado efectos cito y genotóxico del formulado comercial de glifosato sobre organismos de E. fetida.

\subsection{Fracción líquida-elución}

\subsection{Ensayos con plántulas de $V$. faba}

Las plántulas de $V$. faba fueron expuestas durante 48 h a la elución del suelo correspondiente a una muestra ambiental post-aplicación de glifosato. Se utilizó un control correspondiente al Medio Hoagland y otro preparado mediante la elución de un suelo no tratado. Éste control se llevó a cabo para asegurar que los efectos observados sólo se deban a los tóxicos movilizados en la fase acuosa por el proceso de extracción y no a componentes presentes en el suelo no tratado. No se observaron diferencias significativas $(p>0,05)$ entre los parámetros evaluados correspondientes el medio Hoagland y la elución del suelo control.

Tanto en las plántulas expuestas cómo en las plántulas control se determinó la biomasa, actividad de dos enzimas relacionadas al estrés oxidativo (CAT y GPOD) y nivel de peroxidación de lípidos.

\section{Efectos sobre la biomasa}

La biomasa de las plántulas de $V$. faba expuestas durante $48 \mathrm{~h}$ a la elución de la muestra ambiental post-aplicación de glifosato no evidenció cambios estadísticamente significativos $(\mathrm{p}>0,05)$ respecto al control. Sin embargo, se observó una tendencia hacia el incremento de la biomasa de las plántulas expuestas con respecto a las plántulas control. Algunos estudios previos indican que el glifosato estimula el crecimiento de poblaciones algales por estimulación de la fotosíntesis (Cedergreen y Olesen, 2010).

\section{Efectos sobre enzimas del estrés oxidativo CAT y GPOD}

Los resultados obtenidos para la cuantificación de la actividad enzimática se presentan en la Tabla 24. La muestra del suelo proveniente de una zona de cultivo de soja post-aplicación de glifosato ejerció una estimulación de la actividad de la CAT en las raíces de las plántulas 
estadísticamente significativa $(\mathrm{p}<0,05)$ con respecto al control, del orden del $816 \%$. La actividad de la enzima GPOD en raíces expuestas no evidenció cambios estadísticamente significativos $(\mathrm{p}>0.001)$ con respecto al control.

Tabla 24. Efectos expresados como media y desviación estándar (entre paréntesis), sobre la biomasa ( $\mathrm{g}$ de peso fresco), actividad enzimática ( $\mathrm{mM}$ de $\mathrm{H}_{2} \mathrm{O}_{2} / \mathrm{mg}$ proteína/min) y peroxidación lipídica ( $\mu$ mol MDA/g de peso fresco) de la elución acuosa de la muestra ambiental post-aplicación de glifosato en plántulas de $V$. faba

\begin{tabular}{lccc}
\hline & Control Hoagland & Suelo control & Muestra ambiental \\
\hline Biomasa & 0,39 & 0,41 & 0,6 \\
& $(0,09)$ & $(0,21)$ & $(0,19)$ \\
CAT & 16,18 & 33,45 & $148,25^{* *}$ \\
& $(5,97)$ & $(14,04)$ & $(24,35)$ \\
GPOD & 1,07 & 2,09 & 0,92 \\
& $(0,52)$ & $(1,21)$ & $(0,21)$ \\
MDA & 23,1 & 29,9 & 24,61 \\
& $(14,4)$ & $(8,5)$ & $(0,43)$
\end{tabular}

**Diferencias estadísticamente significativas, $\mathrm{p}<0,05$

La disponibilidad del glifosato depende de su capacidad potencial para movilizarse entre los diferentes compartimentos ambientales (Gonzalez et al, 2010). Debido a factores intrínsecos del suelo, los procesos de adsorción y desorción del plaguicida al mismo pueden verse afectados facilitando su dispersión al medio acuoso (Moorman et al, 2001; Walker et al, 2005).

Diferentes organismos acuáticos pueden verse afectados por la presencia de glifosato en dicho ambiente. Sobrero et al (2007) han demostrado la toxicidad del formulado comercial de glifosato en la macrófita acuática Lemna gibba (Magnoliophyta, Araceae). Tsui y Chu (2003) observaron efectos adversos del glifosato sobre una batería de organismos acuáticos, demostrando la acción sobre diversos organismos no blanco. El glifosato ha inducido genotoxicidad en peces de la especie Cnesterodon decemmaculatus (Pisces, Poecillidae) (Vera-Candioti et al, 2013a). Estudios realizados han demostraron la capacidad del compuesto de inducir mortalidad y malformaciones en larvas del anfibio Scinax nasicus (Anura, Hylidae) (Lajmanovich et al, 2003). Además se ha observado que este herbicida fue capaz de producir 
alteraciones bioquímicas, fisiológicas e histológicas en Prochilodus lineatus (Langiano y Martinez, 2008) y efectos adversos en el metabolismo general, estrés oxidativo y alteraciones del sistema de defensa antioxidante en Carassius auratus (Lushchak et al, 2009). Asimismo, fue capaz de inducir daño en el ADN de las especies Tilapia rendalli (Grisolia, 2002) y C. auratus (Cavaş y Könen, 2007).

Jain y Bhalla-Sarin (2001) han demostrado que el glifosato es capaz de inducir un incremento en la actividad de la enzima de detoxificación Glutationtransferasa. Los resultados obtenidos en el presente trabajo respecto al incremento de la actividad de la enzima catalasa indicarían la acción sobre la generación de especies reactivas del oxígeno, estimulando una de las enzimas del sistema de defensa antioxidante.

\section{Efectos sobre la peroxidación lipídica}

Luego de $48 \mathrm{~h}$ de exposición a la elución correspondiente a la muestra ambiental postaplicación de glifosato no se observaron diferencias estadísticamente significativas $(\mathrm{p}>0,05)$ en el nivel de peroxidación lipídica, respecto a las plántulas controles.

\subsection{Ensayos de cito y genotoxicidad en celomocitos de E. fetida ex vivo}

\section{Citotoxicidad}

La muestra ambiental post-aplicación de glifosato, produjo un incremento estadísticamente significativo $(\mathrm{p}<0,05)$ en la citotoxicidad de los celomocitos expuestos ex vivo del orden del $33 \%$ (Tabla 25).

Tabla 25. Citotoxicidad de la elución en PBS de la muestra ambiental post-aplicación de glifosato sobre los celomocitos de E. fetida. Valores expresados como \% de células no viables

\begin{tabular}{cc}
\hline Muestra & $\%$ Citotoxicidad \\
\hline Control & 11 \\
Muestra ambiental & $33 * *$
\end{tabular}

**Diferencias estadísticamente significativas, $\mathrm{p}<0,05$

Como ha sido desarrollado anteriormente, previamente a la acción citotóxica por parte de la elución, la viabilidad celular puede verse comprometida por alteración de la permeabilidad de su sistema de membranas. Casabé et al (2007) han observado una disminución en la retención del colorante en celomocitos de E fetida expuestos al herbicida glifosato. En forma similar, 
Piola et al (2013) han observado el mismo efecto en celomocitos de E. andrei. Estos resultados evidencian una acción a nivel celular causada por la exposición de los celomocitos al glifosato, indicando la sensibilidad de los celomocitos de lombrices de tierra como sistemas de ensayo.

\section{Índices tróficos}

Para los celomocitos de E. fetida expuestos ex vivo durante 1 h a la elución correspondiente a la muestra ambiental post-aplicación de glifosato se determinaron los índices tróficos los cuales son presentados en la Tabla 26.

Tanto el índice LITA como LITAR en celomocitos expuestos disminuyeron de manera estadísticamente significativa $(\mathrm{p}<0,05)$ con respecto al control.

Tabla 26. Índices tróficos con sus desviación estándar (entre paréntesis) para celomocitos expuestos durante $1 \mathrm{~h}$ a la elución de la muestra ambiental post-aplicación de glifosato

\begin{tabular}{cccc}
\hline Muestra & LITA & LITAR & ICCT \\
\hline Control & 0,68 & 1,62 & 6,0 \\
& $(0,02)$ & $(0,03)$ & $(0,04)$ \\
Muestra ambiental & $0,58^{* *}$ & $1,26^{* *}$ & 6,07 \\
& $(0,04)$ & $(0,02)$ & $(0,05)$ \\
\hline
\end{tabular}

**Diferencias estadísticamente significativas, $\mathrm{p}<0,05$

\section{Proporciones celulares}

Para la elución de la muestra ambiental post-aplicación de glifosato se determinaron las proporciones celulares de los diferentes tipos de celomocitos (Figura 15).

La proporción de eleocitos disminuyó de manera estadísticamente significativa $(p<0,05)$ para los celomocitos expuestos a la elución de la muestra ambiental post-aplicación de glifosato. Mientras tanto, la proporción relativa de amebocitos se incrementó de manera significativa $(\mathrm{p}<0,05)$ para la misma muestra evaluada. Este descenso en la proporción de eleocitos se encontró acompañado del descenso en los índices LITA y LITAR, los cuales consideran la relación entre el número de eleocitos y el número total de celomocitos. 


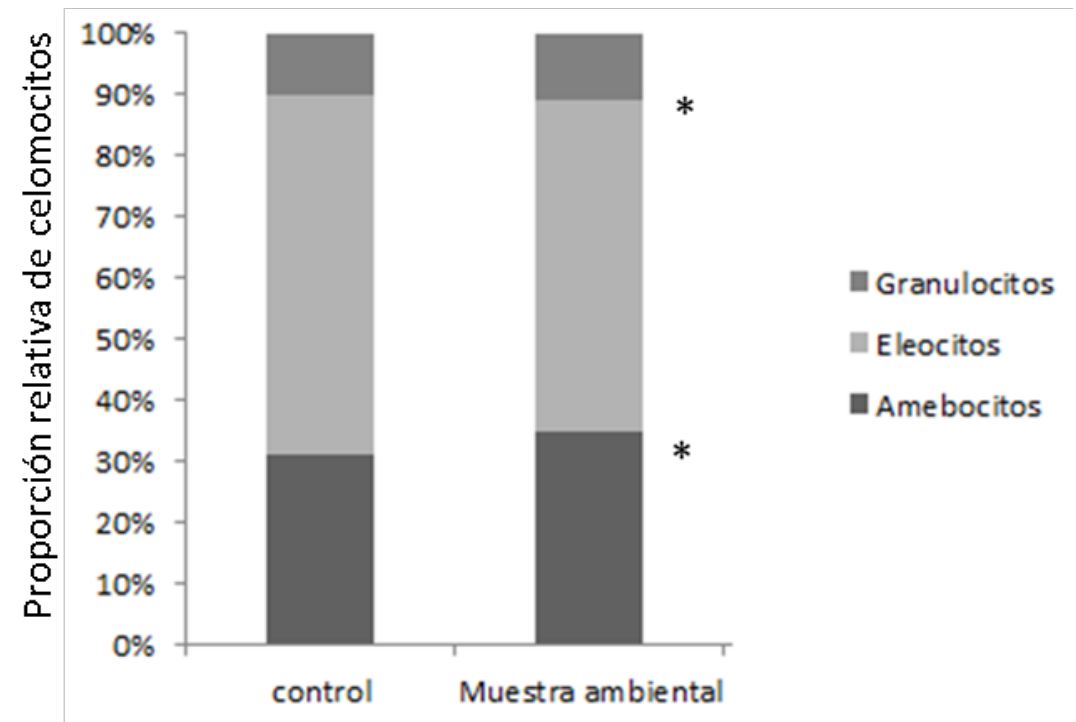

Figura 15. Proporciones celulares de celomocitos de E. fetida expuestos de manera ex vivo a la elución de la muestra ambiental post-aplicación de glifosato. *Diferencias estadísticamente significativos con respecto al control, $\mathrm{p}<0,05$

\section{Genotoxicidad en celomocitos de E. fetida ex vivo}

La genotoxicidad generada por la elución correspondiente a las muestras ambientales postaplicación de glifosato fue determinada mediante el ensayo cometa. Los resultados correspondientes a este ensayo pueden observarse en la Figura 16.

La elución provocó un incremento estadísticamente significativo $(\mathrm{p}<0,05)$ en la migración del ADN. Los celomocitos de E. fetida expuestos ex vivo a la elución evidenciaron un \% ADN cola de $9,8 \%$.

Este incremento del daño al ADN observado por celomocitos de E. fetida expuestos a glifosato evidencian la actividad genotóxica del plaguicida. Es importante considerar que el glifosato ha sido clasificado por la IARC como un compuesto probablemente carcinógeno para el hombre (IARC, 2015). Además, su acción genotóxica ha sido evidenciada en diversos sistemas de ensayo (Vera-Candioti et al, 2013 a; Grisolia, 2002; Cavaş y Könen, 2007). Asimismo, Piola et al (2013) han informado que dos diferentes formulaciones de glifosato fueron capaces de inducir daño al $\mathrm{ADN}$ de celomocitos de E. andrei evaluado mediante el ensayo cometa. 


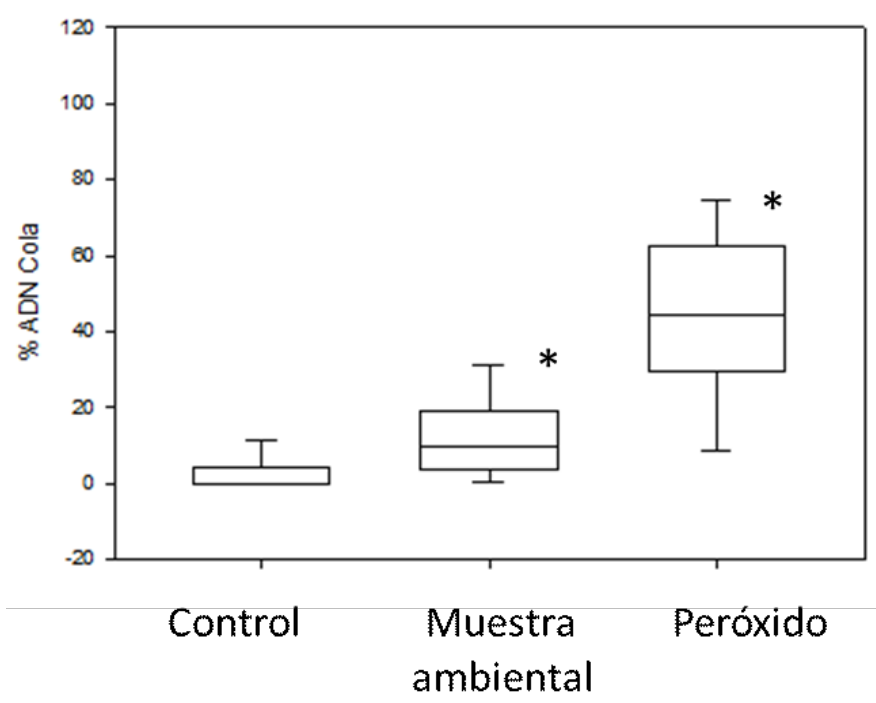

Figura 16. Genotoxicidad de la elución de la muestra ambiental post-aplicación de glifosato en celomocitos de E. fetida expuestos ex vivo durante 1 h. Los límites del "boxplot" representan los cuartiles $25 \%$ y $75 \%$, mientras que la línea central corresponde a la mediana de los valores. Las barras indican los valores mínimos y máximos. * Diferencias estadísticamente significativas con el control, $\mathrm{p}<0,05$

\subsubsection{Post-aplicación de clorpirifos}

\subsection{Muestra entera}

\subsection{Ensayos de germinación y elongación de las raíces con L. sativa}

La fitotoxicidad de una muestra ambiental post-aplicación de clorpirifos proveniente de suelos con cultivo intensivo se determinó mediante el ensayo de germinación y elongación de raíces en L. sativa. Los resultados para ambos parámetros se presentan en la Tabla 27.

El suelo ambiental post-aplicación de clorpirifos ejerció una inhibición del 82,2\% en la germinación de las semillas. Este valor resultó estadísticamente significativo $(p<0,05)$ con respecto al control.

Para el parámetro de elongación de raíces se observó una inhibición estadísticamente significativa $(\mathrm{p}<0,05)$ con un valor de $76,1 \%$ en la longitud de las mismas para organismos expuestos al suelo ambiental post-aplicación de clorpirifos.

Como consecuencia de la aplicación del clorpirifos, los ecosistemas terrestres se encuentran expuestos a la acción de este insecticida. Su persistencia en los suelos puede verse alterada por las características intrínsecas del mismo. La vida media de disipación es significativamente más larga en suelos orgánicos que en suelos minerales (Gebremariam et al, 2012). Asimismo algunas condiciones climáticas pueden favorecer la disipación del 
clorpirifos. Los procesos bióticos y abióticos, incluyendo la hidrólisis enzimática y la fotolítica son vías importantes en su degradación (Gebremariam et al, 2012), siendo incrementada la fotodegradación en climas tropicales (Chai et al, 2008). Tanto las vías aeróbicas como aneróbicas resultan importantes rutas de biodegradación (US EPA, 2006).

Esta posible persistencia y degradación del clorpirifos podría explicar la acción fitotóxica exhibida por el suelo ambiental post-aplicación de clorpirifos, evidenciada como la inhibición de la germinación y la disminución de la longitud de las raíces en L. sativa.

Tabla 27. Efecto fitotóxico de una muestra ambiental post-aplicación de clorpirifos sobre la germinación de las semillas y la elongación de las raíces en $L$. sativa

\begin{tabular}{ccccc}
\hline Muestra & $\begin{array}{c}\text { Semillas germinadas/ } \\
\text { semillas expuestas }\end{array}$ & $\begin{array}{c}\text { \%Inhibición } \\
\text { Germinación }\end{array}$ & $\begin{array}{c}\text { Elongación de } \\
\text { raíces }(\mathrm{cm})\end{array}$ & $\begin{array}{c}\text { \% Inhibición } \\
\text { elongación de raíces }\end{array}$ \\
\hline Control & $15 / 20$ & 0 & 2,8 & 0 \\
Muestra ambiental & $3 / 20$ & $82,2^{* *}$ & 0,67 & $76,1^{* *}$ \\
\hline
\end{tabular}

**Diferencias estadísticamente significativas con respecto al control, $\mathrm{p}<0,05$

\subsection{Ensayos de cito y genotoxicidad en celomocitos de E. fetida in vivo}

La muestra ambiental de suelo proveniente de la zona de cultivo intensivo de soja postaplicación de clorpirifos no evidenció efectos significativos $(p>0,05)$ en la mortalidad de organismos de E. fetida luego de 14 días de exposición.

\section{Citotoxicidad}

La citotoxicidad de la muestra ambiental post-aplicación de clorpirifos sobre celomocitos de organismos de E. fetida expuestos durante 7 y 14 días se determinó mediante el ensayo de exclusión con Azul de Tripán. Los resultados para este ensayo pueden observarse en la Tabla 28.

La muestra ambiental ejerció un efecto citotóxico estadísticamente significativo $(p<0,05)$ en los celomocitos de organismos expuestos para ambos tiempos de exposición. 
Tabla 28. Citotoxicidad inducida por una muestra ambiental post-aplicación de glifosato en celomocitos de E. fetida expuestos in vivo durante 7 y 14 días. Valores expresados como \% de células no viables

\begin{tabular}{ccc}
\hline Muestra & 7 días & 14 días \\
\hline Control & 10,4 & 12,5 \\
Muestra ambiental & $15,9^{* *}$ & $26,1^{* *}$ \\
\hline Diferencias estadísticamente significativas con respecto al control, $\mathrm{p}<0,05$
\end{tabular}

\section{Índices tróficos}

A partir de los mismos organismos expuestos in vivo a las muestras ambientales postaplicación de glifosato durante 7 y 14 días se determinaron los índices tróficos LITA, LITAR e ICCT, los cuales se muestran en la Tabla 29.

Para el día 7 de exposición se observó para los Índices LITA y LITAR una disminución de su valor estadísticamente significativa $(\mathrm{p}<0,001)$. Opuestamente, el índice ICCT permaneció sin alteraciones significativas. Para el día 14 de exposición los índices LITA y LITAR disminuyeron su valor de manera estadísticamente significativa $(\mathrm{p}<0,001)$ contrariamente el Índice ICCT, el que aumentó su valor de manera significativa con respecto a los organismos control.

Tabla 29. Índices tróficos con sus desviación estándar en organismos de E. fetida expuestos in vivo durante 7 y 14 días a un suelo ambiental post-aplicación de clorpirifos

\begin{tabular}{ccccccc}
\hline Muestra & \multicolumn{3}{c}{ Día 7} & & \multicolumn{3}{c}{ Día 14} & \\
& LITA & LITAR & ICCT & LITA & LITAR & ICCT \\
\hline Control & 0,69 & 1,61 & 6,00 & 0,69 & 1,61 & 6,00 \\
& $(0,02)$ & $(0,05)$ & $(0,03)$ & $(0,02)$ & $(0,05)$ & $(0,03)$ \\
Muestra & $0,61^{*}$ & $1,35^{*}$ & 6,04 & $0,55^{*}$ & $1,10^{*}$ & $6,15^{*}$ \\
ambiental & $(0,02)$ & $(0,04)$ & $(0,03)$ & $(0,02)$ & $(0,02)$ & $(0,01)$ \\
\hline
\end{tabular}

$*$ Diferencias significativas con respecto al control, $\mathrm{p}<0,001$

\section{Proporciones celulares}

Las proporciones celulares para los organismos expuestos in vivo durante 7 y 14 días a la muestra ambiental post-aplicación de clorpirifos se presentan en la Figura 17. 
Para el día 7 de exposición no se observaron diferencias estadísticamente significativas $(\mathrm{p}>0,05)$ para ninguno de los tres tipos celulares estudiados. En el caso del tiempo de exposición correspondiente a 14 días, la proporción de eleocitos disminuyó de manera estadísticamente significativa $(\mathrm{p}<0,05)$ mientras que la relación de amebocitos presentó un aumento significativo con respecto al control $(\mathrm{p}<0.05)$.

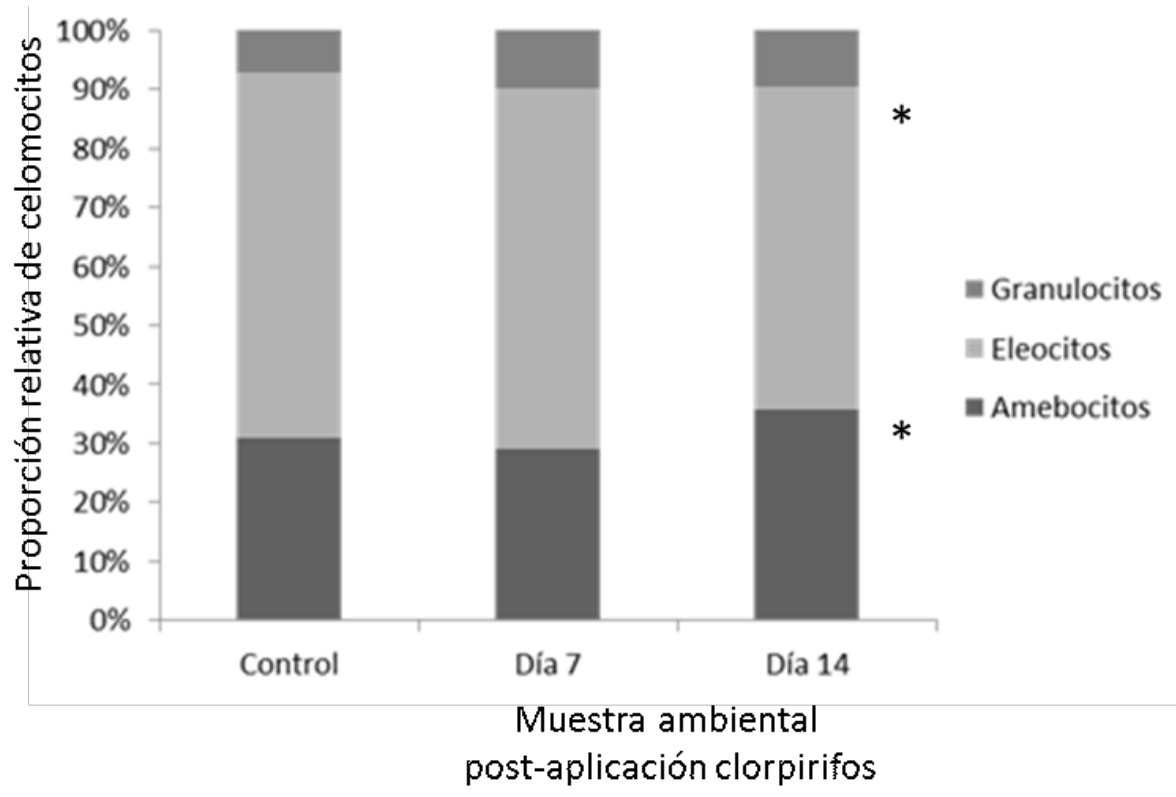

Figura 17. Proporciones celulares de organismos de E. fetida expuestos in vivo a muestras ambientales post-aplicación de clorpirifos durante 7 y 14 días. *Diferencias estadísticamente significativas con respecto al control, $\mathrm{p}<0,05$

Genotoxicidad en celomocitos expuestos in vivo

La genotoxicidad causada por la muestras ambiental post-aplicación de clorpirifos fue determinada mediante el ensayo cometa. Los resultados correspondientes a los tiempos de exposición de 7 y 14 días se presentan en la Figura 18.

A ambos tiempos evaluados, la exposición de organismos de E. fetida al suelo ambiental postaplicación de clorpirifos generó un incremento significativo $(\mathrm{p}<0,001)$ del daño genotóxico en los celomocitos de los mismos. Los valores de \% ADN Cola resultaron 26,9 y 32,7\% para el día 7 y 14 de exposición, respectivamente.

La aplicación continua de plaguicidas puede alterar los procesos naturales del suelo y asimismo afectar a organismos no blanco. Los suelos son ecosistemas complejos y los componentes presentes en los mismos pueden modular los efectos de los plaguicidas (Tarradelas et al, 1996). Los plaguicidas pueden alterar además la composición 
microbiológica del suelo, modificando su metabolismo y potencial de biodegración (Carlile, 2005). Las lombrices de tierra participan activamente en el mantenimiento de su fertilidad y estructura, debido a esto, la contaminación por la aplicación de plaguicidas que afecten a este grupo biológico, determinará cambios en la calidad físico-química del mismo (Tarradelas et al, 1996; Carlile, 2005; Römbke et al, 2005). Así las lombrices de tierra, representan un grupo relevante a ser utilizado para la evaluación de los efectos tóxicos causados por agroquímicos. De manera general los biomarcadores pueden dividirse en específicos y no específicos en base a su aplicación (Svendsen et al, 1997). Biomarcadores no específicos brindan una aproximación del estrés general que resulta de un amplio rango de contaminantes, mientras que los biomarcadores específicos permiten evaluar los efectos que se encuentran directamente vinculados con un contaminante específico (Scott-Fordsmand y Weeks, 1997). Cuando se evalúan los posibles efectos tóxicos originados por el clorpirifos, en general se recurre a un biomarcador específico tal como la actividad de la enzima acetilcolinesterasa (Calisi et al, 2009). La función de la enzima es hidrolizar la acetilcolina durante la neurotransmisión del impulso nervioso (Thompson, 1991). Dado que la actividad de la enzima es alterada por la presencia de OP, puede ser utilizada para diagnosticar la exposición a tales plaguicidas tanto en vertebrados como en invertebrados (Booth et al, 2000). La actividad de esta enzima se ha visto severamente inhibida en lombrices de tierra de la especie Aporrectodea caliginosa expuestas a clorpirifos (Booth et al, 2000). Asimismo SanchezHernandez et al (2014) han reportado una inhibición en la actividad enzimática de la acetilcolinesterasa para la misma especie expuesta a clorpirifos. Venkateswara Rao et al (2003) observaron una inhibición de la actividad de la enzima en organismos de E. fetida expuestas a clorpirifos.

Si bien este biomarcador ha demostrado ser sensible y específico para la detección de exposiciones a OP, otros biomarcadores deben ser aplicados para evaluar de manera efectiva los riesgos potenciales por exposición a plaguicidas (Svendsen et al, 1997). En el desarrollo del presente trabajo de Tesis doctoral se trabajó con biomarcadores de daño celular y genotoxicidad. Los resultados obtenidos indican que el formulado comercial evaluado actúa sobre el material genético comprometiendo la integridad del mismo y ejerciendo un efecto genotóxico tanto en organismos expuestos de manera in vivo como ex vivo. Además, hemos podido demostrar que el insecticida altera la viabilidad de los celomocitos de E. fetida, induciendo citotoxicidad. Estos resultados son concordantes con lo reportado por Casabe et al (2007) y Piola et al (2013). Ambos autores han reportado un incremento en el daño 
genotóxico evidenciado mediante el ensayo cometa en celomocitos de organismos de E. fetida expuestos a clorpirifos.

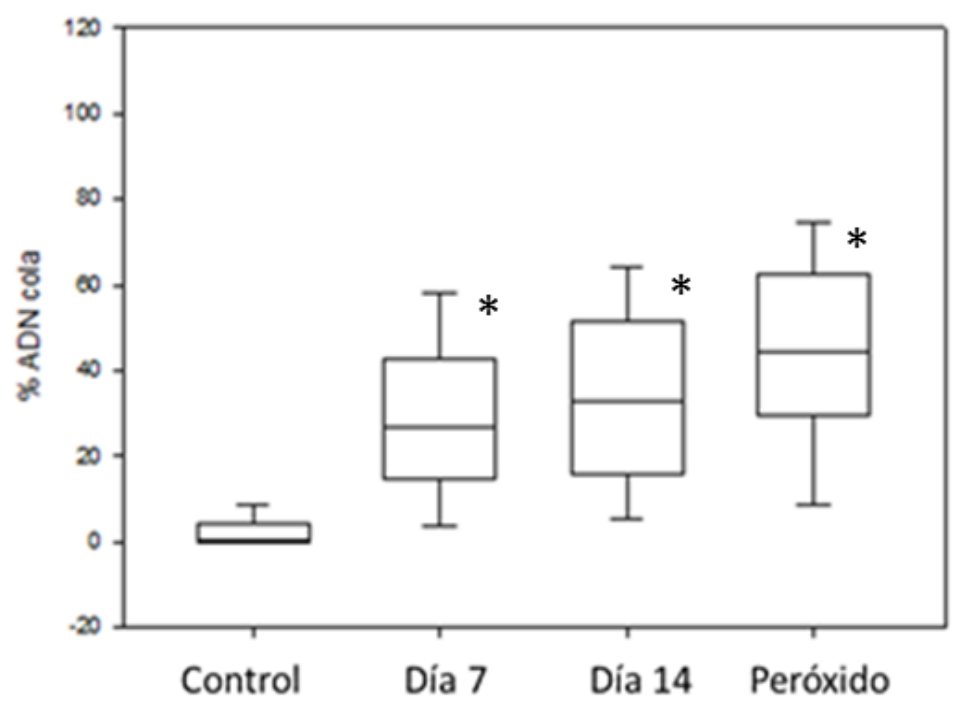

Figura 18. Genotoxicidad de la muestra ambiental post-aplicación de clorpirifos en celomocitos de E. fetida expuestos ex vivo durante 7 y 14 días. Los límites del "boxplot" representan los cuartiles $25 \%$ y $75 \%$, mientras que la línea central corresponde a la mediana de los valores. Las barras indican los valores mínimos y máximos. * Diferencias estadísticamente significativas con el control, $\mathrm{p}<0,001$

\subsection{Fracción líquida- elución}

\subsection{Ensayos con plántulas de $V$. faba}

Se expusieron plántulas de $V$. faba durante 48 h a la elución del suelo correspondiente a una muestra ambiental post-aplicación de clorpirifos. Se utilizaron en el ensayo dos controles, uno correspondiente al Medio Hoagland y otro con la elución de un suelo no tratado. Tanto en las plántulas expuestas cómo en las plántulas control se determinó la biomasa. En forma conjunta, en las raíces de estas plántulas se cuantificó, por un lado, el nivel de actividad de dos enzimas relacionadas al estrés oxidativo (CAT y GPOD) y por otro lado, el nivel de peroxidación de lípidos.

\section{Efectos sobre la biomasa}

La biomasa de las plántulas de $V$. faba expuestas durante $48 \mathrm{~h}$ a la elución de la muestra ambiental post-aplicación de clorpirifos no evidenció cambios estadísticamente significativos 
$(\mathrm{p}>0,05)$. Sin embargo, se observó una tendencia a un descenso en este parámetro para las plántulas expuestas con respecto a las plántulas control.

\section{Efectos sobre enzimas del estrés oxidativo CAT y GPOD}

La actividad de CAT y GPOD se determinó en raíces de plántulas de $V$. faba. Los resultados obtenidos se presentan en la Tabla 30. Se observó una estimulación de la actividad de la CAT estadísticamente significativa $(\mathrm{p}<0,05)$ con respecto al control del orden del $227 \%$. La enzima GPOD no evidenció cambios estadísticamente significativos $(p>0,05)$ en su nivel de actividad para la elución de la muestra ambiental post-aplicación de clorpirifos.

\section{Efectos sobre la peroxidación lipídica}

Luego de 48 h de exposición a la elución no se observaron modificaciones estadísticamente significativas $(\mathrm{p}>0,05)$ en el nivel de peroxidación lipídica.

Tabla 30. Efectos expresados como media y desviación estándar, sobre la biomasa ( $\mathrm{g}$ de peso fresco), actividad enzimática ( $\mathrm{mM}$ de $\mathrm{H}_{2} \mathrm{O}_{2} / \mathrm{mg}$ proteína/min) y peroxidación lipídica ( $\mu$ mol MDA/g de peso fresco) de la elución acuosa de una muestra ambiental post-aplicación de clorpirifos en plántulas de $V$. faba

\begin{tabular}{cccc}
\hline & Control Hoagland & Suelo control & Muestra ambiental \\
\hline Biomasa & 0,67 & 0,52 & 0,33 \\
& $(0,17)$ & $(0,15)$ & $(0,15)$ \\
CAT & 25,1 & 27,7 & $82,2^{* *}$ \\
& $(5,3)$ & $(1,61)$ & $(23,7)$ \\
GPOD & 5,05 & 4,97 & 6,19 \\
& $(0,47)$ & $(0,58)$ & $(2,56)$ \\
MDA & 15,03 & 14,6 & 12,99 \\
& $(7,1)$ & $(7,5)$ & $(0,89)$ \\
\hline
\end{tabular}

**Diferencias estadísticamente significativas con respecto al control, $\mathrm{p}<0,05$

\subsection{Ensayos de cito y genotoxicidad en celomocitos de E. fetida}

\section{Citotoxicidad}

La muestra ambiental post-aplicación de clorpirifos produjo un incremento estadísticamente significativo $(\mathrm{p}<0,05)$ en la citotoxicidad de los celomocitos expuestos ex vivo del 29\% (Tabla 
31).Como se ha explicado, antes de que la célula sufra la acción citotóxica por parte de la elución, la viabilidad celular puede verse comprometida por alteración de la permeabilidad de su sistema de membranas. Así, un biomarcador utilizado frecuentemente para evaluar la viabilidad celular es la retención del colorante rojo neutro en la membrana lisosomal (Svendsen et al, 1997). Casabé et al (2007) han observado una disminución en la retención del colorante en celomocitos de E. fetida expuestos a clorpirifos.

Tabla 31. Citotoxicidad de la elución en PBS de la muestra ambiental post-aplicación de clorpirifos sobre los celomocitos de E. fetida. Valores expresados como \% de células no viables

\begin{tabular}{cc}
\hline Muestra & \% Citotoxicidad \\
\hline Control & 11 \\
Muestra ambiental & $29 * *$ \\
\hline
\end{tabular}

** Diferencias estadísticamente significativas, $\mathrm{p}<0,05$

\section{Índices tróficos}

Los índices tróficos para los celomocitos de E. fetida expuestos ex vivo durante $1 \mathrm{~h}$ a la elución de una muestra ambiental post-aplicación de clorpirifos se presentan en la Tabla 32.

Los índices LITA y LITAR evidenciaron una disminución en sus valores con respecto a la elución control estadísticamente significativa $(\mathrm{p}<0,05)$.

El índice ICCT no se modificó para la elución de esta muestra ambiental.

Tabla 32. Índices tróficos con su desviación estándar (entre paréntesis) para celomocitos expuestos durante 1 hora a la elución de una muestra ambiental post-aplicación de clorpirifos

\begin{tabular}{cccc}
\hline Muestra & LITA & LITAR & ICCT \\
\hline Control & 0,69 & 1,6 & 6,0 \\
& $(0,02)$ & $(0,03)$ & $(0,01)$ \\
Muestra ambiental & $0,61^{* *}$ & $1,35^{* *}$ & 6,04 \\
& $(0,02)$ & $(0,05)$ & $(0,04)$
\end{tabular}

**Diferencias estadísticamente significativas, $\mathrm{p}<0,05$ 


\section{Proporciones celulares}

Las proporciones celulares de los diferentes tipos de celomocitos de E. fetida expuestos ex vivo durante $1 \mathrm{~h}$ a la elución del suelo post-aplicación de clorpirifos pueden observarse en la Figura 19. La relación de eleocitos disminuyó de manera estadísticamente significativa $(p<0,05)$ para la elución de la muestra ambiental con respecto al control. De manera paralela, la proporción de amebocitos se incrementó de manera significativa $(\mathrm{p}<0,05)$. La disminución de la proporción de eleocitos coincidió con el efecto observado en los índices LITA y LITAR, ya que ambos relacionan el número de eleocitos con el número total de celomocitos.

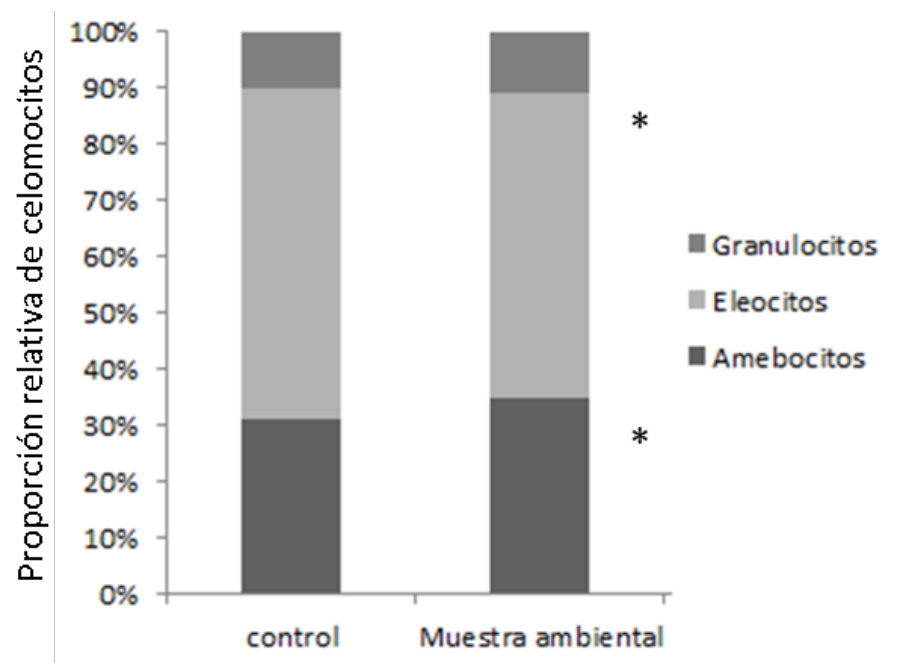

Figura 19. Proporción de celomocitos de E. fetida expuestos ex vivo durante 1 h a la elución de la muestra ambiental post-aplicación de clorpirifos. *Diferencias estadísticamente significativas con respecto al control, $\mathrm{p}<0,05$

\section{Genotoxicidad en celomocitos de E. fetida ex situ}

Los resultados obtenidos de la aplicación del ensayo cometa se observan en la Figura 20.

La elución de la muestra ambiental post-aplicación de clorpirifos provocó un incremento estadísticamente significativo $(\mathrm{p}<0,001)$ en la migración del ADN. Los celomocitos de $E$. fetida expuestos ex vivo a la elución evidenciaron un \% ADN cola de 8,9\%. 


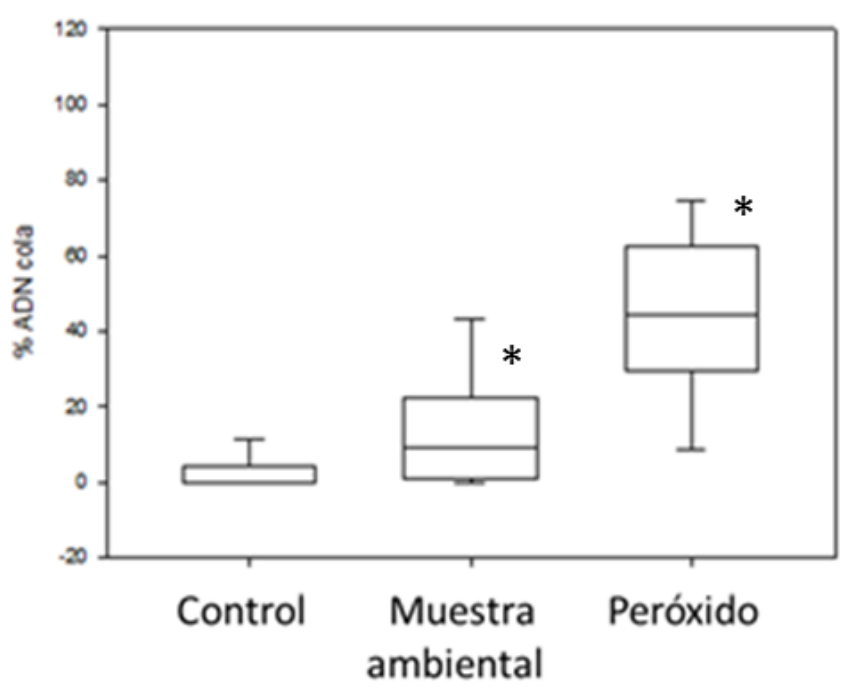

Figura 20. Genotoxicidad de la elución de la muestra ambiental post-aplicación de clorpirifos en celomocitos de E. fetida expuestos ex vivo durante 1 h. Los límites del "boxplot" representan los cuartiles $25 \%$ y $75 \%$, mientras que la línea central corresponde a la mediana de los valores. Las barras indican los valores mínimos y máximos. * Diferencias estadísticamente significativas con el control, $\mathrm{p}<0,001$

\subsubsection{Suelos tratados artificialmente con plaguicidas}

\subsubsection{Parámetros fisicoquímicos del suelo}

El suelo utilizado en el presente trabajo, proveniente de una reserva natural sin acciones humanas, fue caracterizado por Di Marzio et al (2007). Las características fisicoquímicas del suelo utilizado en el presente trabajo se detallan en la Tabla 33. Este suelo presentó un pH ligeramente ácido, con un valor de 6,1. El suelo presentó los siguientes contenidos de C Orgánico, P y N total: 19,3 mg/kg de C orgánico; 26,8 mg/kg de P disponible y 1,7 mg/kg de $\mathrm{N}$ total.

La textura del suelo resultó ser como franco-limoso según la proporción de las partículas que forman en suelo. En este caso la proporción de arcilla-limo-arena resultó ser de 28,5; 48,5 y $23 \%$ respectivamente.

En base a la clasificación de USDA (2003), el suelo correspondió al tipo Molisol, suborden Argiudols, sub-grupo Argidols típico. Estos suelos se caracterizan por presentar color oscuro, con un horizonte superficial rico en humus, en el cual los cationes bivalentes dominan el grado de intercambio (Di Marzio et al, 2007). 
Tabla 33. Principales características fisicoquímicas del suelo utilizado. Valores expresados como C Orgánico y $\mathrm{N}$ total $(\mathrm{mg} / \mathrm{kg}), \mathrm{P}$ disponible $(\mathrm{mg} / \mathrm{kg})$. Contenido de arcilla, limo y arena en $\%$. CIC en $\mathrm{cm}^{3} / \mathrm{kg}$.

\begin{tabular}{cc}
\hline Parámetro & Suelo \\
\hline $\mathrm{pH}$ & 6,1 \\
C Orgánico & 19,3 \\
P disponible & 26,8 \\
N total & 1,7 \\
Contenido de arcilla & 28,5 \\
Contenido de limo & 48,5 \\
Contenido de arena & 23,0 \\
CIC & 30,3 \\
\hline
\end{tabular}

\subsubsection{Suelos tratados con glifosato}

\subsection{Muestra entera}

\subsection{Ensayo de germinación y elongación de las raíces con $L$. sativa}

La fitotoxicidad de los suelos tratados artificialmente con glifosato se determinó mediante el ensayo de germinación de semillas y elongación de raíces en L. sativa.

Se evaluaron las dosis de aplicación recomendadas por los fabricantes de los formulados comerciales utilizados. Para el glifosato se utilizaron las dosis de aplicación correspondientes a 2,5; 4 y 6 L/ha (Tabla 34).

En el caso de la dosis de $6 \mathrm{~L} / \mathrm{ha}$, la misma provocó una inhibición de la germinación de las semillas estadísticamente significativa $(p<0,05)$ del orden del $73,3 \%$. El efecto de dosis menores de aplicación de 2,5 L/ha generó una inhibición de la germinación del $26 \%$, mientras que la dosis de $4 \mathrm{~L} /$ ha causó una inhibición del 6,7\%. Estos efectos no resultaron ser estadísticamente significativos con respecto al control ( $\mathrm{p}>0,05)$.

La CL50-120h estimada para el glifosato resultó ser de 5,1 L/ha con un intervalo de confianza de $95 \%$ de (rango, 4,6-5,6).

Para el parámetro de elongación de las raíces todas las dosis de aplicación evaluadas provocaron una inhibición estadísticamente significativa $(\mathrm{p}<0,05)$ con respecto al control.

Se ha determinado que, para el caso particular en las plantas vasculares, el glifosato afecta el metabolismo de las auxinas interfiriendo en las síntesis de AIA, una importante hormona auxínica (Blackburn y Boutin, 2003). Esta hormona actúa en la regulación del crecimiento, en 
la diferenciación celular en diferentes tejidos, es responsable de la elongación de los coleoptilos y la iniciación de ramas y raíces, y normalmente está presente en las semillas (Heldt, 2005). De esta manera es dable esperar la aparición de efectos fitotóxicos sobre organismos vegetales que compartan estas vías metabólicas.

Diferentes estudios avalan los efectos fitotóxicos del herbicida sobre especies vegetales no blanco mediante la alteración de diversos procesos metabólicos en los mismos.

Fuchs et al (2002) han demostrado que el glifosato fue capaz de generar efectos diversos tales como inhibición de la fotosíntesis, reducción del intercambio de gases en los estomas y disminución de los niveles de los metabolitos del Ciclo de Kalvin en Abutilon theophrasti (Magnoliophyta, Malvaceae). Kogan (2004) ha observado considerables alteraciones morfológicas en organismos de importancia comercial de la especie Asparagus officinalis (Magnoliophyta, Asparagaceae) luego de la aplicación directa del herbicida glifosato. María et al (2005) han reportado que el glifosato provocó alteraciones en el aparato fotosintético y la estructura de los nódulos en organismos de la especie Lupinus albus (Magnoliophyta, Fabaceae). En el caso de plantas de la especie Bolboschoenus maritimus (Liliophyta, Cyperaceae), el glifosato ha demostrado ejercer efectos adversos en el crecimiento de la misma, principalmente por interaccionar con su sistema radicular (Mateos- Naranjo y PerezMartin, 2013).

Los resultados observados para la inhibición de la germinación y la elongación de las raíces en L. sativa, tanto en los suelos tratados artificialmente como en la muestra ambiental postaplicación de glifosato, revelan un efecto fitotóxico del plaguicida y su persistencia en el suelo.

Tabla 34. Efecto fitotóxico de los suelos tratados artificialmente con glifosato sobre la germinación de las semillas y la elongación de las raíces en L. sativa

\begin{tabular}{ccccc}
\hline $\begin{array}{c}\text { Dosis de aplicación de } \\
\text { glifosato } \\
(\mathrm{L} / \mathrm{ha})\end{array}$ & $\begin{array}{c}\text { Semillas } \\
\text { germinadas/semillas } \\
\text { expuestas }\end{array}$ & $\begin{array}{c}\text { Inhibición } \\
\text { Germinación } \\
(\%)\end{array}$ & $\begin{array}{c}\text { Elongación de } \\
\text { raíces }(\mathrm{cm})\end{array}$ & $\begin{array}{c}\text { Inhibición } \\
\text { elongación de } \\
\text { raíces }(\%)\end{array}$ \\
\hline 0 (Control) & $15 / 20$ & 0 & 2,8 & 0 \\
2,5 & $11 / 20$ & 26,6 & 0,96 & $65,7^{* *}$ \\
4 & $14 / 20$ & 6,7 & 1,3 & $53,9^{* *}$ \\
6 & $4 / 20$ & $73,3^{* *}$ & 0,76 & $72,8^{* *}$
\end{tabular}

** Diferencias estadísticamente significativas con respecto al control, $\mathrm{p}<0,05$ 


\subsection{Ensayos de cito y genotoxicidad en celomocitos de E. fetida in vivo}

Las dosis de aplicación evaluadas no incrementaron significativamente la mortalidad de organismos de E. fetida expuestas in vivo durante 14 días con respecto al control. Casabé et al (2007) han observado que si bien el glifosato alteró de manera significativa la viabilidad de los cocones de E. andrei, no se produjo mortalidad de organismos expuestos al formulado comercial del glifosato en suelos.

\section{Citotoxicidad}

La citotoxicidad de los suelos tratados artificialmente a las dosis de aplicación del plaguicida glifosato sobre celomocitos de organismos de E. fetida expuestos durante 7 y 14 días pueden observarse en la Tabla 35.

Para el día 7 de exposición, la citotoxicidad aumentó con las dosis de aplicación evaluadas, siendo este incremento estadísticamente significativo para las dosis de aplicación correspondientes a 4 y 6 L/ha. Para el día 14 de exposición todas las dosis de aplicación evaluadas produjeron un creciente efecto citotóxico en los celomocitos de organismos expuestos con valores de células no viables del 19,4; 18,6 y 21,4\% para las dosis de aplicación correspondientes a 2,5; 4 y $6 \mathrm{~L} / \mathrm{ha}$, respectivamente. Este efecto es estadísticamente significativo para todas las dosis de aplicación evaluadas $(\mathrm{p}<0,05)$.

En forma similar, otros autores han reportado una disminución en la estabilidad de la membrana lisosomal en celomocitos de E. andrei expuestas al herbicida (Casabé et al, 2007; Piola et al, 2013).

Tabla 35. Citotoxicidad inducida por glifosato en celomocitos de E. fetida expuestos de manera in vivo durante 7 y 14 días. Valores expresados como \% de células no viables

\begin{tabular}{ccc}
\hline Dosis de aplicación (L/ha) & 7 días & 14 días \\
\hline 0 (Control) & 10,2 & 12,5 \\
2,5 & 15 & $19,4^{* *}$ \\
4 & $19,5^{* *}$ & $18,6^{* *}$ \\
6 & $23,2^{* *}$ & $21,4^{* *}$ \\
\hline
\end{tabular}

$* *$ Diferencias estadísticamente significativas con respecto al control, $\mathrm{p}<0,05$ 


\section{Índices tróficos}

A partir de los mismos organismos expuestos in vivo a los suelos tratados artificialmente con glifosato durante 7 y 14 días se determinaron los índices tróficos LITA, LITAR e ICCT los cuales se muestran en la Tabla 36.

Para el día 7 de exposición, el Índice LITA disminuyó de manera estadísticamente significativa $(\mathrm{p}<0,05)$ para todas las dosis de aplicación ensayadas. Acorde a esta disminución, se observó el mismo comportamiento para el Índice LITAR cuyo descenso también resultó estadísticamente significativo $(\mathrm{p}<0,05)$ a todas las dosis de aplicación. El índice ICCT no presentó alteraciones independientemente de las dosis de aplicación de glifosato y los tiempos de exposición ( $\mathrm{p}>0,05)$.

Para el día 14 de exposición, los Índices LITA y LITAR evidenciaron un descenso estadísticamente significativo $(\mathrm{p}<0,05)$ para todas las dosis de aplicación evaluadas.

Tabla 36. Índices tróficos en organismos de E. fetida expuestos in vivo a suelos tratados con diferentes dosis de aplicación con glifosato. Entre paréntesis se indica la desviación estándar

\begin{tabular}{ccccccc}
\hline (L/ha) & \multicolumn{3}{c}{ Día 7} & & Día 14 & \\
& LITA & LITAR & ICCT & LITA & LITAR & ICCT \\
\hline 0 & 0,69 & 1,6 & 6,00 & 0,69 & 1,6 & 6,00 \\
& $(0,02)$ & $(0,05)$ & $(0,03)$ & $(0,02)$ & $(0,05)$ & $(0,03)$ \\
2,5 & $0,57 * *$ & $1,21^{* *}$ & 6,03 & $0,58 * *$ & $1,12 * *$ & 6,02 \\
& $(0,02)$ & $(0,05)$ & $(0,02)$ & $(0,02)$ & $(0,04)$ & $(0,04)$ \\
4 & $0,59 * *$ & $1,28^{* *}$ & 6,04 & $0,58 * *$ & $1,19 * *$ & 6,03 \\
& $(0,02)$ & $(0,07)$ & $(0,07)$ & $(0,02)$ & $(0,06)$ & $(0,05)$ \\
& $0,60 * *$ & $1,21 * *$ & 6,07 & $0,54 * *$ & $1,02 * *$ & 6,01 \\
& $(0,03)$ & $(0,05)$ & $(0,03)$ & $(0,02)$ & $(0,06)$ & $(0,02)$
\end{tabular}

** Diferencias significativas con respecto al control, $\mathrm{p}<0,05$

\section{Proporciones celulares}

Las proporciones de los diferentes tipos de celomocitos para los organismos de E. fetida expuestos in vivo fueron calculados en los organismos expuestos a 7 y 14 días a los suelos tratados artificialmente con glifosato (Figura 21 y Figura 22). 


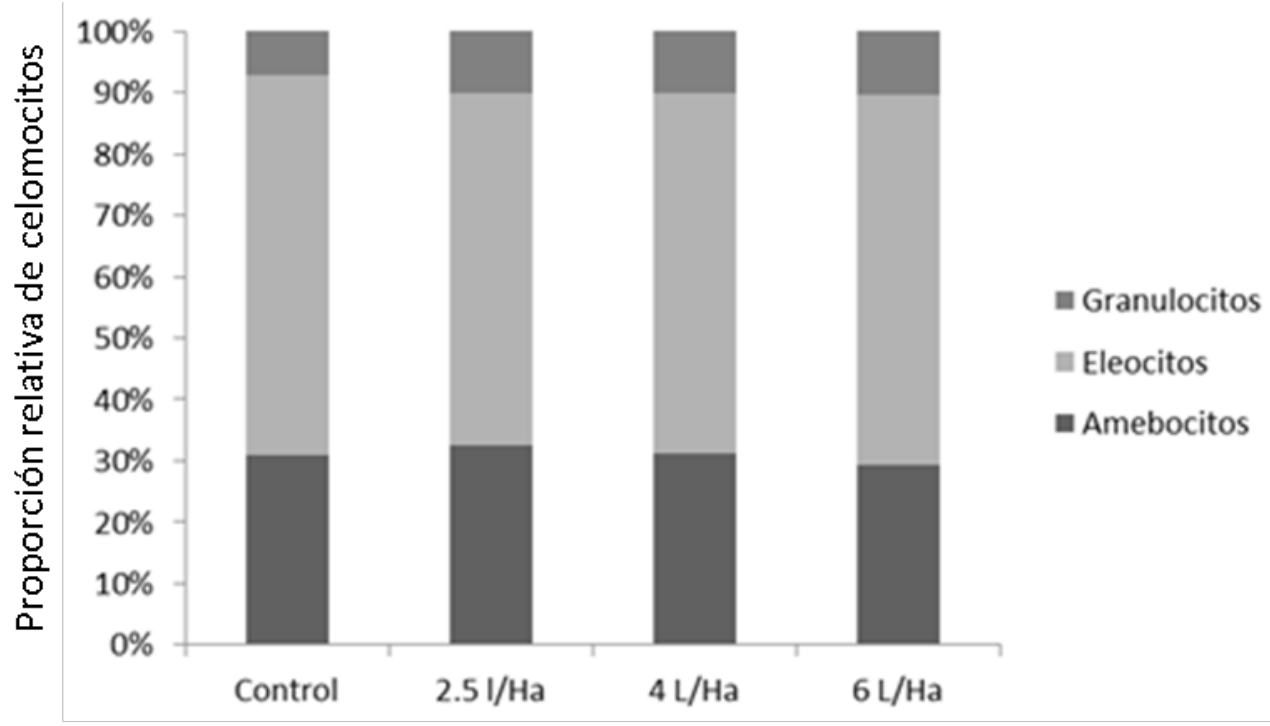

Dosis de aplicación de glifosato

Figura 21. Proporciones celulares en organismos de E. fetida expuestos in vivo durante 7 días a suelos tratados artificialmente con glifosato

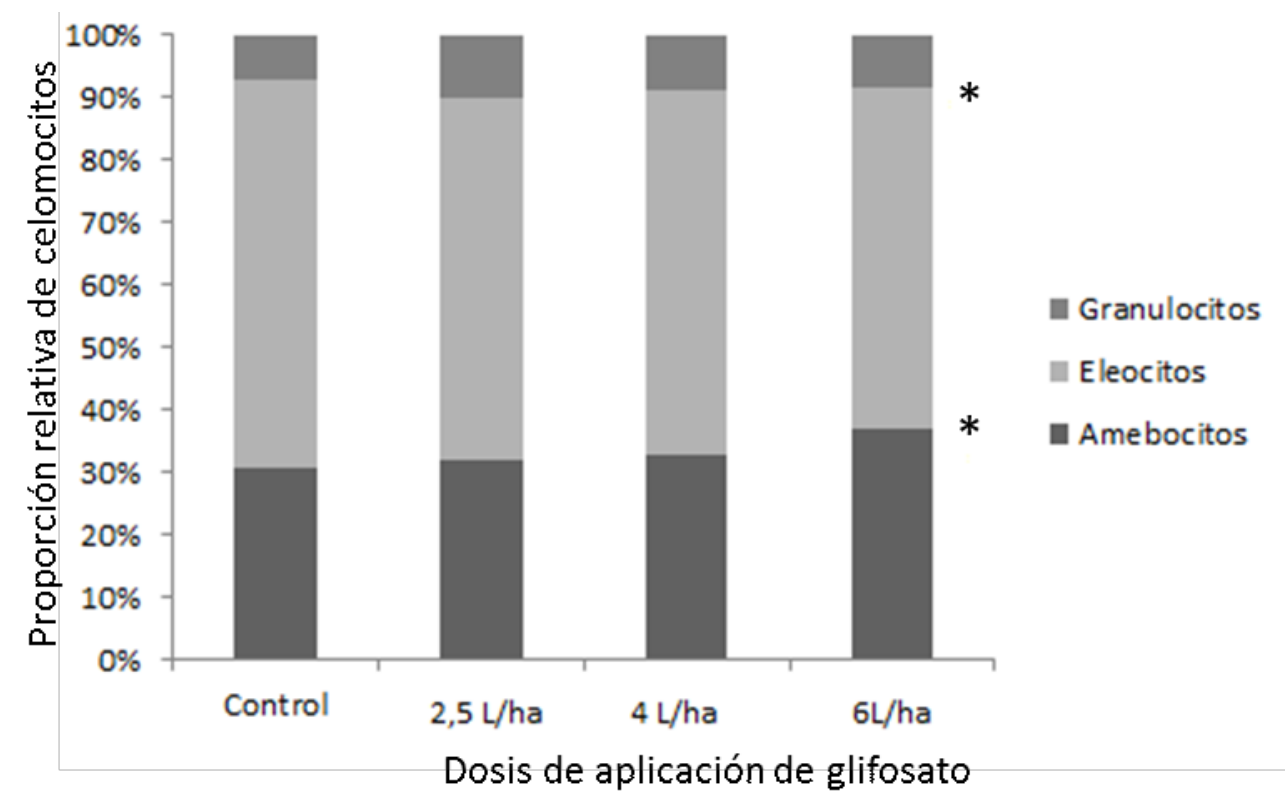

Figura 22. Proporciones celulares en organismos de E. fetida expuestos in vivo durante 14 días a suelos tratados artificialmente con glifosato. *Diferencias estadísticamente significativas con el control, $\mathrm{p}<0,05$

Las proporciones de los tres tipos celulares se mantuvieron sin modificaciones significativas para el día 7 de exposición. Sin embargo, los eleocitos evidenciaron una tendencia al descenso en su proporción relativa, la cual fue coincidente con la disminución de los Índices LITA y LITAR. Para el día 14 de exposición, la proporción de eleocitos presentó un marcado 
descenso en su proporción relativa, volviéndose este cambio estadísticamente significativo $(\mathrm{p}<0,05)$ para la dosis de aplicación de $6 \mathrm{~L} / \mathrm{ha}$. De manera similar, los amebocitos incrementaron su proporción de manera significativa para esta misma dosis de aplicación $(\mathrm{p}<0,05)$.

Genotoxicidad en celomocitos de E. fetida in vivo

Los resultados obtenidos correspondientes a la genotoxicidad al cabo de los tiempos de exposición de 7 y 14 días pueden observarse en la Figuras 23 y Figura 24, respectivamente.

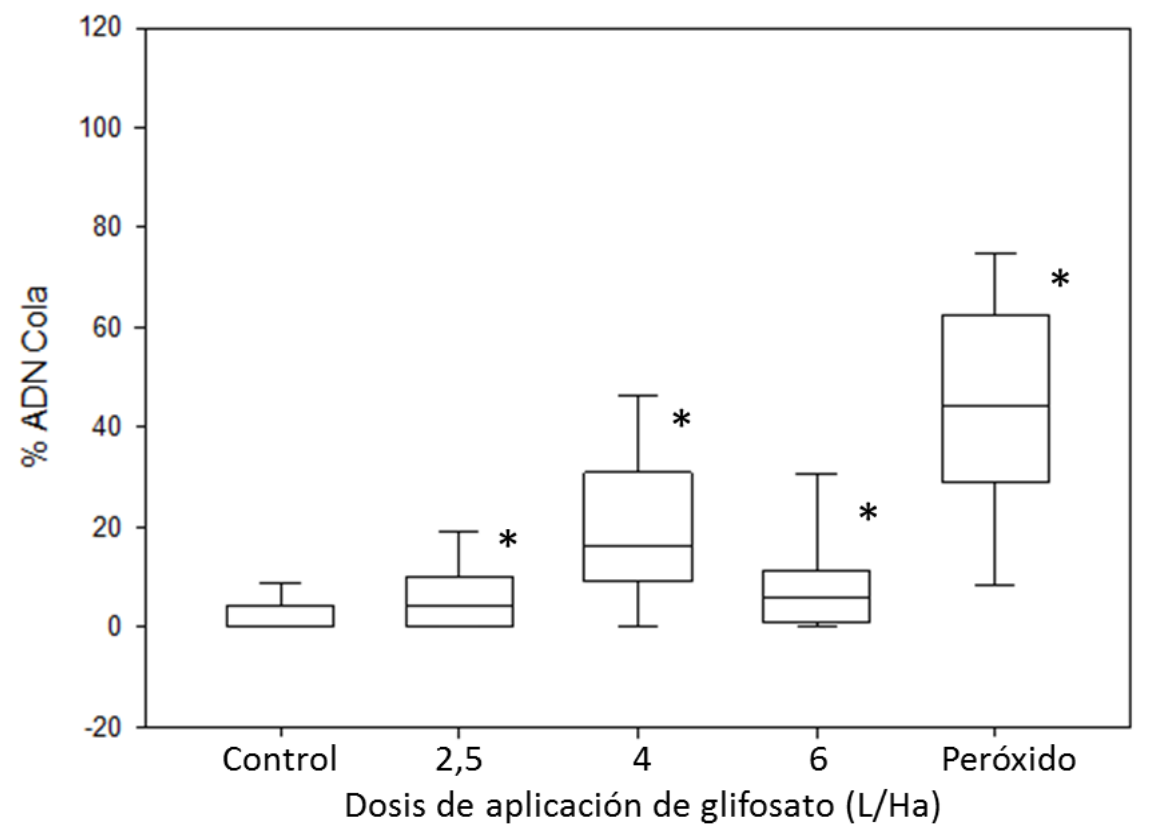

Figura 23. Genotoxicidad de los suelos tratados artificialmente con glifosato en celomocitos de E. fetida expuestos in vivo durante 7 días. Los límites del "boxplot” representan los cuartiles $25 \%$ y $75 \%$, mientras que la línea central corresponde a la mediana de los valores.

Las barras indican los valores mínimos y máximos. * Diferencias estadísticamente significativas con el control, $\mathrm{p}<0,001$

Para el día 7 de exposición, todas las dosis de aplicación de glifosato evaluadas incrementaron la migración del ADN de manera estadísticamente significativa $(\mathrm{p}<0,001)$. El \% ADN cola para las dosis de aplicación de 2,5; 4 y 6 L/ha resultó ser de 30,1; 18,1 y 12,6\%, respectivamente. 


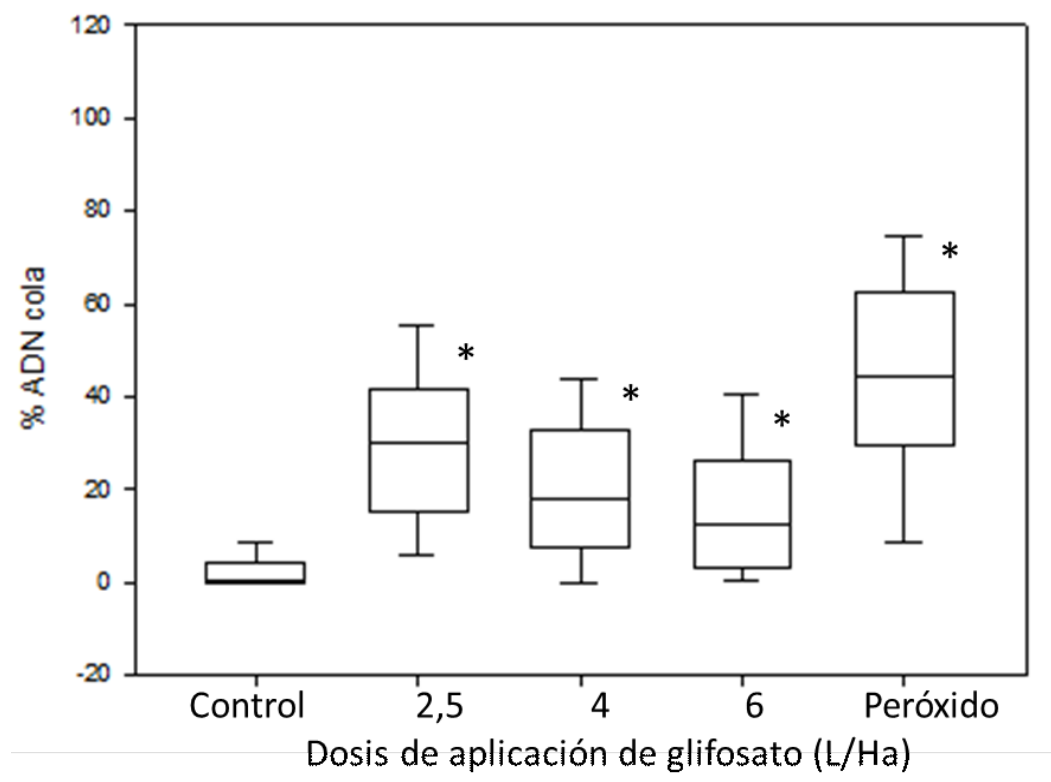

Figura 24. Genotoxicidad de los suelos tratados artificialmente con glifosato en celomocitos de E. fetida expuestos in vivo durante 14 días. Los límites del "boxplot" representan los cuartiles $25 \%$ y $75 \%$, mientras que la línea central corresponde a la mediana de los valores.

Las barras indican los valores mínimos y máximos. * Diferencias estadísticamente significativas con el control, $\mathrm{p}<0,001$

Para el día 14 de exposición, todas las dosis de aplicación de glifosato evaluadas provocaron daño genotóxico en los celomocitos de organismos de E. fetida expuestos in vivo. El \% de ADN cola resultó ser de 4,1; 16,3 y 5,8 \% para las dosis de aplicación de glifosato correspondientes a 2,5; 4 y 6 L/ha, respectivamente. Estos valores resultaron ser estadísticamente significativos $(\mathrm{p}<0,001)$ con respecto al control.

\subsection{Fracción líquida- elución}

\subsection{Ensayos con plántulas de V.faba}

Las plántulas de $V$. faba fueron expuestas durante $48 \mathrm{~h}$ a las eluciones de los suelos artificialmente tratados con las diferentes dosis de aplicación correspondientes a 2,5; 4 y 6 L/ha de glifosato. En el caso de las eluciones de los suelos se realizó un control correspondiente al Medio Hoagland y otro a la elución de un suelo no tratado Los parámetros de ambas controles no arrojaron diferencias estadísticamente significativas (Tabla 37)

Tanto en las plántulas expuestas cómo en las plántulas control se determinó la biomasa. En forma conjunta, en las raíces de estas plántulas se cuantificó, por un lado, el nivel de actividad 
de dos enzimas relacionadas al estrés oxidativo CAT y GPOD y, por otro lado, el nivel de peroxidación de lípidos.

\section{Efectos sobre biomasa}

La biomasa de las plántulas de $V$. faba expuestas durante $48 \mathrm{~h}$ a las eluciones de los suelos tratados artificialmente con glifosato no presentó cambios estadísticamente significativos $(\mathrm{p}>0,05)$. Sin embargo se observó una tendencia hacia el incremento de la biomasa a medida que aumentan las dosis de aplicación. Este fenómeno podría relacionarse con un aumento en la actividad fotosintética en diferentes productores primarios reportada anteriormente por otros autores (Cedergreen et al, 2007; Sáenz et al, 2012).

\section{Efectos sobre enzimas del estrés oxidativo CAT y GPOD}

Los resultados obtenidos para la cuantificación de la actividad enzimática se presentan en la Tabla 37.

Tabla 37. Efectos expresados como media y desviación estándar (entre paréntesis), sobre la biomasa ( $\mathrm{g}$ de peso fresco), actividad enzimática ( $\mathrm{mM}$ de $\mathrm{H}_{2} \mathrm{O}_{2} / \mathrm{mg}$ proteína/min) y peroxidación lipídica ( $\mu \mathrm{mol} \mathrm{MDA} / \mathrm{g}$ de peso fresco) de la elución acuosa de suelos artificialmente tratados con glifosato sobre plántulas de $V$. faba

\begin{tabular}{|c|c|c|c|c|c|}
\hline & \multirow{3}{*}{$\begin{array}{l}\text { Control } \\
\text { Hoagland }\end{array}$} & \multirow{3}{*}{$\begin{array}{l}\text { Suelo } \\
\text { control }\end{array}$} & \multicolumn{3}{|c|}{ Dosis de aplicación de Glifosato (L/ha) } \\
\hline & & & \multirow[t]{2}{*}{2,5} & \multirow[t]{2}{*}{4} & \multirow[t]{2}{*}{6} \\
\hline & & & & & \\
\hline \multirow[t]{2}{*}{ Biomasa } & 0,39 & 0,41 & 0,47 & 0,5 & 0,48 \\
\hline & $(0,09)$ & $(0,21)$ & $(0,12)$ & $(0,17)$ & $(0,08)$ \\
\hline \multirow[t]{2}{*}{ CAT } & 16,2 & 33,4 & $268,7 * *$ & $140,1 * *$ & 15,2 \\
\hline & $(5,9)$ & $(14,04)$ & $(30,3)$ & $(27,5)$ & $(5,75)$ \\
\hline \multirow[t]{2}{*}{ GPOD } & 1,07 & 2,09 & 3,21 & 3,25 & 3,66 \\
\hline & $(0,52)$ & $(1,21)$ & $(1,77)$ & $(1,25)$ & $(1,0)$ \\
\hline \multirow[t]{2}{*}{ MDA } & 23,1 & 29,9 & 29,4 & 20,5 & 15,13 \\
\hline & $(14,4)$ & $(8,5)$ & $(4,57)$ & $(6,21)$ & $(4,02)$ \\
\hline
\end{tabular}

** Diferencias estadísticamente significativas con respecto al control, $\mathrm{p}<0,05$ 
La actividad de la enzima CAT evidenció una fuerte estimulación, estadísticamente significativa $(\mathrm{p}<0,05)$ del orden del $1560 \%$ para la dosis de aplicación de glifosato correspondiente a 2,5 L/ha. Asimismo, la enzima se encontró estimulada de manera significativa $(\mathrm{p}<0,05)$ para la dosis de aplicación de $4 \mathrm{~L} / \mathrm{ha}$ en una magnitud del $775 \%$.

La actividad de la enzima GPOD no presentó cambios estadísticamente significativos $(\mathrm{p}>0,05)$ independientemente de las dosis de aplicación de glifosato ensayadas.

\section{Efectos sobre peroxidación lipídica}

Los niveles de MDA en raíces de las plántulas expuestas a la elución de los suelos tratados artificialmente con las diferentes dosis de aplicación de glifosato se muestran en la Tabla 37. La elución de los suelos tratados artificialmente con glifosato no provocó una modificación estadísticamente significativa $(\mathrm{p}>0,05)$ en el contenido de MDA en comparación con el control, independientemente de las dosis de aplicación evaluadas.

\subsection{Ensayos de cito y genotoxicidad en celomocitos de E. fetida ex vivo}

\section{Citotoxicidad}

La citotoxicidad de la elución acuosa de los suelos tratados artificialmente con diferentes dosis de aplicación de glifosato se presenta en la Tabla 38.

Tabla 38. Citotoxicidad de las eluciones en PBS de los suelos tratados artificialmente con glifosato sobre los celomocitos de E. fetida. Valores expresados como \% de células no viables

\begin{tabular}{cc}
\hline Dosis de aplicación (L/ha) & $\%$ Citotoxicidad \\
\hline 0 (control) & 11 \\
2,5 & $23 * *$ \\
4 & $35^{* *}$ \\
6 & $42^{* *}$ \\
\hline
\end{tabular}

**Diferencias estadísticamente significativas, $\mathrm{p}<0,05$

Todas las dosis de aplicación de glifosato ensayadas ejercieron un efecto citotóxico estadísticamente significativo $(\mathrm{p}<0,05)$. La respuesta resultó positiva a medida que se incrementaron las dosis de aplicación evaluadas sobre los celomocitos de E. fetida expuestos ex vivo durante $1 \mathrm{~h}$. 


\section{Índices tróficos}

Los índices tróficos para los celomocitos expuestos ex vivo pueden observarse en la Tabla 39.

Tabla 39. Índices tróficos para celomocitos expuestos durante 1 hora a las eluciones de los suelos artificialmente tratados con glifosato. Entre paréntesis se indica la desviación estándar

\begin{tabular}{cccc}
\hline $\begin{array}{c}\text { Dosis de aplicación } \\
\text { de glifosato (L/ha) }\end{array}$ & LITA & LITAR & ICCT \\
\hline 0 & 0,68 & 1,61 & 6,0 \\
& $(0,02)$ & $(0,03)$ & $(0,04)$ \\
2,5 & $0,58^{* *}$ & $1,26^{* *}$ & 6,02 \\
& $(0,01)$ & $(0,02)$ & $(0,04)$ \\
4 & $0,56^{* *}$ & $1,31^{* *}$ & 6,01 \\
& $(0,02)$ & $(0,01)$ & $(0,02)$ \\
6 & $0,54^{* *}$ & $1,41^{* *}$ & $5,94 * *$ \\
& $(0,05)$ & $(0,03)$ & $(0,02)$ \\
\hline
\end{tabular}

**Diferencias estadísticamente significativas, $\mathrm{p}<0,05$

Tanto el Índice LITA como LITAR disminuyeron de manera significativa $(\mathrm{p}<0,05)$ para todas las dosis de aplicación de glifosato ensayadas. El Índice ICCT evidenció una disminución estadísticamente significativa $(\mathrm{p}<0,05)$ para la elución del suelo tratado artificialmente con la mayor dosis de aplicación de glifosato.

\section{Proporciones celulares}

Las proporciones celulares para los organismos de E. fetida expuestos ex vivo durante $1 \mathrm{~h} \mathrm{a}$ las eluciones de los suelos tratados artificialmente con diferentes dosis de aplicación de glifosato se presentan en la Figura 25.

La proporción relativa de eleocitos disminuyó de manera estadísticamente significativa $(\mathrm{p}<0,05)$ para las dosis de aplicación de 4 y $6 \mathrm{~L} / \mathrm{ha}$. Paralelamente, la proporción de amebocitos se incrementó de manera significativa $(\mathrm{p}<0,05)$ para las mismas dosis de aplicación. 


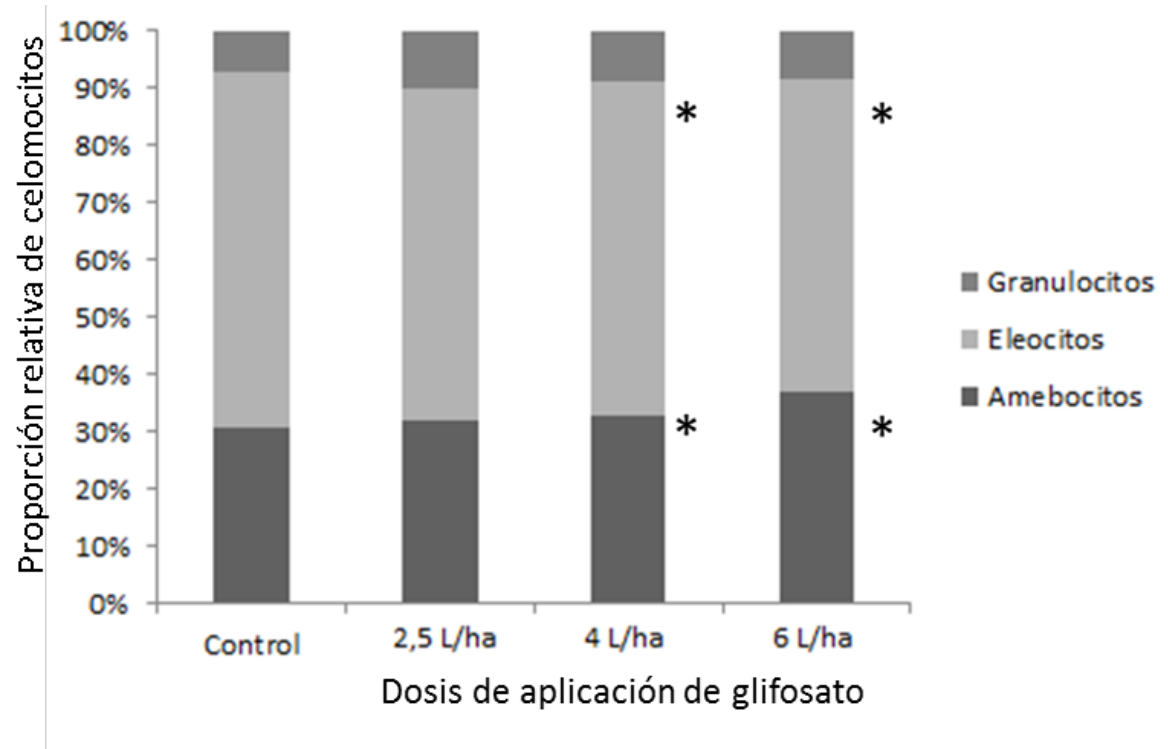

Figura 25. Proporciones celulares de organismos de E. fetida expuestos ex vivo a suelos tratados artificialmente con glifosato durante $1 \mathrm{~h}$. *Diferencias estadísticamente significativos con el control, $\mathrm{p}<0,05$

Genotoxicidad en celomocitos de E. fetida ex situ

Los resultados de los efectos genotóxicos de las muestras tratadas con glifosato pueden observarse en la Figura 26.

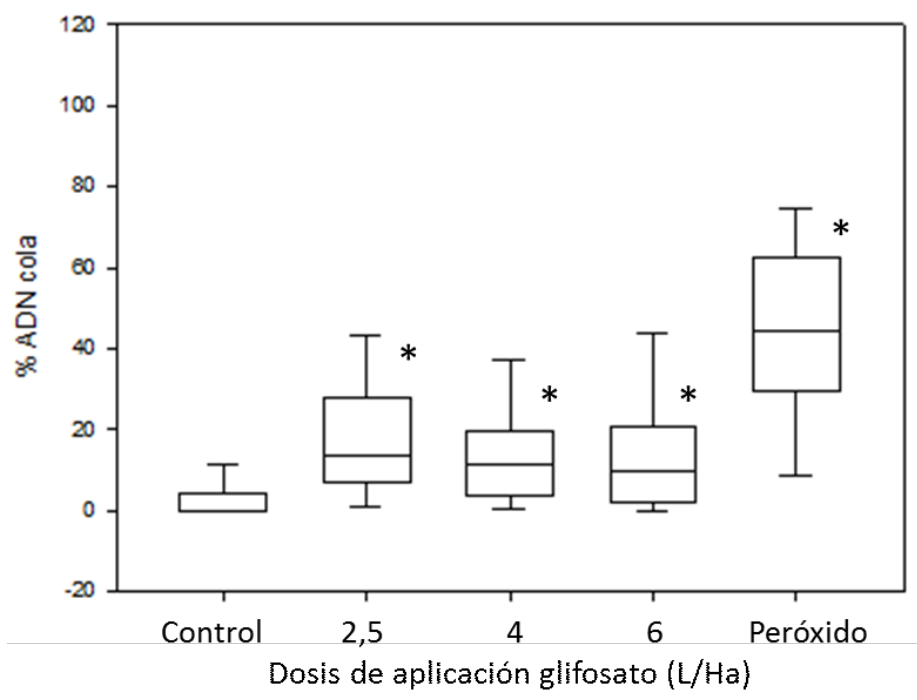

Figura 26. Genotoxicidad de las eluciones de los suelos tratados artificialmente con glifosato en celomocitos de E. fetida expuestos ex vivo durante $1 \mathrm{~h}$. Los límites del "boxplot" representan los cuartiles $25 \%$ y $75 \%$, mientras que la línea central corresponde a la mediana de los valores. Las barras indican los valores mínimos y máximos. * Diferencias estadísticamente significativas con el control, $\mathrm{p}<0,001$ 
Todas las dosis de aplicación de glifosato evaluadas incrementaron la migración del ADN de manera estadísticamente significativa $(\mathrm{p}<0,001)$.

El \% ADN cola para las dosis de aplicación de 2,5; 4 y 6 L/ha resultó ser de 13,8; 11,2 y $9,4 \%$, respectivamente.

\subsubsection{Suelos tratados con clorpirifos}

\subsection{Muestra entera}

\subsection{Ensayos de germinación y elongación de las raíces con L. sativa}

La fitotoxicidad de los suelos tratados artificialmente con el insecticida clorpirifos se determinó mediante el ensayo de germinación de semillas y elongación de raíces en L. sativa. En el ensayo realizado el porcentaje de germinación en las placas control fue mayor al 65\%. De esta manera, se cumplió el criterio de aceptabilidad requerido por la normativa seguida (US EPA, 1996).

Se evaluaron las dosis de aplicación recomendadas por los fabricantes de los formulados comerciales utilizados. Para el clorpirifos se utilizaron las dosis de aplicación correspondientes a 1 y $2 \mathrm{~L} / \mathrm{ha}$ (Tabla 40).

Tabla 40. Efecto fitotóxico de los suelos tratados artificialmente con clorpirifos sobre la germinación de las semillas y la elongación de las raíces en L. sativa

\begin{tabular}{ccccc}
\hline $\begin{array}{c}\text { Dosis de aplicación de } \\
\text { Clorpirifos } \\
(\mathrm{L} / \mathrm{ha})\end{array}$ & $\begin{array}{c}\text { Semillas } \\
\text { germinadas/semillas } \\
\text { expuestas }\end{array}$ & $\begin{array}{c}\text { Inhibición } \\
\text { Germinación } \\
(\%)\end{array}$ & $\begin{array}{c}\text { Elongación de } \\
\text { raíces }(\mathrm{cm})\end{array}$ & $\begin{array}{c}\text { Inhibición } \\
\text { elongación de } \\
\text { raíces }(\%)\end{array}$ \\
\hline 0 (Control) & $15 / 20$ & 0 & 2,8 & 0 \\
1 & $6 / 20$ & $62,3^{* *}$ & 0,86 & $69,3^{* *}$ \\
2 & $7 / 20$ & $53,3^{* *}$ & 0,82 & $70,7^{* *}$ \\
\hline
\end{tabular}

** Diferencias estadísticamente significativas con respecto al control, $\mathrm{p}<0,05$

Las dosis de aplicación de clorpirifos evaluadas ejercieron un efecto fitotóxico sobre la especie L. sativa. Este efecto se manifestó como una inhibición de la germinación estadísticamente significativa $(\mathrm{p}<0,05)$ para ambas dosis de aplicación.

Para la elongación de las raíces se observó una inhibición estadísticamente significativa $(\mathrm{p}<0,05)$ para ambas dosis de aplicación evaluadas. Esta disminución en la longitud de las 
raíces fue de similar magnitud, con valores de inhibición del 69,3 y 70,7\% para las dosis de 1 y $2 \mathrm{~L} / \mathrm{ha}$, respectivamente.

Acerca de la fitotoxicidad del clorpirifos, Gange et al (1992) han observado que el insecticida es capaz de reducir la germinación de semillas de Spergula arvensis. En otros ensayos con productores primarios, el clorpirifos ha provocado efectos adversos sobre la macrófita Lemna minor (Sáenz et al, 2009). Stratton (1987) observó una disminución en la diversidad de diatomeas frente a la exposición a clorpirifos.

\subsection{Ensayos de cito y genotoxicidad en celomocitos de E. fetida in vivo}

Las dosis de aplicación de clorpirifos ensayadas no incrementaron significativamente la mortalidad de organismos de E. fetida expuestas in vivo durante 14 días con respecto al control. Casabé et al (2007) han observado que el insecticida clorpirifos no produjo mortalidad ni alteró la reproducción de ejemplares de E. andrei.

\section{Citotoxicidad}

La citotoxicidad sobre celomocitos de organismos de E. fetida expuestos in vivo durante 7 y 14 días se presentan en la Tabla 41.

Ambas dosis de aplicación y tiempos de exposición generaron un incremento estadísticamente significativo $(\mathrm{p}<0,05)$ en la citotoxicidad de los celomocitos de E. fetida. Otros autores han reportado alteraciones a nivel de la membrana lisosomal en cemolocitos de E. andrei (Casabé et al, 2007) expuestos al clorpirifos in vivo. Nuestros resultados concuerdan con lo observado por estos autores.

Tabla 41. Citotoxicidad de los suelos tratados artificialmente con clorpirifos en celomocitos de E. fetida expuestos in vivo durante 7 y 14 días. Valores expresados como \% de células no viables

\begin{tabular}{ccc}
\hline $\begin{array}{c}\text { Dosis de } \\
\text { aplicación (L/ha) }\end{array}$ & Día 7 & Día 14 \\
\hline Control & & 10,5 \\
1 & 9,2 & $25,2^{* *}$ \\
2 & $15,7^{* *}$ & $31,7^{* *}$ \\
\hline
\end{tabular}

**Diferencias estadísticamente significativas con respecto al control, $\mathrm{p}<0,05$ 


\section{Índices tróficos}

A partir de los mismos organismos expuestos in vivo durante 7 y 14 días a los suelos tratados artificialmente con clorpirifos se determinaron los índices tróficos LITA, LITAR e ICCT, los cuales se muestran en la Tabla 42.

Tabla 42. Índices tróficos en organismos de E. fetida expuestos in vivo a suelos tratados con clorpirifos. Entre paréntesis se indica la desviación estándar

\begin{tabular}{ccccccc}
\hline (L/ha) & \multicolumn{3}{c}{ Día 7} & & \multicolumn{3}{c}{ Día 14 } \\
& LITA & LITAR & ICCT & LITA & LITAR & ICCT \\
\hline 0 & 0,69 & 1,61 & 6,00 & 0,69 & 1,61 & 6,00 \\
& $(0,02)$ & $(0,05)$ & $(0,03)$ & $(0,02)$ & $(0,05)$ & $(0,03)$ \\
\multirow{2}{*}{1} & $0,63 * *$ & $1,30^{* *}$ & 6,07 & $0,58^{* *}$ & $1,05^{* *}$ & $6,14^{* *}$ \\
& $(0,02)$ & $(0,07)$ & $(0,03)$ & $(0,01)$ & $(0,04)$ & $(0,04)$ \\
& $0,59^{* *}$ & $1,32^{* *}$ & 6,06 & $0,51^{* *}$ & $1,01^{* *}$ & $6,10^{* *}$ \\
& $(0,02)$ & $(0,07)$ & $(0,08)$ & $(0,02)$ & $(0,03)$ & $(0,02)$ \\
\hline
\end{tabular}

** Diferencias significativas con respecto al control, $\mathrm{p}<0,05$

Para el día 7 de exposición, los Índices LITA y LITAR evidenciaron una disminución estadísticamente significativa $(\mathrm{p}<0,05)$ a ambas dosis de aplicación de clorpirifos evaluadas. Para el día 14 de exposición, nuevamente se observó una disminución estadísticamente significativa de ambos índices LITA y LITAR $(\mathrm{p}<0,05)$ con respecto a los organismos control.

El índice ICCT sólo incrementó su valor significativamente $(\mathrm{p}<0,05)$ para ambas dosis de aplicación ensayadas a los 14 días de exposición.

\section{Proporciones celulares}

Las proporciones de los diferentes tipos de celomocitos fueron calculadas para los ejemplares de E. fetida expuestos in vivo durante 7 y 14 días a los suelos tratados artificialmente con clorpirifos (Figura 27 y Figura 28).

Para el día 7 de exposición no se observaron modificaciones significativas $(\mathrm{p}>0,05)$ en la relación de los tres tipos celulares. Contrariamente, para el día 14 de exposición la proporción de eleocitos disminuyó de manera estadísticamente significativa $(\mathrm{p}<0,05)$ a ambas dosis de aplicación evaluadas, con un consecuente incremento de la proporción de granulocitos. Los 
amebocitos aumentaron su proporción de manera significativa $(\mathrm{p}<0,05)$ con la mayor dosis de aplicación evaluada.

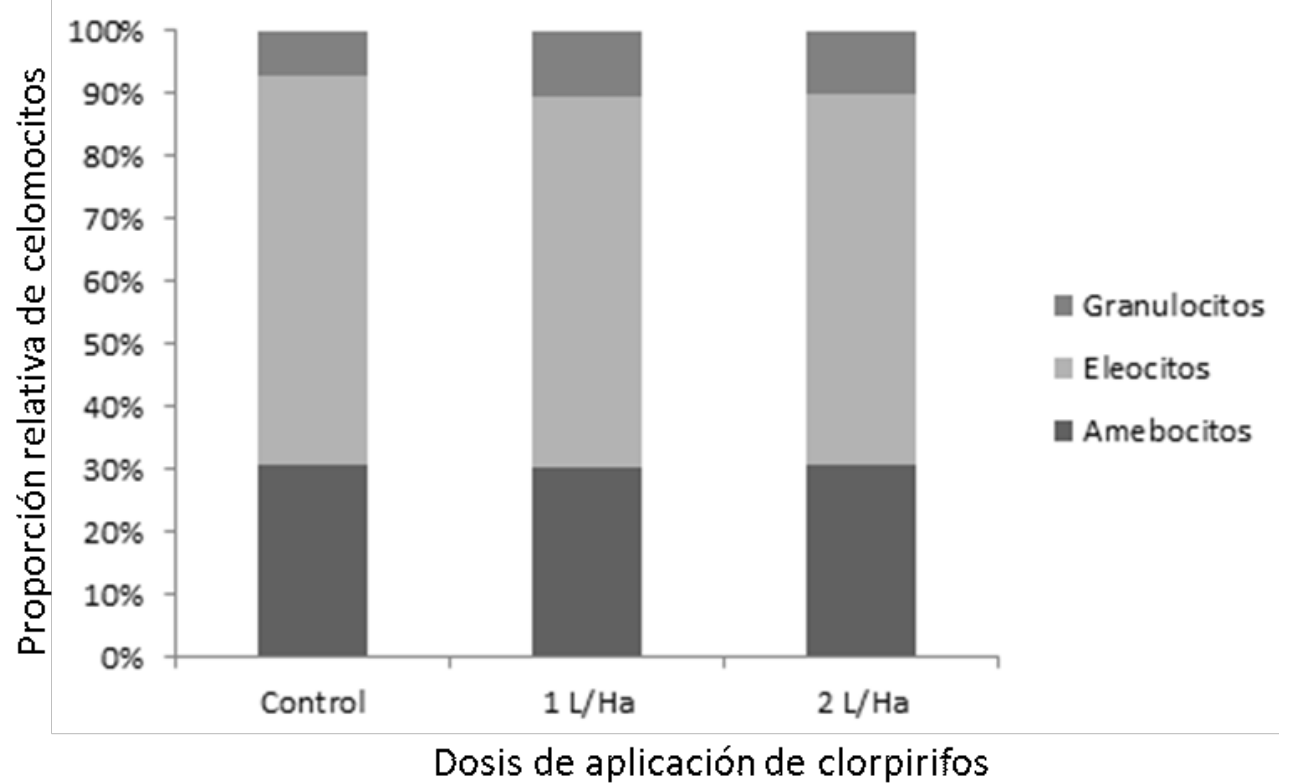

Figura 27. Proporciones celulares de organismos de E. fetida expuestos in vivo durante 7 días a suelos tratados artificialmente con clorpirifos.

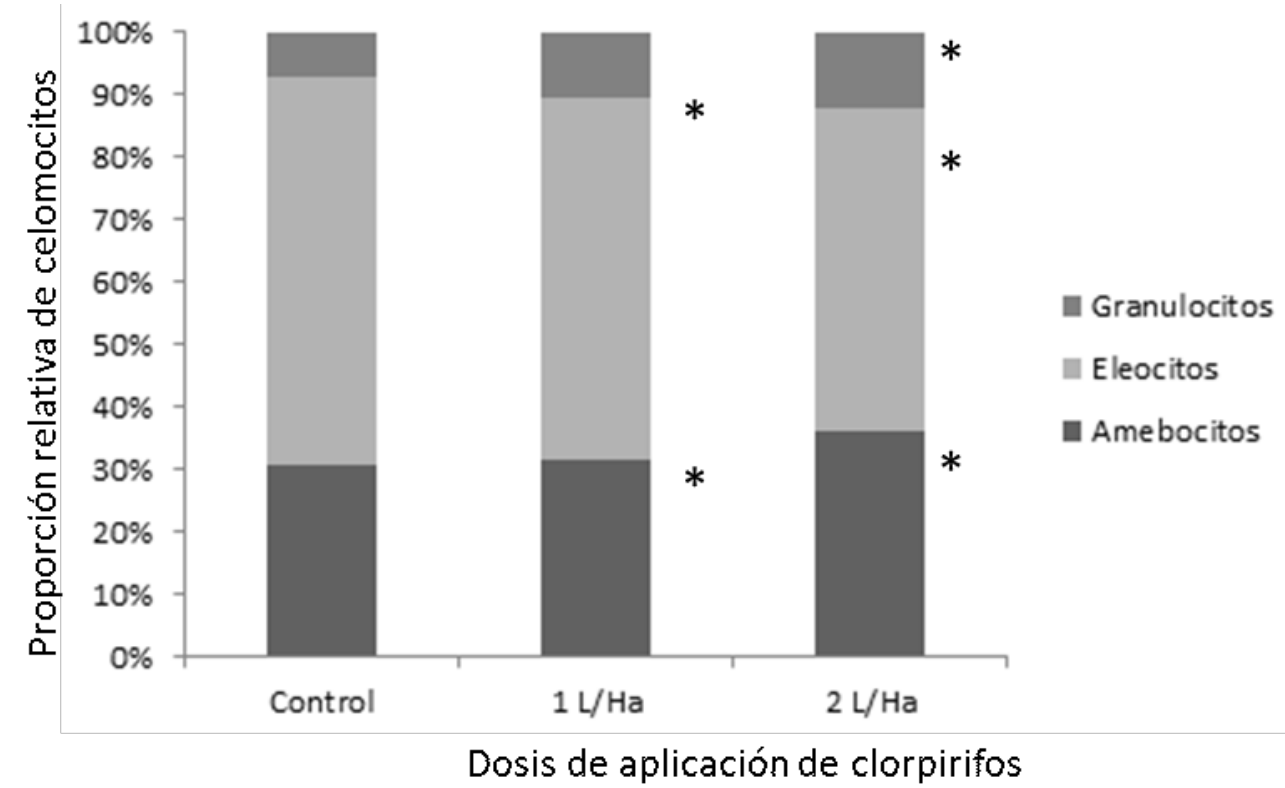

Figura 28. Proporciones celulares de organismos de E. fetida expuestos in vivo durante 14 días a suelos tratados artificialmente con clorpirifos. *Diferencias estadísticamente significativos con el control, $p<0,05$ 
Estos resultados, concuerdan con lo observado para los índices tróficos que tienen en cuenta la relación de eleocitos/celomocitos totales (LITA y LITAR) los cuales disminuyeron notoriamente para el día 14 de exposición.

\section{Genotoxicidad en celomocitos de E. fetida in vivo}

La genotoxicidad de los suelos tratados artificialmente con las diferentes dosis de aplicación de clorpirifos fue cuantificada por medio del ensayo cometa. Los resultados correspondientes a los tiempos de exposición de 7 y 14 días pueden observarse en la Figura 29 y Figura 30, respectivamente.

Para el día 7 de exposición, ambas dosis de aplicación de clorpirifos evaluadas incrementaron la migración del ADN de manera estadísticamente significativa $(\mathrm{p}<0,001)$. El \% ADN cola para las dosis de aplicación de 1 y 2 L/ha resultó ser de 5,4 y 26,4 \%, respectivamente.

Para el día 14 de exposición, ambas dosis de aplicación de clorpirifos ensayadas provocaron daño genotóxico en los celomocitos de ejemplares de E. fetida expuestos in vivo. El \% de ADN cola resultó ser de 18,1 y 14,9\% para las dosis de aplicación de clorpirifos correspondientes a 1 y $2 \mathrm{~L} / \mathrm{ha}$, respectivamente. Estos valores resultaron ser estadísticamente significativos $(\mathrm{p}<0,001)$ con respecto al control.

El clorpirifos es un insecticida ampliamente utilizado en la agricultura.Sin embargo, existen reportes que evidencian neurotoxicidad, desórdenes en el desarrollo y alteraciones inmunológicas vinculadas con su exposición, entre otros aspectos negativos (Auman et al, 2000). Dentro de los efectos no deseados, es importante determinar la genotoxicidad potencial del compuesto. Así existen reportes previos que indican la inducción de daño genético en diferentes sistemas biológicos por parte del clorpirifos (Byrne et al, 1998; Bomser y Casida, 2001; Tian y Yamauchi, 2003; Mehta et al, 2008; Crumpton et al, 2000). Casabé et al (2007) han observado un incremento en la migración del ADN evaluado mediante el ensayo cometa en celomocitos de E. andrei. Estudios realizados demuestran que los insecticidas OP poseen propiedades alquilantes y fosforilantes (Preston y Hoffman, 2008; Costa, 2008) que podrían ser las causas de daño al ADN. Sin embargo, otros autores postulan otros mecanismos de genotoxicidad para el clorpirifos, tales como una reacción directa del mismo sobre la molécula de ADN (Wild, 1975; Saleha Banu et al, 2001; Lee y Steinert, 2003; Ali et al, 2009). A este proceso podría sumarse el daño sobre la estructura de ADN, producido por la generación de EROs a partir de la exposición a clorpirifos (Gupta, 2010). 


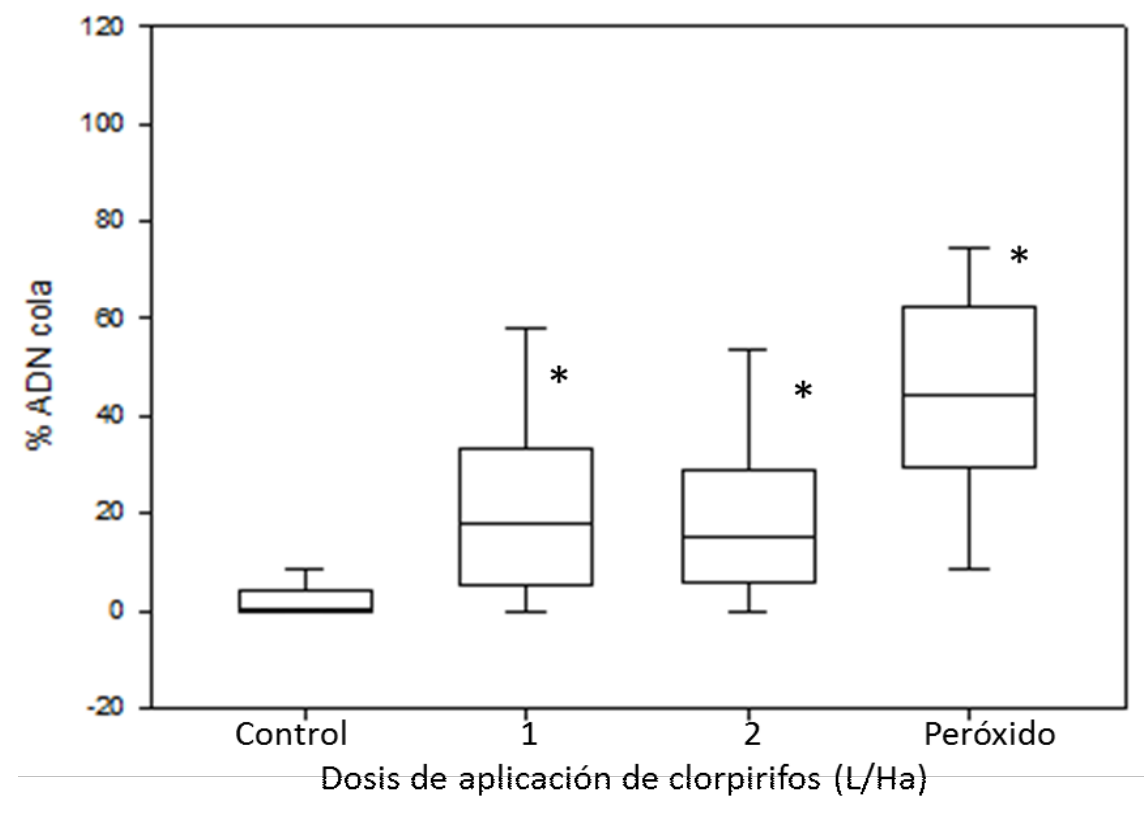

Figura 29. Genotoxicidad de los suelos tratados artificialmente con clorpirifos en celomocitos de E. fetida expuestos in vivo durante 7 días. Los límites del "boxplot" representan los cuartiles $25 \%$ y $75 \%$, mientras que la línea central corresponde a la mediana de los valores.

Las barras indican los valores mínimos y máximos.* Diferencias estadísticamente significativas con el control, $\mathrm{p}<0,001$

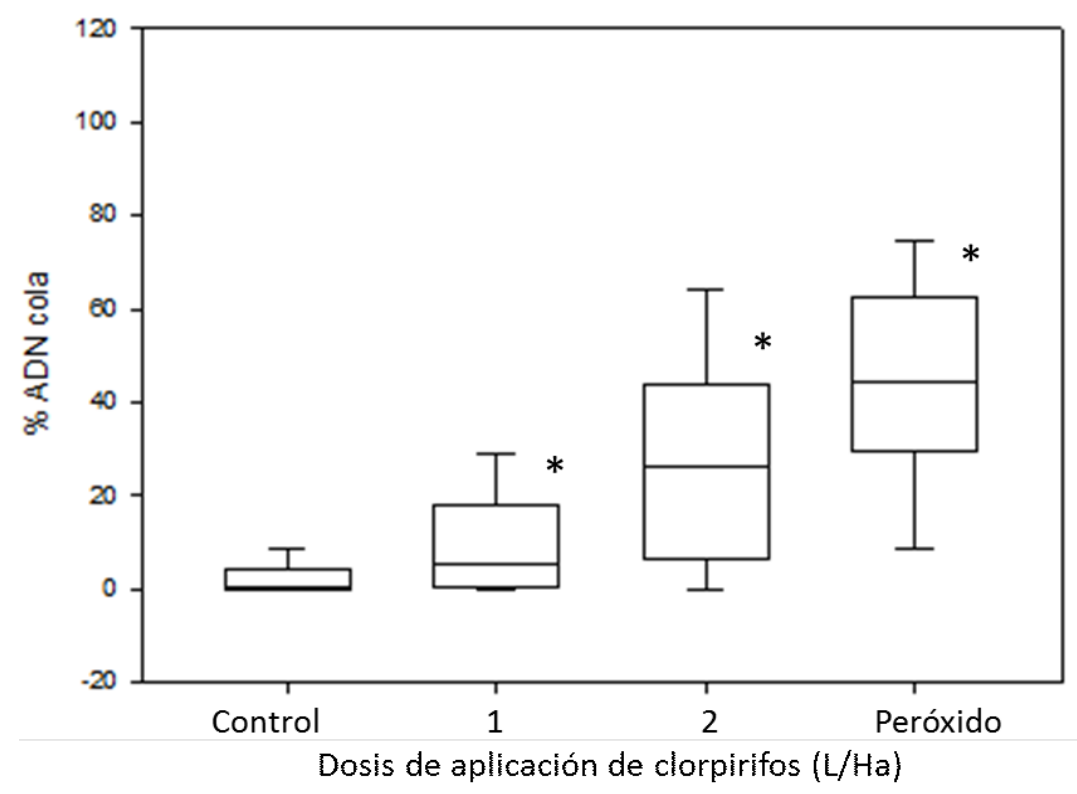

Figura 30. Genotoxicidad de los suelos tratados artificialmente con clorpirifos en celomocitos de E. fetida expuestos in vivo durante 14 días. Los límites del "boxplot" representan los cuartiles $25 \%$ y $75 \%$, mientras que la línea central corresponde a la mediana de los valores. Las barras indican los valores mínimos y máximos. * Diferencias estadísticamente significativas con el control, $\mathrm{p}<0,001$ 


\subsection{Fracción líquida- Elución}

\subsection{Ensayos con plántulas de V.faba}

Las plántulas de $V$. faba fueron expuestas durante $48 \mathrm{~h}$ a las eluciones de los suelos artificialmente tratados con dos dosis de aplicación del insecticida clorpirifos, correspondientes a 1 y $2 \mathrm{~L} / \mathrm{ha}$. Se realizaron en el ensayo dos controles, uno correspondiente al Medio Hoagland y otro con la elución de un suelo no tratado. Para todos los parámetros evaluados la comparación entre el medio Hoagland y la elución del suelo control no arrojó diferencias estadísticamente significativas.

Tanto en las plántulas expuestas cómo en las plántulas control se determinó la biomasa. En forma conjunta, en las raíces de estas plántulas se cuantificó por un lado el nivel de actividad de dos enzimas relacionadas al estrés oxidativo, CAT y GPOD, y por otro lado, el nivel de peroxidación de lípidos (Tabla 43).

Tabla 43. Efectos expresados como media y desviación estándar (entre paréntesis), sobre la biomasa ( $\mathrm{g}$ de peso fresco), actividad enzimática ( $\mathrm{mM}$ de $\mathrm{H}_{2} \mathrm{O}_{2} / \mathrm{mg}$ proteína/min) y peroxidación lipídica ( $\mu \mathrm{mol} \mathrm{MDA} / \mathrm{g}$ de peso fresco) de la elución acuosa de suelos tratados artificialmente con clorpirifos en plántulas de $V$. faba

\begin{tabular}{ccccc}
\hline \multirow{5}{*}{ Biomasa } & \multicolumn{3}{c}{ Dosis de aplicación (L/ha) } \\
& Control & Suelo & 1 & 2 \\
& Hoagland & control & & \\
& $(0,17)$ & 0,15 & 0,17 & 0,12 \\
CAT & 25,1 & 27,7 & $77,8 * *$ & 22,1 \\
& $(5,3)$ & $(1,61)$ & $(23,3)$ & $(14,0)$ \\
\multirow{3}{*}{ GPOD } & 5,05 & 3,97 & 6,14 & 6,6 \\
& $(0,47)$ & $(0,58)$ & $(1,5)$ & $(1,34)$ \\
\multirow{2}{*}{ MDA } & 15,1 & 14,6 & 25,3 & 22,5 \\
& $(7,1)$ & $(7,5)$ & $(9,1)$ & $(2,6)$
\end{tabular}

** Diferencias estadísticamente significativas con respecto al control, $\mathrm{p}<0,05$

\section{Efectos sobre biomasa}

El efecto sobre la biomasa de las plántulas de $V$. faba expuestas durante $48 \mathrm{~h}$ a ambas dosis de aplicación del insecticida clorpirifos se presenta en la Tabla 43. Ninguna de las 
concentraciones de la elución ensayadas provocaron una alteración estadísticamente significativa en la biomasa de las plántulas expuestas comparadas con el control $(p>0,05)$.

\section{Efectos sobre enzimas del estrés oxidativo CAT y GPOD}

Luego de 48 h de exposición de las plántulas de V. faba a las eluciones correspondientes a ambas dosis de aplicación de clorpirifos se evaluó la actividad de CAT y GPOD. Los resultados obtenidos para la cuantificación de la actividad enzimática se presentan en la Tabla 43.

La actividad de la enzima CAT presentó un efecto estimulatorio estadísticamente significativo $(p>0,05)$ del orden del $210 \%$ para la dosis de aplicación de clorpirifos correspondiente a 1 $\mathrm{L} / \mathrm{ha}$.

La enzima GPOD no evidenció cambios significativos $(p>0,05)$ en su actividad para ninguna de las dosis de aplicación de clorpirifos evaluadas.

Si bien el clorpirifos se considera poco tóxico para especies vegetales, los resultados observados parecerían evidenciar efectos adversos sobre los mismos. Amer y Farah (1983) han reportado que el insecticida organofosforado clorpirifos generó la inducción anormalidades en la mitosis de meristemas radiculares de V. faba. En esta especie de planta se ha vinculado el estrés oxidativo con la genotoxicidad evaluada mediante la formación de micronúcleos (Béraud et al, 2007).

\section{Efectos sobre peroxidación lipídica}

Los niveles de MDA en raíces de las plántulas expuestas a la elución de los suelos tratados artificialmente con ambas dosis de aplicación de clorpirifos se muestran en la Tabla 43. La elución de los suelos tratados artificialmente con clorpirifos no provocó una modificación estadísticamente significativa $(p>0,05)$ en el contenido de MDA en comparación con el control, independientemente de las dosis de aplicación evaluadas.

\subsection{Ensayos de cito y genotoxicidad en celomocitos de E. fetida ex vivo}

\section{Citotoxicidad}

La citotoxicidad de la elución acuosa de los suelos tratados artificialmente con diferentes dosis de aplicación de clorpirifos se presenta en la Tabla 44.

Ambas dosis de aplicación de clorpirifos ensayadas ejercieron un efecto citotóxico estadísticamente significativo $(\mathrm{p}<0,05)$. El porcentaje de células no viables (evidenciadas con Azul de Tripán) se incrementó de manera dependiente con la dosis de aplicación evaluada. 
Tabla 44. Citotoxicidad de las eluciones en PBS de los suelos tratados artificialmente con clorpirifos sobre los celomocitos de E. fetida, Valores expresados como \% de células no viables

\begin{tabular}{cc}
\hline Dosis de aplicación (L/ha) & $\%$ Citotoxicidad \\
\hline 0 (control) & 11 \\
1 & $26^{* *}$ \\
2 & $34^{* *}$
\end{tabular}

**Diferencias estadísticamente significativas, $\mathrm{p}<0,05$

\section{Índices tróficos}

A partir de los celomocitos expuestos ex vivo durante $1 \mathrm{~h}$ a las eluciones de los suelos tratados artificialmente con clorpirifos se determinaron los índices tróficos LITA, LITAR e ICCT, los cuales se muestran en la Tabla 45 .

Los Índices LITA y LITAR descendieron de manera significativa $(\mathrm{p}<0,05)$ para ambas dosis de aplicación de clorpirifos. En el caso del Índice ICCT no mostró modificaciones estadísticamente significativas ( $\mathrm{p}>0,05)$.

Tabla 45. Índices tróficos para celomocitos expuestos durante 1 hora a los suelos tratados artificialmente con diferentes dosis de aplicación de clorpirifos. Entre paréntesis se indica la desviación estándar

\begin{tabular}{cccc}
\hline $\begin{array}{c}\text { Dosis de aplicación de } \\
\text { clorpirifos (L/ha) }\end{array}$ & LITA & LITAR & ICCT \\
\hline 0 & 0,69 & 1,62 & 6,0 \\
& $(0,02)$ & $(0,03)$ & $(0,01)$ \\
1 & $0,63^{* *}$ & $1,3^{* *}$ & 6,1 \\
& $(0,02)$ & $(0,03)$ & $(0,02)$ \\
2 & $0,51^{* *}$ & $1,32^{* *}$ & 6,06 \\
& $(0,01)$ & $(0,02)$ & $(0,04)$
\end{tabular}

**Diferencias estadísticamente significativas, $\mathrm{p}<0,05$

\section{Proporciones celulares}

Las proporciones celulares de los celomocitos expuestos ex vivo durante $1 \mathrm{~h}$ a las eluciones de los suelos tratados artificialmente con diferentes dosis de aplicación de clorpirifos se 
presentan en la Figura 31. Para ambas dosis de aplicación, la proporción de eleocitos disminuyó de manera significativa mientras que la relación de amebocitos se incrementó. Ambas modificaciones en la proporción resultaron estadísticamente significativas $(p<0,05)$ con respecto a valores controles.

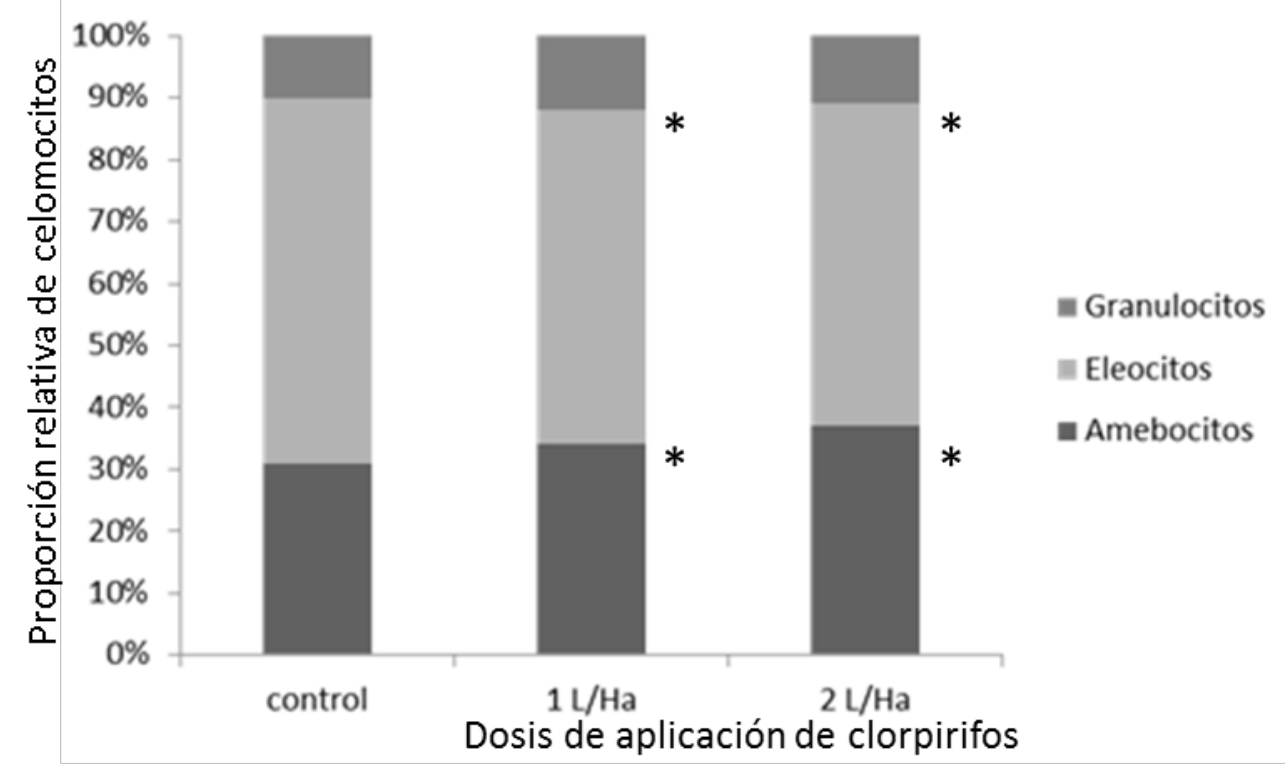

Figura 31. Proporciones celulares de organismos de E. fetida expuestos ex vivo a eluciones de suelos tratados artificialmente con clorpirifos durante $1 \mathrm{~h}$. *Diferencias estadísticamente significativa con el control, $\mathrm{p}<0,05$

Genotoxicidad en celomocitos de E. fetida ex vivo

Los resultados de la genotoxicidad ejercida por suelos tratados artificialmente con las diferentes dosis de clorpirifos se pueden observarse en la Figura 32.

Todas las dosis de aplicación de clorpirifos ensayadas incrementaron la migración del ADN de manera estadísticamente significativa $(\mathrm{p}<0,001)$. El \% ADN cola para las dosis de aplicación de 1 y $2 \mathrm{~L} /$ ha resultó ser de 1,5 y 4,4\%, respectivamente.

Estos resultados de genotoxicidad en fase líquida son coincidentes con lo observado por diferentes grupos, avalando la acción genotóxica del insecticida clorpirifos. Estudios realizados por Vera-Candioti et al (2013 b, 2013 c) revelaron la acción genotóxica del clorpirifos, mediante en ensayo del cometa, en ejemplares de Cnesterodon decemmaculatus expuestos en condiciones de laboratorio. Asimismo, otros estudios llevados a cabo con peces de la especie Channa punctacus (Perciformes, Channidae) han demostrado la acción 
genotóxica del clorpirifos mediante un incremento de la frecuencia de micronúcleos en eritrocitos circulantes (Ali et al, 2008; Kumar, 2012).

Nuestros resultados concuerdan con estos hallazgos previos, ya que se evidenció daño en el ADN mediante la aplicación del ensayo cometa en celomocitos del oligoqueto E. fetida.

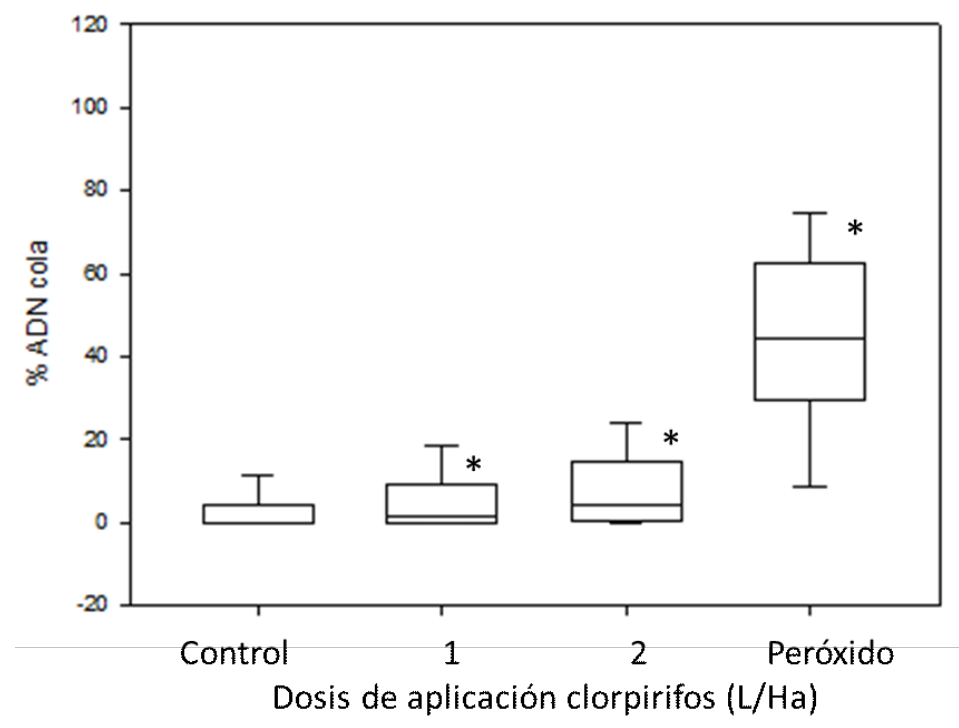

Figura 32. Genotoxicidad de las eluciones de los suelos tratados artificialmente con clorpirifos en celomocitos de E. fetida expuestos ex vivo durante 1 h. Los límites del "boxplot" representan los cuartiles $25 \%$ y $75 \%$, mientras que la línea central corresponde a la mediana de los valores. Las barras indican los valores mínimos y máximos. * Diferencias estadísticamente significativas con el control, $\mathrm{p}<0,001$ 


\subsubsection{Evaluación integrada de los suelos estudiados}

En el caso de las muestras ambientales post- aplicación de glifosato y los suelos tratados artificialmente con el herbicida, los ensayos de germinación de semillas y elongación de raíces en $L$. sativa evidenciaron un efecto fitotóxico provocado por el mismo. Asimismo, los ensayos con ejemplares de E. fetida expuestos in vivo durante 14 días evidenciaron efectos cito y genotóxicos tanto en los suelos ambientales como en los artificialmente tratados. Cabe destacar que para ambos tratamientos se observó un incremento en la genotoxicidad al aumentar el tiempo de exposición.

Para el caso de la elución de los suelos, se evidenció el efecto cito y genotóxico en celomocitos de E. fetida expuestos ex vivo durante $1 \mathrm{~h}$. El ensayo de $V$. faba evidenció el efecto en las enzimas de estrés oxidativo tanto en las muestras ambientales como en aquellas artificialmente tratadas con el herbicida.

En el caso del insecticida clorpirifos, tanto las muestras ambientales como los suelos artificialmente tratados, evidenciaron efectos fitotóxicos sobre la germinación y la elongación de las raíces en L. sativa luego de 120 h de exposición.

Asimismo, los suelos incrementaron la genotoxicidad en ejemplares de E. fetida expuestos de manera in vivo durante 14 días.

Las eluciones de los suelos evidenciaron el efecto cito y genotóxico de los mismos sobre celomocitos de E. fetida expuestos ex vivo luego de un tiempo de exposición de $1 \mathrm{~h}$. El ensayo de $V$. faba permitió demostrar el efecto sobre enzimas de estrés oxidativo luego de $48 \mathrm{~h}$ de exposición.

Para la evaluación ecotoxicológica de los suelos tratados con plaguicidas tanto el ensayo en $L$. sativa y la cito y genotoxicidad en celomocitos de $E$. fetida expuestos durante $1 \mathrm{~h}$ resultaron ser indicadores adecuados. Es este aspecto, ambos serían biomarcadores útiles a la hora de revelar la toxicidad de los suelos tratados con las diferentes clases de plaguicidas debido a que permiten trabajar con diferentes organismos y brindan resultados precisos en un corto período de tiempo. Sin embargo, para obtener una visión más integral de la toxicidad asociada a ambos plaguicidas, sería necesario complementar estos ensayos con exposiciones más prolongadas a fin de intentar comprender los efectos a niveles de organización superiores al celular e individual así como también los mecanismos activados en los organismos expuestos. 


\subsubsection{Conjunto de variables seleccionadas para la evaluación ecotoxicológica de suelos}

Para la evaluación de las matrices sólidas correspondientes a suelos tratados con plaguicidas es posible seleccionar un conjunto de variables de mayor sensibilidad para la evaluación ecotoxicológica de los mismos (Tabla 46). Para la selección de la sensibilidad relativa se eligió el parámetro más sensible para las variables determinadas para el herbicida glifosato y el insecticida clorpirifos. Esta selección se realizó en base a su menor CMEO. Para ambos plaguicidas, éste resultó ser tanto la cito y genotoxicidad en celomocitos expuestos ex vivo durante $1 \mathrm{~h}$ como la elongación de raíces en $L$. sativa expuestas durante $120 \mathrm{~h}$. A partir de estos parámetros elegidos se estimó la sensibilidad con respecto al mismo para cada variable de respuesta.

Los parámetros más sensibles para la determinación de efectos ecotoxicológicos resultaron ser la elongación de raíces en $L$. sativa y la cito y genotoxicidad en celomocitos de E. fetida expuestos ex vivo durante $1 \mathrm{~h}$. Sin embargo, esta sensibilidad no es sustancialmente diferente entre parámetros, ya que en ambos plaguicidas evaluados las CMEO corresponden a las menores dosis de aplicación evaluadas, en otras palabras $2,5 \mathrm{~L} / \mathrm{ha}$ para el glifosato y $1 \mathrm{~L} / \mathrm{ha}$ para el clorpirifos. Esto refleja una alta toxicidad de ambos plaguicidas sobre organismos no blanco tanto del reino vegetal como del reino animal. Para el insecticida clorpirifos puede observarse en la Tabla 46 que la batería de bioensayos y variables de respuesta no es del todo necesaria para la evaluación ecotóxica de los suelos tratados con el mismo. Este factor evidencia que ensayos más prolongados brindarían la misma información que aquellos de períodos de exposición más breves.

Entre los índices propuestos como biomarcadores puede observarse que los índices LITA y LITAR son más sensibles que el índice ICCT para ambos plaguicidas. Asimismo, el cambio en las proporciones celulares en celomocitos expuestos ex vivo durante $1 \mathrm{~h}$ resultaría ser un índice de alta sensibilidad para la evaluación de efectos a cortos períodos de exposición. En el caso de los estudios de efecto genotóxico, ambos tiempos de exposición resultaron ser adecuados para la detección del daño al material hereditario orinado por ambos plaguicidas. Estas variables de respuesta seleccionadas permiten además la evaluación de los efectos de los plaguicidas en organismos de diferentes niveles tróficos. Tanto en los suelos tratados con el herbicida glifosato como con el insecticida clorpirifos se observan efectos en estas variables de respuesta. Si bien estas variables poseen una sensibilidad semejante y permiten la 
detección de daño temprano en los organismos, los estudios que evalúen diferentes variables de respuesta y mayores tiempos de exposición son necesarios para la comprensión integral de los efectos provocados en el caso del herbicida glifosato. Particularmente, los estudios de genotoxicidad son necesarios debido a la persistencia de estos contaminantes en los ambientes terrestres, y la vinculación con efectos en poblaciones humanas.

Tabla 46. Sensibilidad relativa de los parámetros evaluados para las matrices sólidas correspondientes a suelos tratados con plaguicidas. (Nd: no determinado)

\begin{tabular}{|c|c|c|}
\hline Variable & Glifosato & Clorpirifos \\
\hline \multicolumn{3}{|l|}{ Muestra sólida } \\
\hline Germinación en L. sativa & 2,4 & 1 \\
\hline Elongación de raíces en $L$. sativa & 1 & 1 \\
\hline LITA $14 \mathrm{~d}$ & 1 & 1 \\
\hline LITAR $14 \mathrm{~d}$ & 1 & 1 \\
\hline ICCT $14 \mathrm{~d}$ & $\mathrm{Nd}$ & 1 \\
\hline Proporciones celulares $14 \mathrm{~d}$ & 2,4 & 2 \\
\hline Genotoxicidad $14 \mathrm{~d}$ & 1 & 1 \\
\hline \multicolumn{3}{|l|}{ Elución } \\
\hline CAT & 1 & 1 \\
\hline Citotoxicidad en celomocitos & 1 & 1 \\
\hline LITA $1 \mathrm{~h}$ & 1 & 1 \\
\hline LITAR $1 \mathrm{~h}$ & 1 & 1 \\
\hline ICCT $1 \mathrm{~h}$ & 2,4 & $\mathrm{Nd}$ \\
\hline Proporciones celulares $1 \mathrm{~h}$ & 1 & 1 \\
\hline Genotoxicidad $1 \mathrm{~h}$ & 1 & 1 \\
\hline
\end{tabular}




\section{CONCLUSIONES}


Las conclusiones finales del presente Trabajo de Tesis Doctoral se presentan siguiendo como eje central las hipótesis planteadas al inicio del mismo, las cuáles se resumen a continuación:

- El grado de contaminación de una matriz sólida (suelo, residuo) puede evidenciarse integralmente determinando efectos biológicos sobre distintas variables de respuesta.

- Las muestras ambientales deben ser estudiadas utilizando especies de niveles tróficos diferentes para definir la presencia / efecto de sustancias tóxicas.

En este contexto y partiendo de la primera hipótesis de trabajo, podemos afirmar que las matrices sólidas ensayadas ejercieron efectos tóxicos y que los mismos fueron evidenciados mediante la utilización de una batería de ensayos biológicos en conjunto con la determinación de diferentes variables de respuesta. La sensibilidad relativa de estas variables permitió determinar la toxicidad de las matrices sólidas evaluadas y cuantificar su peligrosidad para el ambiente.

Las matrices sólidas estudiadas correspondientes a los residuos industriales presentaron como contaminantes principales metales y compuestos orgánicos. Por otra parte, las muestras de suelo fueron representativas de la contaminación por la aplicación de agroquímicos, específicamente de la presencia del herbicida glifosato y del insecticida clorpirifos. De esta manera, se trabajó con matrices sólidas representativas de dos escenarios de contaminación ambiental de actual relevancia no sólo a nivel mundial sino de nuestro país, en lo particular. La utilización de una batería de organismos, bioensayos y biomarcadores propuestos permitió determinar la acción perjudicial de todas las matrices sólidas evaluadas. Por otra parte, la utilización de organismos en diferentes estadios de su ciclo de vida permitió evaluar la sensibilidad de los mismos como herramientas para el monitoreo ecotoxicológico de muestras sólidas. Asimismo, la sensibilidad diferencial cuantificada, para cada una de las variables de respuesta elegida, permitirá seleccionar aquellas más sensibles y prácticas para fines regulatorios. En este punto, es más que importante destacar que la tendencia mundial para la clasificación de residuos se basa en la caracterización ecotoxicológica de los mismos. Esta caracterización implica, no sólo la cuantificación de las sustancias químicas presentes en las mismas, sino que se complementa con la evaluación de las respuestas biológicas producidas por estos residuos a través de diferentes sistemas de ensayo (Moser y Römbke, 2005; Wilke et al, 2008; Pandard y Römbke 2013). Todas las matrices sólidas fueron evaluadas acorde a dos 
enfoques, el residuo en forma entera y su fracción líquida o elución acuosa. Esta aproximación resulta ser necesaria para comprender la movilidad de los tóxicos presentes en las matrices sólidas y para comprender la toxicidad del residuo de manera integral (Ferrari et al, 1999; van Gestel et al, 2001; Domene et al, 2008; Stiernströn et al, 2011; Widziewicz et al, 2012; Pandard y Römbke, 2013).

El amplio espectro de parámetros biológicos evaluados evidenció un diferente grado de toxicidad asociado a las matrices sólidas estudiadas. Considerando el análisis integrado de los mismos se puede afirmar que en el caso de las matrices sólidas correspondientes a residuos industriales, el residuo de cosmética resultó ser más tóxico que el residuo de arena de fundición. Ambos residuos provocaron efectos letales y sub-letales en los organismos de prueba utilizados. En el caso de las matrices sólidas correspondientes a suelos tratados con plaguicidas, tanto el herbicida glifosato como el insecticida clorpirifos, ejercieron efectos tóxicos sobre los organismos de prueba. Es de destacar que en la mayoría de los parámetros evaluados las CMEO de ambos plaguicidas fueron coincidentes con las menores dosis de aplicación evaluadas. Estas dosis correspondieron a 2,5 L/ha de glifosato y $1 \mathrm{~L} / \mathrm{ha}$ para el clorpirifos. Así, los organismos de prueba utilizados en la presente batería de evaluación ecotoxicológica evidenciaron los efectos tóxicos de ambas dosis mínimas de aplicación.

En este aspecto, es importante remarcar que para las menores dosis de aplicación evaluadas se observaron efectos genotóxicos a períodos de exposición correspondientes a 1 h, 7 y 14 días. Estos efectos podrían vincularse con el riesgo a niveles supraespecíficos, ya que podrían ser causantes de la depleción de organismos en los poblaciones. Asimismo, la genotoxicidad de los plaguicidas representa un riesgo para la salud humana (WHO, 2006). Por lo antes expuesto, se resalta el elevado riesgo ambiental que representa la utilización de ambos plaguicidas para la biota, ya que las especies utilizadas en los bioensayos no corresponden a organismos blanco de ambos plaguicidas. Asimismo, una incorrecta aplicación de los plaguicidas en los cultivos, sobre todo la duplicación de dosis de aplicación, conllevaría un incremento de los efectos perjudiciales de los plaguicidas sobre la biota presente.

En lo que respecta a la segunda hipótesis, se puede afirmar que debido a la sensibilidad diferencial de los organismos a los compuestos químicos presentes en las matrices sólidas estudiadas, es necesaria la evaluación ecotoxicológica que abarque distintos tiempos y vías de exposición en relación a los niveles tróficos considerados. Además, en términos ecológicos, esto tiene una asociación directa con el rol que cada uno de estos organismos tiene en el ecosistema. Las plantas como productores primarios, son necesarias en una evaluación 
ecotoxicológica debido a su importante papel energético para el funcionamiento de los ecosistemas (Tarradellas et al, 1997; Foester et al, 2009). Asimismo, las lombrices de tierra, son los macroinvertebrados que representan la mayor proporción de la biomasa de los suelos, participan en el reciclado de nutrientes y mantenimiento de su estructura (Sauvé et al, 2002; Xiao et al, 2006; Spurgeon y Hopkin, 1995; Heimbach, 1985, 1992; van Gestel et al, 1992).

Entre todos las respuestas biológicas evaluadas se resaltan aquellas de mayor sensibilidad y menor tiempo de exposición para los fines regulatorios. Así una evaluación ecotoxicológica de matrices sólidas correspondientes a residuos industriales debería, a partir de los resultados presentados en este Trabajo de Tesis Doctoral, incluir al menos el ensayo de elongación de raíces en L. sativa y la evaluación de cito y genotoxicidad en celomocitos de E. fetida expuestos ex vivo durante 1 hora.

Los resultados generados ponen de manifiesto la necesidad de evaluar ecotoxicológicamente los residuos sólidos industriales antes de decidir y definir su disposición final en el ambiente. La reglamentación ambiental, nacional o provincial, que la regula debería basarse en el análisis conjunto de parámetros físicoquímicos y ensayos biológicos. Desde este punto de vista, la legislación nacional vigente, tendría no solamente que definir sobre que especies evaluar un conjunto de variables de respuesta, sino, además, incorporar criterios de niveles de aceptabilidad para los mismos. Este nivel de aceptabilidad permitiría minimizar los riesgos ambientales asociados a la disposición de residuos. La definición de valores estándares de referencia es también un punto importante a tener en cuenta para el monitoreo de las celdas o cavas donde se entierran en la actualidad.

En el caso de la evaluación potencial que surge por la aplicación de los agroquímicos glifosato y clorpirifos, los resultados obtenidos permiten concluir que aún en las dosis más bajas de aplicación de los mismos se registran efectos tóxicos. Estos efectos se evidenciaron independientemente de la variable de respuesta elegida como de la especie ensayada. Dejando de manifiesto el peligro real que estas dosis representan para los organismos no-blanco durante las aplicaciones de dosis de efectividad agrícola. Por lo cual, una combinación de variables de respuesta que contemple la utilización de organismos pertenecientes a diferentes niveles tróficos es apta para la determinación de la peligrosidad de muestras de origen ambiental. Dentro de este conjunto de variables, se recomienda la realización de ensayos de cortos períodos de exposición. Asimismo, debido a que la genotoxicidad representa un efecto biológico de importancia, una batería de ensayos debería incluir la evaluación de efectos genotóxicos debida al tratamiento con plaguicidas. 
Por otra parte, es necesaria la caracterización ecotóxica de las matrices sólidas tanto en su forma entera como su elución para identificar los efectos perjudiciales que puede provocar la movilización de tóxicos en el ambiente. Debido a que el agua es el principal medio de dispersión de contaminantes, la evaluación ecotoxicológica de la elución acuosa permite predecir el comportamiento de las sustancias químicas en el ambiente debido a las precipitaciones. En este aspecto, los resultados obtenidos en el presente Trabajo de Tesis Doctoral permiten afirmar que la movilidad de sustancias contaminantes genera efectos tóxicos en los organismos de prueba estudiados. Los ensayos realizados con celomocitos de $E$. fetida expuestos de manera ex vivo durante un lapso tan breve como el de $1 \mathrm{~h}$, representan una valiosa herramienta para la evaluación de efectos deletéreos en breves períodos de tiempo. La determinación de la genotoxicidad resultó ser una herramienta esencial de evaluación por la evaluación de los efectos causados por los agroquímicos glifosato y clorpirifos.

La aplicación de una batería de ensayos que consideren las variables de respuesta tradicionales (inhibición del crecimiento, sobrevivencia, entre otros) en conjunto con biomarcadores a nivel bioquímico, celular y molecular, constituyen un procedimiento experimental integrado para la evaluación de residuos y suelos agrícolas. La determinación de los efectos biológicos sumado a la determinación de parámetros físicoquímicos de tales matrices, permite la comprensión de los efectos sobre diferentes organismos y sus posibles mecanismos de acción. Esta evaluación integrada genera las herramientas adecuadas para determinar la ecotoxicidad de un residuo y/o suelo. La correcta clasificación de un residuo como ecotóxico o no ecotóxico, que contribuya en la toma de decisiones para su posterior tratamiento, es de suma importancia para evitar el deterioro ambiental generado por la incorporación de contaminantes al ecosistema terrestre y su potencial de movilización a las aguas subterráneas. Por otra parte, la evaluación de los efectos ecotóxicos provocados por la aplicación de plaguicidas en los suelos rurales, permite advertir los efectos perjudiciales originados por prácticas agrícolas inadecuadas o el uso excesivo de los mismos en los sistemas de cultivo intensivos.

La determinación de los efectos ecotóxicos es de suma importancia ya que la presencia de contaminantes en los ecosistemas, no sólo es perjudicial para el ambiente, sino que pueden provocar efectos adversos en la salud humana. Estos efectos conducen a un detrimento de las condiciones de estabilidad delos sistemas naturales. Debido a que el ecosistema terrestre es soporte de ambientes rurales y urbanos, es necesario evitar la dispersión de contaminantes que alteren la calidad de los mismos. De este modo, la evaluación ecotoxicológica de matrices 
sólidas presenta una elevada trascendencia para evitar y prevenir la degradación ambiental originada por la presencia de sustancias contaminantes. 


\section{Referencias bibliográficas}


Achary V, Parinandi N, Panda B. 2013. Calcium channel blockers protect against aluminum-induced DNA damage and block adaptive response to genotoxic stress in plant cells. Mutation Research, 751:130-138.

Adamowicz A, Wojtaszek A. 2001. Morphology and phagocytotic activity of coelomocytes in Dendrobaena veneta (Lumbricidae). Zoologica Polonidae, 46:91-104.

Adamowicz A. 2005. Morphology and ultrastructure of the earthworm Dendrobaena veneta (Lumbricidae) coelomocytes. Tissue and Cell, 37(2):125-133.

AFNOR, 2004. NF T90-327. Soil quality - assessment of genotoxic effects to higher plants micronucleus test on Vicia faba. En: AFNOR, Saint-Denis, p. 13.

Ali D, Nagpure NS, Kumar S, Kumar R, Kushwaha B, Lakra WS. 2009. Assessment of genotoxic and mutagenic effects of chlorpyrifos in freshwater fish Channa punctatus (Bloch) using micronucleus assay and alkaline single-cell gel electrophoresis. Food and Chemical Toxicology, 47(3):650-656.

Ali D, Nagpure NS, Kumar S, Kumar R, Kushwaha B. 2008. Genotoxicity assessment of acute exposure of chlorpyrifos to freshwater fish Channa punctatus (Bloch) using micronucleus assay and alkaline single-cell gel electrophoresis. Chemosphere, 71:1823-1831.

Amer SM, Farah OR. 1983. Cytological effects of pesticides. Effects of the phosphorothioate insecticide dursban on the mitosis of Vicia faba. Cytologia, 48:27-33.

American Society for Agricultural Engineers Standard (ASAE), Norma S-327.1. Spray Tip Classification by Droplet Size, Developed by the Pest Control and Fertilizer Application Committee; approved by the Power and Machinery Division Standards Committee; adopted by ASAE PM41. Pp 64-68.

An J, Zhou Q, Sun Y, Xu Z. 2009. Ecotoxicological effects of typical personal care products on seed germination and seedling development of wheat (Triticum aestivum L.). Chemosphere, 76(10):1428-1434.

ANMAT. Administración Nacional de Medicamentos, Alimentos y Tecnología Médica. http://www.anmat.gov.ar/cosmeticos/Cosmeticos.asp . Acceso Julio 2015.

APHA-AWWA-WPCF, 1998. Method 2540. In: Franson M (Ed.). Standard methods for the examination of water and wastewater. 20th ed. American Public Association. American Water Works. Association. Water Environment Federation, Washington.

Argenbio. Consejo Argentino para la Información y el Desarrollo de Biotecnología. http://www.argenbio.org/index. Acceso Julio 2015.

Ashby J. 1988. Comparison of techniques for monitoring human exposure to genotoxic Chemicals. Mutation Research, 204:542-551.

Auman JW, Seidler FJ, Slotkin TA. 2000. Neonatal chlorpyrifos exposure targets multiple proteins governing the hepatic adenylyl cyclase signaling cascade: implications for neurotoxicity. Development Brain Research, 121:19-27.

Bakry FA, Ismail SM, El-Atti MS. 2015. Glyphosate herbicide induces genotoxic effect and physiological disturbances in Bulinus truncatus snails. Pesticide Biochemistry and Physiology, 123:24-30.

Belz RG, Cedergreen N, Sørensen H. 2008. Hormesis in mixtures - Can it be predicted? Science of the Total Environment, 404(1):77-87.

Beraud E, Cotelle S, Leroy P, Ferard JF. 2007. Genotoxic effects and induction of phytochelatins in the presence of cadmium in Vicia faba roots. Mutation Research 633:112-116

Bernard F, Brulle F, Dumez S, Lemiere S, Platel A, Nesslany F, Cuny D, Derama A, Vandenbulcke F. 2014. Antioxidant responses of Annelids, Brassicaceae and Fabaceae to pollutants: A review. Ecotoxicology and Environmental Safety:1-31. 
Betts KS. 2010. Endocrine damper?: Flame retardants linked to male hormone, sperm count changes. Environmental Health Perspectives, 118(3): A130.

Bigorgne E, Cossu-Leguille C, Bonnard M, Nahmani J. 2010. Genotoxic effects of nickel, trivalent and hexavalent chromium on the Eisenia fetida earthworm. C

Blackburn L, Boutin C. 2003. Subtle effects of herbicide use in the context of genetically modified crops: a case study with glyphosate. Ecotoxicology, 12:271-285.

Blus LJ. 2002. Organochlorine pesticides. En: Handbook of Ecotoxicology - Section II Hoffman DJ, Rattner BA, Burton GA (Eds.). Lewis Publishers, p 313-341.

Bogacki J, Naumczyk J, Marcinowski P, Kucharska M. 2011. Treatment of cosmetic wasterwater using physicochemical and chemical methods. Chemik, 65(2):94-97.

Bolognesi C, Bonatti S, Degan P, Gallerani E, Peluso M, Rab- boni R, Roggieri P, Abbondandolo A. 1997. Genotoxic activity of glyphosate and its technical formulation Roundup. Journal of Agricultural and Food Chemistry, 45:1957-1962.

Bomser JA, Casida JE. 2001. Diethylphosphorylation of rat cardiac M2 muscarinic receptor by chlorpyrifos oxon in vitro. Toxicology Letters:21-26.

Bonnard M, Eom IC, Morel JL, Vasseur P. 2009. Genotoxic and reproductive effects of an industrially contaminated soil on the earthworm Eisenia fetida. Environmental Molecular Mutagenesis, 50:60-67.

Booth LH, Hodge S, O'Halloran, K. 2000. Use of cholinesterase in Aporrectodea Caliginosa (Oligochaeta; Lumbricidae) to detect organophosphate contamination: comparison of laboratory tests, mesocosms, and field studies. Environmental Toxicology, 19(2):417-422.

Booth LH, O'Halloran, K. 2001. A comparison of biomarker responses in the earthworm Aporrectodea caliginosa to the organophosphorus insecticides diazinon and chlorpyrifos. Environmental Toxicology and Chemistry, 20(11):2494-2502.

Boxman AW, Krabbendam H, Bellemakers MJS, Roelofs JGM. 1991. Effects of ammonium and aluminum on the development and nutrition of Pinus nigra in hydroculture. Environmental Pollution, 73:119-136.

Breure AM, Mulder C, Römbkke J, Ruff A. 2005. Ecological classification and assessment concepts in soil protection. Ecotoxicology and Environmental Safety, 62:211-229

Brusseau ML. 1997. Transport and fate of toxicant in soils. En: Soil Ecotoxicology Tarradellas J, Bitton G, Rossel D (Eds). CRC Press Boca Raton, FL, Estados Unidos, p 33-53.

Burton GA, Denton DL, Ho K Ireland DS. 2002. Sediment toxicity testing: issues and methods. En: Handbook of Ecotoxicology - Section I. Hoffman, DJ, Rattner B, Burton GA, Cairns J (Eds). Lewis Publishers, p $111-151$.

Byrne S, Shurdut BA, Saunders DG. 1998. Potential chlorpyrifos exposure to residents following standard crack and crevice treatment. Environmental Health Perspectives, 106:725-731.

Cajaraville MP, Bebianno MJ, Blasco J, Porte C, Sarasquete C, Viarengo A. 2000. The use of biomarkers to assess the impact of pollution in coastal environments of the Iberian Peninsula: a practical approach. The Science of the Total Environment, 247:295-311.

Calabrese EJ, Baldwin LA. 2001. Hormesis: a generalizable and unifying hypothesis. Critical Reviews in Toxicology, 31:353-424.

Calabrese EJ. 2005. Paradigm lost, paradigm found: the re-emergence of hormesis as a fundamental dose response model in the toxicological sciences. Environmental Pollution, 138:378-411.

Calabrese EJ. 2013. Hormetic mechanisms. Critical Reviews in Toxicology, 43(7):580-606.

Calisi A, Lionetto MG, Schettino T. 2009. Pollutant-induced alterations of granulocyte morphology in the earthworm Eisenia foetida. Ecotoxicology and Environmental Safety, 72(5):1369-1377.

CAPA, 2015. www.capa.org.ar.

Carlile WR. 2006. Pesticide selectivity, Health and the environment. Cambridge University Press, Cambridge, p 299 
Carnin RL, Folgueras MV, Luvizao RR, Correia SL, da Cunha CJ, Dungan RS. 2012. Use of an integrated approach to characterize the physicochemical properties of foundry green sands. Thermochimica Acta, 543:150-155.

Carrano AV, Natarajan AT. 1988. Considerations for population monitoring using cytogenetic techniques. Mutation Research, 204:379-406.

Carter MR. 1993. Soil sampling and methods of analysis. Lewis Publishers, Boca Raton Fl, Estados Unidos. 823p.

Casabe N, Piola L, Fuchs J, Oneto ML, Pamparato L, Basack S, Giménez R, Massaro R, Papa JC, Kesten, E. 2007. Ecotoxicological assessment of the effects of glyphosate and chlorpyrifos in an Argentine soya field. Journal of Soils and Sediments, 7(4):232-239.

CASAFE Cámara de Sanidad Agropecuaria y Fertilizantes. Buenos Aires, Argentina. http://www.casafe.org/.2012. Acceso Julio 2015.

CASAFE, 2009. La Argentina 2050. La revolución tecnológica del agro. Hacia el desarrollo integral de nuestra sociedad. Cámara de Sanidad Agropecuaria y Fertilizantes, 744.

Casas R.R. 2005. Efecto de la intensificación agrícola sobre los suelos. Ciencia Hoy. 15(87): 4243.

Cavalcante DG, Martinez CBR, Sofia SH. 2008. Genotoxic effects of Roundup ${ }^{\circledR}$ on the fish Prochilodus lineatus. Mutation Research, 655:41-46.

Cavaş T, Könen S, 2007. Detection of cytogenetic and DNA damage in peripheral erythrocytes of goldfish (Carassius auratus) exposed to a glyphosate formulation using the micronucleus test and the comet assay. Mutagenesis, 22:263-268.

Cedergreen N, Abbaspoor M, SØrensen H, Streibig, J. 2007. Is mixture toxicity measured on a biomarker indicative of what happens on a population level? A study with Lemna minor. Ecotoxicology and Environmental Safety, 67:323-332.

Cedergreen N, Olesen CF. 2010. Can glyphosate stimulate photosynthesis? Pesticide Biochemistry and Physiology, 96(3):140-148.

Cedergreen N, Streibig JC. 2005. The toxicity of herbicides to non-target aquatic plants and algae: assessment of predictive factors and hazard. Pesticide Management Science, 61:1152-1160

Chang LW, Meier JR, Smith MK. 1997. Application of plant and earthworm bioassays to evaluate remediation of a lead-contaminated soil. Archives of Environmental Contamination and Toxicology, 32(2):166-171.

Chaoui A, Mazhoudi S, Ghorbal MH, El Ferjani E. 1997. Cadmium and zinc induction of lipid peroxidation and effects on antioxidant enzyme activities in bean (Phaseolus vulgaris L.). Plant Science, 127(2):139-147.

Chen G, White P. 2004. The mutagenic hazards of aquatic sediments: A review. Mutation Research Reviews in Mutation Research, 567(2-3):151-225.

Chuang YYE, Chen Y, Gadisetti Chandramouli, VR, Cook JA, Coffin D, Tsai MH, DeGraff W, Yan H, Zhao S, Russo A, Liu ET, Mitchell JB. 2002. Gene expression after treatment with hydrogen peroxide, menadione, or t-butyl hydroperoxide in breast cancer cells. Cancer Research, 62:6246-6254.

Clément B, Colin J R, Le Dû-Delepierre A. 1997. Estimation of the hazard of landfills through toxicity testing of leachates. Chemosphere, 35:2783-2796.

Clements C, Ralph S, Petras M. 1997. Genotoxicity of select herbicides in Rana catesbeiana tadpoles using the alkaline single-cell gel DNA electrophoresis (comet) assay. Environmental and Molecular Mutagenesis, 29:277-288.

Clements WH y Newman MC. 2002. Community Ecotoxicology. Wiley Ltd, Chichester, Inglaterra, $336 \mathrm{p}$.

Collange B, Wheelock CE, Rault M, Mazzia C, Capowiez Y, Sanchez-Hernandez, JC. 2010. Inhibition, recovery and oxime-induced reactivation of muscle esterases following chlorpyrifos exposure in the earthworm Lumbricus terrestris. Environmental Pollution, 158(6):2266-2272. 
Collins AR, Oscoz AA, Brunborg G, Gaivão I, Giovannelli L, Kruszewski M, Smith C, Štětina, R. 2008. The comet assay: Topical issues. Mutagenesis, 23(3):143-151.

Collins AR. 2004. The comet assay for DNA damage and repair - Principles, applications, and limitations. Molecular Biotechnology, 26:249-261.

Connell Des W. 2005. Basic concepts of environmental chemistry. CRC Press Boca Ratón Fl, Estados Unidos, $461 \mathrm{p}$.

Contardo-Jara V, Klingelmann E, Wiegand C. 2009. Bioaccumulation of glyphosate and its formulation Roundup Ultra in Lumbriculus variegatus and its effects on biotransformation and antioxidant enzymes. Environmental Pollution, 157(1):57-63.

Conti M. 2005. Principios de Edafología con énfasis en suelos argentinos. Editorial Facultad de Agronomía UBA, Argentina, $430 \mathrm{p}$.

Cordova Rosa EV, Simionatto EL, Souza Sierra MM, Bertoli SL, Radetski CM. 2001. Toxicity based criteria for the evaluation of textile wastewater treatment efficiency. Environmental Toxicology and Chemistry, 20:839-845.

Cordova Rosa EV, Valgas C, Souza Sierra MM, Correa AXR, Radetski CM. 2003. Biomass growth, micronucleus induction and antioxidant stress enzyme responses in Vicia faba exposed to cadmium in solution. Environmental Toxicology and Chemistry, 22:645-649.

Cortet J, Gomot-De Vauflery A, Poinsot-Balaguer N, Gomot L, Texier C, Cluzeau D. 1999. The use of invertebrate soil fauna in monitoring pollutant effects. European Journal of Soil Biology, 35(3):115-134.

Cossarizza A, Cooper EL, Suzuki MM, Salvioli S, Capri M, Gri G, Quaglino D, Franceschi C. 1996. Earthworm leukocytes that are not phagocytic and cross-react with several human epitopes can kill human tumor cell lines. Experimental Cell Research, 224(1):174-182.

Costa LG (2008). Toxic effects of pesticides. En Casarett LJ y Doull's J. Toxicology, The basic science of Poisons, 6th Klaassen, C.D.; Amdus, M.O.; y Dowll, J. (Eds) Macmillan Publishing Company.

Cotelle S, Férard JF. 1999. Comet assay in genetic ecotoxicology: A review. Environmental and Molecular Mutagenesis, 34(4):246-255.

Cronquist A. 1981. An integrated system of classification of flowering plants. Columbia University Press. $1262 \mathrm{p}$.

Crumpton TL, Seidler FJ, Slotkin TA. 2000. Is oxidative stress involved in the developmental neurotoxicity of chlorpyrifos? Development. Brain Research, 121:189-195.

Currie Z, Prosser RS, Rodriguez-Gil JL, Mahon K, Poirier D, Solomon KR. 2015. Toxicity of Cúspide 480SL $\AA$ spray mixture formulation of glyphosate to aquatic organisms. Environmental Toxicology and Chemistry, 34(5):1178-1184.

De Simone C, Piccolo A, De Marco A. 1992. Genotoxic effect induced by herbicides atrazine glyphosate in plants of Vicia faba grown in different soils. Science of the Total Environment, 123-124:233-240.

Demidchik V. 2015. Mechanisms of oxidative stress in plants: From classical chemistry to cell biology. Environmental and Experimental Botany, 109:212-228.

Dhawan A, Bajpayee M, Parmar D. 2008. Comet assay: a reliable tool for the assessment of DNA damage in different models. Cell Biology and Toxicology, 25:5-32.

Di Marzio WD, Sáenz ME, Montivero C, Alberdi JL, Tortorelli MC and Ambrini G. 2007. Genotoxicity of acqueous elutions of industrial soils. Bulletin of Environmental Contamination and Toxicology, 74:637-644.

Di Marzio WD, Saenz ME, Lemiere S, Vasseur P, 2005. Improved single cell gel electrophoresis assay for the earthworm Eisenia foetida. Environmental and Molecular Mutagenesis, 46(4):246-252.

Di Marzio WD, Sáenz ME. 2013. Ecotoxicología. EUDEBA, Buenos Aires, 325 p. 
Di Salvatore M, Carafa A M, Carratú G. 2008. Assessment of heavy metals phytotoxicity using seed germination and root elongation test: A comparison of two growth substrates. Chemosphere, 73:1461-1464.

Dietz KJ, Stork T, Finkemeier I, Lamkemeyer P, Li W, El-Tayeb M. 2008. The Role of Peroxiredoxins in Oxygenic Photosynthesis of Cyanobacteria and Higher Plants: Peroxide Detoxification or Redox Sensing? In: Adams B, Adams W, Mattoo AK (Eds) Advances in Photosynthesis and Respiration Series. Photoprotection, Photoinhibition, Gene Regulation and Environment Vol 21. Springer, p 303-316.

Du L, Li G, Liu M, Li Y, Yin S, Zhao J, Zhang X. 2015. Evaluation of DNA damage and antioxidant system induced by di-n-butyl phthalates exposure in earthworms (Eisenia fetida). Ecotoxicology and Environmental Safety, 115:75-82.

Duke SO. 1988. Glyphosate. En: Herbicides: chemistry, degradation and mode of action. Kearney PC y Kaufman DD (Eds) Marcel Dekker, p1-70.

Eaton DL, Daroff RB, Autrup H, Bridges J, Buffler P, Costa LG, Coyle J,McKhann G, Mobley WC, Nadel L, Neubert D, Schulte- Hermann R, Spencer PS. 2008. Review of the toxicology of chlorpyrifos with an emphasis on human exposure and neuro-development. Critical Reviews Toxicology, 38:1-125.

Egert M, Tevini M. 2002. Influence of drought on some physiological parameters symptomatic for oxidative stress in leaves of chives (Allium schoenoprasum) Environmental and Experimental Botany, 48 (1):43-49.

Esplugas S, Bila DM, Krause LG, Dezotti M. 2007. Ozonation and advanced oxidation technologies to remove disrupting chemicals (EDCs) and pharmaceuticals and personal care products (PPCPs) in water effluents. Journal of Hazardous Materials, 149:631-642.

Eyambe GS, Goven AJ, Fitzpatrick LC, Venables BJ, Cooper EL. 1991. A non-invasive technique for sequential collection of earthworm (Lumbricus terrestris) leukocytes during subchronic immuno-toxicity studies. Laboratory Animals, 25:61-67.

Fatta-Kassinos D, Kalavrouziotis IK, Koukoulakis PH, Vasquez, MI. 2011. The risks associated with wastewater reuse and xenobiotics in the agroecological environment. Science of the Total Environment, 409(19):3555-3563.

Faust F, Kassie F, Knasmuller S, Boedecker RH, Mann M, Mersch-Sundermann V. 2004. The use of the alkaline comet assay with lympho- cytes in human biomonitoring studies. Mutation Research, 566:209-229.

Fenech M, Morley A. 1985. Measurement of micronuclei in lymphocytes. Mutation Research, 147:29-36.

Fenech M. 2000. The in vitro micronucleus technique. Mutation Research, 455:81-95.

Ferrari B, Radetski CM, Veber AM, Ferard JF. 1999. Ecotoxicological assessment of solid wastes: a combined liquid- and solid-phase testing approach using a battery of bioassays and biomarkers. Environmental Toxicology and Chemistry, 18:1195-202.

Foerster B, Firla C, Junker T. 2009. Plant test. En: Moser H and Römbke J (Eds) Ecotoxicological Characterization of Waste. Springer, New York, p 117-128.

Foltête AS, Masfaraud JF, Bigorgne E, Nahmani J, Chaurand P, Botta C, Labille J, Rose J, Férard JF, Cotelle S. 2011. Environmental impact of sunscreen nanomaterials: Ecotoxicity and genotoxicity of altered $\mathrm{TiO}_{2}$ nanocomposites on Vicia faba. Environmental Pollution 159:2515-2522.

Fountain MT, Brown VK, Gange AC, Symondson WOC, Murray PJ. 2007. The effects of the insecticide chlorpyrifos on spider and Collembola communities. Pedobiologia, 51(2):147158.

Fourie F, Reinecke S, Reinecke J. 2007. The determination of earthworm species sensitivity differences to cadmium genotoxicity using the comet assay. Ecotoxicology and Environmental Safety, 67(3):361-368. 
Foyer C, Trebst A, Noctor G. 2008. Signaling and Integration of Defense Functions of Tocopherol, Ascorbate and Glutathione. En: Adams B, Adams W, Mattoo AK (Eds) Advances in Photosynthesis and Respiration Series. Photoprotection, Photoinhibition, Gene Regulation and Environment Vol 21. Springer, p 242-260.

Fuchs MA, Geiger DR, Reynolds TL, Bourque JE. 2002. Mechanisms of glyphosate toxicity in velvetleaf (Abutilon theophrasti medikus). Pesticide and Biochemical Physiology, 74:27-39

Fugère N, Brousseau P, Krzystyniak K, Coderre D, Fournier M. 1996. Heavy metal-specific inhibition of phagocytosis and different in vitro sensitivity of heterogeneous coelomocytes from Lumbricus terrestris (Oligochaeta). Toxicology, 109(2-3):157-166.

Gallego S, Benavides M, Tomaro M. 2002. Involvement of an antioxidant defense system in the adaptive response to heavy metal ions in Helianthus annuus L. cells. Plant Growth Regulation, 36:267-273.

Gebremariam SY, Beutel MW, Yonge DR, Flury M, Harsh JB. 2012. Adsorption and desorption of chlorpyrifos to soils and sediments. Environmental Contamination and Toxicology 215:12375.

González Vejares S, Sabat P, Sanchez-Hernandez, JC. 2010. Tissue-specific inhibition and recovery of esterase activities in Lumbricus terrestris experimentally exposed to chlorpyrifos. Comparative Biochemistry and Physiology - C Toxicology and Pharmacology, 151(3):351359.

Griffiths HR. 2005. Chemical Modifications of Biomolecules by Oxidants. En: Hutzinger O (Eds) The Handbook of Environmental Chemistry Vol. 2. Springer-Verlag Berlin Heidelberg, p. $33-62$.

Grisolia CK, 2002. A comparison between mouse and fish micronucleus test using cyclophosphamide, mitomycin C and various pesticides. Mutation Research, 518:145-150.

Groppa MD, Tomaro ML, Benavides MP. 2007. Polyamines and heavy metal stress: The antioxidant behavior of spermine in cadmium- and copper-treated wheat leaves. BioMetals, 20(2):185195.

Gupta SC, Mishra M, Sharma A, Deepak Balaji TGR, Kumar R, Mishra RK, Chowdhuri DK, 2010. Chlorpyrifos induces apoptosis and DNA damage in Drosophila through generation of reactive oxygen species. Ecotoxicology and Environmenal Safety 73:1415-1423.

Gutteridge J y Halliwell B. 2000. Free radicals and antioxidants in the year 2000: a historical look to the future. Annals of the New York Academy of Sciences. Vol 899 (1):136-147.

Habig C y Di Giulio T. 1991. Biochemical characteristics of cholinesterases in aquatic organisms. En: Cholinesterase-inhibiting insecticides. Their impact on wildlife and the environment. Chemicals in agriculture Vol 2. P. Mineau (Ed). Elsevier, p 19-33.

Hammad AM, Gürkan MO. 2012. Side effects of some crop protection products on non-target soil invertebrates. Journal of Turkish Entomology, 36 (2):169-176.

Harrison RM, 1996. Pollution: causes, effects and control. 3rd Ed, RSC, Cornwall, Rieno Unido, 480 p.

Hartwig A. 1995. Current aspects in metal genotoxicity. Bio- metals, 8:3-11.

Heimbach F. 1985. Comparison of laboratory methods, using Eisenia fetida and Lumbricus terrestris, for the assessment of the hazard of chemicals to earthworms. Pflanzenk. Pflanzen, 92:186-193.

hemosphere, 80(9):1109-1112.

Hill EF. 2002. Organophosphorus and Carbamate insecticides. En: Handbook of Ecotoxicology Section II. Hoffman DJ, Rattner BA, Burton GA (Eds.). Lewis Publishers, p 281-313

Hoagland DR, Arnon DI. 1950. The Water Culture Method for Growing Plants without Soil. Agricultural Experimental Station of the University of California, Berkeley, Circular 347:137. 
Hornsby AG, Don Wauchope R, Herner AE. 1996. Pesticide properties in the environment. SpringerVerlag New York, Inc. 227 p.

Horváthová E, Slameňová D, Hlinčíková L, Mandal TK, Gábelová A, Collins AR. 1998. The nature and origin of DNA single-strand breaks determined with the comet assay. Mutation Research/DNA Repair, 409(3):163-171.

IARC. 1990. Monographs Volume 49. Chromium, Nickel and welding. International Agency for Reseache on Cancer, Lyon, 687p.

IARC. 1993. Monographs Volume 54: Beryllium, Cadmium, Mercury, and Exposures in the Glass Manufacturing Industry. International Agency for Reseache on Cancer, Lyon. 444 p.

IARC. 2015. IARC Monographs Volume 112: evaluation of five organophosphate insecticides and herbicides. International Agency for Research on Cancer, Lyon.

Ingersoll CG. 1995. Sediment test. En: Rand GM (Ed.) Fundamentals of aquatic toxicology: effects, environmental fate, and risk assessment. Taylor \& Francis, Washington, Estados Unidos, p 231-255

IRAM. Norma IRAM 29114. 2008. Método de ensayo de toxicidad aguda con semillas de lechuga. Método en papel.

Jackson RE, Pietre HN. 2004. Influence of Roundup Ready soybean and Roundup Ultra herbicide on Geocoris punctipes (Say) (Heteroptera: Lygaeidae) in the laboratory. Journal of Entomology Science, 39:55-61.

Jha AN. 2004. Genotoxicological studies in aquatic organisms: an overview. Mutation Research, 552:1-17

Jha AN. 2008. Ecotoxicological applications and significance of the comet assay. Mutagenesis, 23(3):207-221

Jin-Clark Y, Lydy MJ, Zhu, KY. 2002. Effects of atrazine and cyanazine on chlorpyrifos toxicity in Chironomus tentans (Diptera: Chironomidae). Environmental Toxicology and Chemistry, 21(3):598-603

Kappus H. 1985. Lipid peroxidation: mechanisms, analysis, enzymology and biological relevance. En: Sies H (Ed). Oxidative Stress, Academic Press, Londres, p 273-310

Kasprzyk-Hordern B, Dinsdale RM, Guwy AJ. 2009. The removal of pharmaceuticals, personal care products, endocrine disruptors and illicit drugs during wastewater treatment and its impact on the quality of receiving waters. Water Research, 43:363-380

Khan SU. 1980. Pesticide in the soil environment. El sevier Publ 247 p.

Kielak E, Sempruch C, Mioduszewska H, Klocek J, Leszczyński B. 2011. Phytotoxicity of Roundup Ultra 360 SL in aquatic ecosystems: Biochemical evaluation with duckweed (Lemna minor L.) as a model plant. Pesticide Biochemistry and Physiology, 99(3):237-243

Końca K, Lankoff A, Banasik A, Lisowska H, Kuszewski T, Gózd S, Koza Z, Wojcik A. 2003. A cross platform public domain PC image analysis program for the comet assay. Mutation Research, 534:15-20

Kranner I, Colville L. 2011. Metals and seeds: Biochemical and molecular implications and their significance for seed germination. Environmental and Experimental Botany, 72:93-105

Kruszewski M, Green MHL, Lowe JE Szumiel I. 1994. DNA strand breakage, cytotoxicity and mutagenicity of hydrogen peroxide treatment at $4 \mathrm{C}$ and $37 \mathrm{C}$ in L5178Y sublines. Mutation Research, 308:233-241

Kula C. 1996. Development of a test method on sublethal effects of pesticides on the earthworms species Eisenia fetida/Eisenia Andrei- comparison of 2 ring tests. Mitteilungen aus der Biologischen Bundesanstalt, 320: 50-81

Kula C. 1997. Endpoints in laboratory testing with earthworms: experience whit regard to regulatory decisions for plant protection products. En: Sheppard, S. 1997. Advances in Earthworm Ecotoxicology: Proceedings from the Second International Workshop on Earthworm Ecotoxicology, April 1997, Amsterdam, the Netherlands. SETAC Foundation pp 413 
Kumaravel TS, Jha AN. 2006. Reliable Comet assay measurements for detecting DNA damage induced by ionising radiation and chemicals. Mutation Research - Genetic Toxicology and Environmental Mutagenesis, 605(1-2):7-16

Lajmanovich RC, Sandoval MT, Peltzer PM, 2003. Induction of mortality and malformation in Scinax nasicus tadpoles exposed to glyphosate formulations. Bulletin of Environmental Contamination and Toxicology, 70:612-618

Lee RF, Steinert S. 2003. Use of the single cell gel electrophoresis/comet assay for detecting DNA damage in aquatic (marine and freshwater) animals. Mutation Research - Reviews in Mutation Research, 544(1):43-64.

Leng ML, Leovey EM y Zubkoff PL. 1995. Agrochemical environmental fate. State of the art. CRC Press, Lewis Publishers. 432 p.

Ley 24051, 1993. Reglamentación de la Ley 24051, Decreto $\mathrm{N}^{\circ}$ 831/ 93. En Boletín Oficial Argentina, Residuos peligrosos, Buenos Aires.

Li M, Liu Z, Xu Y, Cui Y, Li D, Kong Z. 2009. Comparative effects of Cd and Pb on biochemical response and DNA damage in the earthworm Eisenia fetida (Annelida, Oligochaeta). Chemosphere, 74(5): 621-625.

Lin D, Zhou Q, Xie X, Li Y. 2010. Potential biochemical and genetic toxicity of triclosan as an emerging pollutant on earthworms (Eisenia fetida). Chemosphere, 81(10):1328-1333

Lock K, Janssen CR. 2001. Cadmium toxicity for terrestrial invertebrates: taking soil parameters affecting bioavaibility into account. Ecotoxicology, 10:315-322.

Lourenço J, Pereira R, Silva A, Carvalho F, Oliveira J, Malta M, Mendo S. 2012. Evaluation of the sensitivity of genotoxicity and cytotoxicity endpoints in earthworms exposed in situ to uranium mining wastes. Ecotoxicology and Environmental Safety, 75(1): 46-54.

Lowry O, Rosebrough N, Farr A, Randall R. 1951. Protein measurement with the folin phenol reagent. Journal of Biological Chemistry, 193:265-275.

Lushchak OV, Kubrak OI, Storey JM, Storey KB, Lushchak VI. 2009. Low toxic herbicide Roundup induces mild oxidative stress in goldfish tissues. Chemosphere 76:932-937.

Manahan SE. 1990. Hazardous Waste Chemistry, Toxicology and Treatment. Lewis Pub. 378 p.

Manahan SE. 2001. Fundamentals of Environmental Chemistry. CRS Press Boca Ratón, FL, Estados Unidos, $994 \mathrm{p}$.

Mañas F, Peralta L, Raviolo J, Ovando HG, Weyers A, Ugnia L, Gonzalez Cid M, Larripa I, Gorla, N. 2009. Genotoxicity of glyphosate assessed by the comet assay and cytogenetic tests. Environmental Toxicology and Pharmacology, 28(1):37-41.

Martin ML, Ronco AE. 2006. Effect of mixtures of pesticides used in the direct seeding technique on non-target plant seeds. Bulletin of Environmental Contamination and Toxicology, 77: 228236.

Martínez RS, Di Marzio WD, Sáenz ME, 2015. Genotoxic effects of Chlorpyrifos and Tebuconazole on green algae. Ecotoxicology, 24:45-54.

Mateos-Naranjo E, Perez-Martin A. 2013. Effects of sub-lethal glyphosate concentrations on growth and photosynthetic performance of non-target species Bolboschoenus maritimus. Chemosphere, 93(10):2631-2638.

McCollum CW, Ducharme NA, Bondesson M, Gustafsson JA. 2011. Developmental toxicity screening in zebrafish. Birth Defects Research, 93:67-114

Mehta A, Verma RS, Srivastava N. 2008. Chlorpyrifos-induced DNA damage in rat liver and brain. Environmental Molecular Mutagenesis, 49:426-433

Miguel R E, Ruiz de Galarreta V A, Banda Noriega R B, 2009. Impacto al recurso hídrico subterráneo por vertedero de residuos de industria de fundición en Tandil, Buenos Aires Argentina: un estudio preliminar. Boletín Geológico y Minero. 120, 583-594.

Miguel RE, Ippolito JA, Porta AA, Noriega RB, Dungan RS (2013) Use of Standardized Procedures to Evaluate Metal Leaching from Waste Foundry Sands. J Environ Qual 42:615 - 620 
Miguel RE, Ippolito JA, Porta AA, Noriega RB, Dungan RS. 2013. Use of Standardized Procedures to Evaluate Metal Leaching from Waste Foundry Sands. Journal of Environmental Quality, 42:615-62

Miller B, Albertini S, Locher F, Thybaud V, Lorge E. 1997. Comparative evaluation of the in vitro micronucleus test and the in vitro chromosome aberration test: industrial experience. Mutation Research, 392:45-59.

Moser H, Römbke J, 2009. Ecotoxicological Characterization of Waste. Springer, New York, USA. p 300.

Moser H, Römbke J, Donnevert G, Becker R. 2009. Ecotoxicological characterization of waste Results and experiences of a Ring test. En Ecotoxicological Characterization of Waste. Springer, New York, USA. p 300.

Mottier A, Kientz-Bouchart V, Serpentini A, Lebel JM, Jha AN, Costil K. 2013. Effects of glyphosate-based herbicides on embryo-larval development and metamorphosis in the Pacific oyster, Crassostrea gigas. Aquatic Toxicology, 128-129:67-78.

Mudry MD, Carballo MA. 2006. Genética toxicológica. De los cuatro vientos editorial. p 669.

Mugni H, Ronco A, Bonetto C. 2011. Insecticide toxicity to Hyalella curvispina in runoff and stream water within a soybean farm (Buenos Aires, Argentina). Ecotoxicology and Environmental Safety, 74(3): 350-354.

Mullineaux P, Karpinski S, Creissen G. 2008. Integration of Signaling in Antioxidant Defenses. En: Adams B, Adams W, Mattoo AK (Eds) Advances in Photosynthesis and Respiration Series. Photoprotection, Photoinhibition, Gene Regulation, and Environment 21. Springer, p 224235.

Neuhauser EF, Loehr RC, Malecki MR, Milligan DL, Durkin PR. 1985. The toxicity of selected organic chemicals to the earthworm Eisenia fetida. Journal of Environmental Quality, 14(3):383-8.

Newman MC, Clements WH. 2008. Ecotoxicology: a comprehensive treatment. CRC Press, Boca Raton, FL, Estados Unidos, 852 p.

Newman MC, Jagoe H. 1996. Ecotoxicology: a hierarchical treatment. CRC Press Boca Raton, FL, Estados Unidos, $411 \mathrm{p}$.

Nogueira Cardoso EJ y Lopes Alves PR. 2012. Soil Ecotoxicology. En: Ecotoxicology G Begum (Ed.) InTech Publishers. p 27-50.

Noworyta-Glowacka J, Bankowski R, Siennicka J, Wiadrowska B, Ludwicki JK. 2012. Influence of chlorpyrifos on the profile of subpopulations of immunoactive cells and their phagocytic activity in an experimental in vivo model. Annals of Agricultural and Environmental Medicine, 19:483-486.

Ntalli NG, Menkissoglu-Spiroudi, U. 2011. Pesticides of Botanical Origin : A Promising Tool in Plant Protection. Pesticides- Formulations, Effects, Fate, 1-23.

Oggier DM, Lenard A, Kury M, Hoeger B, Affolter M, Fent K. 2011. Effects of the protein kinase inhibitor PKC412 on gene expression and link to physiological effects in zebrafish Danio rerio eleuthero-embryos. Toxicological Sciences 119:104-115.

Olchawa E, Bzowska M, Stürzenbaum SR, Morgan AJ, Plytycz B. 2006. Heavy metals affect the coelomocyte-bacteria balance in earthworms: Environmental interactions between abiotic and biotic stressors. Environmental Pollution, 142(2):373-381.

Organization for Economic Cooperation and Development OECD. 2004. Earthworm reproduction test. Guideline for Testing Chemicals no. 222. Paris, France.

Organization for Economic Cooperation and Development OECD. 1984. Test No. 207 Earthworm Acute Toxicity Tests. Paris, France.

Östling O, Johanson KJ. 1984. Microelectrophoretic study of radiation-induced DNA damages in individual mammalian cells. Biochemical and Biophysical Research Community, 123:291298. 
Pandard P, Devillers J, Charissou A, Poulsen V, Jourdain M, Ferard J. 2006. Selecting a battery bioassays for ecotoxicological characterization of wastes. Science of the Total Environment, 363:114-125.

Pandard P, Römbke J. 2013. Proposal for a "Harmonized" Strategy for the Assessment of the HP 14 Property. Integrated Environmental Assessment Management, 9: 665-672.

Perry P, Wolff S. 1974. New Giemsa method for the differential staining of sister chromatid. Nature, 261:156-161.

Piccolo A, Celano G, Arienzo M, Mirabella AJ. 1994. Adsoption and desorption of glyphosate in some european soils. Environmental Science Health, Part B, 29:1105.

Piola L, Fuchs J, Oneto ML, Basack S, Gimenez R, Massaro R, Papa JC, Kesten, Casabe, N. 2009. Biomarkers for the assessment of chlorpyrifos effects on earthworms and on soil functional parameters. Pesquisa Agropecuaria Brasileira, 44(8):874-880.

Piola L, Fuchs J, Oneto ML, Basack S, Kesten E, Casabé N. 2013. Comparative toxicity of two glyphosate-based formulations to Eisenia andrei under laboratory conditions. Chemosphere, 91(4):545-551.

Plewa MJ, Kargalioglu Y, Vankerk D, Minear RA, Wagner ED. 2000. Development of quantitative comparative cytotoxicity and genotoxicity assays for environmental hazardous chemicals, Water Science and Technology, 42:109-116.

Plytycz B, Cygal M, Lis-Molenda U, Klimek M, Mazur AI, Duchnowski M, Morgan AJ. 2011. Characteristics of immune-competent amoebocytes non-invasively retrieved from populations of the sentinel earthworm Lumbricus rubellus (Annelida; Oligochaeta; Lumbricidae) inhabiting metal polluted field soils. Ecotoxicology and Environmental Safety, 74(4):719726.

Poletta GL, Larriera A, Kleinsorge E, Mudry MD, 2009. Genotoxicity of the herbicide formulation Roundup ${ }^{\circledR}$ (glyphosate) in broad-snouted caiman (Caiman latirostris) evidenced by the Comet assay and the Micronucleus test. Mutation Research, 672:95-102.

Preston JR, Au A, Bender MA, Brewen JG, Carrano AV, Heddle JA, Mofee AF, Woff S, Wasson JS. 1981. Mammalian in vivo and in vitro cytogenetic assays: a report of US EPA's genotoxic program. Mutation Research, 87:147-188.

Preston JR, Hoffman GR. 2008. En Casarett LJ y Doull's J. Toxicology, The basic science of Poisons, 6th Klaassen, C.D.; Amdus, M.O.; y Dowll, J. (Eds) Macmillan Publishing Company.

Qiao M, Chen Y, Wang CX, Wang Z, Zhu YG. 2007. DNA damage and repair process in earthworm after in-vivo and in vitro exposure to soils irrigated by wastewaters. Environmental Pollution, 148(1):141-147.

Qiu H, Geng J, Ren H, Xia X, Wang X, Yu Y. 2013. Physiological and biochemical responses of Microcystis aeruginosa to glyphosate and its Roundup ${ }^{\circledR}$ formulation. Journal of Hazardous Materials, 248-249(1):172-176.

Radetski CM, Ferrari B, Cotelle S, Masfaraud JF, Ferard JF. 2004. Evaluation of the genotoxic, mutagenic and oxidant stress potentials of municipal solid waste incinerator bottom ash leachates. Science of the Total Environment 333:209- 216.

Radic S, Cvjetko P, Glavas K, Roje V, Pevalek-Kozlina B, Pavlica M. 2009. Oxidative stress and DNA damage in broad bean (Vicia faba L) seedlings induced by thallium. Environmental Toxicology and Chemistry, 28:89-196.

Rand GM. 1995. Fundamentals of aquatic toxicology: effects, environmental fate, and risk assessment. Taylor \& Francis, Washington, Estados Unidos, 1125 p.

Reeves JF, Davies SJ, Dodd NJF, Jha AN. 2008. Hydroxyl radicals (OH) are associated with titanium dioxide (TiO2) nanoparticle-induced cytotoxicity and oxidative DNA damage in fish cells. Mutation Research/Fundamental and Molecular Mechanisms of Mutagenesis, 640:113122. 
Reif R, Suárez SD, Omil FG, Lema JM. 2008. Fate of pharmaceuticals and cosmetics ingredients during the operation of a MBR treating sewage. Desalination, 221:511-517.

Reinecke SA, Reinecke AJ. 2004. The comet assay as biomarker of heavy metal genotoxicity in earthworms. Archives Environmental Contamination and Toxicology, 46:208-215.

Reinecke SA, Reinecke AJ. 2007. The impact of organophosphate pesticides in orchards on earthworms in the Western Cape, South Africa. Ecotoxicology and Environmental Safety, 66(2):244-251.

Rombke J y Moltmann JF. 1996. Applied Ecotoxicology. Lewis Publishers, Boca Raton, FL, Estados Unidos, $282 \mathrm{p}$.

Römbke J, Breure AM, Mulder C, Rutgers M. 2005. Legislation and ecological quality assessment of soil: Implementation of ecological indication systems in Europe. Ecotoxicology and Environmental Safety, 62:201-210.

Romero DM, Ríos de Molina MC, Juárez AB. 2011. Oxidative stress induced by a commercial glyphosate formulation in a tolerant strain of Chlorella kessleri. Ecotoxicology and Environmental Safety, 74(4):741-747.

Royal Society of Chemistry. 1987. The agrochemical handbook of the Royal Society of Chemistry. Nottingham, England.

Sáenz ME, Di Marzio WD, Alberdi JL. 2012. Assessment of Cyfluthrin commercial formulation on growth, photosynthesis and catalase activity of green algae. Pesticide Biochemistry and Physiology, 104:50-57.

Sáenz ME, Di Mazio WD, Ambrini G. 2009. Toxicidad de insecticidas organofosforados utilizados en cultivo de soja sobre productores primarios. RAECA, 1(1):29-36.

Salazar AM, Herrera LA. 1992. Daño genético inducido por agentes físicos y químicos, Revista de la Facultad de Medicina UNAM, 35:75-81.

Saleha Banu B, Danadevi K, Rahman MF, Ahuja YR, Kaiser J. 2001. Genotoxic effect of monocrotophos to sentinel species using comet assay. Food and Chemical Toxicology, 39:361-366.

Sanchez-Hernandez JC, Narvaez C, Sabat P, Martínez Mocillo S. 2014. Integrated biomarker analysis of chlorpyrifos metabolism and toxicity in the earthworm Aporrectodea caliginosa. Science of the Total Environment, 490:445-455.

Sanchez-Hernandez JC. 2006. Earthworm biomarkers in ecological risk assessment. Reviews of Environmental Contamination and Toxicology, 188:85-126.

Saterbak A, Toy R, Wong D, McMain B, Williams P, Dorn P, Brzuzy L. 1999. Ecotoxicological and analytical assessment of hydrocarbon-contaminated soils and application to ecological risk assessment. Environmental Toxicology and Chemistry, 18:1591-1607.

Sauvé S, Hendershot W, Allen HE. 2000. Solid-solution partitioning of metals in contaminated soils: dependence on $\mathrm{pH}$, total burden, and organic matter. Environmental Science Technology, 34:1125-1131.

Schmid W. 1976. The micronucleus test for cytogenetic analysis. En: Chemical Mutagens. Principles and Methods for their detection. A. Hollander (Ed.), p 31-53.

Schneider MI, Sánchez N, Pineda S, Chi H, Ronco A. 2009. Impact of glyphosate on the development, fertility and demography of Chrysoperla externa (Neuroptera: Chrysopidae): Ecological approach. Chemosphere, 76(10):1451-1455.

Schröder P, Krutmann J. 2005. Environmental Oxidative Stress - Environmental Sources of ROS: Reactions Processes. En: Hutzinger O (Ed) The Handbook of Environmental Chemistry Vol. 2. Springer-Verlag Berlin Heidelberg, p 19-31.

Schultz E, Vaajasaari K, Joutti A, Ahtiainen J. 2002. Toxicity of industrial wastes and waste leaching test eluates containing organic compounds. Ecotoxicology and Environmental Safety, 52(3):248-255. 
Scott-Fordsmand J, Weeks JM. 1997. Review of selected biomarkers in eartworms. En: Sheppard, S. 1997. Advances in Earthworm Ecotoxicology: Proceedings from the Second International Workshop on Earthworm Ecotoxicology, April 1997, Amsterdam, the Netherlands. SETAC Foundation, 173-189.

Sforzini S, Boeri M, Dagnino A, Oliveri L, Bolognesi C, Viarengo A. 2012. Genotoxicity assessment in Eisenia andrei coelomocytes: A study of the induction of DNA damage and micronuclei in earthworms exposed to B[a] P and TCDD-spiked soils. Mutation Research - Genetic Toxicology and Environmental Mutagenesis, 746(1):35-41.

Shafer DA. 1982. Alternate replication bypass mechanism for sister chromatid exchange formation. En: Sandberg AA (Ed) Program Topics Cytogenetic, p 67-98.

Shi-ping Z, Chang-qun D, Hui FU, Yu-hui C, Xue-hua W, Ze-fen YU. 2007. Toxicity assessment for chlorpyrifos-contaminated soil with three different earthworm test methods, 19:854-858.

Siddique R, Kaur G, Rajor A, 2010. Waste foundry sand and its leachate characteristic. Resources, Conservation and Recycling. 54, 1027-1036.

Sihtmäe M, Blinova I, Künnis-Beres K, Kanarbik L, Heinlaan M, Kahru A.2013. Ecotoxicological effects of different glyphosate formulations. Applied Soil Ecology, 72:215-224.

Singh NP, McCoy MT, Tice RR, Schneider E. 1988. A simple technique for quantitation of low levels of DNA damage in individual cells. Experimental Cell Research, 175:184-191.

Slotkin TA. 2011. Does early-life exposure to organophosphate insecticides lead to prediabetes and obesity?. Reproductive Toxicology, 31:297-301.

Sobrero MC, Rimoldi F, Ronco AE. 2007. Effects of the glyphosate active ingredient and a formulation on Lemna gibba L. at different exposure levels and assessment end-points. Bulletin of Environmental Contamination and Toxicology, 79 (5):537-543.

Soloneski S, González M, Piaggio E, Reigosa MA, Larramendy ML. 2001. Effect of the dithiocarbamate pesticide zineb and its commercial formulation, Azzurro®. Genotoxic evaluation on cultured human lymphocytes exposed in vitro. Mutagenesis, 16:487-493.

Soloneski S, Kujawski M, Scuto A, Larramendy ML. 2015. Carbamates: A study on genotoxic, cytotoxic, and apoptotic effects induced in Chinese hamster ovary (CHO-K1) cells. Toxicology In Vitro, 29:834-844.

Soloneski S, Reigosa MA, Larramendy ML. 2002. Effect of the dithiocarbamate pesticide zineb and its commercial formulation, Azzurro ${ }^{\circledR}$. Clastogenesis on immunophenotyped human lymphocytes assessed by the micronucleus test. Environmental and Molecular Mutagenesis, 40:57-62.

Sprague JB. 1973. The ABC's of pollutant bioassay using fish. Biological methdos for the assessment of water quality. ASTM STP 528, American Society for Testing and Material: 630.

Sprankle P, Meggitt WF, Penner D. 1975. Rapid inactivation of glyphosate in soils. Weed Science, 23:224-228.

Spurgeon DJ, Hopkin SP. 1996. The effects of metal contamination on earthworm populations around a smelting works: quantifying species effects. Applied Soil Ecology, 4:147-160.

Spurgeon DJ, Stürzenbaum SR, Svendsen C, Hankard PK, Morgan J, Weeks JM, Kille P. 2004. Toxicological, cellular and gene expression responses in earthworms exposed to copper and cadmium. Comparative Biochemistry and Physiology - C Toxicology and Pharmacology, 138(1):11-21.

Stead IM.1998. La vida en el antiguo Egipto. Editorial AKAD. Pp 72.

Stiernström S, Hemström K, Wik O, Carlsson G, Bengtsson BE, y Breitholtz M. 2011. An ecotoxicological approach for hazard identification of energy ash. Waste Management, 31(2):342-352.

SW846. Method 3550C, Ultrasonic extraction. http://www.epa.gov/osw/hazard/ testmethods/sw846/pdfs/3550c.pdf (acceso 13 may 2015). 
Tarradellas J, Bitton G, Rossel D. 1997. Soil Ecotoxicology. CRC Press Boca Raton, FL, Estados Unidos, $386 \mathrm{p}$.

Taylor JH. 1958. Sister chromatid exchanges in tritium-labeled chromosomes. Genetics, 43:515-529.

Tesfamariam T, Bott S, Cakmak I, Römheld V, Neumann G. 2009. Glyphosate in the rhizosphereRole of waiting times and different glyphosate binding forms in soils for phytotoxicity to non-target plants. European Journal of Agronomy, 31(3):126-132.

Tian Y, Yamauchi T. 2003. Micronucleus formation in 3-day mouse embryos associated with maternal exposure to chlorpyrifos during early preimplantation period. Reproduction Toxicology, 17:401-405.

Tice RR, Agurell E, Anderson D, Burlinson D, Hartmann A, Kobayashi H, Miyamae Y, Rojas E, Ryu JC, Sasaki YF. 2000. Single cell gel/comet assay: guidelines for in vitro and in vivo genetic toxicology testing. Environmental and Molecular Mutagenesis, 35:206-221.

Tiessen H, Moir J. 1993. Total and Organic carbon. In: Soil Chemical Analyses. Martin Carter (Ed). Lewis Publishers, Boca Raton, $187 \mathrm{p}$.

Tsui MTK, Chu LM. 2003. Aquatic toxicity of glyphosate-based formulations: Comparison between different organisms and the effects of environmental factors. Chemosphere, 52(7):1189-1197.

US EPA. 1996a. Algal Toxicity, Tiers I and II. Ecological Effects Test Guidelines. OPPTS 850.5400. EPA 712-C-96-164.

US EPA. 1996b. Ecological Effects Guidelines, Aquatic Invertebrate Acute Toxicity Test, Fresh water Daphnids, OPPTS 850.1010. EPA 7101: 1-10.

US EPA. 1996c. Ecological Effects Test Guidelines: Fish Acute Toxicity Test, Freshwater and Marine. EPA 712-C-96-118, OPPTS 850.1075.

US EPA. 2002a. Methods for Measuring the Acute Toxicity of Effluents and Receiving Waters to Freshwater and Marine. Organisms. Fifth Edition. EPA-821-R-02-012.

US EPA. 2002b. Short-term Methods for Estimating the Chronic Toxicity of Effluents and Receiving Waters to Freshwater Organisms. Fourth Edition, Washington, DC 20460, EPA- Ecological Effects Characterization. Last updated on May 09, 2012.

US EPA. 2012. Technical Overview of Ecological Risk Assessment Analysis Phase: Ecological Effects Characterization. Last updated on May 09, 2012.

Valerio ME, García JF, Peinado FM. 2007. Determination of phytotoxicity of soluble elements in soils, based on a bioassay with lettuce (Lactuca sativa L). Science of the Total Environment, 378(1-2):63-66.

Van Assche F y Clijsters H. 1986. Inhibition of photosynthesis in Phaseolus vulgaris by treatment with toxic concentrations of zinc: effects on electron transport and photophosphorylation. Physiology Plant, 66:717-721.

Van Assche F, Cardinaels C, Clijsters H. 1988. Induction of enzyme capacity in plants as a result of heavy metal toxicity: dose-response relations in Phaseolus vulgaris L., treated with zinc and cadmium. Environmental Pollution, 52:103-115.

Van der Oost R, Porte-Visa C, van den Brink NW. 2005. Biomarkers in environmental assessment. En: Ecotoxicological testing of marine and freshwater ecosystems: emerging techniques, trends, and strategies. CRC Press, Boca Raton, FL, Estados Unidos, 271 p.

Van Herwijnen R, Laverye T, Poole J, Hodson ME, Hutchings TR. 2007. The effect of organic materials on the mobility and toxicity of metals in contaminated soils. Applied Geochemistry, 22(11), 2422-2434.

Vangronsveld J, Clijsters H. 1992. A biological test system for the evaluation of metal phytotoxicity and immobilization by additives in metal-contaminated soils by application of a modified alumino-silicate: biological evaluation. En Barcelo J (Ed). Environmental contamination. Proceedings of the $4^{\text {th }}$ International Conference, Barcelona, Edinburgo, CEP-Consultants, $p$ 283-285. 
Vasseur P, Cossu-Leguille C. 2003. Biomarkers and community indices as complementary tools for environmental safety. Environment International, 28(8):711-717.

Vázquez M. 2005. Acidez del suelo. En: Tecnologías en análisis de suelos. Liliana Marbán y Silvia Ratto. Buenos Aires: AACS. pp: 69-88.

Vazquez M.E. 2006. Calcio y magnesio. Acidez y alcalinidad de los suelos. En Fertilidad de suelos y fertilización de cultivos. H.E. Echeverría y F.O. Garcia (eds). Editorial INTA. Buenos Aires. Argentina. pp. 161-189.

Vendrell E, Gómez de Barreda Ferraz D, Sabater C, Carrasco JM. 2009. Effect of glyphosate on growth of four freshwater species of phytoplankton: a microplate bioassay. Bulletin of Environmental Contamination and Toxicology, 82:538-542.

Venkateswara Rao J, Surya Pavan Y, Madhavendra SS. 2003. Toxic effects of chlorpyrifos on morphology and acetylcholinesterase activity in the earthworm, Eisenia foetida. Ecotoxicology and Environmental Safety, 54(3):296-301.

Vera-Candioti J, Soloneski S, Larramendy ML. 2013a. Single-cell gel electrophoresis assay in the ten spotted live-bearer fish, Cnesterodon decemmaculatus (Jenyns, 1842), as bioassay for agrochemical-induced genotoxicity. Ecotoxicology and Environmental Safety, 98:368-373.

Vera-candioti J, Soloneski S, Larramendy ML. 2013b. Evaluation of the genotoxic and cytotoxic effects of glyphosate-based herbicides in the ten spotted live-bearer fish Cnesterodon decemmaculatus. Ecotoxicology and Environmental Safety, 89: 166-173.

Vera-candioti J, Soloneski S, Larramendy ML. 2013c. Chlorpyrifos-Based Insecticides Induced Genotoxic and Cytotoxic Effects in the Ten Spotted Live-Bearer Fish, Cnesterodon decemmaculatus (Jenyns, 1842). Environmental Toxicology, 29 (12):1390-1398.

Verma S, Dubey R. 2003. Lead toxicity induces lipid peroxidation and alters the activities of antioxidant enzymes in growing rice plants. Plant Science, 164:645-655.

Verschaeve L, Gilles J. 1995. Single cell gel electrophoresis assay in the earthworm for the detection of genotoxic compounds in soils. Bulletin of Environmental Contamination and toxicology, 54:112-119.

Volpe MG, Nazzaro M, Coppola R, Rapuano F, Aquino P. 2012. Determination and assessments of selected heavy metals in eye shadow cosmetics from China, Italy, and USA. Microchemical Journal, 101:65-69.

Voua Otomo P, Reinecke S, Reinecke J. 2014. Using the comet assay to assess the combined and separate genotoxic effects of $\mathrm{Cd}$ and $\mathrm{Zn}$ in Eisenia andrei (oligochaeta) at different temperatures. Bulletin of Environmental Contamination and Toxicology, 92(3): 285-288.

Walker CH, Hopkin SP, Sibly RM, Peakall DB. 2006. Principles of Ecotoxicology, 3rd Ed, Taylor \& Francis, Boca Raton, FL 315 p.

Wang CR, Wang XR, Tian Y, Yu HX, Gu XY, Du WC, Zhou H. 2008. Oxidative stress, defense response, and early biomarkers for lead-contaminated soil in Vicia faba seedlings. Environmental Toxicology and Chemistry, 27(4):970-977.

Wang W, 1987. Root elongation method for toxicity testing of organic an inorganic pollutants. Environmental Toxicolology and Chemistry 6:409-414.

Wang X y Gong Z. 1998. Assessment and analysus of soil quality changes after eleven years of reclamation in subtropical China. Geoderma, 81:339-355.

Wang Y, Cang T, Zhao X, Yu R, Chen L, Wu C, Wang Q. 2012. Comparative acute toxicity of twenty-four insecticides to earthworm, Eisenia fetida. Ecotoxicology and Environmental Safety, 79:122-128.

Welten R. 2000. Ecotoxicity of contaminated suspended solids for filter feeders (Daphnia magna). Archives of Environmental Contamination and Toxicology, 39 (3): 315-323.

Widziewicz K, Kalka J, Skonieczna M, Madej P. 2011. The Comet Assay for the Evaluation of Genotoxic Potential of Landfill Leachate. The Scientific World Journal, 1:1-8. 
Wild D. 1975. Mutagenicity studies on organophosphorus insecticides. Mutation Research, 32: 133150.

Wilke B, Riepert F, Koch C, Kuhne T. 2008. Ecotoxicological characterization of hazardous wastes. Ecotoxicology and Environmental Safety, 70:283-293.

Williams GM, Kroes R, Munro IC. 2000. Safety evaluation and risk assessment of the herbicide Roundup and its active ingredient, glyphosate, for humans. Regulatory Toxicology and Pharmacology, 31:117-165.

Wogan GN. 1992. Molecular epidemiology in cancer risk assessment and prevention: Recent progress and avenues for future research. Environmental Health Perspectives, 19:167-178.

Wolff S, Bodycote J, Painter RB. 1974. Sister chromatid exchanges induced in Chinese hamster cells by UV irradiation of different stages of the cell cycle: the necessity for cell to pass through $\mathrm{S}$. Mutation Research, 25:73-81.

Wong PK. 2000. Effects of 2,4-D,glyphosate and paraquat on growth, photosynthesis and chlorophylla synthesis of Scenedesmus quadricauda. Chemoshere, 41:177-182.

World Health Organization (WHO). 1984. International Programme on Chemical Safety. Environmental Health Criteria $\mathrm{N}^{\circ} 39$ : Paraquat and Diquat, 1-99 p.

World Health Organization (WHO). 1986. International Programme on Chemical Safety. Environmental Health Criteria $N^{\circ}$ 63: Organophosphorus insecticides: a general introduction, $181 \mathrm{p}$.

World Health Organization (WHO). 1988. International Programme on Chemical Safety. Environmental Health Criteria $\mathrm{N}^{\circ}$ 61: Chromium, 197 p.

World Health Organization (WHO). 1991. International Programme on Chemical Safety. Environmental Health Criteria $\mathrm{N}^{\circ} 108$ : Nickel, 383 p.

World Health Organization (WHO). 1992. International Programme on Chemical Safety. Environmental Health Criteria $\mathrm{N}^{\circ} 134$ : Cadmium, $280 \mathrm{p}$.

World Health Organization (WHO). 1994. International Programme on Chemical Safety. Environmental Health Criteria $\mathrm{N}^{\circ} 159$ : Glyphosate, $175 \mathrm{p}$.

World Health Organization (WHO). 1995. International Programme on Chemical Safety. Environmental Health Criteria $\mathrm{N}^{\circ}$ 165: Inorganic Lead, $300 \mathrm{p}$.

World Health Organization (WHO). 1997. International Programme on Chemical Safety. Environmental Health Criteria $\mathrm{N}^{\circ}$ 194: Aluminum, $282 \mathrm{p}$.

World Health Organization (WHO). 1998. International Programme on Chemical Safety. Environmental Health Criteria $\mathrm{N}^{\circ} 200$ : Copper, 360 p.

World Health Organization (WHO). 2001. International Programme on Chemical Safety. Environmental Health Criteria $\mathrm{N}^{\circ} 221$ : Zinc, 360 p.

Wu B, Liu Z, Xu Y, Li D, Li M. 2012. Combined toxicity of cadmium and lead on the earthworm Eisenia fetida (Annelida, Oligochaeta). Ecotoxicology and Environmental Safety, 81:122126.

Wu F, Zhang G, Dominy P. 2003. Four barley genotypes respond differently to cadmium: lipid peroxidation and activities of antioxidant capacity. Environmental and Experimental Botany, 50:67-78.

Xiao N, Jing B, Ge F, Liu X. 2006. The fate of herbicide acetochlor and its toxicity to Eisenia fetida under laboratory conditions. Chemosphere, 62(8):1366-1373.

Young BJ, Riera NI, Beily ME, Bres PA, Crespo DC, Ronco AE. 2012. Toxicity of the effluent from an anaerobic bioreactor treating cereal residues on Lactuca sativa. Ecotoxicology and Environmental Safety, 76(1):182-186.

$\mathrm{Yu}$ SJ. 2008. The toxicology and biochemistry of insecticides. CRC Press Taylor \& Francis, Washington, Estados Unidos, 283 p.

Zang Y, Zhong Y, Luo Y, Kong ZM, 2000. Genotoxicity of two novel pesticides for the earthworm Eisenia fetida. Environmental Pollution, 108:271-278. 
Zhang Y, Shen G, Yu Y, Zhu H. 2009. The hormetic effect of cadmium on the activity of antioxidant enzymes in the earthworm Eisenia fetida. Environmental Pollution, 157(11):3064-3068. 


\section{Trabajos relacionados a la presente Tesis doctoral}

La presente Tesis Doctoral dio lugar a los siguientes trabajos publicados y en preparación:

Trabajos publicados:

- Curieses SP, Sáenz ME, Di Marzio WD. 2011. Producción de celomocitos de Eisenia fetida en cultivos de laboratorio para estudios de genotoxicidad. Revista Argentina de Ecotoxicología y Contaminación Ambiental, 2(1):79-86.

- Curieses SP, Sáenz ME, Larramendy ML, Di Marzio WD. Ecotoxicological evaluation of foundry sands and cosmetic sludges using new earthworm biomarkers. En revisión en Ecotoxicology

Trabajos en preparación:

- Curieses SP, Di Marzio WD, Larramendy ML, Sáenz ME. Ecotoxicological characterization of two industrial wastes by higher plants. A enviar

- Curieses SP, García Velazco N, Sáenz ME, Bilbao Castellanos E, Soto M, Di Marzio WD. Profiling of molecular stress responses to silver nanoparticles in coelomocytes of earthworm Eisenia fetida after several exposure times. En preparación

Presentaciones de resultados de la presente Tesis Doctoral en Congresos:

- Curieses SP, Sáenz ME, Alberdi JL, Di Marzio WD. Cyto and genotoxicity of two industrial wastes on coelomocytes of Eisenia fetida. SETAC EUROPA 25st Annual Meeting, Barcelona, España.

- Curieses SP, Sáenz ME, Alberdi JL, Di Marzio WD. Ecotoxicological assessment of the effects of agrochemicals on non-target organisms. SETAC EUROPA 25st Annual Meeting, Barcelona, España.

- Curieses SP, Di Marzio WD, Alberdi JL, Sáenz ME. Biomarkers of exposure to whole and elutions of two industrials wastes on Vicia faba and Lactuca sativa. SETAC EUROPA 25st Annual Meeting, Barcelona, España.

- Sáenz ME, Di Marzio WD, Curieses SP, Alberdi JL. Biorremediación de residuos industriales. $4^{\circ}$ Congreso de Ciencias Ambientales COPIME, 2013. Buenos Aires, Argentina. 
- Di Marzio WD, Sáenz ME, Curieses SP, Alberdi JL, 2012. New earthworm endpoints based on coelomocites. SETAC World Congress VI y SETAC EUROPA 22st Annual Meeting, Berlin, Alemania.

Presentaciones en Congresos de trabajos relacionados:

- Martínez RS, Di Marzio WD, Alberdi JL, Curieses SP, Sáenz ME. Effect of Ni, Zn and their mixtures on different morphological variables of duckweed. SETAC EUROPA 25st Annual Meeting, Barcelona, España.

- Sáenz ME, Di Marzio WD, Curieses SP, Bišová K. The DNA damaging antibiotic Zeocin affects cell cycle progression in green algae S. quadricauda and C. reinhardtii. SETAC EUROPA 25st Annual Meeting, Barcelona, España.

- Di Marzio WD, Curieses SP, Sáenz ME. Induced genotoxicity by silicon nanoparticles with different Zeta potential on earthworm coelomocytes. SETAC EUROPA 24st Annual Meeting, Basilea, Suiza.

- Di Marzio WD, Curieses SP, Alberdi JL, Sáenz ME. Geno y citotoxicidad de residuos industriales especiales no- ecotóxicos. Ponencia presentada en $4^{\circ}$ Congreso de Ciencias Ambientales COPIME, 2013. Buenos Aires, Argentina.

- Sáenz ME, Di Marzio WD, Curieses SP, Alberdi JL. Biorremediación de residuos industriales. $4^{\circ}$ Congreso de Ciencias Ambientales COPIME, 2013. Buenos Aires, Argentina.

- Di Marzio WD, Sáenz ME, Curieses S, Alberdi JL, 2012. Toxicity identification evaluation for wastewater treatment plant working at different industrial and municipal scales. SETAC World Congress VI y SETAC EUROPA 22st Annual Meeting, Berlin, Alemania.

- Sáenz ME, Di Marzio WD, Alberdi JL, Curieses S, 2012. The effects on non-target species of novel products applied together with herbicides and insecticides in relation to transgenic soybean crops in Argentina. SETAC World Congress VI y SETAC EUROPA 22st Annual Meeting, Berlin, Alemania. 